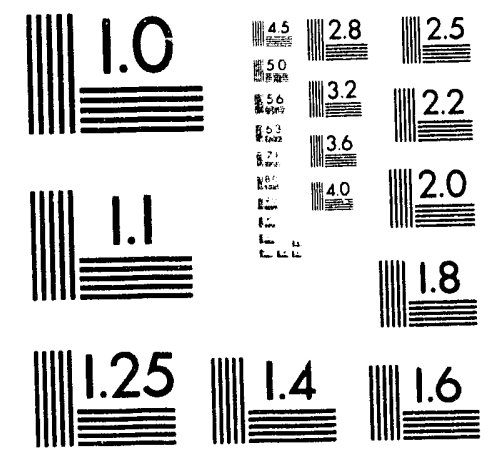



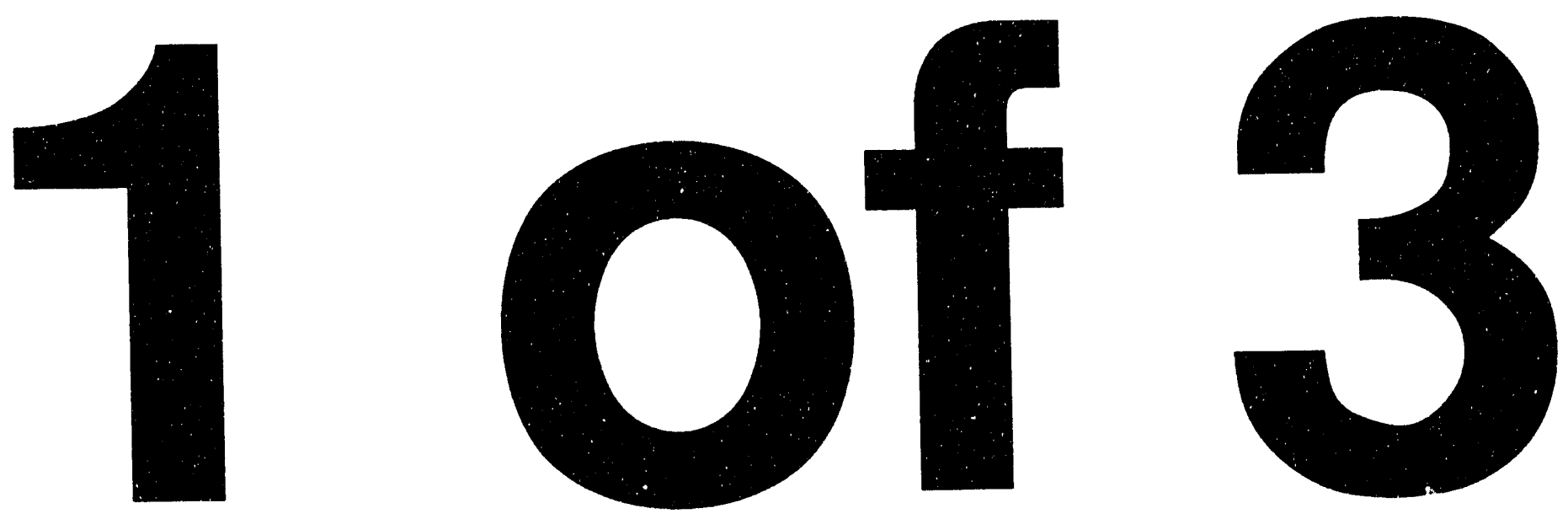


\section{Examination of Incentive Mechanisms}

for Innovative Technologies Applicable to Utility and Nonutility Power Generators

\section{K.A. McCermott, ${ }^{*}$ K.A. Bailey, and D.W. South}

Technology and Environmental Policy Section, Environmenia! Assessmerit and Information Sciences Division,

Argonne National Laboratory, 9700 South Cass Avenue, Argonne, Illinois 60439-4832

January 1992 (revised August 1993)

Work sponsored by United States Department of Energy, Assistant Secretary for Fossil Energy

"McDermott is now affiliated with the Illinois Commerce Commission. 


\section{CONTENTS}

ACKNOWLEDGMENTS $\ldots \ldots \ldots \ldots \ldots \ldots \ldots \ldots \ldots \ldots \ldots \ldots \ldots \ldots \ldots$

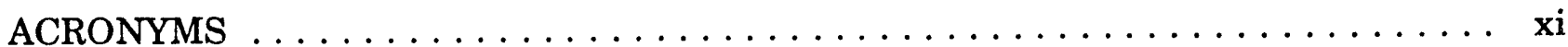

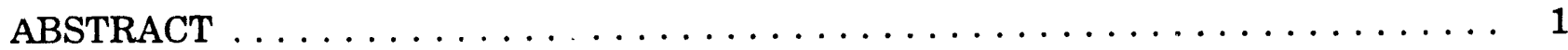

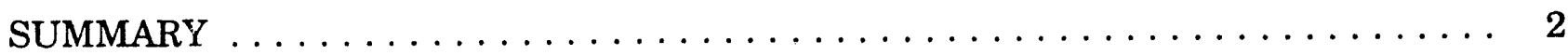

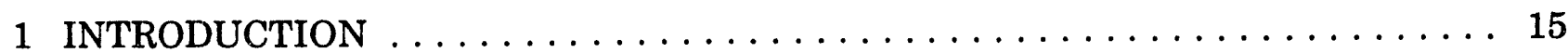

1.1 Problem Context $\ldots \ldots \ldots \ldots \ldots \ldots \ldots \ldots \ldots \ldots \ldots \ldots$

1.1.1 Incentives to Mitigate Innovative Technology Risks . . . . . . . . . 16

1.1.2 Incentives to Minimize Production and Project Costs $\ldots \ldots \ldots \ldots$

1.1.3 Alternative Objectives and the Use of Incentives . . . . . . . . . 21

1.2 Report Organization .......................... 21

2 CAPACITY ANND TECHNOLOGY CHOICE: THE ROLE OF RISK,

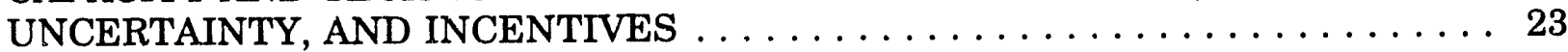

2.1 Rational Choice of Investment Projects . . . . . . . . . . . . . . 24

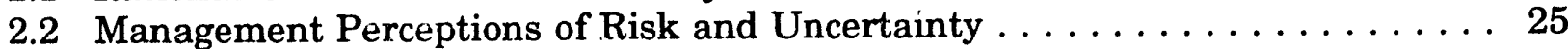

2.3 Categorizing the Nature of Innovative Technology Risks . . . . . . . . . . . 29

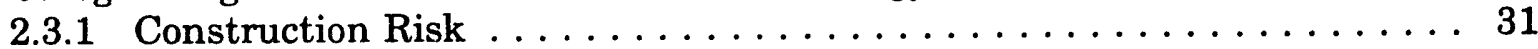

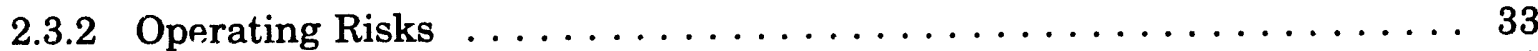

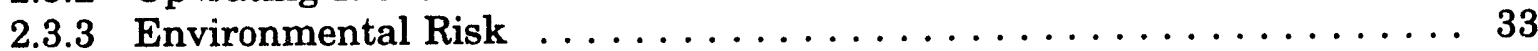

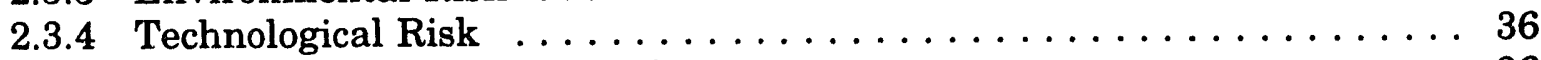

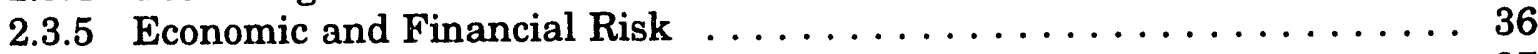

2.3.6 Regulatory Risk ....................... 37

3 A METHODOLOGY FOR CALCULATING THE EX ANTE OPPORTUNITY COSTS OF INNOVATIVE TECHNOLOGY RISK . . . . . . . . . . . . 41

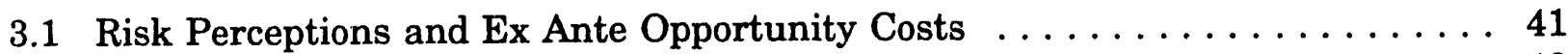

3.2 Operationalizing the Ex Ante Opportunity Cost Calculation . . . . . . . . 43

3.3 Estimating the Cost of Ex Ante Incremental Risk . . . . . . . . . . . 47

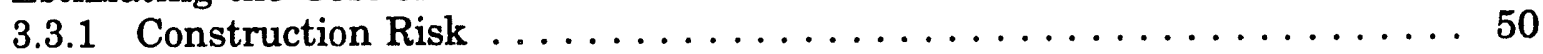

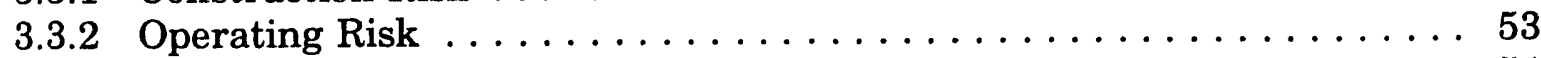

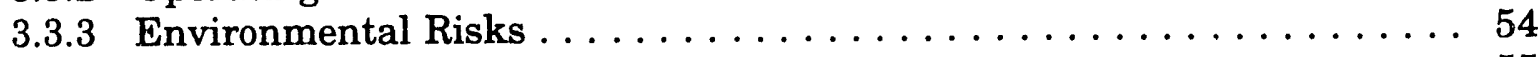

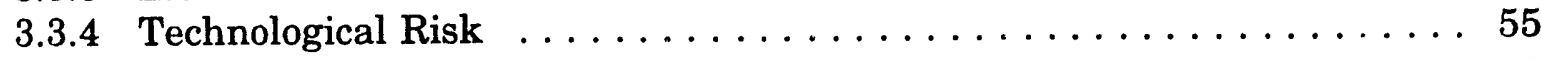

4 RECOGNITION OF SPECIFIC RISKS AND ADOPTION OF SPECIALIZED AND GENERAL REGULATORY INCENTIVE MECHANISMS . . . . . . . . . . . 59

4.1 Alternative Incentive Programs $\ldots \ldots \ldots \ldots \ldots \ldots$

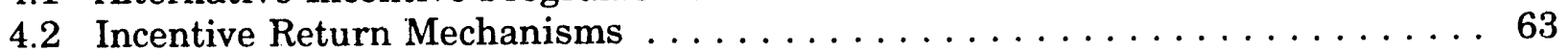

4.3 Non-Rate of Return Incentive Mechanisms . . . . . . . . . . . . . . . 64 


\section{CONTENTS (Cont.)}

4.4 Recognizing Technological Risk: Efficiency Standards

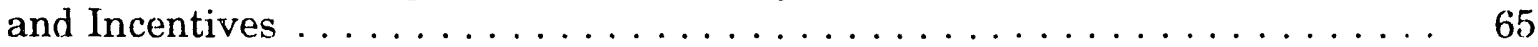

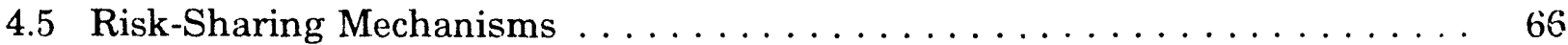

4.5.1 Risk Sharing: Rate Base Phase-ins and Prudence Reviews . . . . . 67

4.6 Alternative Incentive Mechanisms to Address Technological Risk . . . . . . . . 68

4.6.1 Prospective Prudence $\ldots \ldots \ldots \ldots \ldots \ldots \ldots \ldots \ldots \ldots . \ldots \ldots$

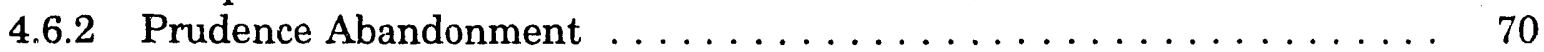

4.6.3 Accelerated Depreciation . . . . . . . . . . . . . . . . . . . . 70

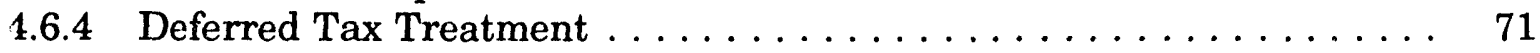

4.6.5 Construction Work in Progress $\ldots \ldots \ldots \ldots \ldots \ldots \ldots \ldots \ldots \ldots \ldots \ldots \ldots \ldots$

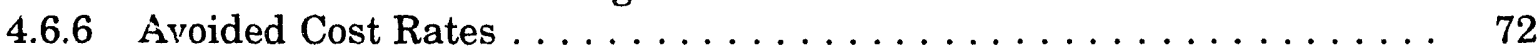

4.6.7 Treatment of Grants . . . . . . . . . . . . . . . . . . 72

4.6.8 Expensing Demonstration Costs $\ldots \ldots \ldots \ldots \ldots \ldots \ldots \ldots \ldots .72$

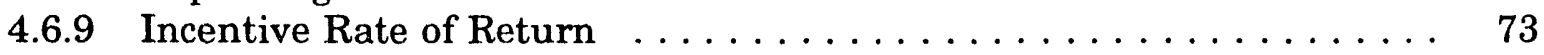

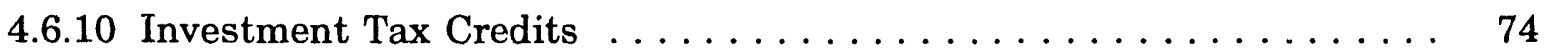

4.6.11 Special Treatment of Emission Alternatives ............. 74

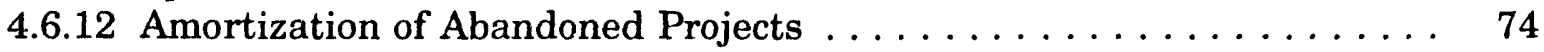

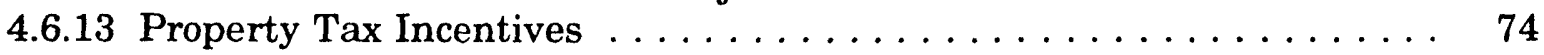

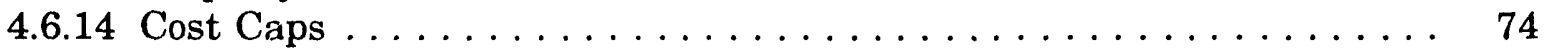

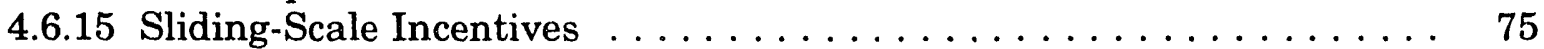

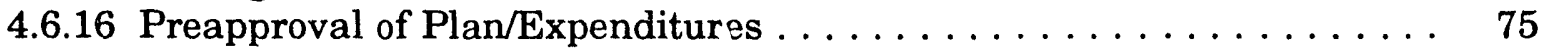

5 ANALYSIS OF REGULATORY INCENTIVES FOR THE ADOPTION OF INNOVATIVE TECHNOLOGY BY UTILITY POWER GENERATORS $\ldots \ldots \ldots 77$

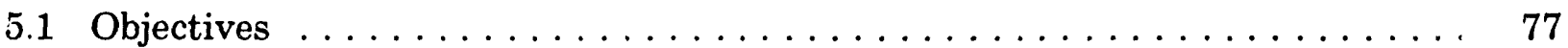

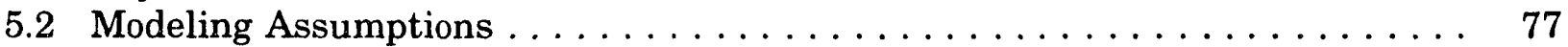

5.3 Model Results . . . . . . . . . . . . . . . . . . . . . . 81

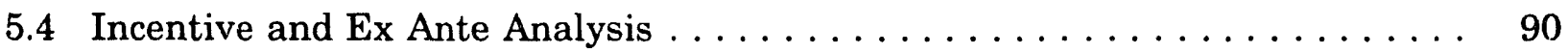

6 INCENTIVES FOR THE ADOPTION OF INNOVATIVE TECHNOLOGIES FOR NONUTILITY GENERATORS $\ldots \ldots \ldots \ldots \ldots \ldots . . \ldots 5$

6.1 Nonutility Generation and Public Utilities: Differences and Choices . . . . . 96

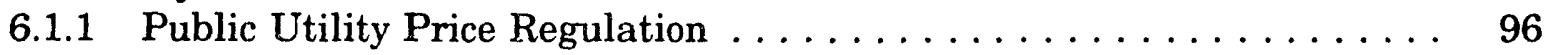

6.1.2 Nonutility Pricing: Competitive Bidding and Avoided Cost . . . . . 97

6.2 Nonutility Generator Market Issues . . . . . . . . . . . . . . . . 99

6.2.1 Environmental Considerations and Nonutility Generators . . . . . 100

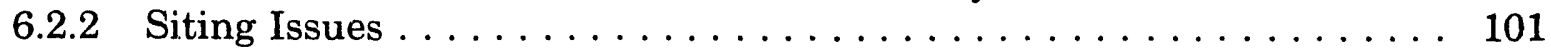

6.2.3 Transmission Access . . . . . . . . . . . . . . . . . . . . . . 102

6.2.4 Treatment of Environmental Pass-through . . . . . . . . . . . 102

6.3 Nonutility Generator Technology Choice . . . . . . . . . . . . . . . . . 103

6.4 Interviews with Nonutility Generators $\ldots \ldots \ldots \ldots \ldots \ldots \ldots \ldots$

6.4.1 Perceived Risks of Clean Coal Technology and Incentive Adoption ............................ 107

6.4.2 Incentive Mechanisms and Their Effect on Operations . . . . . . 108 


\section{CONTENTS (Cont.)}

6.4.3 Concerns about CCT and the Use of Incentives under

Competitive Processes . . . . . . . . . . . . . . . . . . . . 109

6.5 NUG Characteristics and Development $\ldots \ldots \ldots \ldots \ldots \ldots \ldots \ldots \ldots . \ldots \ldots$

6.5.1 Capital-Intensive Nature of NUGs $\ldots \ldots \ldots \ldots \ldots \ldots \ldots \ldots \ldots 111$

6.5.2 Expense Contracting and Cost Pass-through $\ldots \ldots \ldots \ldots \ldots \ldots 112$

6.5.3 Debt Financing and Leverage ..................... 113

6.6 Qualitative Risk Assessment of NUG Projects:

A Financial View ............................. 114

6.6.1 Qualitative Risk Factors . . . . . . . . . . . . . . . . 114

6.6.2 Importance of Contractual Assurances and Guarantees . . . . . . . 116

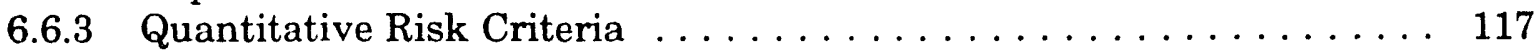

6.7 Financial Institution Project Evaluation $\ldots \ldots \ldots \ldots \ldots \ldots \ldots \ldots \ldots \ldots$

6.8 NUG Payback Period Model $\ldots \ldots \ldots \ldots \ldots \ldots \ldots \ldots \ldots \ldots \ldots \ldots \ldots$

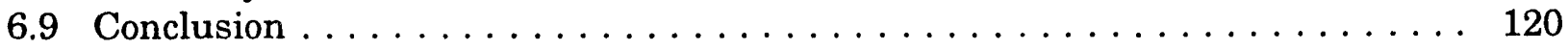

7 ANALYSIS OF INCENTIVES TO ADOPT INNOVATIVE

TECHNOLOGY BY NONUTILITY POWER GENERATORS . . . . . . . . 123

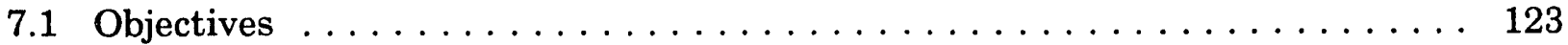

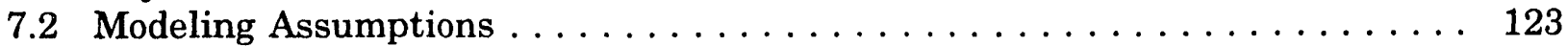

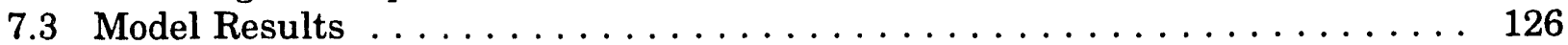

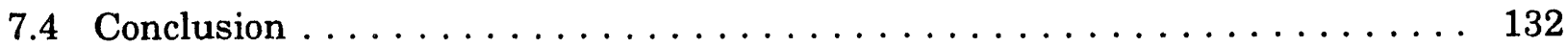

8 SUMMARY AND CONCLUSION $\ldots \ldots \ldots \ldots \ldots \ldots \ldots \ldots \ldots \ldots \ldots \ldots$

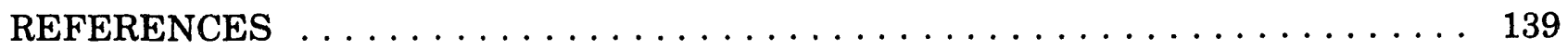

APPENDIX A: Comparison of Alternative Rate of Return Methodologies . . . . . 151

APPENDIX B: Modeling Approach and Assumptions . . . . . . . . . . . 165

APPENDIX C: Nonutility Generators: Technology Choice under the Clean Air Act Amendments of $1990 \ldots \ldots \ldots \ldots \ldots \ldots \ldots .177$

APPENDIX D: Federal and State Regulatory Incentives for the Adoption of Clean Coal Technology $\ldots \ldots \ldots \ldots \ldots \ldots 187$

\section{FIGURES}

S.1 Summary of Technology Adoption and Effects of Incentives ........... 3

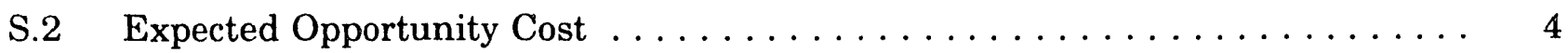

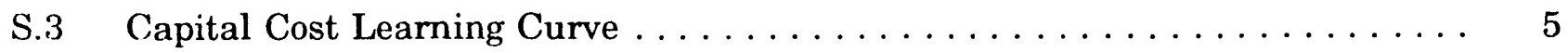




\section{FIGURES (Cont.)}

S.4 Incentive Cost and Total Revenue Requirement Savings in $2015 \ldots \ldots \ldots$

S.5 Incentive Cost and Societal Savings in $2015 \ldots \ldots \ldots \ldots \ldots$

1 Effect of Incentives on Expected Project Costs and Variances . . . . . . . . 19

$2 \quad$ Capital Cost Learning Curve $\ldots \ldots \ldots \ldots \ldots \ldots \ldots \ldots \ldots \ldots$

3a Capital Costs of Nuclear Units $\ldots \ldots \ldots \ldots \ldots \ldots \ldots \ldots \ldots \ldots$

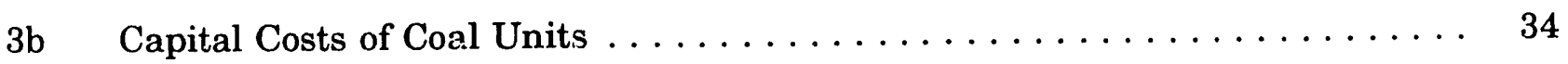

4 Two-Stage Risk Evaluation Process . . . . . . . . . . . . . . . . 42

$5 \quad$ Choice Process under Uncertainty . . . . . . . . . . . . . . . 43

$6 \quad$ Expected Opportunity Cost $\ldots \ldots \ldots \ldots \ldots \ldots \ldots \ldots \ldots \ldots \ldots$

7 The Distribution of Delays by Years before Completion, from the
Population of Delayed Coal-Fired Power Plants $\ldots \ldots \ldots \ldots \ldots \ldots$

8 Difference in Expected Cost of Conventional Technologies and Innovative Technologies $\ldots \ldots \ldots \ldots \ldots \ldots \ldots$

9 Power Pools in the U.S. Simulated in ARGUS . . . . . . . . . . . . . 47

10 Ex Ante Incremental Cost of Risk Calculation Method: Illustrative

Cost Categories and Weights $\ldots \ldots \ldots \ldots \ldots \ldots \ldots \ldots \ldots \ldots \ldots \ldots \ldots \ldots \ldots \ldots$

B.1 Interaction of Build, Dispatch, Emissions and Control,
and Cost Supply and Transportation Modules in ARGUS $\ldots \ldots \ldots$. . . . 168

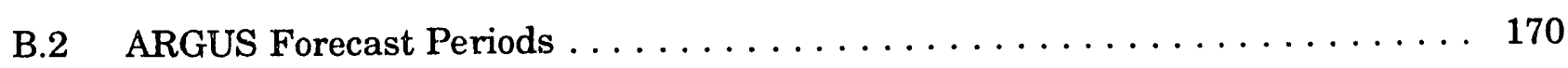

B.3 CSTM Supply Regions $\ldots \ldots \ldots \ldots \ldots \ldots \ldots \ldots \ldots \ldots$

\section{TABLES}

S.1 Categories of Risk: Sources and Iinpacts $\ldots \ldots \ldots \ldots \ldots$

S.2 Risks Associated with Utility Plant Construction $\ldots \ldots \ldots \ldots \ldots$

S.3 Risk Classification . . . . . . . . . . . . . . . . . . . . 8 


\section{TABLES (Cont.)}

S.4 Present Value of Total Revenue Requirement: Utility Analysis _... . . . . 9

S.5 Equity Value per Share by Scenario: Utility Analysis . . . . . . . . . . . . . 10

S.6 Annual $\mathrm{SO}_{2}$ Emissions Attributable to New Baseload Generation:

Utilitv Analysis . . . . . . . . . . . . . . . . . . . . 11

S.7 Annual $\mathrm{NO}_{\mathrm{x}}$ Emissions Attributable to New Baseload Generation:

Utility Analysis . . . . . . . . . . . . . . . . . . . . . 11

S.8 Net Present Value and Payback Periods for Alternative Scenarios:

NUG Analysis . . . . . . . . . . . . . . . . . . . . . 12

S.9 Incentive or Incremental Cost of Risk: NUG Analysis . . . . . . . . . . . 12

S.10 Societal Cost of Alternative Technologies: NUG Analysis . . . . . . . . . . . 12

S.11 Annual $\mathrm{SO}_{2}$ and $\mathrm{NO}_{\mathrm{x}}$ Emissions: NUG Analysis . . . . . . . . . . . 12

1 Categories of Risk: Sources and Impacts $\ldots \ldots \ldots \ldots \ldots$

2 Trends in Construction Costs of Coal-Fired Plants . . . . . . . . . . . 31

$3 \quad$ Number and Length of Construction Delays of Coal-Fired Power Plants . . . . . 32

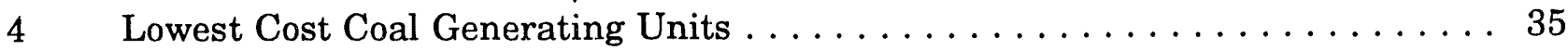

$5 \quad$ Risks Associated with Utility Plant Construction $\ldots \ldots \ldots \ldots \ldots$

$6 \quad$ New CCT Unit Characteristics $\ldots \ldots \ldots \ldots \ldots \ldots \ldots \ldots \ldots$

$7 \quad$ New Gas-Fired Unit Characteristics $\ldots \ldots \ldots \ldots \ldots \ldots \ldots$

8 New Capacity Additions for $1995-2000$ by Pool . . . . . . . . . . . . 50

$9 \quad$ Increase in Unserved Energy, Unserved Energy Costs, and Operating

Costs for a 1 Unit Delay in Power Pool $7 \ldots \ldots \ldots \ldots \ldots \ldots$

10 Increases in Capital Cost for a 1 Unit Delay in Power Pool $7 \ldots \ldots 2$

11 Trends in Estimation of Coal-Fired Plant Costs . . . . . . . . . . 53

12 Power Pool 11 - Increased Operating Costs Associated

with Increased Heat Rate of a PFBC Unit . . . . . . . . . . . . . . . 53

13 Forced Outage System Costs Associated with a PFBC Unit:

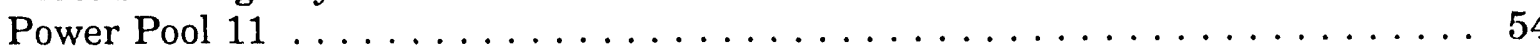




\section{TABLES (Cont.)}

14 Controlled $\mathrm{SO}_{2}$ Emissions Differentials $\ldots \ldots \ldots \ldots \ldots$

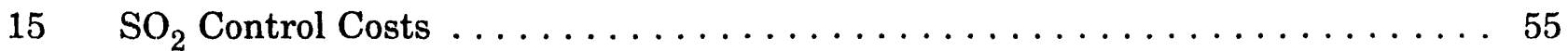

16 Nuclear Unit Cancellations in the Base Case: Status as of June 30, $1982 \ldots \ldots 7$

17 Hypothetical Incremental Cost of Risk $\ldots \ldots \ldots \ldots \ldots \ldots$

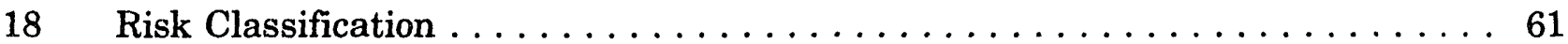

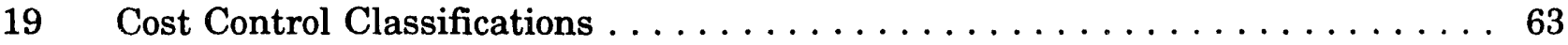

20 Technology Modeling Assumptions $\ldots \ldots \ldots \ldots \ldots \ldots \ldots \ldots$

$21 \quad$ Modeling Assumptions for Capacity and Finance $\ldots \ldots \ldots \ldots \ldots \ldots$

$22 \quad$ Capacity Additions $\ldots \ldots \ldots \ldots \ldots \ldots \ldots \ldots \ldots \ldots \ldots \ldots \ldots \ldots$

$23 \quad$ Fuel Cost $\ldots \ldots \ldots \ldots \ldots \ldots \ldots \ldots \ldots \ldots \ldots \ldots \ldots \ldots \ldots \ldots$

24 Modeling Assumptions for Environmental Criteria $\ldots \ldots \ldots \ldots \ldots$

25 Fixed O\&M. Expenditures Required to Increase Unit Capacity Factors . . . . . 81

26 Present Value of the Sum of Total Revenue Requirements for

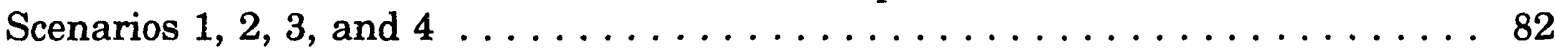

27 Present Value of the Sum of $\mathrm{SO}_{2}$ Allowance Costs at \$500/Allowance

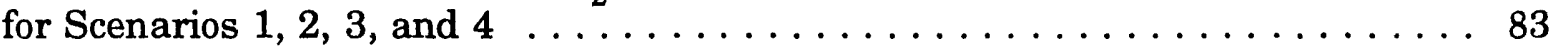

28 Present Value of the Sum of $\mathrm{SO}_{2}$ Allowance Costs at \$200/Allowance

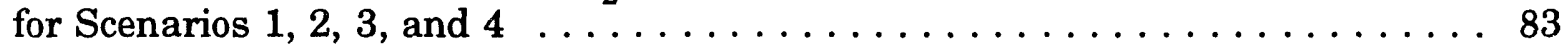

29 Equity Value per Share for Scenarios 1, 2, 3, and $4 \ldots \ldots \ldots \ldots$

30 Present Value of the Sum of Total Revenue Requirements for Scenarios 1, 2, 5, 6, and $7 \ldots \ldots \ldots \ldots \ldots \ldots \ldots \ldots \ldots \ldots \ldots$

31 Present Value of the Sum of $\mathrm{SO}_{2}$ Allowance Costs at $\$ 500 /$ Allowance for Scenarios 1, 2, 5, 6, and 7

32 Present Value of the Sum of $\mathrm{SO}_{2}$ Allowance Costs at \$200/Allowance for Scenarios 1, 2, 5, 6, and 7 


\section{TABLES (Cont.)}

$35 \quad \mathrm{SO}_{2}$ Emissions Attributable to New Baseload Generation $\ldots \ldots \ldots \ldots \ldots 90$

$36 \quad \mathrm{NO}_{\mathrm{x}}$ Emissions Attributable to New Baseload Generation $\ldots \ldots \ldots \ldots \ldots 91$

37 The Risk Perceptions of CCT and the Acceptance of Incentives . . . . . . . . 108

$38 \quad$ Perceptions of Incentives for the Adoption of CCTs $\ldots \ldots \ldots \ldots \ldots \ldots \ldots$

$39 \quad$ Ranking of Incentives for Adoption of CCT . . . . . . . . . . . . . . 109

40 Operational and Construction Characteristics ................. 124

41 Modeling Assumptions for Financial Characteristics . . . . . . . . . . . 125

42 Modeling Assumptions for Environmental Criteria $\ldots \ldots \ldots \ldots \ldots \ldots \ldots$

$43 \quad$ Financial Criteria for Base Case Scenarios $\ldots \ldots \ldots \ldots \ldots \ldots \ldots \ldots$

44 Construction Cost Overrun Scenario with Incentive $\ldots \ldots \ldots \ldots \ldots \ldots \ldots$

45 Forced Outage Rate Scenarios and Incentives $\ldots \ldots \ldots \ldots \ldots \ldots \ldots \ldots$

C.1 $\mathrm{SO}_{2}$ Compliance Costs — Capital and Incremental Costs $\ldots \ldots \ldots \ldots \ldots$

C.2 $\mathrm{SO}_{2}$ Compliance Cost Allowances for Illinois Bituminous $\ldots \ldots \ldots \ldots \ldots 183$

C.3 $\mathrm{SO}_{2}$ Compliance Cost Allowances for Wyoming Subbituminous $\ldots \ldots \ldots \ldots 184$

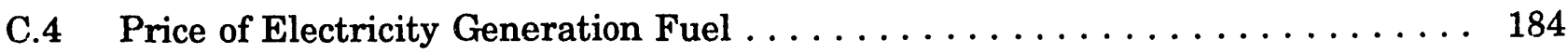

C.5 Marginal Costs per Fuel, O\&M, and $\mathrm{SO}_{2}$ Allowances $\ldots \ldots \ldots \ldots \ldots \ldots$

D.1 CCT Incentive Program: High-Sulfur Coal States

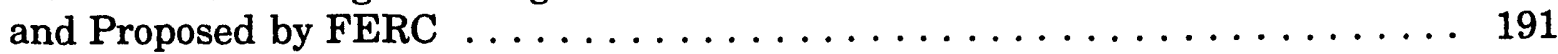




\section{ACKNOWLEDGMENTS}

The authors wish to acknowledge the integral role played by Thomas Grahame of the U.S. Department of Energy, Office of Fossil Energy, in the preparation of this report. His in-depth understanding of power generation issues provided considerable guidance in the definition of scenarios and interpretation of results. The authors also wish to recognize the support, understanding, and patience exercised during some difficult periods of this study.

Two Argonne National Laboratory staff members provided valuable input to the study. K. Guziel simulated the ARGUS model used to determine the incremental cost of risk values for the illustrative utility. E. Bodmer, who developed the Public Utility Planning System used to determine ratepayer impacts, assisted in the model simulations.

Finally, appreciation is extended to N. Sutley, policy director of the National Independent Energy Producers, for assistance in obtaining nonutility generator views on innovative technology adoption and incentive mechanisms, and to the nonutility generators and money market staff who provided valuable insight into their business environment. 


\section{ACRONYMS, INITIALISMS, AND ABBREVIATIONS}

\begin{tabular}{|c|c|}
\hline ABMA & American Boiler Manufacturers Association \\
\hline AFBC & atmospheric fluidized-bed combustor/combustion \\
\hline AFUDC & allowance for funds used during construction \\
\hline A.J & Averch-Johnson \\
\hline APP & affiliated power producers \\
\hline APPI & Argonne Power Plant Inventory \\
\hline $\mathrm{APT}$ & arbitrage pricing theory \\
\hline ARGUS & Argonne Utility Simulation (Model) \\
\hline CAAA & Clean Air Act Amendments of 1990 \\
\hline CAPM & capital asset pricing model \\
\hline CBOT & Chicago Board of Trade \\
\hline $\mathrm{CCT}$ & clean coal technology \\
\hline CCTP & Clean Coal Technology Program \\
\hline $\mathrm{CF}$. & capacity factor \\
\hline $\mathrm{CO}_{2}$ & carbon dioxide \\
\hline COS̆I & cost-of-service index \\
\hline CRA & credit rating approach \\
\hline CSTM & Coal Supply and Transportation Model \\
\hline CWIP & construction work in progress \\
\hline $\mathrm{D}$ & Democrat; member of the Democratic Party \\
\hline DSM & demand-side management \\
\hline $\mathrm{DPU}$ & Department of Public Utilities \\
\hline ECAR & East Central Area Reliability Cocrdination Agreement \\
\hline ECM & Emissions and Controi Module \\
\hline EEI & Edison Electric Institute \\
\hline EIA & Energy Information Administration \\
\hline ELDC & equivalent load duration curve \\
\hline EPA & U.S Environmental Protection Agency \\
\hline EPRI & Electric Power Research Institute \\
\hline ERCOT & Electric Reliability Council of Texas \\
\hline EWG & exempt wholesale generator \\
\hline FAC & fuel adjustment clause \\
\hline FERC & Federal Energy Regulatory Commission \\
\hline FGD & flue-gas desulfurization \\
\hline FOR & forced outage rate \\
\hline FTC & Federal Trade Commission \\
\hline ICARUS & Investigation of Costs and Reliability in Utility Systems \\
\hline ICC & Illinois Commerce Commission \\
\hline ICR & incremental cost oî risk \\
\hline ICTAP & Innovative Control Technology Advisory Panel \\
\hline IGCC & integrated coal gasification combined cycle \\
\hline IPP & Independent Power Producers \\
\hline
\end{tabular}




\begin{tabular}{|c|c|}
\hline IROR & incentive rate of return \\
\hline IRP & integrated resource planning \\
\hline IRS & U.S. Internal Revenue Service \\
\hline LULU & locally undesirable land use \\
\hline MAAC & Mid-Atlantic Area Council \\
\hline MAIN & Mid-America Interpool Network \\
\hline MAPP & Mid-Continent Area Council \\
\hline NAPAP & National Acid Precipitation Assessment Program \\
\hline NARUC & National Association of Regulatory Utility Commissioners \\
\hline NERA & National Economic Research Associates, Inc. \\
\hline NERC & North American Electric Reliability Council \\
\hline NES & National Energy Strategy \\
\hline NGCC & natural gas combined cycle \\
\hline NIEP & National Independent Energy Producers \\
\hline NIMBY & not in my backyard \\
\hline $\mathrm{NO}_{x}$ & oxides of nitrogen \\
\hline NPCC & Northeast Power Coordinating Council \\
\hline NPV & net present value \\
\hline NSR & new source review \\
\hline NUG & nonutility generator \\
\hline $\mathrm{O} \& \mathrm{M}$ & operation and maintenance \\
\hline OTA & Office of Technology Assessment \\
\hline PFBC & pressurized fluidized-bed combustor/combustion \\
\hline P\&L & power and light \\
\hline PSCo. & power service company \\
\hline PSD & prevention of significant deterioration \\
\hline PUC & public utility commission \\
\hline PUHCA & Public Utility Holding Company Act \\
\hline PUPS & Public Utility Planning System \\
\hline PURPA & Public Utility Regulatory Policies Act \\
\hline $\mathrm{QF}$ & qualifying facility \\
\hline $\mathrm{RAC}$ & risk-adjusted cost \\
\hline RAMC & Resource Allocation and Mine Costing \\
\hline $\mathrm{R} \& \mathrm{D}$ & research and development \\
\hline $\mathrm{RD} \& \mathrm{D}$ & research, development, and demonstration \\
\hline RFP & request for proposal \\
\hline $\mathrm{RP}$ & risk premium \\
\hline SEC & Securities and Exchange Commission \\
\hline SERC & Southeastern Electric Reliability Council \\
\hline $\mathrm{SO}_{2}$ & sulfur dioxide \\
\hline SPP & Southeast Power Pool \\
\hline
\end{tabular}


TAG $^{\mathrm{TM}} \quad$ technical assessment guide

TRR total revenue requirements

TVA Tennessee Valley Authority

WSCC Western System Coordinating Council

\section{Units of Measure}

$\begin{array}{ll}\text { Btu } & \text { British thermai unit } \\ \text { d } & \begin{array}{l}\text { day } \\ \text { dollar }\end{array} \\ \$ & \text { gigawatt-hour } \\ \text { GWh } & \text { kilowatt } \\ \text { kW } & \text { kilowatt-hour } \\ \text { kWh } & \text { pound } \\ \text { lb } & \text { million Btu }\left(B t u \times 10^{6}\right) \\ \text { MMBtu } & \text { megawatt } \\ \text { MW } & \text { megawatt (electric) } \\ \text { MWe } & \text { year } \\ \text { yr } & \end{array}$




\title{
EXAMINATION OF INCENTIVE MECHANISMS FOR INNOVATIVE TECHNOLOGIES APPLICABLE TO UTILITY AND NONUTILITY POWER GENERATORS
}

by

\author{
K.A. McDermott, K.A. Bailey, and D.W. South
}

\begin{abstract}
Innovative technolggies, built by either utility or nonutility power generators, have the potential to lower costs with less environmental emissions than conventional technologies. However, the public-good nature of information, along with uncertain costs, performance, and reliability, discourages rapid adoption of these technologies. The effect of regulation of electricity production may also have an adverse impact on motivation to innovate. Slower penetration of cleaner, more efficient technologies could result in greater levels of pollution, higher electricity prices, and, to a certain extent, a reduction in international competitiveness.

Regulatory incentives could encourage adoption and deployment of innovative technologies of all kinds, including clean coal technologies. Such incentives must be designed to offset risks inherent in innovative technology and encourage cost-effective behavior. To evaluate innovative and conventional technologies equally, the incremental cost of risk (ICR) of adopting the innovative technology must be determined. Through the ICR, the magnitude of incentive required to make a utility (or nonutility) power generator equally motivated to use either conventional or innovative technologies can be derived.

Two technology risks are examined: a construction risk, represented by a $15 \%$ cost overrun, and an operating risk, represented by a increased forced outage rate (decreased capacity factor). Different incentive mechanisms and measurement criteria are used to assess the effects of these risks on ratepayers and shareholders. In most cases, a regulatory incentive could offset the perceived risk $s$ while encouraging costeffective behavior by both utility and nonutility power generators. Not only would the required incentive be recouped, but the revenue requirements would be less for the innovative technology; also, less environmental pollution would be generated. In the long term, ratepayers and society would benefit from innovative technologies.
\end{abstract}




\section{SUMMARY}

Innovative technolegies could achieve many domestic energy policy goals delineated in the U.S. Department of Energy's National Er ergy Strategy and satisfy environmental requirements defined in the Clean Air Act Amcndments of 1990 and other environmental legislation. Because of their innovative nature and because they need to be demonstrated satisfactorily at commercial size before they will be commercially accepted, such technologies retain certain perceived technical, operational, or environmental risks. Deployment of innovative technologies with the potential to reduce costs and emissions needs to be accelerated.

Such innovative technologies could include various renewable, nuclear, or fossilfueled generators, as well as mole efficient conservation improvements. This report discusses incentives for innovative clean mal technologies, although the incentives could apply to other innovative technologies.

Regulatory incentives can encourage accelerated deployment of innovative technologies. The environment for adopting innovative technologies is characterized by uncertainties associated with construction costs, reliability, and operating costs. These uncertainties represent significant risks that must be reduced to encourage managers to adopt an innovative plant or technology design. Regulatory incentives can be used to either reduce the risk of adopting a precommercialized technology or re , ard a firm for adopting an innovative technology. In addition, regulatory incentives can be used to improve efficiency in the construction and operation of innovative technologies. Incentives can tie rewards and penalties to unit reliability, or systematic incentives can include price caps to encourage firms to reduce costs and thereby produce short-run profits.

Figure S.1 summarizes the effects of incentive on the adoption of technology. Using incentives to mitigate extraordinary risks allows more rapid achievement of policy goals without causing undue losses to society. It also encourages efficient construction and operation of innovative technologies. This report discusses both types of incentive and presents a practical method of risk analysis that can be applied to accelerate the commercial deployment of the innovative technology. Hypothetical applications of regulatory incentives to innovative technologies are given for nonutility generators (NUGs) and the utility sector.

Risk analysis is a multistage process that first addresses the probability of an event occurring and then examines the probability of a range of consequences from that event, as indicated in Figure S.2. Risk analysis can lead to inferences about the expected cost of adopting an innovative technology. Risk analysis and estimation of expected costs, in turn, can lead to inferences about the magnitude of the incentives required to offset the expected costs of adopting the innovative technology. The expected costs of adopting a conventional technology are compared with those of adopting an innovative technology. The difference is the risk-adjusted cost of the technology, which can form the basis for an examination of the magnitude of the incentive. 


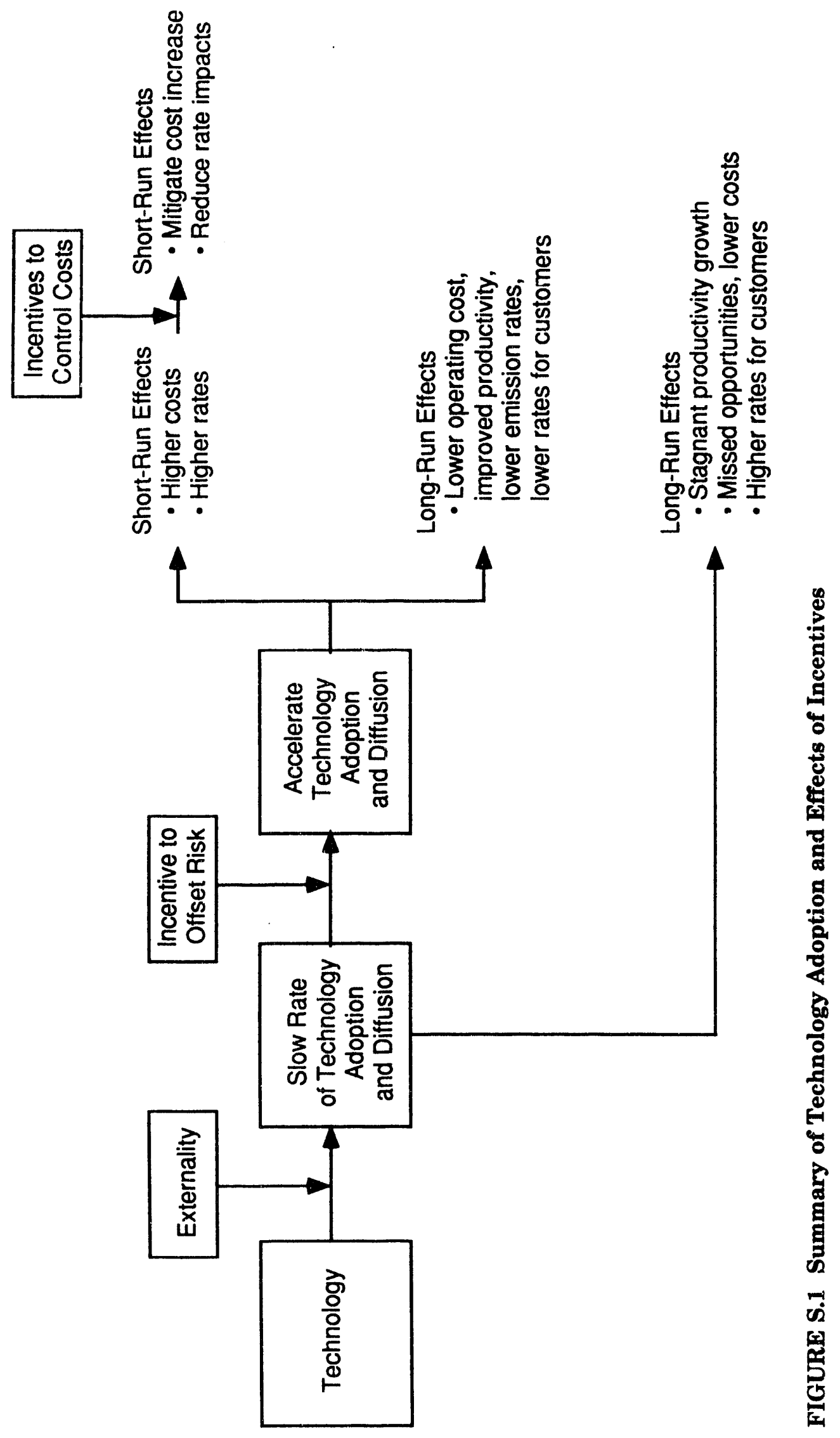



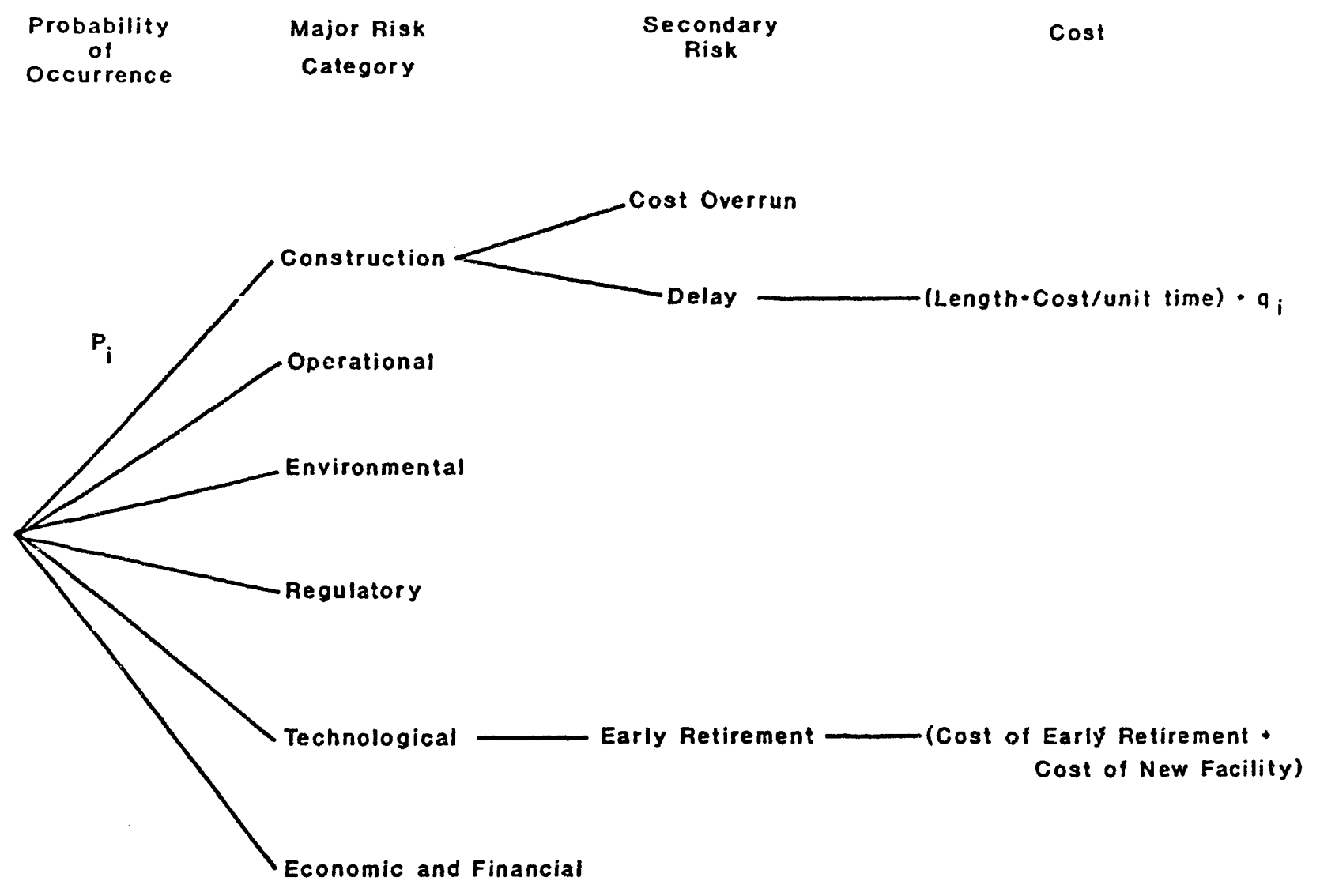

FIGURE S.2 Expected Opportunity Cost

The size and type of incentive needed to induce a utility or NUG to adopt an innovative technology depend on a number of variables. Each state commission, utility, or NUG needs to examine the range of uncertainties and opportunity costs that pertain to the technology under consideration and the conditions (financial, operational, and technical) facing the firm that is making the choice. No single rule can be applied; incentives are, in a certain sense, idiosyncratic and must be tailored to specific circumstances. Utilities and NUGs also face fundamentally different operating and financial conditions. Commissions can develop a number of incentive options and allow a utility or NUG to select the option that offsets its perceived risks most directly.

Consumers do not need to offer incentives for a large number of plants before an innovative technology can be deployed. As depicted in Figure S.3, the technology only needs to be applied to a few generating units to resolve any related problems and uncertainties and derive accurate costs and operating characteristics. Therefore, incentive programs are inherently of a limited nature and involve only a few projects. In certain cases, utilities and NUGs could adopt or request incentives that might not affect the costs paid by customers. For example, commissions could approve a prospective cap on construction costs that would be included in the rate base if the project, were abandoned. This type of incentive might reduce the perceived risk of undertaking a project, which, if successful, would result in no 


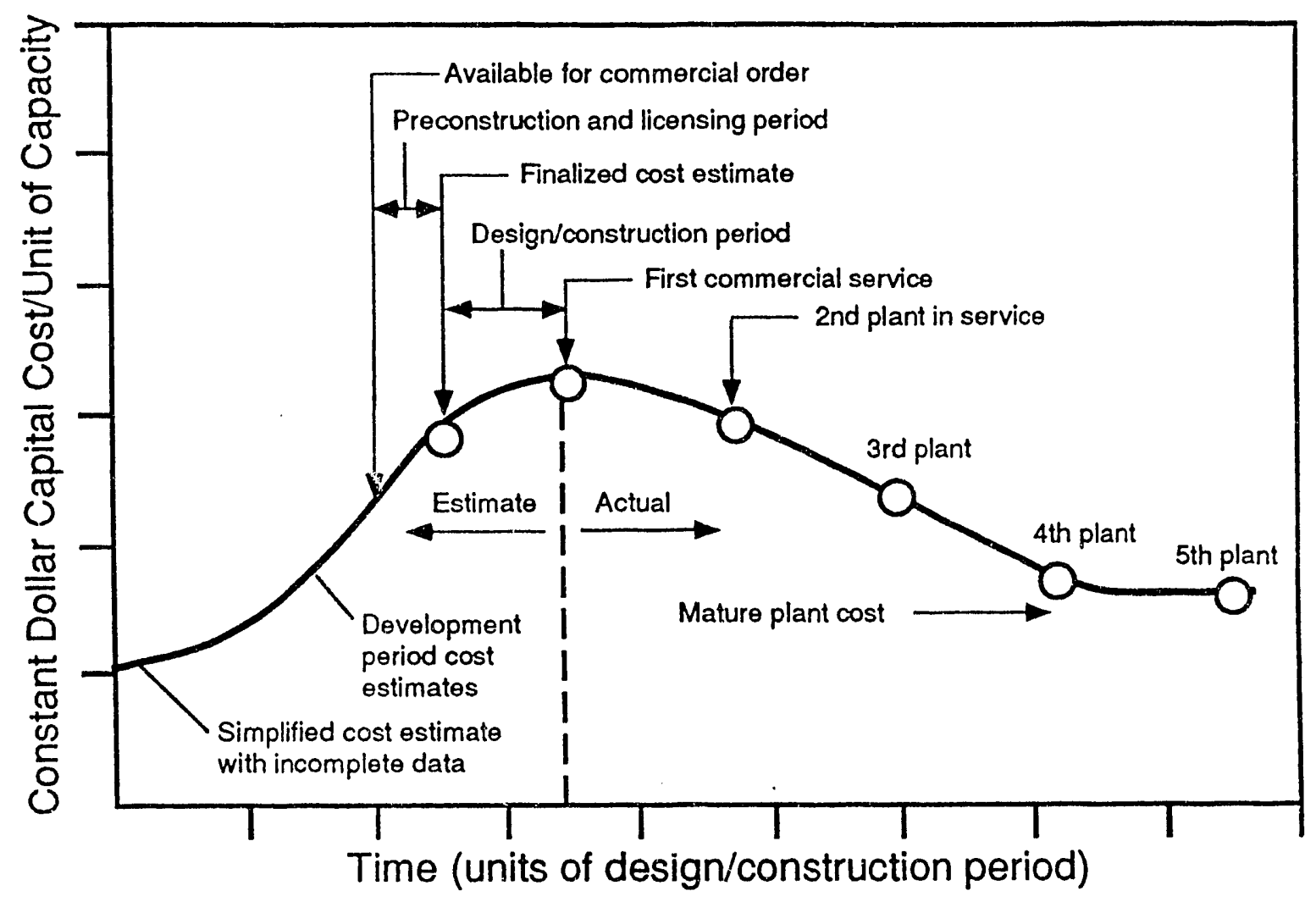

\section{FIGURE S.3 Capital Cost Learning Curve}

additional costs to ratepayers. In fact, such an incentive could potentially lower the ultimate costs to the consumer, if the financial community were to perceive the innovative technology in a positive (or less risky) light and reduce the cost of capital to the utility or NUG.

Six major categories of risk exist for utilities that adopt innovative generating technologies: (1) capital or construction risk, (2) performance or operational risk, (3) environmental risk, (4) technological risk, (5) economic and financial risk, and (6) regulatory risk. Within each of these risk categories are secondary (consequences) risks. The major and secondary risks are indicated in Table S.1. Incentives can be used to (1) reduce the risk of adopting an innovative technology and (2) reward the firm for adopting an innovative technology. ${ }^{1}$ Table S.2 indicates the dual role of incentives in reducing and rewarding risk for utilities. Table S. 3 summarizes plant construction risks and the incentives that can be used to mitigate those risks.

1 The reward for risk-taking encourages efficiency in the utility. By allowing the utility to choose from a menu of incentive programs, the public utility commission gains information on those risks the utility regards as particularly threatening, and the utility incurs fewer "transiction" costs in implementing an incentive that it chooses (it does not have io adapt to an incentive that it considers unwieldy). 
TABLE S.1 Categories of Risk: Sources and Impacts

1. Construction risk

- Risk of delay

- Cost overrun/capital cost risk

2. Operational risk

- Efficiency risk (heat rate)

- Operational and maintenance risk

- Availability/reliability risk

3. Environmental risk

- Emission control risk

- Waste treatment risk

- Siting risk

- Future regulatory risk

4. Technological risk

- Premature obsolescence/early retirement (exogenous forces)

- Technical change

- Regulatory change

- Economic change

- Technology failure/early retirement (endogenous forces)

- Abandon project before completion

- Abandon project after completion

5. Economic and financial risk

- Reduced demand for output

- Perceived financial risk (bond/stock ratings)

- Other exogenous shocks

6. Regulatory risk

- Regulatory lag

- Cost recovery risk

- Ratebase disallowance

a. Prudent expenditure test

b. Used and useful test

- Operating cost disallowence

Policymakers can use an ex ante analysis of risk to estimate the magnitude of incentive required to encourage firms to adopt innovative technologies. This type of analysis can provide an incentive to use the innovative technology more efficiently. Ex ante analysis in this case implies an examination of risks associated with different innovative technologies before they are adopted/constructed. This report addresses the risk of construction cost overruns and increased forced outage rates for pressurized fluidized-bed combustion (PFBC) units in utility applications and for integrated gasification combined cycle (IGCC) units in NUG applications. ${ }^{2}$

2 The technologies selected are for illustrative purposes only and do not convey a technology preference by either utilities or NUGs. 
TABLE S.2 Risks Associated with Utility Plant Construction

\begin{tabular}{|c|c|c|c|}
\hline $\begin{array}{l}\text { Life-Cycle } \\
\text { Stage }\end{array}$ & Risk & $\begin{array}{l}\text { Regulatory } \\
\text { Issue }\end{array}$ & $\begin{array}{l}\text { Sharing } \\
\text { Procedure }\end{array}$ \\
\hline \multirow[t]{2}{*}{ Construction } & Delay & $\begin{array}{l}\text { Treatment of cost } \\
\text { increases }\end{array}$ & Use of cost caps \\
\hline & Cancellation & $\begin{array}{l}\text { Treatment of } \\
\text { sunk costs }\end{array}$ & $\begin{array}{l}\text { Limitations on } \\
\text { construction work in } \\
\text { progress (CWIP) } \\
\text { Partial return of } \\
\text { investment costs } \\
\text { overtime } \\
\text { Limit return on } \\
\text { unamortized costs }\end{array}$ \\
\hline \multirow[t]{2}{*}{$\begin{array}{l}\text { Addition to } \\
\text { available } \\
\text { generation }\end{array}$} & Excess capacity & $\begin{array}{l}\text { Treatment of } \\
\text { excess capacity }\end{array}$ & $\begin{array}{l}\text { Partial inclusion of } \\
\text { investment in rate } \\
\text { base } \\
\text { Exclusion of other } \\
\text { capacity from rate } \\
\text { base }\end{array}$ \\
\hline & Rate shock & $\begin{array}{l}\text { Methods for } \\
\text { inclusion } \\
\text { in rate base }\end{array}$ & $\begin{array}{l}\text { Phase-in } \\
\text { Partial inclusion } \\
\text { in rate base } \\
\text { "Mirror" CWIP }\end{array}$ \\
\hline \multirow[t]{2}{*}{ Operation } & $\begin{array}{l}\text { Failure to } \\
\text { operate as } \\
\text { planned }\end{array}$ & Cost of repairs & $\begin{array}{l}\text { Phase-in } \\
\text { Grant partial recovery }\end{array}$ \\
\hline & & $\begin{array}{c}\text { Cost of replacement } \\
\text { power and energy }\end{array}$ & $\begin{array}{l}\text { Grant partial recovery } \\
\text { of replacement costs } \\
\text { Performance } \\
\text { standards with } \\
\text { penalties }\end{array}$ \\
\hline \multirow[t]{2}{*}{ Retirement } & Early retirement & $\begin{array}{c}\text { Cost of replacement } \\
\text { power and energy }\end{array}$ & $\begin{array}{l}\text { Partial recovery of } \\
\text { remaining plant } \\
\text { costs }\end{array}$ \\
\hline & $\begin{array}{l}\text { Retirement } \\
\text { allowance } \\
\text { inadequate }\end{array}$ & Excess costs & $\begin{array}{l}\text { Limit return on } \\
\text { unamortized costs } \\
\text { Partial recovery of } \\
\text { replacement costs } \\
\text { Partial recovery of } \\
\text { excess costs }\end{array}$ \\
\hline
\end{tabular}

Source: Stutz (1986). 
TABLE S.3 Risk Classification

\begin{tabular}{|c|c|c|c|c|}
\hline $\begin{array}{c}\text { Type } \\
\text { of } \\
\text { Incentive }\end{array}$ & Capital Risk & $\begin{array}{c}\text { Performance/ } \\
\text { Operating Risk }\end{array}$ & Regulatory Risk & $\begin{array}{c}\text { Environmental } \\
\text { Risk } \\
\end{array}$ \\
\hline \multirow[t]{2}{*}{$\begin{array}{l}\text { Reduce } \\
\text { project } \\
\text { risk }\end{array}$} & $\begin{array}{l}\text { Prospective } \\
\text { prudency } \\
\text { preapproval } \\
\text { capital } \\
\text { expense caps }\end{array}$ & $\begin{array}{l}\text { Immediate cost } \\
\text { recovery } \\
\text { through fuel } \\
\text { adjustment } \\
\text { clauses of } \\
\text { clean coal } \\
\text { technology } \\
\text { (CCT) expen- } \\
\text { ditures }\end{array}$ & $\begin{array}{l}\text { Elimination of } \\
\text { retroactive } \\
\text { used and } \\
\text { useful tests }\end{array}$ & $\begin{array}{l}\text { Preapproval } \\
\text { accelerated } \\
\text { siting process }\end{array}$ \\
\hline & $\begin{array}{l}\text { Construction } \\
\text { work in } \\
\text { progress }\end{array}$ & & $\begin{array}{l}\text { Prudent } \\
\text { abandonment } \\
\text { rules }\end{array}$ & \\
\hline \multirow[t]{2}{*}{$\begin{array}{l}\text { Reward } \\
\text { risk } \\
\text { taking }\end{array}$} & $\begin{array}{l}\text { Incentive rate of } \\
\text { return }\end{array}$ & $\begin{array}{l}\text { Rapid } \\
\text { amortization } \\
\text { of CCT } \\
\text { expenditures }\end{array}$ & $\begin{array}{l}\text { Amortization of } \\
\text { abandoned/ } \\
\text { canceled } \\
\text { plants }\end{array}$ & $\begin{array}{l}\text { Discretionary } \\
\text { use of bonus } \\
\text { emission } \\
\text { allowances }\end{array}$ \\
\hline & & $\begin{array}{l}\text { Additional cost } \\
\text { recovery via } \\
\text { avoided cost } \\
\text { pricing for } \\
\text { CCT }\end{array}$ & & \\
\hline
\end{tabular}

The utility analysis entailed the comparison of pulverized coal/flue-gas desulfurization (PC/FGD) capacity additions versus PFBC capacity additions with and without regulatory incentives in terms of ratepayer impacts and shareholder equity. It assumes that risk events could occur with respect to the first two PFBC units (e.g., construction overruns and environmental control failure). All subsequent PFBC units (called second-generation units) are assumed to have technical improvements in terms of operating efficiencies and reduced construction costs that preclude the need for riskcompensating incentives.

Several scenarios are used to examine the impact on rates and shareholder equity of (1) an assumed construction cost overrun of $15 \%$ and (2) an assumed increase in forced outage rates that could occur with the introduction of a precommercial technology, such as a PFBC. The incentives used were a sliding-scale cost-sharing incentive for the construction cost overrun (and "underrun") and a sliding-scale mechanism rewarding the firm for reducing the forced outage rate on the basis of the magnitude of the reduction. Table S.4 indicates the impact on ratepayers from the use of alternative technologies and incentives in the case of 
TABLE S.4 Present Value of Total Revenue Requirement: Utility Analysis

\begin{tabular}{lrrrr}
\hline & \multicolumn{4}{c}{$\begin{array}{c}\text { Present Value of Total Revenue } \\
\text { Requirement, by Year }\left(1990 \$ 10^{6}\right)\end{array}$} \\
\cline { 2 - 5 } \multicolumn{1}{c}{ Capacity Added } & 2000 & 2005 & 2010 & 2015 \\
\hline PC/FGD & 14,538 & 19,261 & 23,154 & 26,311 \\
PFBC & 14,514 & 19,131 & 22,759 & 25,616 \\
& {$[+23]^{\mathrm{a}}$} & {$[+129]$} & {$[+395]$} & {$[+694]$} \\
Incentive/forced-outage rate & 14,536 & 19,164 & 22,795 & 25,653 \\
& {$[+2]$} & {$[+97]$} & {$[+360]$} & {$[+658]$} \\
Incentive/cost overrun & 14,665 & 19,282 & 22,910 & 25,768 \\
& {$[-127]$} & {$[-21]$} & {$[+244]$} & {$[+543]$} \\
\hline
\end{tabular}

a Bracketed number indicates savings from adopting PFBC.

a risk event confronted by a regulated utility. The impact on shareholder equity value per share is indicated in Table S.5. In the case of the forced outage rate with the applied kilowatt-hour premium, the incentive compensates the adopting utility for added fixed operations and maintenance expenditures needed to correct the forced outage rate. While ratepayers must pay the cost of the incentive ( $\$ 36$ million, $1990 \$$ ), fuel savings more than compensate for the added expenditures. In the case of the $15 \%$ construction cost overrun, ratepayers pay half the cost of the overrun ( $\$ 148$ million, $1990 \$$ ). Although ratepayers pay an additional cost in early years, significant savings are realized after 2010.

Equity value per share is a measure of one value of one company to shareholders. In Table S.5, in all but the year 2000, the adoption of PFBC under any scenario is preferable to shareholders.

As indicated in Figure S.4, regulatory incentives generate significant cost savings. In the forced outage rate scenario, the incentive cost is $\$ 36$ million (1990 $\$$ ). The total revenue requirement savings (as compared to the total revenue requirements of the $\mathrm{PC} / \mathrm{FGD}$ scenario) is $\$ 658$ million (1990 \$) in 2015. The ratio of incentive cost to total revenue requirement savings is $1: 18$. In the incentive with the $15 \%$ cost overrun scenario, the incentive cost is $\$ 148$ million ( $1990 \$$ ). The total revenue requirement savings (as compared to the total revenue requirements of the PC/FGD scenario) is $\$ 543$ million (1990 $\$$ ) in 2015. The ratio of incentive cost to total revenue requirement savings is 1:3.7.

Also of interest are the relative sulfur dioxide $\left(\mathrm{SO}_{2}\right)$ and oxides of nitrogen $\left(\mathrm{NO}_{\mathrm{x}}\right)$ emissions resulting from the addition of PC/FGD capacity versus the addition of PFBC technology. The $\mathrm{SO}_{2}$ and $\mathrm{NO}_{\mathbf{x}}$ emissions are indicated in Tables S.6 and S.7, respectively. 
TABLE S.5 Equity Value per Share by Scenario: Utility Analysis

\begin{tabular}{lllll}
\hline & \multicolumn{4}{c}{$\begin{array}{c}\text { Equity } \\
\text { Value per Share, by Year } \\
(1990 \$)\end{array}$} \\
\cline { 2 - 5 } \multicolumn{1}{c}{ Capacity Added } & 2000 & 2005 & 2010 & 2015 \\
\hline & & & & \\
PC/FGD & 16.65 & 21.77 & 25.89 & 29.72 \\
PF'3C & 16.87 & 27.45 & 30.14 & 32.63 \\
Incentive/forced-outage rate & 16.81 & 27.45 & 30.15 & 32.64 \\
Incentive/cost overrun & 15.87 & 26.89 & 29.97 & 31.24 \\
\hline
\end{tabular}

\section{Millions of 1990 \$}

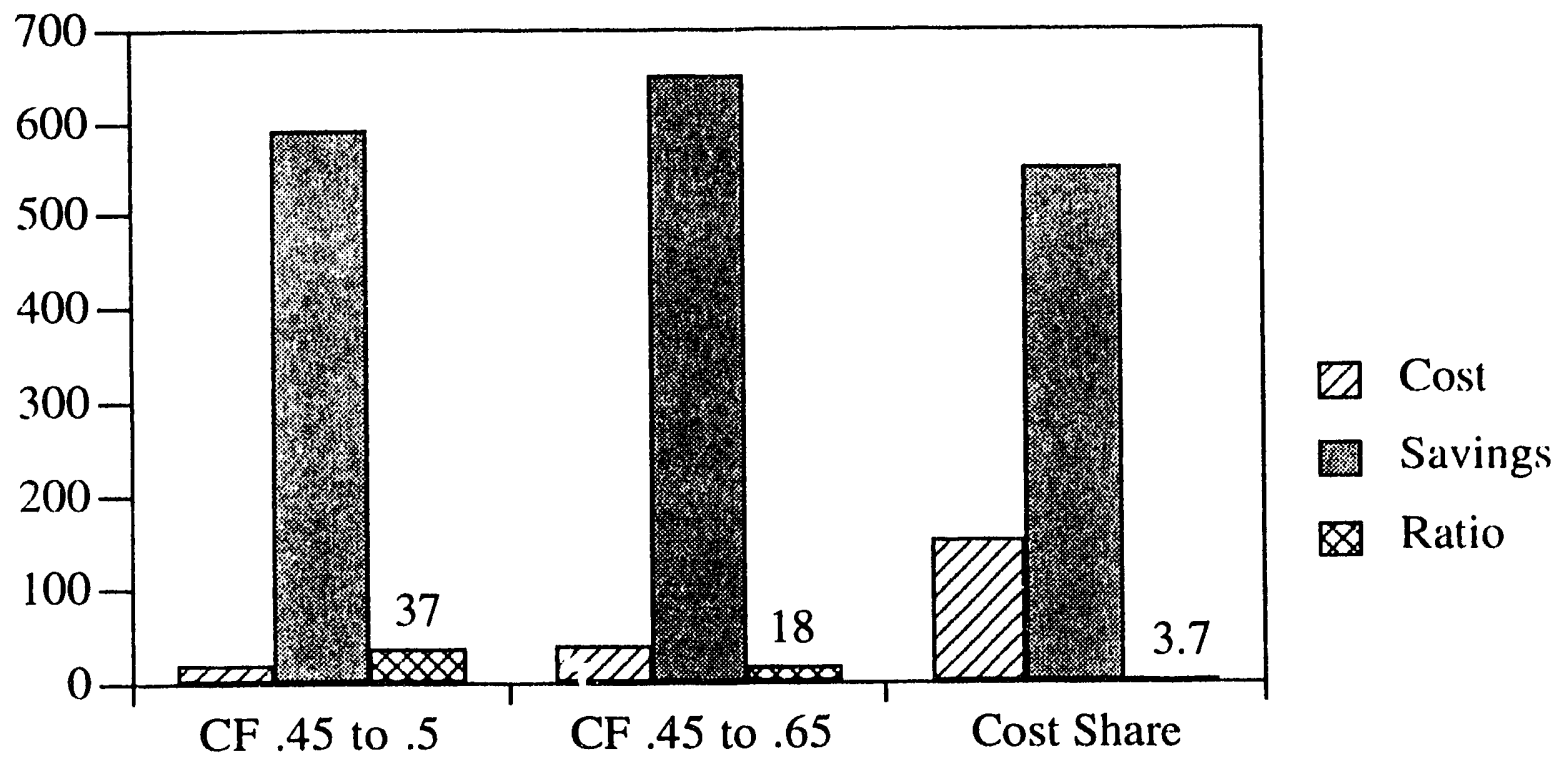

FIGURE S.4 Incentive Cost and Total Revenue Requirement Savings in 2015 (CF = capacity factor)

As indicated in the scenarios, although (year 2000) near-term losses could result from the adoption of incentives for an innovative clean coal technology, the long-run benefits to ratepayers, utility shareholders, and the environment are considerable and offset near-term losses.

The NUG regulatory incentive analysis compares a PC/FGD project with an IGCC project of similar size. Two possible risk events are associated with the adoption of the IGCC: a 15\% construction cost overrun and an increased forced outage rate. To address the risk of construction cost overrun, a sliding-scale cost-sharing mechanism splits the overrun cost between the NUG/developer and the host utility through a front-end loading of the 
TABLE S.6 Annual $\mathrm{SO}_{2}$ Emissions Attributable to New Baseload Generation: Utility Analysis

\begin{tabular}{|c|c|c|c|c|}
\hline \multirow[b]{2}{*}{ Technology } & \multicolumn{4}{|c|}{$\mathrm{SO}_{2}$ Emissions, by Year ( $10^{3}$ tons $)$} \\
\hline & 2000 & 2005 & 2010 & 2015 \\
\hline $\mathrm{PC} / \mathrm{FGD}$ & 26,689 & 40,033 & 53,378 & 76,254 \\
\hline PFBC & 11,930 & 18,369 & 24,808 & 35,846 \\
\hline
\end{tabular}

TABLE S.7 Annual NO Emissions Attributable to New Baseload Generation: Utility Analysis

\begin{tabular}{lcccc}
\hline & \multicolumn{4}{c}{ NO $_{\mathbf{x}}$ Emissions, by Year (tons) } \\
\cline { 2 - 5 } \multicolumn{1}{c}{ Technology } & 2000 & 2005 & 2010 & 2015 \\
\hline \multirow{2}{*}{ PC/FGD } & & & & \\
PFBC & 23,946 & 35,994 & 47,994 & 68,560 \\
\hline
\end{tabular}

demand charge. To address the risk of the forced outage rate, a bonus based on the availability of the unit is added to the demand charge. The company is given an incentive to decrease the forced outage rate. Two criteria are evaluated to determine the impact of the incentives and technology choice: the debt payback period and the net present value (NPV) of the project.

The NPV and payback period of the alternative scenarios are indicated in Table S.8. To determine the magnitude of the ex ante incentive, probabilities of a risk event occurring were assigned: The probability of a construction cost overrun is 0.5 , the probability of an irreparable increased forced outage rate is 0.2 , and the probability of a repairable forced outage rate is 0.4 . Table S.9 shows the level of incent ve required to make the firm indifferent to the choice between PC/FGD and IGCC, given the indicated risks.

On a societal basis, total costs (i.e., operational, construction, $\mathrm{SO}_{2}$ allowance purchase, and incentive costs) along with the associated risk events are considered for the alternative technologies. If previously specified probabilities of the risk events occurring are assumed, the societal costs of the alternative technologies would be as indicated in Table S.10. Table S.11 indicates the annual $\mathrm{SO}_{2}$ and $\mathrm{NO}_{\mathrm{x}}$ emissions associated with each unit.

As indicated in Figure S.5, regulatory incentives generate significant cost savings. In the incentive with the forced outage rate scenario, the incentive demand charge's cost is $\$ 8.05$ million (1992 \$). The societal savings (as compared to the total costs of the PC/FGD) 
TABLE S.8 Net Present Value and Payback Periods for Alternative Scenarios: NUG Analysis

\begin{tabular}{lcc}
\hline \multicolumn{1}{c}{ Scenario } & $\begin{array}{c}\text { Debt } \\
\text { Payback } \\
\text { Period (yr) }\end{array}$ & $\begin{array}{c}\text { Net Present Value } \\
\left(1992 \$ 10^{6} ;\right. \\
30 \text {-year life })\end{array}$ \\
\hline PC/FGD & 16 & 2.21 \\
IGCC & 16 & 54.56 \\
IGCC/15\% & 21 & -78.95 \\
$\quad$ construction cost overrun & & -127.43 \\
IGCC/increased \\
forced outage rate
\end{tabular}

TABLE S.9 Incentive or Incremental Cost of Risk (ICR): NUG Analysis

\begin{tabular}{lc}
\hline Scenario/Incentive & $\begin{array}{l}\text { Incentive or ICR } \\
\text { Level }\left(1992 \$ 10^{6}\right)\end{array}$ \\
\hline Cost overrun/sliding-scale, front-end loading & 16.51 \\
Forced outage rate/energy charge incentive & 8.05 \\
\hline
\end{tabular}

TABLE S.10 Societal Cost of Alternative Technologies: NUG Analysis

\begin{tabular}{lc}
\hline \multicolumn{1}{c}{ Scenario } & $\begin{array}{c}\text { Net Present } \\
\text { Value of } \\
\text { Social Costs } \\
\left(1992 \$ 10^{6}\right)\end{array}$ \\
\hline PC/FGD & 1,592 \\
IGCC/possible 15\% construction & 1,513 \\
cost overrun & 1,559 \\
outage rate & \\
\hline
\end{tabular}

TABLE S.11 Annual $\mathrm{SO}_{2}$ and NO Emissions: NUG Analysis (tons)

\begin{tabular}{lrr}
\hline $\begin{array}{l}\text { Annual } \\
\text { Emissions }\end{array}$ & \multicolumn{1}{c}{$\mathrm{SO}_{2}$} & \multicolumn{1}{c}{$\mathrm{NO}_{\mathrm{x}}$} \\
\hline IGCC & 530.68 & 796.02 \\
PC/FGD & $2,859.53$ & $2,142.51$ \\
\hline
\end{tabular}




\section{Millions of $1992 \$$}

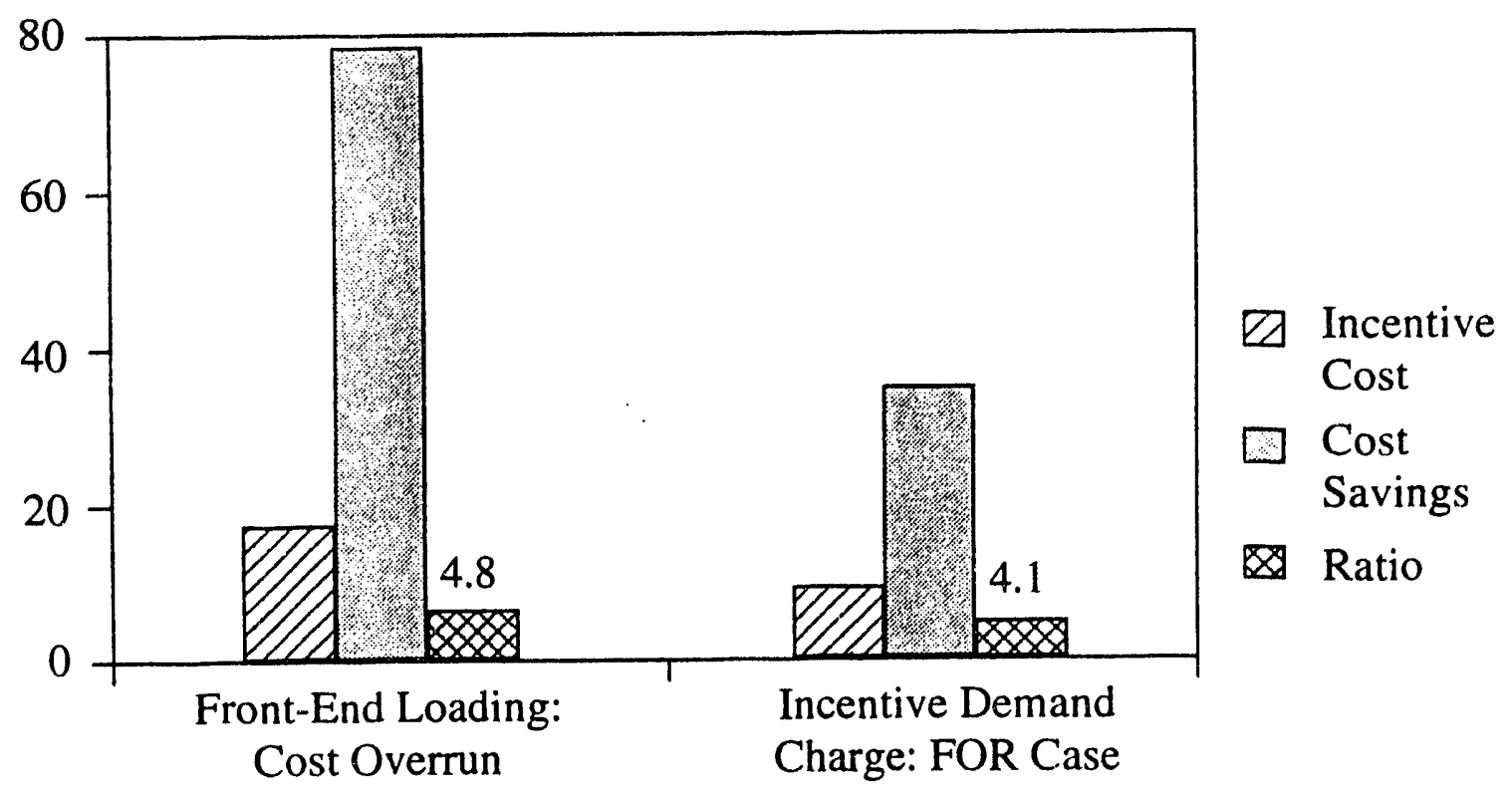

FIGURE S.5 Incentive Cost and Societal Savings in 2015 (FOR = forced outage rate)

is $\$ 33$ million (1992 \$). The ratio of incentive cost to societal savings is 1:4.1. In the incentive with the $15 \%$ cost overrun scenario, the front-end loading of the cost overrun incentive cost is $\$ 16.51$ million (1992 \$). The societal savings (as compared to the total cost of the PC/FGD) is $\$ 79$ million (1992 $\$$ ). The ratio of incentive cost to total revenue requirement savings is $1: 4.8$.

Society benefits from use of regulatory incentives to encourage adoption of IGCC (or to make the company indifferent to which project is chosen). Given the two possible risk event scenarios, the IGCC is clearly a superior choice from a social perspective.

Regulatory incentives can address the issue of innovative technology adoption, and ex ante risk analysis can assess the magnitude and type of incentive required to encourage the adoption of innovative technologies. As demonstrated by the results of the utility and NUG scenarios, innovative CCTs, although they can increase risks associated with construction and operation, can be beneficial to society and the utility/NUG. The commercial implementation of CCTs will be more rapid if regulatory incentives are used to address the risk problems. 


\section{INTRODUCTION}

The purpose of this report is to identify and assess the process through which perceived technological risks influence the choice of power plant technologies by power generators in regulated and unregulated markets. In addition, this report examines the potential effects that incentive programs can have on both the choice of innovative technologies, by mitigating the perceived risks, and the effort to control project costs. By explicitly identifying the role played by perceived risks and the potential for incentive mechanisms to cost-effectively reduce these impediments to the adoption of innovative technologies, this report is designed to help public policymakers and regulators recognize the valuable role that incentive mechanisms can play as a strategic policy option.

The concepts of risk and uncertainty manifest themselves within the power generating industry and regulatory process in a number of ways. This report attempts to achieve these objectives:

- Assess (as comprehensively as possible) the many dimensions of risk that can affect the choice of technology.

- Develop a conceptual framework to quantify the perceived cost impacts that influence capacity planners and utility management in general; provide hypothetical examples to highlight the use of this conceptual framework in estimating the cost effects resulting from the risk exposure when innovative technologies are examined.

- Evaluate how alternative incentive mechanisms can apply to overcome innovative technology risks and control project costs.

The estinated costs that are developed in the hypothetical case illustrate how this evaluation process can be used by policymakers and regulators to establish targeted incentive programs designed to mitigate the perceived risks and overcome the barriers to adopting innovative technologies. To make the examples concrete, clean coal technologies (CCTs) are used to highlight the applicability of incentive mechanisms. ${ }^{3}$

The perceived risks of adopting innovative technologies affect the direct analysis of the expected costs of constructing a new plant as estimated by both utility and nonutility generator (NUG) planners. In addition, these risks play a fundamental role in evaluating the expected rate base and financial impact to which a utility will expose itself when undertaking a construction program. Given the wide variety of potential incentive mechanisms, a thorough analysis requires the development of some form of financial and rate impact criteria

3 Amendments proposed by Senator Ford (D-Ky.) to S. 1220 (National Energy Security Act of 1991) during Congressional mark-up reflect one example in which incentive mechanisms are currently being advocated. In 1989, incentives were also endorsed by the Innovative Control Technology Advisory Panel (ICTAP) as a means of stimulating CCT development (ICTAP 1989). 
that can allow policymakers/regulators to evaluate the appropriateness and applicability of particular incentives under the variety of utility/NUG conditions that may arise. Such an analysis is developed in this report to assist regulatory commissions and public policymakers in implementing incentive policies.

\subsection{PROBLEM CONTEXT}

To clarify the scope of this research effort, the context in which the technology choice problem arises must be clearly defined. As will become obvious, the problems inherent in the selection of a new plant's technology are not restricted to regulated firms. The problems face competitive markets as well and have been a source of major policy concern to government agencies overseeing the competitiveness of the market economy and the efficiency of regulated industries. The reason for this concern is clear. It is only through the adoption of new technical processes that a dynamic economy can improve its efficiency and pass the benefits of technical progress on to consumers. If impediments to this progress arise, the entire economy and society at large will experience a reduction in their potential standard of living.

At the same time that policymakers are facing the need to stimulate technological innovation, there is also the need to provide regulated and nonregulated firms an incentive to control the costs of the innovative project being developed. In effect, there is a dual incentive problem, in which an incentive is necessary to induce risk taking in the development of innovative technologies and simultaneously to control the costs of constructing and operating the new plant. Furthermore, in examining the nature of incentives, there are two distinct levels at which the incentive may operate. In the most general case, a systemic incentive is part of the overall process (e.g., the incentives associated with the competitive process or traditional rate-base, rate-of-return regulation). Incentives can also be created to meet specific or targeted problems such as power plant performance, construction cost control, or fuel cost control. In this report, both types of incentives (risk mitigating and cost control) as well as environments (systematic and specific) are examined.

To understand the nature of the impediments to adopting new innovative technologies, a brief examination is needed of the institutional context within which regulated and unregulated firms will be rewarded or penalized for accepting the risks associated with adopting an innovative technology. To simplify this exposition, the analysis focuses on the energy industry.

\subsubsection{Incentives to Mitigate Innovative Technology Risks}

Innovation is at the heart of the dynamic, competitive process. To obtain greater profit and a larger market share, firms should invest in the development and commercial application of new cost-saving methods of production. By lowering costs, firms in a competitive market can temporarily reduce their costs below the market price, expand sales, 
and earn the reward of a larger profit. In the long run, competitors will mimic these innovations and reestablish a balance in the market.

Regulation, to the extent that it is designed to mimic the competitive process, should be designed to provide utilities with the incentive to adopt cost-saving innovations to achieve a long-run efficient level of production. Unfortunately, in both competitive and regulated markets, rational decision makers must recognize the actual complexities of undertaking innovative investment projects when uncertainty and technological externalities exist. The simple truth of the matter is that technologies are, to a certain extent, organic in nature. The life cycle of a technology involves a significant learning curve as well as a flow of marginal improvements over its life. As Rosenberg (1982) noted, the expected improvements to existing technologies can lead to a slower diffusion of new technologies. There is, in effect, a bias to work with a familiar process rather than switching to an unfamiliar technique of production. The possibility of falling behind in the cost competition by improving existing processes is perceived as being less risky than switching to a new technology that could potentially fail and leave the firm bankrupt. Moreover, as Cowan (1991) has noted:

When competing technologies are being adopted sequentially, if there is uncertainty about the relative merits of the competitors, the market will under-supply experimentation. There is no incentive for an adopter to experiment with what appears to be an inferior technology in hope of improving the estimate of its merit.

In effect, if a firm adopts and perfects a technology, it is providing information to competitors that can take advantage of this information to the original innovator's disadvantage. As a result, there is an externality associated with innovation that cannot be capitalized by the innovator. As Cowan (1991) suggests, this situation allows for the following policy option:

A central authority can internalize this externality, and so raise the expected discounted value of a stream of adoptions. This suggests there is a place for intervention.

This externality has been given the label "learning externality," and it takes two basic forms: (1) lower construction and operating costs for future plants and (2) improved cost of construction forecasts. Zimmerman (1982, p. 287), in discussing the development of nuclear power, noted that:

The policy debate has centered on the wisdom of government subsidy for the construction of large-scale commercial plants. The goal of subsidizing the plants is not to produce new technological information, since the technology is already proved. Rather, the goal is to overcome obstacles to the introduction of the technology by the private sector.

The problem to be faced is the failure of private incentives to achieve the maximum utilization of a technology that benefits society but does not necessarily benefit the firm 
exposed to the risks of developing the technology. This private market failure constitutes the source of intervention by society in the choice of technology.

The choice of technology is further complicated by the existence of pervasive uncertainties that persist throughout the normal diffusion process associated with a new technology. Sommers (1980), in his analysis of nuclear power generation, identified three critical uncertainties: capital costs, reliability, and construction lead time.

In making a rational decision on the choice of technologies, the decision maker is faced with comparing the well-defined capital cost of proven, state-of-the-art technology with the expected cost of an innovative technology that embodies significant variability. In terms of reliability, the problem is as follows (Sommers 1980, p. 285):

Relative reliability is not per se the issue. Rather it is the difficulty in assessing the true relative reliability ratio that makes rational decisions problematic.

When an untested technology is at the commercial level of operation, there is insufficient experience to evaluate the reliability of the new technology as compared with that of the state-of-the-art technology. With regard to lead times, construction delays can subsume not only the uncertainty of building the new plant but also delays caused by changing regulations, demand uncertainties, and other exogenous factors. Sommers (1980, p. 285) concludes by noting that as a result of these uncertainties, "a large 'gray area' exists for many utilities, that is, the least-cost choice cannot be made with confidence ex ante."

In designing an appropriate intervention strategy, two questions arise:

- What is the nature of the rational decision process in which this incentive mechanism must fit?

- How can regulators develop a set of incentives that will produce the socially optimal rate of innovative technology adoption?

One purpose of this report is to provide an initial answer to these questions by (1) developing a methodology for evaluating the potential incremental costs that a utility or nonregulated generator of electricity faces when undertaking an innovative project and (2) discussing the range of incentive mechanisms available to utility regulators that could be used to overcome the negative effects of the externalities that thwart innovative technology development.

\subsubsection{Incentives to Minimize Production and Project Costs}

Traditionally, regulators have adopted incentive mechanisms designed to enhance the reward for minimizing costs and to penalize inefficiency. These incentives have been designed to operate at either a systemwide level (as in the case of price-cap regulation) or project-specific level (as in the case of power plant performance or construction cost control 
programs). Use of incentive mechanisms is increasing in the regulatory community. In a 1986 survey, Joskow and Schmalensee (1986) identified 19 state commissions and the Federal Energy Regulatory Commission (FERC) as having employed mechanisms. In a recent National Economic Research Associates, Inc. (NERA) survey (NERA 1991), 75 incentive programs were identified involving 30 states and FERC. These 75 programs did not include telephone or natural gas industry incentive programs, which have also grown in the last decade. $^{4}$

Incentives designed to improve performance generally operate by creating a performance target that can involve capacity factors, unit or system reliability, or production costs. A rule is then established that identifies how much of the cost savings or cost overruns will be borne by the utility or consumers on the basis of the relationship between the performance target and actual performance. When an innovative plant or technology is being constructed, the incentive mechanism may reduce the risks faced by customers and stockholders.

Incentive mechanisms provide a greater reward for controlling project cost variability. This effect is depicted in Figure 1, in which the distribution of possible costs and

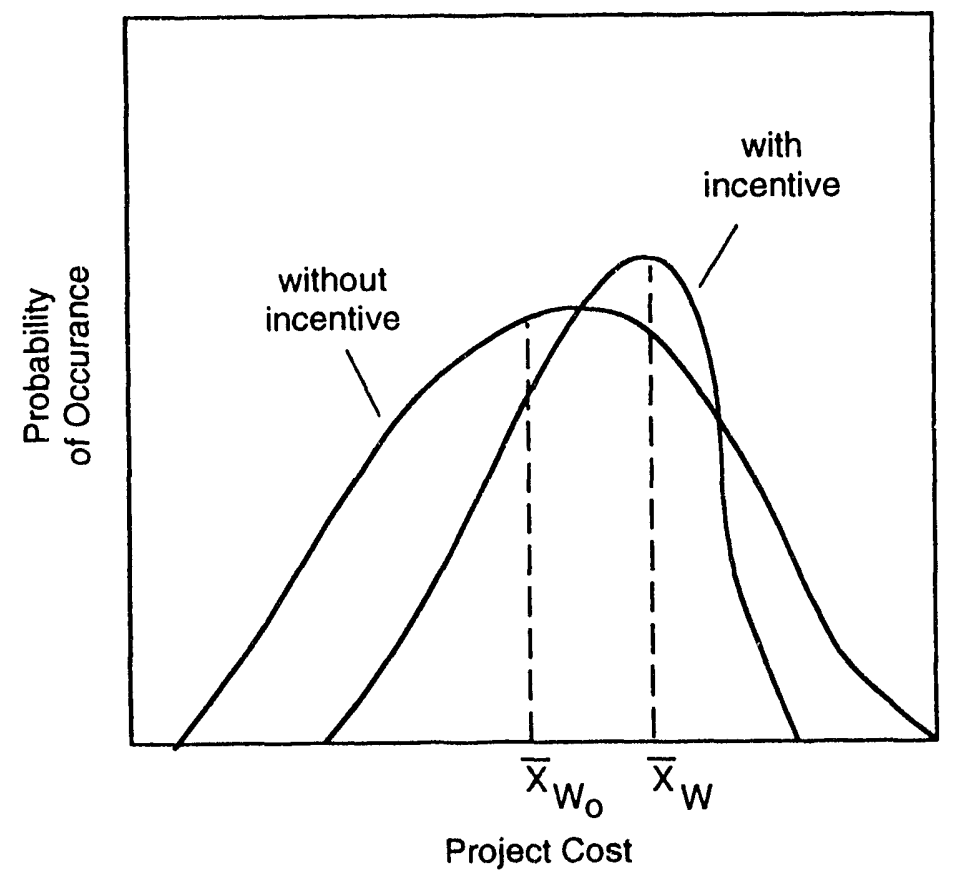

FIGURE 1 Effect of Incentives on Expected Project Costs and Variances

4 Joskow and Schmalensee (1986) provide a summary of state incentive programs since 1977. For additional reviews of both the range of incentive mechanisms and their application at the state and federal level, see Brown et al. (1989), McDermott (1980a,b; 1981), and NERA (1991) for the most recent compilation of state programs. 
the expected cost of the project without incentives are given by distribution $\mathrm{W}_{0}$. Uncier an incentive, the reward for controlling costs will result in the implementation of procedures that reduce the risk of variation while increasing the expected costs. The incentive effects result in distribution $\mathrm{W}$ and the new expected cost given by $\overline{\mathrm{X}}_{\mathrm{W}}$. In effect, the incentive may result in a trade-off between slightly higher expected costs and a reduction in the risk (variance) of costs. The customer has, in some sense, purchased an insurance policy to minimize the risk of overruns. The cost (premium) associated with the policy is represented by the difference in expected costs $\left(\overline{\mathrm{X}}_{\mathrm{W}_{0}}-\overline{\mathrm{X}}_{\mathrm{W}}\right)$; see Hass (1984) for more information.

In the long run, incentive mechanisms that improve performance will reduce operating costs that are passed through to the customer over time. From a different perspective, the incentive offered to the utility results in consumers sharing risks with utility stockholders. The expected benefit is that more cost-effective, higher performance technologies will be constructed than would have been without the use of the risk-sharing mechanism.

Among the possible incentive approaches that exist, the following set could be used to offset risk or to minimize cost:

- Prospective prudence,

- Prudent abandonment rules,

- Accelerated depreciation,

- Rate-base treatment of deferred taxes,

- Construction work in progress (CWIP),

- Avoided-cost rate adjustments,

- Expensing demonstration costs,

- Incentive rate of return (IROR),

- Amortization of abandoned or canceled plants,

- Preapproved capital expense caps,

- Treatment of subsidies or grants,

- Investment tax credits,

- Special treatment of emission allowances,

- Property tax incentives,

- Preapproval plan/expenditure, 
- Cost cap, and

- Sliding scale.

These incentive options are discussed more fully in Section 5.

\subsubsection{Alternative Objectives and the Use of Incentives}

Besides offsetting risk or minimizing costs, incentives can be designed to promote a variety of objectives. The NERA (1991) study identifies 11 programs currently in place to stimulate electricity conservation and demand-risk management programs. Appendix D reviews recent incentive proposals associated with CCTs and coal production that promote the retention of coal mining employment in states with high-sulfur coal. The range of programs reflected in the literature is indicative of the flexibility and potential value that incentive mechanisms represent as a strategic regulatory policy.

\subsection{REPORT ORGANIZATION}

The report is organized as follows. Section 2 examines the nature of the rational decision process regarding technical choice. Section 3 discusses a methodology for directly estimating the incremental costs associated with adopting an innovative technology. The value of this cost can be used in designing an appropriate incentive for utilities or NUGs to adopt an innovative technology.

Section 4 reviews the alternative incentive mechanisms that can be used to influence technology choice by a public utility or NUG. Section 5 examines the financial effects of incentives on a utility adopting an innovative technology. In Section 6, the NUG environment is reviewed, and in Section 7, the financial effects of alternative incentives applied to a NUG are examined.

Finally, four technical appendixes are provided. Appendix A examines alternative rate-of-return methodologies; Appendix $B$ summarizes the models and assumptions used in this study; Appendix C indicates the effect of the Clean Air Act Amendments of 1990 (CAAA) on NUG technology choice; and Appendix D highlights state and federal regulations promoting CCTs. 


\section{CAPACITY AND TECHNOLOGY CHOICE: THE ROLE OF RISK, UNCERTAINTY, AND INCENTIVES}

One of the most frequently cited problems concerning today's power generation executives is their reluctance to invest in risky projects. ${ }^{5}$ The perception that exposure to excessive risks may result in lower earnings and that the rewards for success do not counterbalance the penalties for failure has raised concerns over how to properly structure the investment incentive environment.

The purpose of this section is to (1) identify the set of potential risks that characterizes the decision to not invest in an innovative technology and (2) develop a link between the expected costs and the magnitude of incentives necessary to induce risk-taking in capacity expansion decisions. In developing the link between risk and incentives, this section highlights the special nature of innovative technology choice, namely, the strong effects of project parameter uncertainty. The differences between risk and uncertainty are discussed, and the importance of demonstration projects as a means of reducing uncertainty to calculable risks is explored.

The role of the market environment in which risky projects are undertaken cannot be understated. The incentive properties of a competitive market are characterized by a symmetry between rewards and penalties, whereas the traditional regulatory market has been characterized in the last decade by an asymmetry between rewards and penalties. ${ }^{6,7}$ This asymmetry has created an additional risk factor (commonly referred to as regulatory risk) that creates further disincentives to adopt innovative technologies. This dimension of regulatory risk may shift the role of experimenting with new technologies away from traditional utilities to the emerging NUGs that have developed since the passage of the National Energy Act in 1978. Provisions relevant to NUGs are found in the Public Utility Regulatory Policies Act (PURPA), P.L. 95-617 (Nov. 9, 1978), 92 Stat. 3144, as amended 1980 and 1986, codified principally at 16 U.S.C. Subsections 2601-45. Given the increasing role of NUGs as energy suppliers (and more recently, to exempt wholesale generators [EWGs] as defined in the Energy Policy Act of 1992 [P.L. 102-486]), the critical question regarding the

5 See Kaplan (1982), Lambert (1986), Michigan PSC (1993), and Rappaport (1978). See also "Advance Plans for Construction of Facilities as Filed with the Commission for Review and Approval Pursuant to Section 196.491, Wis. Stats.," Findings of Fact, Conclusion of Law and Order, Decision 05-EP-6 before the Public Service Commission of Wisconsin, Sept. 18, 1992.

See also South et al. (1991).

7 If regulated companies cannot reap the benefit of good fo tune, they should not be expected to bear the burdens of bad fortune. If the best that they can hope for are rates that just cover their costs (including a fair return), they cannot be expected to undertake projects that carry a significant risk of falling short of covering those costs... Thus, either such project will NOT be undertaken by the regulated companies, or the risk must be at least be shared between investors and consumers. FERC order no. 138, 18 FERC Para. 61, 244 at 61, 502 (trailblazer case). 
ability to bear the risk of innovation may rest with the banking community that finances these projects (Jabbari and Bussa 1992).

At present, the overall impact of the structural changes occurring for public utilities is uncertain. The increasingly competitive nature of the public utility industry may decrease the regulatory risks associated with the adoption of capital intensive and innovative baseload generation technology. Increased competition among utilities and nonutility generators in the wholesale electricity market and possibly in retail electricity markets will provide all firms with rewards from adopting innovative technologies. Future structural and regulatory changes will greatly influence the generation choice of the future.

\subsection{RATIONAL CHOICE OF INVESTMENT PROJECTS}

The theory of rational choice is central to both economic theory and policy. The received theory of rational choice is the expected utility theory (Sugden 1991). This theory attempts to incorporate risk and uncertainty into the decision process by assigning probabilities to potential states of nature that may influence the outcomes of the economic agents action (Shoemaker 1982; Hirschleifer and Riley 1979). In effect, the decision maker selects a course of action that results, not in a single outcome, but in a range of possible outcomes, each weighted by the probability of that outcome occurrence. Recently, this theory has been criticized as a result of the observation of a number of empirical anomalies (Machina 1987). Decision makers often exhibit systematic biases, reversal of preferences, and other actions that cast some doubt on the strict applicability of the expected utility theory.

This problem may arise as a result of the economic agents relying on more or less information than assumed by the theory. For many economists, the problem lies in the sheer complexity of many tasks that economic agents attempt to solve. Simon (1957) has suggested that agents recognize the information and computational limits of their capabilities and choose to employ a "bounded rationality" approach to solving complex problems. Others have recognized that when uncertainty prevails, agents experience "regret" and "disappointment" and thereby modify their decision-making approaches (Kahneman and Tversky 1979; Loomes and Sugden 1982).

These characteristics of extreme uncertainty, limited information, and computational ability are associated with the problem of selecting among conventional and innovative technologies in the power generating industry. Moreover, the possibility that regulatory authorities could limit the capital recovery on failed projects, or projects that do not perform up to current standards, injects a strong element of potential regret and disappointment into the decision process. This can induce a strong element of risk aversion into the utility or NUG decision framework when evaluating innovative technologies. When these problems are added to the learning and forecasting externality problems that arise in the selection of innovative projects, there may arise a significant bias to avoid the selection of innovative technologies and a preference for conventional technology design. 
The problems facing the utility or NUG decision maker are made even more difficult by the paucity of data regarding the essential parameters associated with an innovative technology. This lack of data reduces the effectiveness of standard statistical techniques used to evaluate projects. In effect, the decision makers face a condition of uncertainty as opposed to risk, and this creates a further impediment to the adoption of an innovative technology.

Unfortunately, in order to design an appropriate incentive, knowledge or an estimate of the expected costs of an innovative technology is also required by the regulator. For an incentive mechanism to be effective, it must result in a balance between the expected costs of a conventional technology and the innovative technology so that the choice of technology can be limited to the inherent characteristics and advantages that each option offers. An incentive should also provide an inducement to select the innovative technology that does not result in ratepayers absorbing an undue or unfair burden of the costs.

The purpose of this chapter is to provide a methodological approach for estimating the size of the incentive that may be required to induce utilities and NUGs to adopt an innovative technology. This incentive would be designed to offset the potential uncertainties that decision makers face and mitigate the potential regret or disappointment in an ex ante fashion so that a more rational choice of technology can be achieved, which could overcome the externalities preventing the socially optimal rate of innovation from occurring.

\subsection{MANAGEMENT PERCEPTIONS OF RISK AND UNCERTAINTY}

The role of risk perceptions cannot be understated when considering the problem of investment in new technologies to augment existing capacity in the electric generation market. ${ }^{8}$ While the concept of "risk" is most often thought of as the hazard created by the act of speculating on investments or undertaking gambles, risk itself is a basic and unavoidable component of every general factor under which most analyses of investments are characterized. There is an important - and not altogether subtle - distinction between the problem of choice under risk and choice under conditions of uncertainty.

It is important to clarify the differences between risk and uncertainty because they each have dramatically different impacts on the behavior of managers considering investment decisions. Risk has been described by economists as the condition under which economic agents know the characteristics of the probability distribution associated with a random event (such as its mean and variance). In this case, accurate probability statements can be made and used in making a rational decision. Uncertainty, on the other hand, is a condition for which there is insufficient information regarding the relevant probabilities. In these

8 For a summary of the recent work on risk perception, see Nieves et al. (1990). 
situations, no statement can be made regarding the likelihood of an event. This distinction was made quite plainly by Keynes (1937):

By 'uncertain' knowledge I do not mean merely to distinguish what is known for certain from what is only probable. The game of roulette is not subject, in that sense, to uncertainty; nor is the prospect of a victory bond being drawn. Or, again, the expectation of life is only slightly uncertain. Even the weather is only moderately uncertain. The sense in which I am using the term is that in which the prospect of a European war is uncertain, or the price of copper and the rate of interest twenty years hence, or the obsolescence of a new invention ... About these matters there is not scientific basis on which to form any calculable probability ....

In the case of commercially available technology, a sufficient number of observations are available for management to employ the standard techniques of statistical analysis. This method is based on the ability of the observer to develop objective estimates of the frequency of an event, based on the replication of the event. This situation meets the standard definition of risk as characterized by Keynes (1937) and Knight (1921).

However, when we move from the world of repeated events that are known to a world characterized by the unknown and unknowable, then our ability to employ standard statistical analysis and decision theory based on expected values is generally inapplicable. It is this situation that characterizes the decision regarding a new technology with little or no observations of the costs, the time frame, or the success of construction and operation. Nevertheless, as Keynes has noted (1937), in order to make decisions, we must often act as if we were operating in a world of known frequencies:

About these matters, there is no scientific basis on which to form any calculable probability whatever. We simply do not know. Nevertheless, the necessity for action and for decision compels us as practical men to do our best to overlook this awkward fact and to behave exactly as we should if we had behind us a good Benthamite calculation of series of prospective advantages and disadvantages, each multiplied by its appropriate probability, waiting to be summed.

As a result of this condition, managers who recognize the inherent problems of estimating the risks associated with an innovative technology may have perceptions of the risks of adopting the technology that create a significant barrier to its development. It is at this juncture that the role of incentive mechanisms can play a critical function - as a strategic regulatory policy - in developing information that can transform the problem of investing in a new technology from one characterized by uncertainty to a situation of calculable risk.

In this respect, it is important to recognize that it generally requires only four to five completed plants in order to achieve a mature technology and develop sufficient information to begin making accurate estimates of cost, construction lead time, and operation (Flaim et al. 


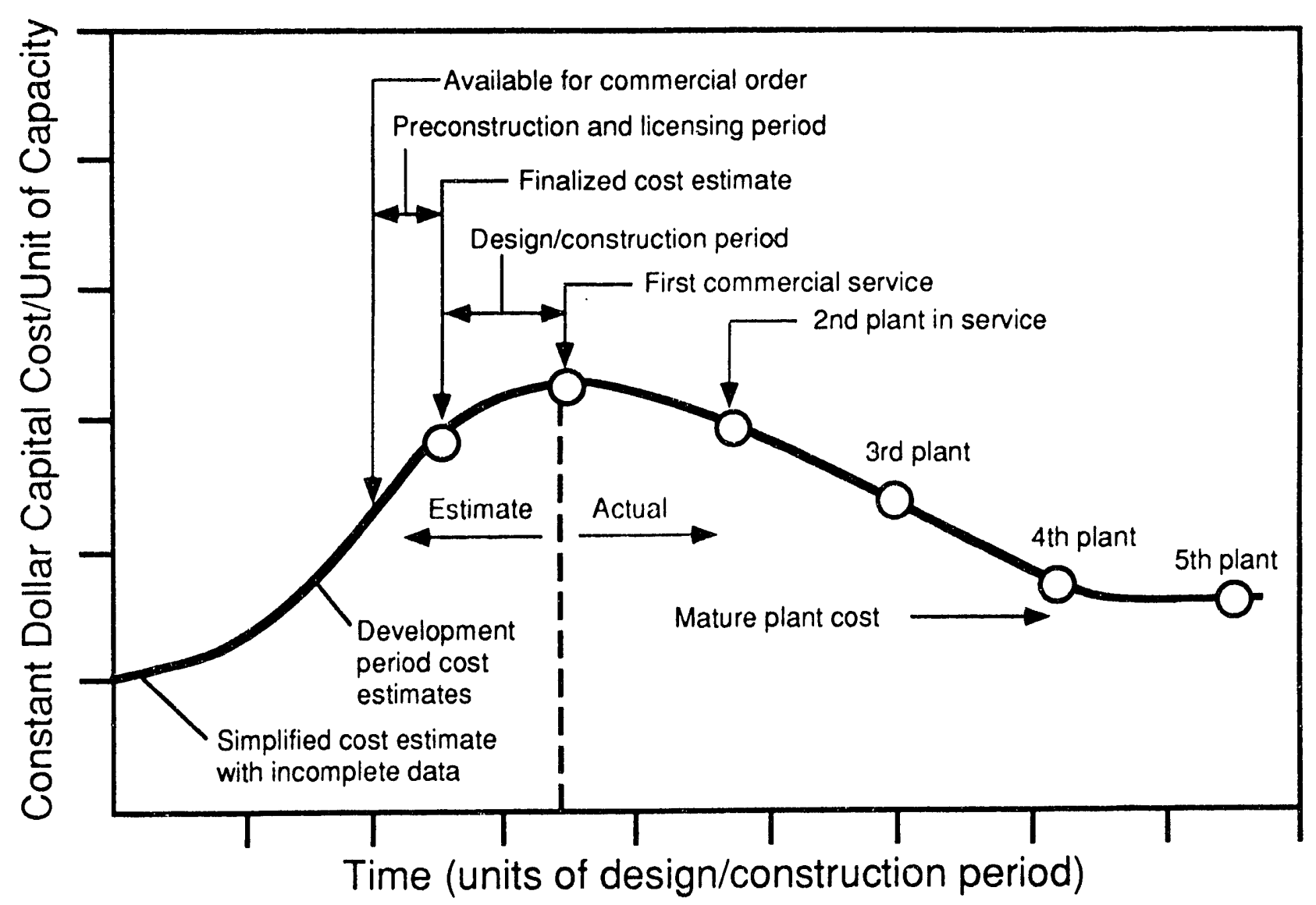

FIGURE 2 Capital Cost Learning Curve (Source: Electric Power Research Institute [EPRI] 1989)

1989). The typical learning curve is depicted in Figure 2. By developing incentive programs that are applied to a limited number of plants representing the technology under development, regulators can improve the future prospects for new, more efficient, and environmentally beneficial plants to be added to the menu available to power generators. This will broaden the opportunities for power generators to achieve a least-cost solution of meeting future load growth and minimize the cost impacts for consumers. In addition, as these plants are completed, they will provide a source of information on the expected costs, construction lags, and operations that can serve as a basis for the calculation of objective estimates of these parameters in the future.

This information problem has been recognized in the past and acted upon by both state and federal regulators. During the 1970s and 1980s, the perceived excess supply of power generation led to a significant number of plant cancellations. ${ }^{9}$ As a result, a gap was beginning to appear in our practical knowledge of the construction and operation of new

9 Between 1974 and 1984, 75 coal-fired generating plants planned for operation in the late 1970s and early 1980s were canceled. See FERC Docket No. RM-88-4-000, p. 13, footnote 22. 
technologies. The consumers' interests were twofold: gains in efficiency and reductions in emissions. The FERC recognized this problem and noted in the Great Plains case that:

The major output from the Great Plains project will not be coal gas; it will be information. Information, first, about the problems arising from the construction and commercial $o_{x}$ eration of a full scale coal gasification plant, problems which might not occur, or be of a different nature, or require different solutions in a smaller scale facility; second, accurate, reliable information as to the cost of gas produced at the lowest level of a crrimercial size plant . . . third, information that the necessary regulating approvals for the commercial size plant can be secured, and fourth, information that such a facility can be built and operated to supplement, as and when necess $y$, other more conventional sources of energy supply. ${ }^{10}$

More recently, the FERC has recognized that the potential shortfalls of capacity in some regional markets has created the neec' for new reliable and economic sources of power. The Commission has recognized the need for:

... regulatory reforms to complement state regulatory efforts to provide utilities with appropriate incentives to select the most economical and reliable supply arrangements from the various opportunities available to them. ${ }^{11}$

In other instances, the FEF $C$ has justified incentives as fulfilling the requirements of the federal energy law. For example, in the Ozark Gas Transmission case, the FERC determined that it was in the consumers' interest to develop the pipeline, given that consumers' interest was defined as the development of a secure, long-term su-ply of natural gas under the Natural Gas Act. ${ }^{12}$

Incentives can play a major role in establishing a base of knowledge that can simultaneously enhance the efficiency of electric generation, minimize the emission of pollutants, and obtain energy independence from reliance on foreign sources of energy. The next section specifies the exact nature of the risks facing a utility or NUG undertaking an innovative project.

1010 FERC Para. 61,066 at $62,146$.

11 FERC Docket No. RM88-4-000, p. 5.

1216 FERC Para. 61, nor. 


\subsection{CATEGORIZING THE NATURE OF INNOVATIVE TECHNOLOGY RISKS}

When conceptualizing the nature of risks that a utility or NUG is exposed to when undertaking an innovative project, the multi-dimensional aspect of risk must be recognized. In addition, the potential positive interactions or trade-offs between various risks must also be reccgnized. For example, if a firm exposes itself to construction risks by skimping on design, it may expose itself to greater operational risks in the future as well. Conversely, by avoiding construction risk through improved design, the firm may lower future operating risk. Six broad categories of risks can be identified: construction, operational, environmental, technological, financial, and regulatory. In Table 1, these risks are delineated; each is discussed in more detail below. It should also be kept in mind that in complex organizations such as a utility, these risks may be viewed differently by capacity planners, financial analysts, and rate design staff. In coming to a final decision, these alternative points of view must be reconciled. Given the scope of this report, these difficulties are not addressed.

The rational utility planner must translate each of these risks into an expected cost associated with the project and use this cost information to modify the expected capital cost and operating cost associated with the project. In the typical utility decision environment, these risks result in an increase in the costs associated with an innovative technology and, as a result, erect an economic barrier to the innovative project's implementation.

In order to counterbalance the reluctance of regulated utilities and NUGs to pursue cost-effective innovative technologies, an incentive mechanism must be developed to reduce the ex ante perceived risk of the planner. In other words, an incentive mechanism should result in a discounting of an innovative project's expected costs so that the planner makes comparisons between the costs of commercial technologies and the risk-adjusted costs of innovative technologies. By proceeding in this fashion, the economic choice being made by the utility or NUG is focused on the inherent expected economic attributes of each technology. ${ }^{13}$

The problem facing the regulator in designing an appropriate incentive is the estimation of the ex ante risk associated with the new technology and the calculation of the risk adjustment costs. This issue will be taken up in Section 3, where an ex ante risk/opportunity cost methodology is presented. ${ }^{14}$

13 One way to view the problem is that as a result of the incentive, the utility/NUG receives the difference between the expected costs of the risky option and the expected cost of a commercial technology with certainty, and thereby the expected costs of the two options are equivalent. Of course, the actual difference may be compensated by the enhanced technical characteristics of the innovative option.

14 For an example of the more traditional approach to evaluating investment decisions under risk, see EPRI (1982). 
TABLE 1 Categories of Risk: Sources and Impacts

1. Construction risk

a. Risk of delay

b. Cost overrun/capital cost risk

2. Operational risk
a. Efficiency risk (heat rate)
b. Operational and maintenance risk
c. Availability/reliability risk

3. Environmental risk
a. Emission control risk
b. Waste treatment risk
c. Siting risk
d. Future regulatory risk

4. Technological risk

a. Premature obsolescence/early retirement - exogenous forces

1. Technical change

2. Regulatory change

3. Economic change

b. Technology failure/early retirement - endogenous forces

1. Project abandonment before completion

2. Project abandonment after completion

5. Economic and financial risk

a. Reduced demand for output

b. Perceived financial risk (bond/stock ratings)

c. Other exogenous shocks

6. Regulatory risk

a. Regulatory lag

b. Cost recovery risk

1. Rate base allowance

a. Prudent expenditure test

b. Use and useful test

2. Operating cost disallowance 
Each of the specific risks outlined in Table 1 will be associated with any project, whether employing conventional or innovative technologies. In addition, each utility/NUG will perceive these risks with different intensities and may have a variety of preferences for learning specific risks (the importance of this aspect of risk performance and aversion for incentive design will be discussed below). In the remainder of this section, each of the risks identified in Table 1 will be briefly discussed with regard to its potential effect on capacity/technology choice decisions.

\subsubsection{Construction Risk}

Given that the majority of our current knowledge regarding construction risks stems from the experiences of the 1970s and 1980s, this information will be analyzed to provide an indication of its potential importance in effecting perceived risks. In the data related to construction cost overruns, it is evident that both the mean and the variance of costs (low plant versus high plant costs) increased (see Table 2). In most cases where increases in variation are occurring, this would result in an increased perception of risk. ${ }^{15}$ In most cases, this escalation in cost occurred for plants of known commercial design; thus, the risk expressed in these data would reflect a lower bound in the possible escalations that might be expected with an innovative technology. This lower bound, however, may be counterbalanced by the fact that many of the innovative technologies being examined today are of a smaller unit scale.

TABLE 2 Trends in Construction Costs of Coal-Fired Plants $^{\text {a }}$

\begin{tabular}{cccc}
\hline $\begin{array}{c}\text { Year of } \\
\text { Operation }\end{array}$ & $\begin{array}{c}\text { Low-Plant } \\
\text { Costs } \\
(\text { mixed current } \\
\$ / \mathrm{kW})\end{array}$ & $\begin{array}{c}\text { Average-Plant } \\
\text { Costs } \\
\text { (mixed current } \\
\$ / \mathrm{kW})\end{array}$ & $\begin{array}{c}\text { High-Plant } \\
\text { Costs } \\
\text { (mixed current } \\
\$ / \mathrm{kW})\end{array}$ \\
\hline 1971 & 126 & 157 & 180 \\
1972 & 158 & 176 & 221 \\
1973 & 158 & 243 & 292 \\
1974 & 162 & 237 & 331 \\
1975 & 170 & 270 & 360 \\
1976 & 292 & 347 & 499 \\
1977 & 231 & 313 & 377 \\
\hline
\end{tabular}

a Per nameplate capacity, for plants of $300 \mathrm{MW}$ or larger.

Source: DOE (1978).

15 One narrow definition of risk in financial analysis refers to the variability in perceived returns. In this case, the variability in perceived costs will influence the returns earned by a utility and create both planning and financial risk. See DOE (1984). 
Construction delays were common during the 1970s and 1980s. As indicated in Table 3, the mean length of delay varied between slightly more than a year to nearly two years. When the standard deviation is taken into account, some plants were delayed three years or more. The effects of these delays manifest themselves in cost increases through allowance for funds used during construction (AFUDC) accumulation, purchased power to avoid experiencing unserved load, and higher operating costs as inefficient units are operated more. The exact number of cost delays has never been isolated for this period; however, between 1967 and 1979 , the cost per $\mathrm{kW}$ for coal-fired units rose from $\$ 109$ to $\$ 537$. An average of 41 plants were delayed each year between 1974 and 1981, with a mean delay of 14-21 months (see Table 3). While inflation, added regulatory requirements, and higher interest rates contributed to this increase, planners certainly recognize the importance that delays played in this escalation.

One of the major sources of delay is government regulation, with more than 100 types of state, local, and federal permits required to build a coal-fired power plant (Singh et al. 1980). Another source of delay was the reduced growth rate in utility demand that affected the time frame within which new plants would be needed. Delay in this case can be seen as a defensive action on the part of the utility seeking to avoid the application of the "used and useful" criteria to the plant and avoiding a rate base disallowance for the new facility.

TABLE 3 Number and Length of Construction Delays of Coal-Fired Power Plants

\begin{tabular}{|c|c|c|c|c|c|}
\hline \multirow[b]{3}{*}{ Year } & \multirow{2}{*}{\multicolumn{2}{|c|}{ Number of Units }} & \multicolumn{2}{|c|}{$\begin{array}{l}\text { Length of Delay } \\
\text { (months) }\end{array}$} & \multirow{3}{*}{$\begin{array}{c}\text { Total } \\
\text { Delays } \\
(\mathrm{yr})\end{array}$} \\
\hline & & & \multirow[b]{2}{*}{ Mean } & \multirow{2}{*}{$\begin{array}{l}\text { Standard } \\
\text { Deviation }\end{array}$} & \\
\hline & Canceled $^{\mathrm{a}}$ & Delayed & & & \\
\hline $1974 \ldots .$. & 19 & 70 & 16.24 & 11.14 & 94.7 \\
\hline $1975 \ldots .$. & 3 & 56 & 14.18 & 8.33 & 66.2 \\
\hline $1976 \ldots .$. & 8 & 40 & 13.65 & 8.52 & 45.5 \\
\hline $1977 \ldots .$. & - & 18 & 14.83 & 12.20 & 22.3 \\
\hline $1978 \ldots \ldots$ & 2 & 38 & 16.21 & 11.32 & 51.3 \\
\hline $1979 \ldots \ldots$ & 4 & 43 & 18.81 & 12.44 & 67.4 \\
\hline $1980 \ldots$. & 2 & 50 & 19.64 & 13.62 & 81.8 \\
\hline $1981 \ldots \ldots$ & 6 & 20 & 21.10 & 9.53 & 35.2 \\
\hline
\end{tabular}

a Units indefinitely postponed are included in the number of units canceled.

Source: Kidder, Peabody \& Company (1982). 
Figures 3a and $3 b$ serve as a further illustration of the upward drift in capital costs and the increased variance of capital costs for both nuclear and coal units. This trend is further exemplified by examining the cost per kilowatt (in 1982 dollars) for the lowest cost coal units built over the 1968-1986 time period shown in Table 4. The difference between the 1968 and 1986 units is $\$ 414 / \mathrm{kW}$, representing approximately a $216 \%$ increase in costs for the least expensive units completed. As the National Energy Strategy [(NES) 1991a] recognized, the implications of this information are that utilities differ in their capabilities to manage the construction of large projects and that competitive forces that reward the more efficient builders and operators of generating capacity could provide public benefits in the form of lower cost generating units.

\subsubsection{Operating Risks}

Perhaps the most prominent concern of utility executives is the maintenance of system reliability. In many cases, the choice of a technology may be based on its proven track record in experiencing minimal forced outages. New technologies will create certain perceptions of risk when little or nothing is known of the unit operating characteristics. These risks can be translated into expected costs in a rather straightforward manner because purchased power and increased operating costs will be required to fill the gap when a unit fails to operate.

In terms of costs, heat rate and other operational characteristics, while important, contribute a smaller proportion to system operating costs than outages and construction problems. Only early retirement risk approaches the same magnitude of cost that outage and construction overruns create. The early retirement of units will require the acceleration of new construction and potentially the purchase of high-cost replacement power.

\subsubsection{Environmental Risk}

One of the critical factors motivating the development of innovative technologies has been the promulgation of new laws concerning sulfur dioxide $\left(\mathrm{SO}_{2}\right)$, oxides of nitrogen $\left(\mathrm{NO}_{\mathrm{x}}\right)$ and particulate emissions. ${ }^{16}$ In the future, new plants that are built will need to meet regulations for $\mathrm{SO}_{2}, \mathrm{NO}_{\mathrm{x}}$, and other emissions and obtain $\mathrm{SO}_{2}$ emission allowances. The focus of decisions by utilities and NUGs will be on the selection of technologies with low expected emission characteristics. If these plants should fail to perform up to expectations, the result will be increased costs from purchasing additional emission allowances and replacement energy along with potential penalties for failure to meet emission standards (South et al. 1991).

16 Title IV (Acid Rain), Clean Air Act Amendments of 1990 (P.L. 101-549). 


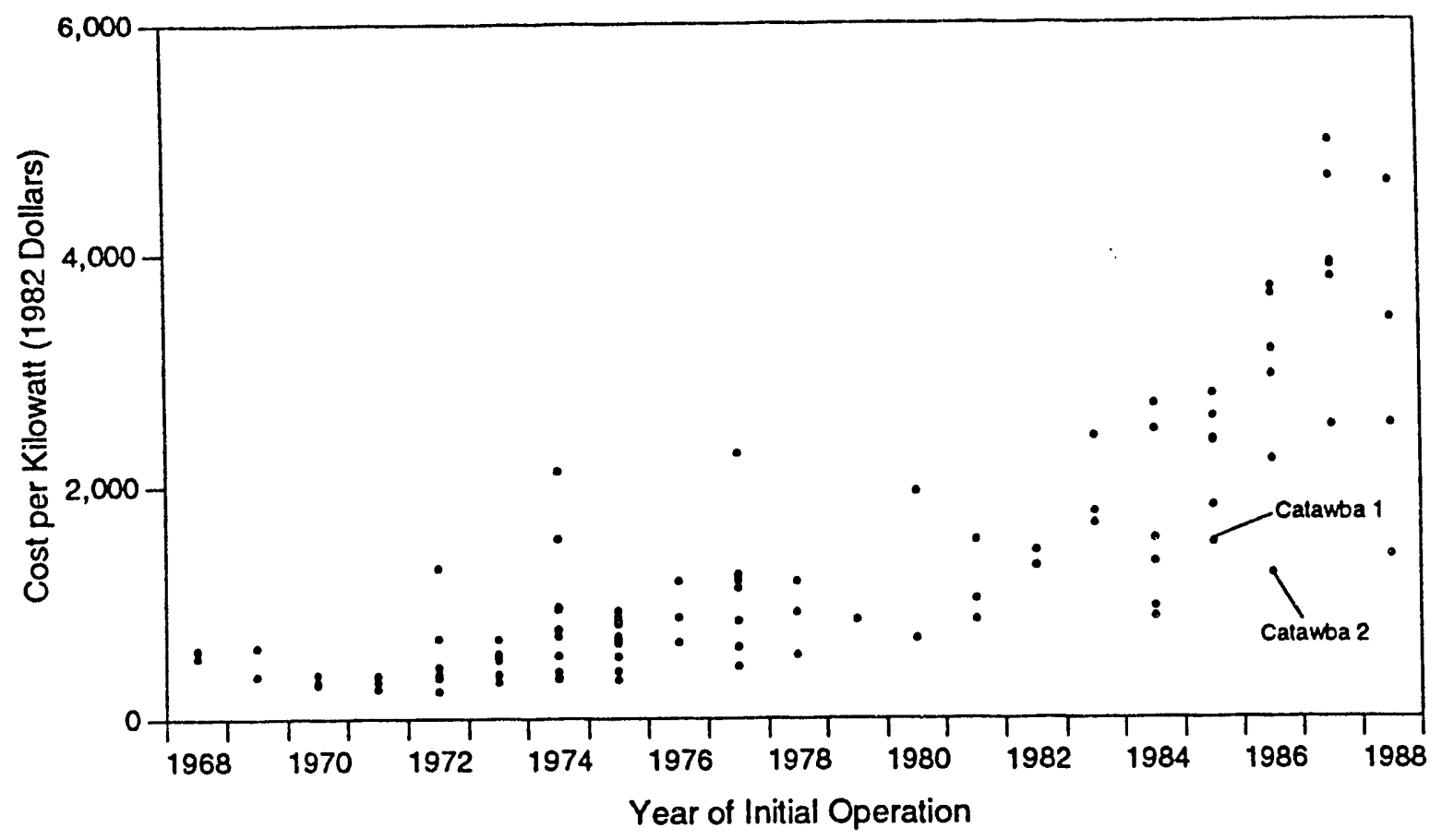

FIGURE 3a Capital Costs of Nuclear Units (1968-1988) (Source: Energy Information Administration, 1988, Nuclear Power Plant Combustion Activity, as referenced in NES 1991a)

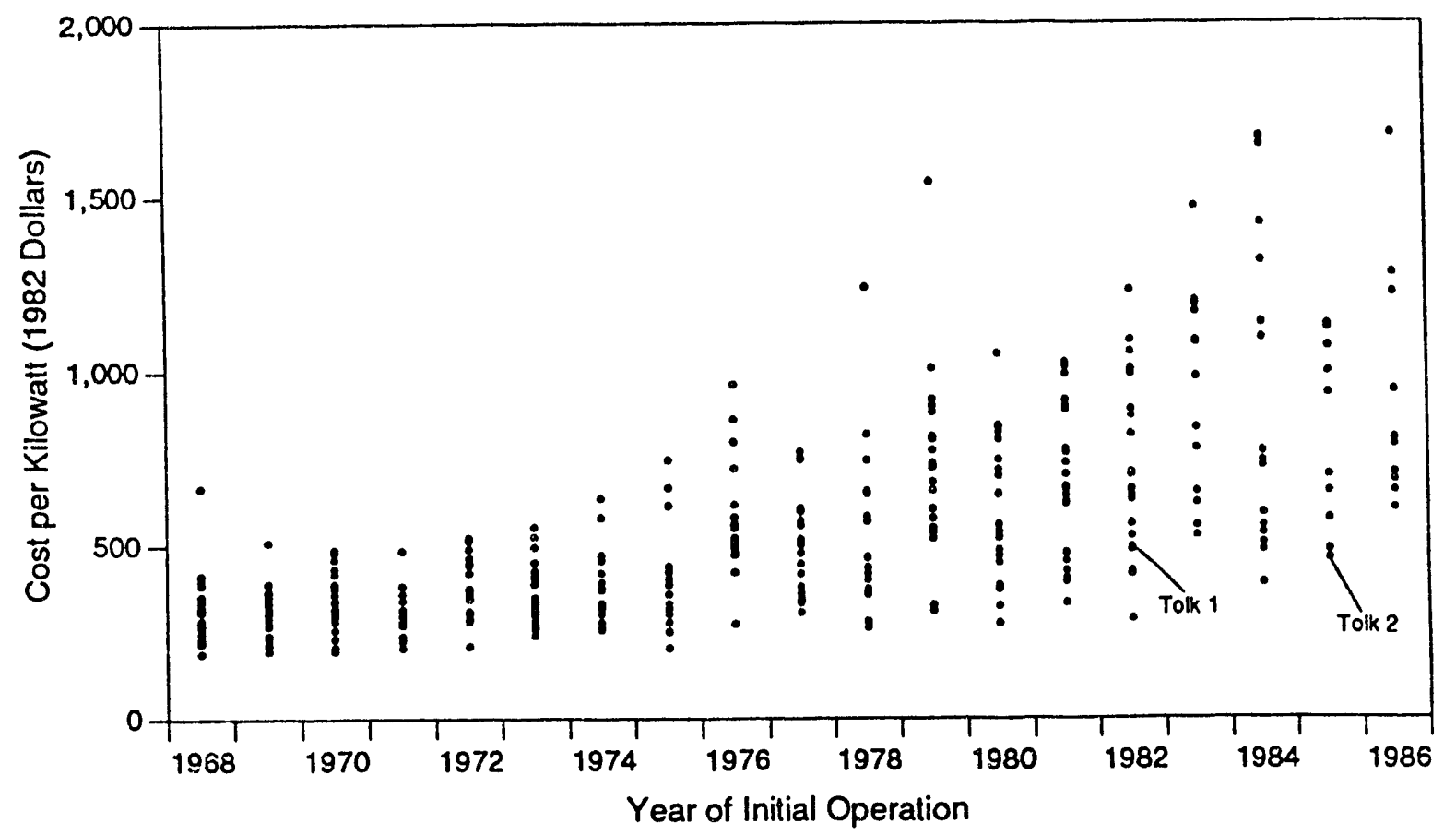

FIGURE 3b Capital Costs of Coal Units (1968-1986) (Source: Utility Data Institute, 1987, Construction Cost8, U.S. Steam Electric Plants, 1966-1986 [UDI-003-87], Washington, D.C. [Oct.], as referenced in NES 1991a) 
TABLE 4 Lowest Cost Coal Generating Units (by Year of Initial Operation)

\begin{tabular}{ccl}
\hline Year & $\begin{array}{c}\text { Cost }^{\text {a }} \\
(\$ / \mathrm{kW})\end{array}$ & \multicolumn{1}{c}{ Unit and Operating Utility } \\
\hline 1968 & 191 & Roxboro 2, Carolina Power \& Light Co. \\
1969 & 198 & Harllee Branch 4, Georgia Power Co. \\
1970 & 197 & Four Corners 5, Arizona Public Service Co. \\
1971 & 207 & Quindaro Three 2, City of Kansas City \\
1972 & 212 & Bowen 2, Georgia Power Co. \\
1973 & 242 & Jack Watson 5, Mississippi Power Co. \\
1974 & 279 & Monroe 4, Detroit Edison Co. \\
1975 & 204 & Monticello 2, Texas Utilities Electric Co. \\
1976 & 274 & Gibson 1, Public Service Co. of Indiana, Inc. \\
1977 & 306 & Sherburne County 2, Northern States Power \\
1978 & 263 & Muskogee 5, Oklahoma Gas \& Electric Co. \\
1979 & 327 & Martin Lake 3, Texas Utilities Electric Co. \\
1980 & 276 & Welsh 2, Southwestern Electric Power Co. \\
1981 & 334 & V.J. Daniel 2, Mississippi Power Co. \\
1982 & 287 & Welsh 3, Southwestern Electric Power Co. \\
1983 & 526 & Mayo 1, Carolina Power and Light Co. \\
1984 & 388 & Ghent 4, Kentucky Utilities Co. \\
1985 & 459 & Tolk 2, Southwestern Public Service Co. \\
1986 & 605 & Okaunion 1, West Texas Utilities Co. \\
\hline
\end{tabular}

a In 1982 dollars.

Source: Utility Data Institute, 1987, Construction Costs, U.S.

Steam Electric Plants, 1966-1986 (UDI-003-87), Washington,

D.C. (Oct.), as referenced in NES (1991a).

In addition, the adoption of any new technology may result in the creation of solid waste streams that are characterized as hazardous and thereby create the potential for higher costs. ${ }^{17}$ Perhaps the most difficult problem to quantify in terms of both risk and cost is the "NIMBY" problem ${ }^{18}$ associated with power plant siting. Many environmental and neighborhood groups oppose the location of coal-fired power plants near residential and scenic areas. The problems created by such intervention in the permitting process have created construction delays and even plant cancellations. ${ }^{19}$ If any of the risk categories clearly represent the problems created by uncertainty associated with risk, it is the possibility of not

17 The complexities created by the interaction of environmental and utility regulatory rules have been succinctly outlined by Ward (1981).

18 Not in my backyard (NIMBY); see Marks and Von Winterfeldt (1984).

${ }^{19}$ For discussion of the effect of visibility concerns on the siting of new power plants, see Loeb and Elliot (1993). 
receiving a siting permit or, more likely, of being forced to make technology, fuel, or capacity changes (Loeb and Filiot 1993).

\subsubsection{Technological Risk}

Technological risk takes two basic forms. The first is associated with exogenous forces such as technical, regulatory, or economic changes that render a technology obsolete. The second form is endogenous - the technology itself fails to be completed or, once completed, requires early retirement or extensive retrofitting costs. These risks are particularly acute when the plant being constructed is a pioneer plant because there is little or no knowledge of the actual performance of the technology. ${ }^{20}$ If a plant should fail to ever operate, or were to operate at a consistently low level of reliability, the regulatory process will likely deny complete capital recovery. If there is no guarantee of cost recovery, the utility/NUG will not wish to incur the risk of a total loss.

Likewise, if it is known that the plant may require premature shutdown and potentially the elimination of cost recovery on the grounds that the plant is not "used and useful," the planner will be reluctant to recommend the technology. Furthermore, retirement of the plant will only result in additional replacement or retrofit costs as noted above.

\subsubsection{Economic and Financial Risk}

Ultimately, all of the risks faced by the builder of an innovative technology will be translated into financial impacts. Cost overruns can squeeze cash flow and deteriorate earnings; delays can result in higher interest costs and deteriorating interest coverage ratios that ultimately result in bond and stock derating. Besides these obvious interconnections, there are also economic and financial risks that are independent of the project but which can drastically affect the risks of undertaking an innovation. For example, by not selecting an innovative technology, a firm may lock itself into a technology that may not be flexible in the f ce of changing environmental regulations, fuel price shocks, or future changes in regulatory policy. Financial fluctuations, interest rate changes, or stock market swings can result in increased project costs or changes in perceptions that such risks should not be financed independent of the inherent reliability and cost effectiveness of the technological option being considered.

20 For greater details on the problems associated with pioneer technologies, see Merron et al. (1981). One program oriented to overcome some of these problems is the Clean Coal Technology Demonstration Program (also reierred to as the CCT Program). The program is designed to take the most promising of the advanced coal-based technologies and, over the next decade, move them into the commercial marketplace through demonstration. These demonstrations will be on a scale large enough to generate all the data, from design, construction, and operation, that are necessary for the private sector to judge their commercial potential and make informed, confident decisions on commercial readiness. The demonstration projects are intended to contribute essential data on technical, environmental, economic, and operational performance to reduce the uncertainties of subsequent commercial-scale applications of the technologies (DOE 1991c). 
During the 1970 period, the four major sources of delay and cancellation cited by utilities were the following (Bundwani 1982):

- Reduction in the rate of growth in electricity demand;

- Financial difficulties, including

- reduced bond coverage ratio,

- higher interest,

- reduced per share equity returns, and

- inability to recover costs until project completion;

- Complex regulatory process; and

- Construction problems, such as

- material and labor shortage, and

- low productivity.

All four of these problem areas tend to be exogenous factors outside the control of the utility/NUG.

\subsubsection{Regulatory Risk}

Regulated firms also face risks associated with the regulatory process itself. A public utility commission (PUC) has the power to review the prudence of all capital expenditures and operating costs to assess the reasonableness of these expenditures. If the expenditures are found unreasonable, they will not be included in the total revenue requirements of the utility. Looking at risk exposure in another way, it is the regulator and not the marketplace that, in part, determines the factors influencing the level and timing of the revenue flows and costs incurred by the utility. Decisions regarding depreciation, treatment of CWIP, and the inclusion or disallowance of construction expenditures or fuel costs all have an impact on the riskiness of the utility's revenue flows. As a result, the utility faces a complex set of incentives in its decision-making process as it attempts to meet present and future demands for its product (i.e., electricity) in a reliable and least-cost manner. Stutz (1986) has analyzed the relationship between construction risk and regulatory options, as summarized in Table 5 . This table highlights the fact that regulators through the prudent choice of policy options can negate not only the regulatory risks perceived by planners and the finance market but also the direct risks associated with adopting innovative technologies.

Perhaps the most significant regulatory risk facing the suppliers of electricity is the potential for inconsistent regulatory policies to be applied over time as the composition of the state and federal regulatory commissions changes. There is no rule or process that requires the intertemporal consistency of policy. The most striking example of the ability of 
TABLE 5 Risks Associated with Utility Plant Construction

\begin{tabular}{|c|c|c|c|}
\hline $\begin{array}{l}\text { Life Cycle } \\
\text { Stage }\end{array}$ & Risks & $\begin{array}{l}\text { Common } \\
\text { Regulatory } \\
\text { Issues }\end{array}$ & $\begin{array}{l}\text { Illustrative } \\
\text { Sharing } \\
\text { Procedures }\end{array}$ \\
\hline \multirow[t]{3}{*}{ Construction } & Delay & $\begin{array}{l}\text { Treatment of Cost } \\
\text { Increases }\end{array}$ & Use of Cost Caps \\
\hline & Cancellation & $\begin{array}{l}\text { Treatment of Sunk } \\
\text { Costs }\end{array}$ & $\begin{array}{l}\text { Limitations on CWIP } \\
\text { Partial Return over Tirne of } \\
\text { Investment Costs }\end{array}$ \\
\hline & & & $\begin{array}{l}\text { Limiting Return on Unamortized } \\
\text { Costs }\end{array}$ \\
\hline \multirow[t]{2}{*}{$\begin{array}{l}\text { Addition to } \\
\text { Available } \\
\text { Generation }\end{array}$} & Excess Capacity & $\begin{array}{l}\text { Treatment of Excess } \\
\text { Capacity }\end{array}$ & $\begin{array}{l}\text { Partial Inclusion of Investment } \\
\text { in Rate Base } \\
\text { Exclusion of Other Capacity } \\
\text { from Rate Base }\end{array}$ \\
\hline & Rate Shock & $\begin{array}{l}\text { Methods for Inclusion } \\
\text { in Rate Base }\end{array}$ & $\begin{array}{l}\text { Phase-in Partial Inclusion in } \\
\text { Rate Base } \\
\text { "Mirror" CWIP }\end{array}$ \\
\hline \multirow[t]{2}{*}{ Operation } & $\begin{array}{l}\text { Failure to Operate } \\
\text { as Planned }\end{array}$ & Cost of Repairs & $\begin{array}{l}\text { Phase-in Granting Partial } \\
\text { Recovery }\end{array}$ \\
\hline & & $\begin{array}{l}\text { Cost of Replacement } \\
\text { Power and Energy }\end{array}$ & $\begin{array}{l}\text { Granting Partial Recovery of } \\
\text { Replacement Costs } \\
\text { Performance Standards with } \\
\text { Penalties }\end{array}$ \\
\hline \multirow[t]{2}{*}{ Retirement } & Early Retirement & $\begin{array}{l}\text { Cost of Replacement } \\
\text { Power and Energy }\end{array}$ & $\begin{array}{l}\text { Partial Recovery of Remaining } \\
\text { Plant Costs }\end{array}$ \\
\hline & $\begin{array}{l}\text { Retirement } \\
\text { Allowance } \\
\text { Inadequate }\end{array}$ & Excess Costs & $\begin{array}{l}\text { Limiting Return on Unamortized } \\
\text { Costs } \\
\text { Partial Recovery of Replacement } \\
\text { Costs } \\
\text { Partial Recovery of Excess Costs }\end{array}$ \\
\hline
\end{tabular}

a CWIP: construction work in progress.

Source: Stutz (1986). 
commissions to switch policy perspectives can be seen between the prudent investment standard or test and the used and useful test in evaluating the inclusion of a new plant in the rate base. If the commission takes a liberal view toward the construction program, it may recognize that hindsight is inappropriate and may apply the prudent investment test. If the commission decides to take a strict retrospective approach, it can apply the used and useful test. It is entirely possible that the same plant being phased into the rate base over time could be judged under both criteria. The effects that these two approaches may have on the financial position of the utility and the rates paid by customers can be radically different, and the possibility of such a switch in policies injects considerable risk into the project selection process. Raffiee and Wendel (1988) have noted that the application of either the used and useful or prudent investment tests can lead to an underinvestment in capacity and a reduction in the deployment of efficient technologies. They find that only an ex ante prudence test that examines mismanagement or fraud ex post will create the proper incentive for efficient capacity additions:

- By using cost-cap incentives, the risks of delays may be minimized.

- By employing phase-ins, rate shock is minimized, and planners receive an exact signal of the expected cost of an error.

- By allowing partial recovery of an early retired plant, some of the risks of innovation are mitigated.

The use of cost-cap incentives has been criticized if it involves the preapproval of construction costs. Preapproval can be viewed as a negative inventive to control costs because the utility can earn a return on this entire amount over the life of the plant once in rate base.

For cost-cap incentives to perform well, they must be designed to reward utilities or NUGs for completing units at lower costs and for maintaining reliability. What is essential for both the regulator and utility/NUG planner is to understand how these risks influence the expected cost of a plant and, in identifying these potential costs, how to develop an appropriate incentive mechanism. In the next section, an ex ante opportunity cost model is developed that can serve as the basis for determining the magnitude of the incentives required to offset the planners' ex ante perceptions of risk. 


\section{A METHODOLOGY FOR CALCULATING THE EX ANTE OPPORTUNITY COSTS OF INNOVATIVE TECHNOLOGY RISK}

Before an incentive mechanism can be employed to induce a utility/NUG to construct an innovative technology, the first step that must be taken is to identify the expected opportunity costs that the decision maker faces when confronied with that choice. An incentive level can then be specified that is correlated with the additional expected costs or undertaking the project and is not arbitrarily selected. Ultimately, a variety of incentive packages can be designed; each package may offer the same discounted present value of revenues but would vary by timing and magnitude and would qualitatively address specific risks to which the planners might be averse. Taking these factors into account would allow the planners to mitigate the risks they feel are critical. Alternatively, the decision maker might be willing to accept incentives that vary in magnitude but that address risks that the planner perceives to be of a particularly critical nature. In either case, by developing a menu of incentive options, regulators may be able to induce the socially optimal investment response.

\subsection{RISK PERCEPTIONS AND EX ANTE OPPORTUNITY COSTS}

To develop an estimate of the expected opportunity costs, it is important to first establish the role of risk perceptions within the decision-making framework. The evaluation of risk commonly involves a two-stage analysis. Risks can be characterized in terms of the outcome (e.g., the chance that an egg is spoiled) and the consequence (e.g., the chance that eating a spoiled egg causes sickness). In the case of a technology, these two stages are the chance that the technology fails or fails to perform as designed and the consequent effect on rates or regulatory treatment.

Figure 4 provides a simple schematic diagram of the two-stage evaluation process. The term $\mathrm{P}_{1}$ represents the subjective probability held by the individual regarding the potential outcomes of any decision, while $\mathrm{P}_{2}$ represents the probability associated with the possible consequences. For more complex decisions, an entire decision tree is made, with separate branches representing the multiple outcomes and multiple consequences associated with each possible outcome. The decision tree approach will be developed more fully below.

The typical planning process involves a planner in the evaluation of a number of options or "action prospects," such as alternative conventional technologies and/or alternative innovative technologies. Schick (1984) introduced the term "action prospect" to describe the problem of choice under uncertainty. A decision maker generally faces a set of options that define the action prospect. The option set of potential actions from which the planner could select to resolve the issue is the aspect being analyzed. 


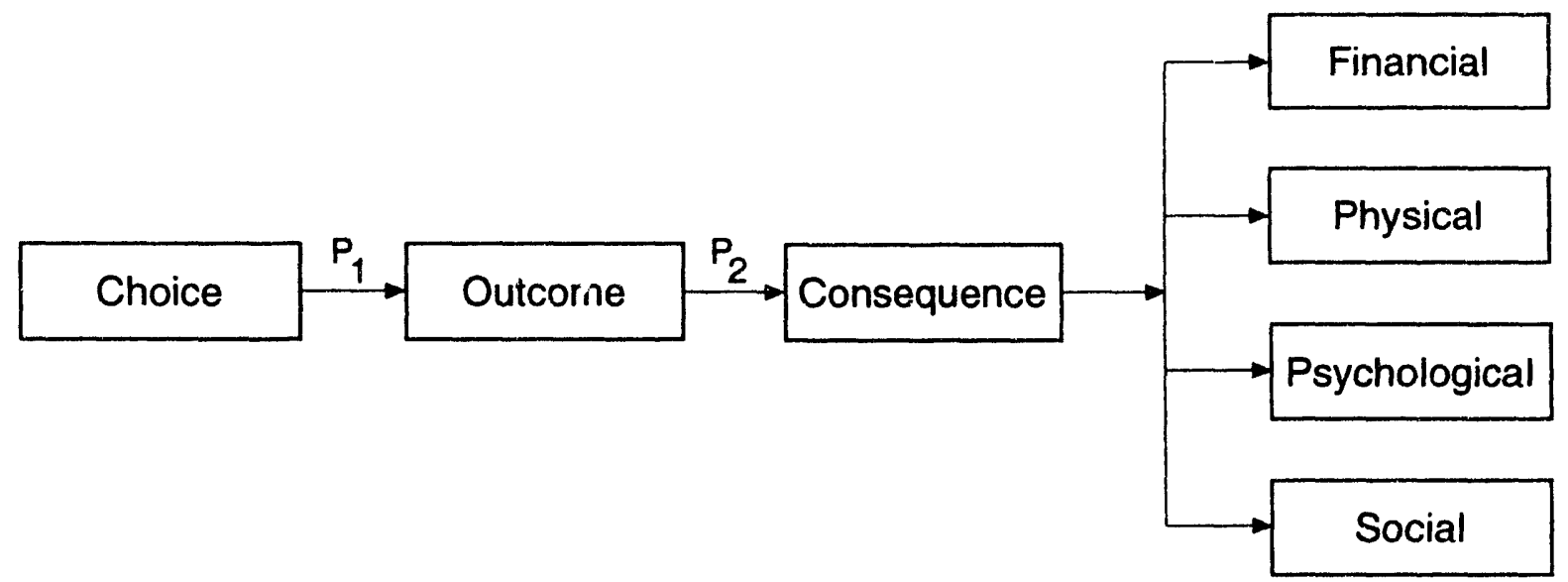

FIGURE 4 Two-Stage Risk Evaluation Process

For example, a utility planner may face an issue such as a system that requires new capacity to reliably meet future load. As Figure 5 depicts, in the process of making such a decision, the planner would weigh goals such as reliability, efficiency, and profit. The planner is faced with a set of options such as a conventional pulverized coal unit with a scrubber, a natural gas combustion turbine (GT) unit, demand-side management (DSM), renewable resources, or an innovative CCT. Each of these options would be analyzed, given the goals and desires of the planner and taking into account the perceived risks. For each option, an expected cost is calculated taking into account the known facts regarding the various parameters. On the basis of the analysis, an ex ante choice is made, and the actual outcomes and their effects are identified ex post.

The purpose of the methodology developed below is to define the analysis that should occur within the box labeled "risk perceptions" in Figure 5. The process developed is an attempt to transform the limited information possessed by the planner into data that allow a form of risk analysis to take place. In effect, a planner has no data on the actual versus expected outcomes associated with an innovative technology, and hence, the standard approach of frequency analysis and statistics can play less of a role in informing the decision.

By developing an ex ante risk/opportunity cost model, the planner and regulator have a tool that can be used to evaluate the options that goes a step beyond the heuristic rules or rules of thumb that decision makers often employ ${ }^{21}$ and ultimately develop a policy that can influence utility and NUG capacity choice decisions.

${ }^{21}$ Heuristic rules are tools employed by decision makers who face a lack of information. These rules are used to "reduce the complex task of assessing probabilities and predicting values to simpler judgmental operations" (Tversky and Kahneman 1982, p. 3). Examples of heuristic rules are similarity of types (representativeness), frequency of similar events (availability), and an initial estimate (anchoring) that is modified by experience. 


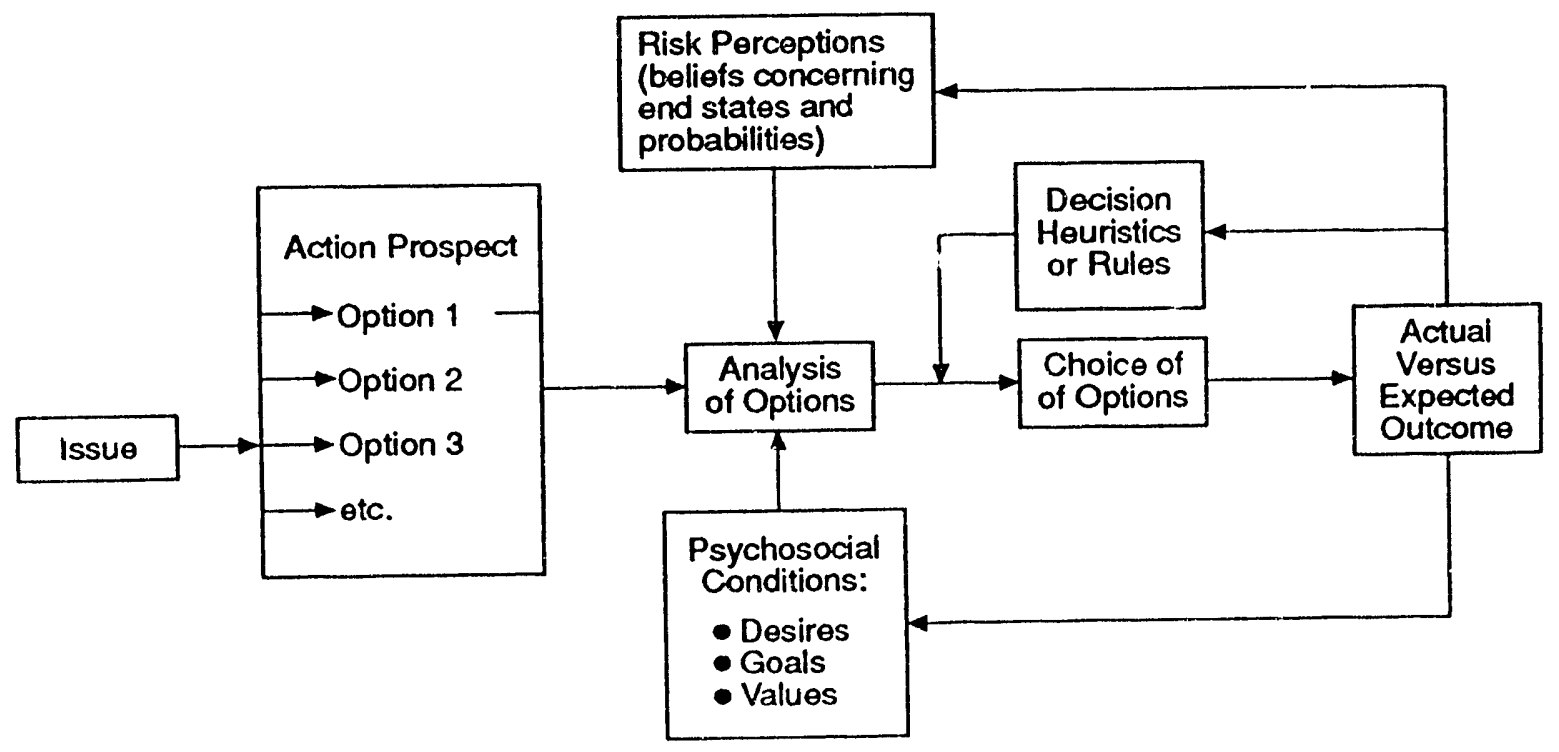

FIGURE 5 Choice Process under Uncertainty

\subsection{OPERATIONALIZING THE EX ANTE OPPORTUNITY COST CALCULATION}

In effect, the problem of the planner is to design a two stage analysis of the risk and outcome effects of an innovative technology, based on the risks characterized in Section 2.0. In the first stage of the analysis, the six major risk categories are used as a basis for establishing a general expected cost framework where each risk category is assigned a probability of occurring (Figure 6). Mathematically, this results in

$$
E(T C)=\Sigma p_{i}\left[\epsilon\left(c_{i}\right)\right]
$$

where

$$
\begin{aligned}
E(T C) & =\text { expected total cost of innovative risk, } \\
p_{i} & =\text { probability that major risk event will occur, } \\
\Sigma p_{i} & =1, \text { and } \\
\varepsilon\left(c_{i}\right) & =\text { expected cost of the major risk event. }
\end{aligned}
$$

To calculate the total expected cost, some assumptions must be made regarding the probabilities. For simplicity, we can view each of the major risk events as mutually exclusive with an equi-probable possibility of occurring. In specific instances, it may be more accurate to assign differing probabilities based on experience. 


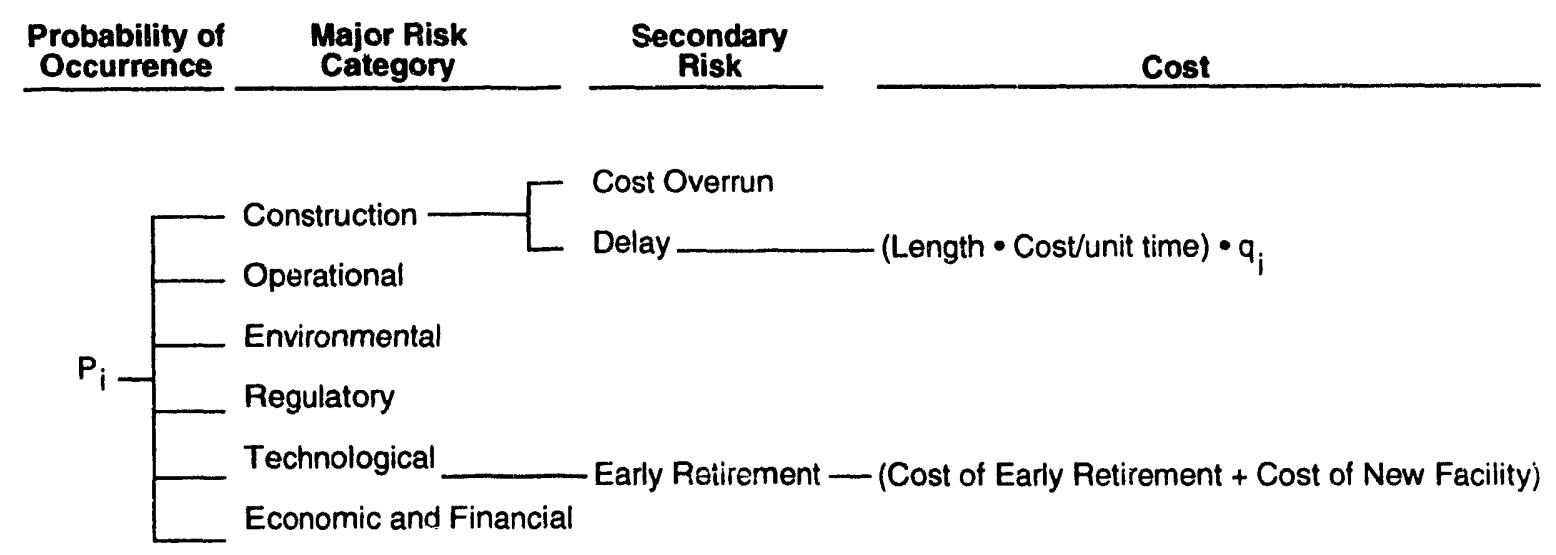

\section{FIGURE 6 Expected Opportunity Cost}

The second quantity needed to calculate the expected total cost is the expected cost of each separate risk event. In effect, each major risk event is the product of specific secondary events that jointly generate the expected costs. For example, in Figure 6, the cost of a delay will depend on the length of the delay and the cost per unit of time associated with delays. It also consists of the costs associated with project cost overruns due to, say, faulty design. In a more sophisticated analysis of this problem, a probability distribution of delays may be developed so that the expected cost of delays is given by

$$
\epsilon\left(c_{i}\right)=\Sigma \text { (length of delay } \times \text { cost/unit of time) } q_{i},
$$

where $\Sigma q_{i}=1$.

For example, as depicted in Figure 7, the percentage of units being delayed could serve as a measure of $q_{i}$, and, based on computer estimates, the cost impact of delays could be calculated by determining the unserved energy, purchased power, and other costs associated with a delay. The probability weight sum of these costs could serve as an expected value of a delay that would then be used in Equation 3.1. Example calculations of this type are provided in Section 3.3.

By repeating this process for each of the major risk categories and their subcomponents, an overall prospective/ex ante opportunity cost measure can be developed. This process would provide a measure of the magnitude of incentive required to adjust, in the planners' mind, the cost of undertaking the innovative project and make it equivalent to existing conventional options. As a result, the planner will compare the standard costs of conventional technologies to the risk-adjusted cost of the innovative technology, where the incremental cost of risk (ICR) is given by

$$
I C R=E(T C)_{1}-E(T C)_{0},
$$




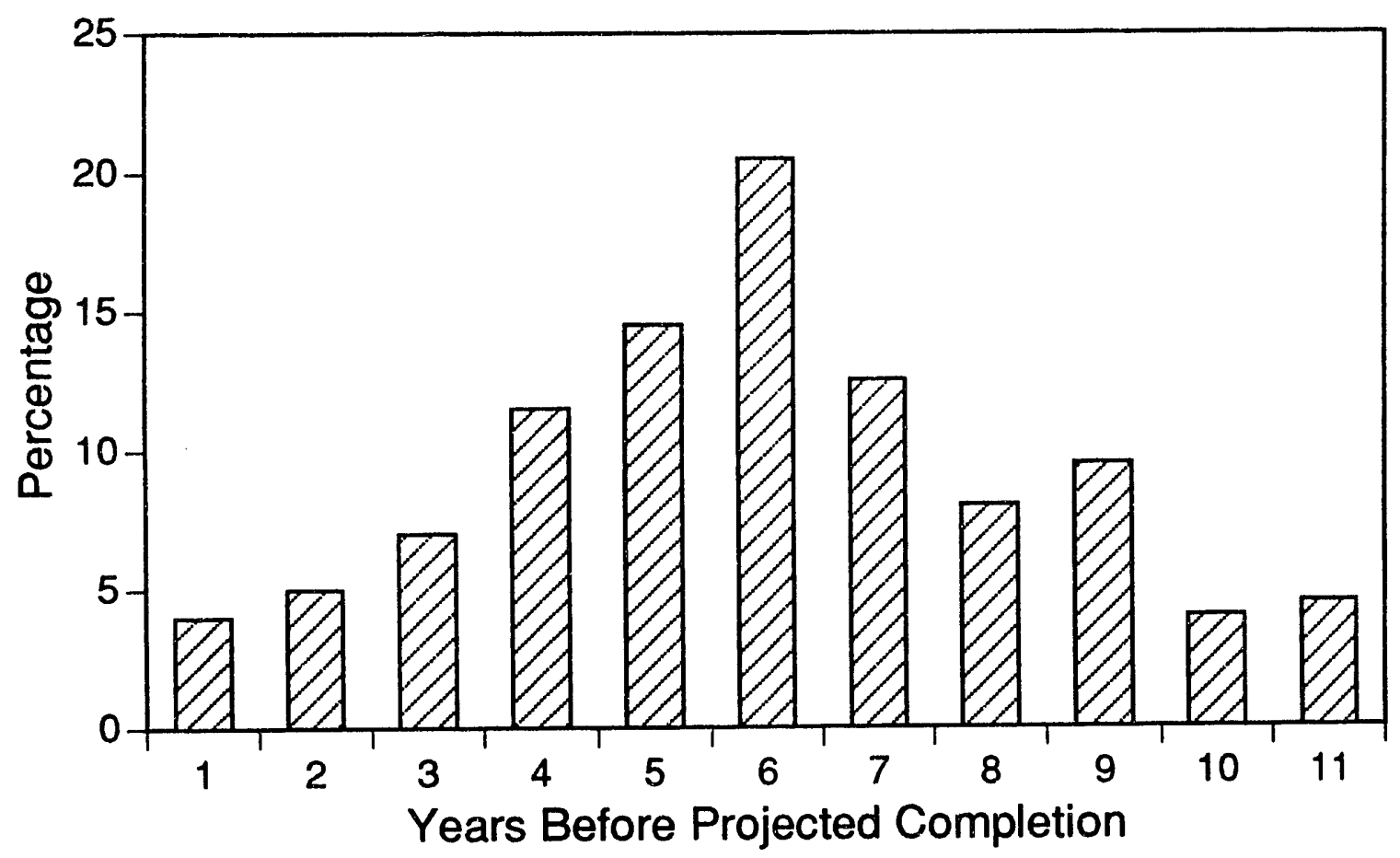

FIGURE 7 The Distribution of Delays by Years before Completion, from the Population of Delayed Coal-Fired Power Plants (Source: Kidder, Peabody \& Co. 1982)

where

$$
\begin{aligned}
& \mathrm{E}(\mathrm{TC})_{\mathrm{i}}=\text { expected total cost of innovative technology, and } \\
& \mathrm{E}(\mathrm{TC})_{\mathrm{c}}=\text { expected total cost of conventional technology. }
\end{aligned}
$$

One way to conceptualize the effect of the ICR on a planner's view of technology choice is depicted in Figure 8. In this example, the difference in the conventional technology, $\mathrm{E}(\mathrm{TC})_{c}$, and the innovative technology, $\mathrm{E}(\mathrm{TC})_{\mathrm{i}}$, is reflected as a difference in the mean or expected cost. Under this condition, a utility planner may reject the innovative approach as simply too expensive. By directly calculating the incremental costs created by innovative risk exposure and offering an incentive of that magnitude, the comparison is then transformed from

$$
\mathrm{E}(\mathrm{TC})_{1}>\mathrm{E}(\mathrm{TC})_{\mathrm{c}}
$$

to

$$
\mathrm{E}(\mathrm{TC})_{\mathrm{i}}-I C R \geq E(T C)_{c}
$$

where $\mathrm{E}(\mathrm{TC})_{\mathrm{i}}-\mathrm{ICR}=\mathrm{RAC}$, the risk-adjusted cost. 


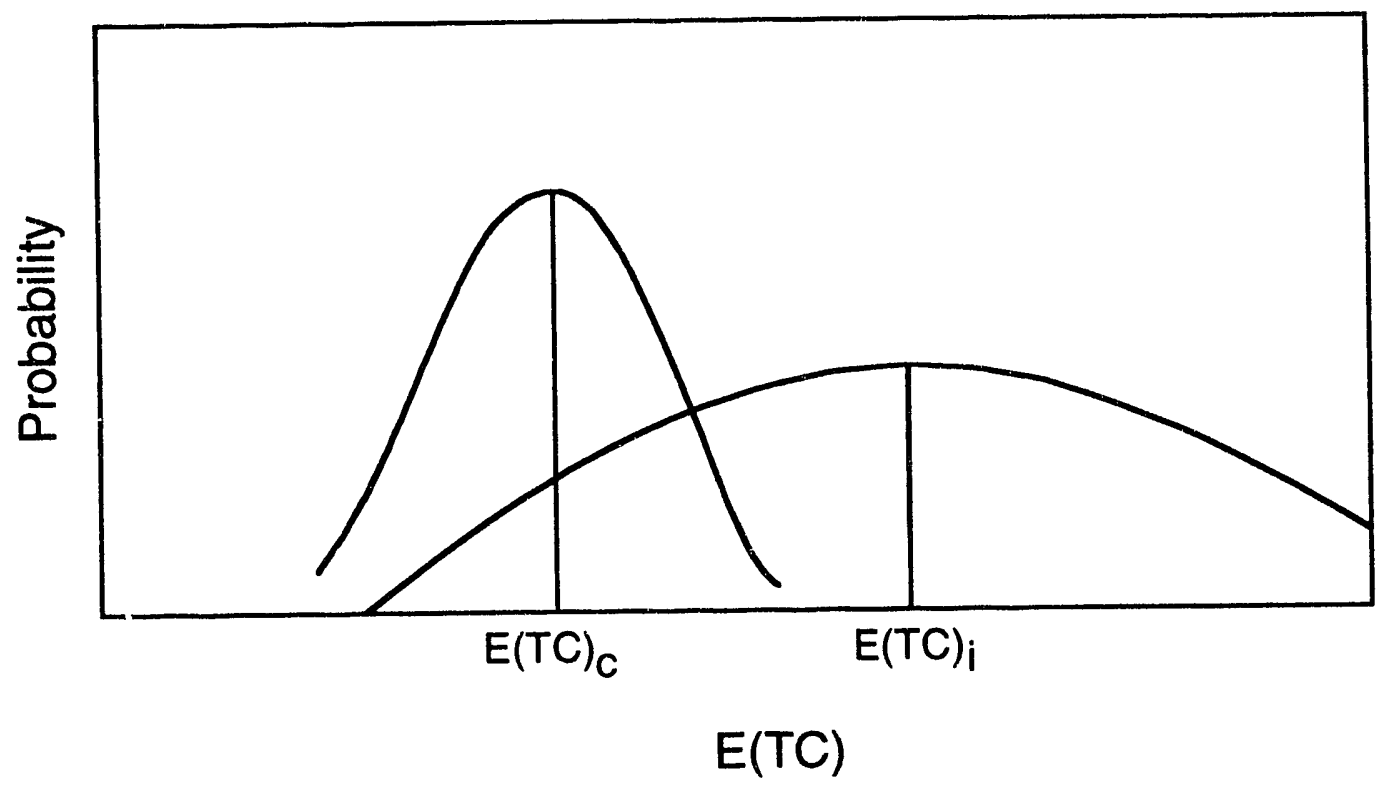

FIGURE 8 Difference in Expected Cost (Mean) of Conventional Technologies $\left[\mathbf{E}(\mathrm{TC})_{c}\right]$ and Innovative Technologies $\left[\mathbf{E}(\mathrm{TC})_{\mathbf{i}}\right]$

If the ICR has been calculated correctly as in Equation 3.3, and this is substituted into Equation 3.5, the expected costs of the innovative technology will approximately equal the expected costs of the conventional technology. ${ }^{22}$ The utility or NUG can now compare the RAC of adopting the innovative technology with the expected cost of the conventional technology. At this point, it is the inherent characteristics of the technology that will affect the decision maker's choice and minimize the effect of uncertainty on the decision.

If the innovative technology has lower operating cost, improved reliability, or environmental characteristics over existing technologies, then on the basis of the riskadjusted cost comparison, the innovative technology should be worth adopting. The planner can now compare not only the two expected costs but also other engineering attributes of each technology. Even if RAC $>\mathrm{E}$ (TC) , $_{\mathrm{c}}$, the difference between the two may be so minimal that the potential advantages of the new technology might outweigh the advantages of a conventional plant. For example, the ability to achieve $99 \% \mathrm{SO}_{2}$ reduction by building an integrated coal gasification combined-cycle (IGCC) power plant may more than offset the advantages of a PC/FGD coal unit with $85-95 \% \mathrm{SO}_{2}$ removal efficiency.

22 If ICR is calculated as in Equation 3.3, the following mathematical operations prove that the incentive creates an equal footing between the innovative and conventional technologies:

$$
\begin{gathered}
E(T C)_{I}-I C R \frac{\geq}{<} E(T C)_{c} \\
E(T C)_{I}-\left[E(T C)_{I}-E(T C)_{c}\right] \frac{\geq}{<} E(T C)_{c} \\
E(T C)_{I}-E(T C)_{I}+E(T C)_{I} \geq E(T C)_{c} \\
E(T C)_{c}=E(T C)_{c}
\end{gathered}
$$


Because most utility and NUG planners will not know the expected cost of an innovative technology in advance, a second option exists for calculating the ICR. This procedure employs an ex. ante or forward-looking approach to estimate the ICR directly from our knowledge or estimates of the potential impacts of each of the major risk categories. Based on this direct ICR calculation, the product would be subtracted from the expected costs of the innovative project to yield a comparison between the expected costs of the conventional option and the risk-adjusted cost of the innovative option. This technique is outlined in the next section.

\subsection{ESTIMATING THE COST OF EX ANTE INCREMENTAL RISK}

To obtain a first-order approximation of the costs associated with an innovative technology, the Argonne Utility Simulation (ARGUS) model was used with other estimation methods (Veselka et al. 1990) to determine the least-cost expansion plan for the period 1995-2015. All power pools in the United States (Figure 9) were simulated with the ARGUS model to evaluate the economic effects of (1) a delay in construction, (2) a reduction in unit efficiency (heat rate), and (3) increased forced outage rates (FORs). The expansion plan for a selected set of power pools (see list below and highlighted power pools in Figure 9) was

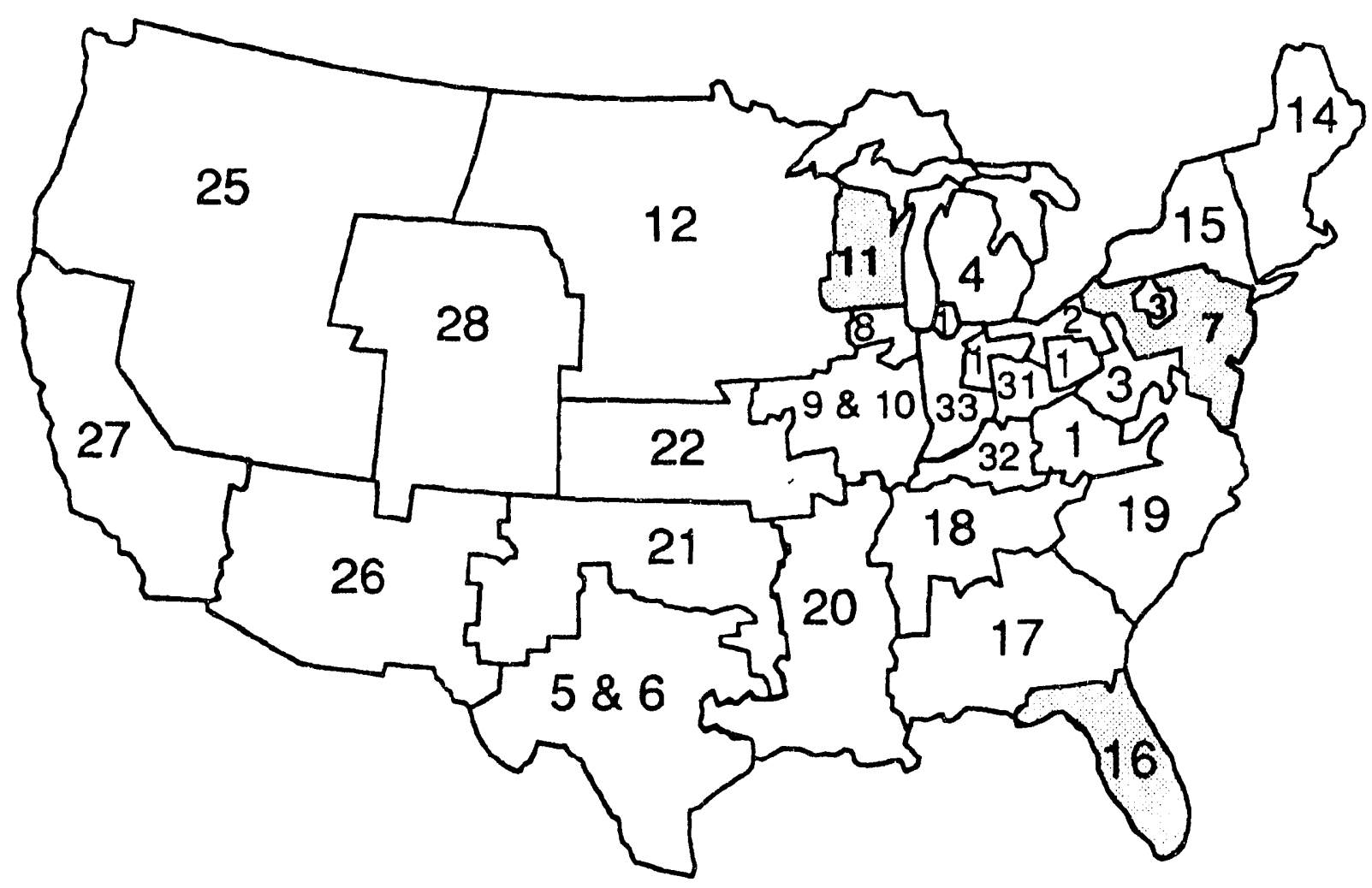

FIGURE 9 Power Pools in the U.S. Simulated in ARGUS (Shaded pools represent those examined in CCT incentive analysis.) 
modified to reflect a delay in the construction of one planned unit, and in a separate analysis, the cost effects of reduced unit efficiency and reliability were examined. The new unit cost and operating characteristics are shown in Tables 6 and 7. The results of the ARGUS Model simulation are depicted in Table 8.

The CCT incentive analysis was conducted in the following power pools:

- Pool 7 - the Pennsylvania-New Jersey-Maryland Interconnection, and associate members of the Mid-Atlantic Area Council (MAAC),

- Pool 11 - the Wisconsin-Upper Michigan Region of the Mid-America Interpool Network (MAIN), and

- Pool 16 - the Florida Subregion of the Southeastern Electric Reliability Council (SERC).

These pools were selected for their variety in terms of load growth, current capacity mix, and proximity to both low- and high-sulfur coal markets. The baseline expansion plans were altered to reflect uncertainties in construction time and operating parameters. The altered

TABLE 6 New CCT Unit Characteristics ${ }^{a}$

\begin{tabular}{lcccc}
\hline \multicolumn{1}{c}{ Characteristic } & IGCC & PFBC & AFBC & PC/FGD \\
\hline Capital cost $(\$ / \mathrm{kW})^{\mathrm{b}}$ & 1,807 & 1,447 & 1,534 & 1,434 \\
Size $(\mathrm{MWe})$ & 200 & 340 & 200 & 300 \\
Fixed O\&M $(\$ / \mathrm{kW})$ & 45.7 & 40 & 32.4 & 30.0 \\
Variable O\&M (mills/kWh) & 3.3 & 6.5 & 7.2 & 6.0 \\
Heat rate (Btu/kWh) & 9,320 & 8,980 & 10,058 & 10,044 \\
Forced outage rate $(\%)$ & 10.7 & 18.9 & 10.2 & 16.4 \\
Scheduled maintenance (d) & 16 & 34 & 34 & 30 \\
Commercial service date & 1994 & 1996 & 1994 & 1989 \\
\hline
\end{tabular}

a All costs are reported in Dec. $1988 \$$.

b Includes AFUDC.

c O\&M: operation and maintenance.

Source: EPRI (1989). 


\begin{tabular}{lcc}
$\begin{array}{l}\text { TABLE } 7 \text { New Gas-Fired Unit } \\
\text { Characteristics }^{\text {a }}\end{array}$ & & \\
\hline \multicolumn{1}{c}{ Characteristic } & NGCC & GT \\
\hline Capital cost $(\$ / \mathrm{kW})^{\mathrm{b}}$ & 488 & 355 \\
Size (MWe) & 210 & 140 \\
Book life (yr) & 30 & 30 \\
Fixed O\&M (\$/kW) & 3.7 & 0.7 \\
Variable O\&M (mills/kWh) & 3.7 & 7.4 \\
Heat rate (Btu/kWh) & 7,740 & 13,800 \\
Forced outage rate $(\%)$ & 5.5 & 3.5 \\
Scheduled maintenance (d) & 15 & 15 \\
Commercial service date & 1991 & 1991 \\
\hline
\end{tabular}

a All costs are reported in Dec. $1988 \$$.

b Includes AFUDC.

c O\&M: operation and maintenance.

Source: EPRI (1989).

expansion plans were compared to the baseline plans to estimate the costs incurred from construction delays and lower performance levels.

To simplify the analysis, the group of six risk categories was reduced to four: construction, operational, environmental, and technological. To a certain extent, the exogenous risks associated with demand changes and inflation will be captured in construction delay and cost overrun estimates. Regulatory risks are in part captured through the analysis of technological risks when the disallowances for cancellation of a plant reflect a portion of the regulatory prudence evaluation.

The ex ante approach employed in this section can be conceptualized using the decision tree depicted in Figure 10. Each of the four major risks is decomposed into two subcategories that are each given a weight of $0.25 .^{23}$ The ARGUS model, along with other methods, is used to estimate the potential costs associated with each subcategory. These costs are then multiplied by the appropriate weights and summed to obtain an estimate of

23 These equal weights were drawn for simplicity and illustration; a different distribution of weights could be used if additional information were known by the decision maker. 
the ex ante ICR. This general process would be used by utility planners, regulators, and lending institutions evaluating the viability of an innovative project. The result achieved is the development of an expected cost that could be incurred in undertaking a project. This value would be added to the best estimate of the engineering costs of building the technology to yield the overall cost of the project. To induce a utility or NUG to undertake the project would require an incentive to offset all or part of this incremental cost.

\subsubsection{Construction Risk}

To simplify and illustrate the calculation of the costs associated with construction risk, two subcategories are analyzed: the costs associated with construction delays and the costs associated with construction cost overruns. In the case of delays, three potential sources of increased costs exist that will be given equal weight. In the process of calculating these costs, delays are assumed to range from one to five years. Each of these possible delays is given equal weight. In more sophisticated analysis of this problem, past data on construction experience could be used to assign unequal weights to each possible occurrence.
TABLE 8 New Capacity Additions for 1995-2000 by Pool

\begin{tabular}{rrr}
$\begin{array}{c}\text { Power } \\
\text { Pool } \\
\text { Number }\end{array}$ & $\begin{array}{c}\text { New Gas } \\
\text { Capacity } \\
\text { (MWe) }\end{array}$ & $\begin{array}{r}\text { New Coal } \\
\text { Capacity } \\
\text { (MWe) }\end{array}$ \\
\hline 1 & 630 & - \\
2 & 630 & 1,360 \\
3 & 420 & 1,020 \\
4 & - & 2,720 \\
$5 / 6$ & - & 13,600 \\
7 & - & 1,700 \\
8 & 1,260 & 340 \\
$9 / 10$ & 2,940 & - \\
11 & - & 2,040 \\
12 & 210 & 680 \\
14 & - & 4,540 \\
15 & - & 4,400 \\
16 & - & 12,140 \\
17 & 10,480 & 5,440 \\
18 & - & 1,360 \\
19 & - & 12,580 \\
20 & - & 3,200 \\
21 & - & 3,620 \\
22 & 2,310 & 1,360 \\
25 & 13,440 & - \\
26 & - & 3,600 \\
27 & - & 6,800 \\
28 & - & 1,020 \\
31 & 680 & - \\
32 & 630 & 340 \\
33 & 840 & 1,020 \\
\hline & & \\
& & \\
& - & \\
& & -
\end{tabular}

The costs associated with delay of a new unit have four components: (1) increased system operating costs, (2) cost for additional purchases (based on increased unserved energy), (3) an increase in construction costs due to the delay, and (4) the increased chance of a disallowance. The increased operating costs include the fuel and variable O\&M costs that result from additional generation by the existing units within the power pool. Because the power pool may not be able to replace all the generation expected from the delayed unit, the system experiences an increase in unserved energy. We assume this increase in unserved energy could be met by purchases from outside the power pool. The cost for these purchases is assumed to be $15.5 \mathrm{mills} / \mathrm{kWh}$. 


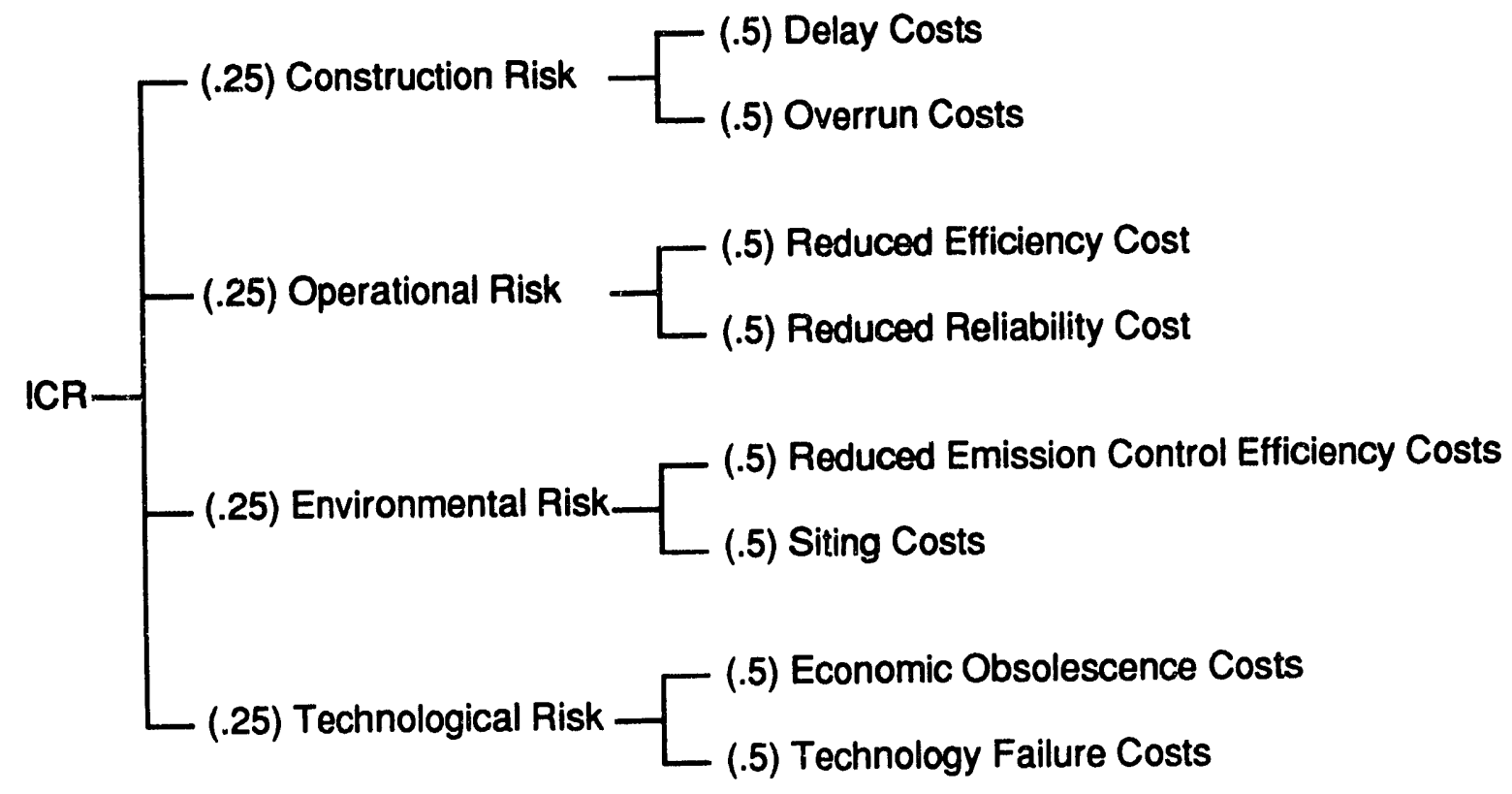

FIGURE 10 Ex Ante Incremental Cost of Risk Calculation Method [E(TC) ]: Ilustrative Cost Categories and Weights

In the case of a construction delay, ARGUS was used to evaluate the delay of the first CCT unit selected as a new capacity addition in power pool 7. This unit was scheduled for operation in 1999. Table 9 shows the costs associated with increased unserved energy and operating costs. Table 10 indicates the additional capital costs resulting from the increased accumulation of AFUDC expenses. If we assume, for simplicity, that each of the five delay scenarios has an equal probability of occurring, and each of the three categories of costs is given equal weight, the expected costs represent the probability-weighted sum of the delay costs for each year, which would result in approximately $\$ 48$ million in expected incremental cost exposure.

A second component of construction risk is that associated with cost overruns. Based on trends identified in Table 11, the ratio of actual cost to estimated costs ranged from 1.29 to 1.83 , with an average of 1.51 . Based on the expected baseline costs of the innovative plant of $\$ 463.3$ million, the overrun could be as much as $\$ 236.2$ million. ${ }^{24}$ If each of these two components was given equal weight, the expected costs (in millions of dollars) of the construction risk would be equal to:

\begin{tabular}{lccc}
\multicolumn{1}{c}{ Risk } & Weight & $\begin{array}{c}\text { Component } \\
\text { Expected } \\
\text { Cost }\left(\$ 10^{6}\right)\end{array}$ & $\begin{array}{c}\text { Expected Cost } \\
\text { of Construction } \\
\text { Risk }\left(\$ 10^{6}\right)\end{array}$ \\
\hline Construction delay & 0.5 & 48.0 & 24.0 \\
Cost overrun & 0.5 & 236.2 & 118.1 \\
Total & & & 142.1 \\
\hline
\end{tabular}

$24 \$ 463.3 \times 1.51=\$ 699.5$. Subtracting $\$ 463.3$ yields $\$ 236.2$ million. 
TABLE 9 Increase in Unserved Energy, Unserved Energy Costs, and Operating Costs for a 1 Unit Delay in Power Pool $7^{\mathrm{a}}$

\begin{tabular}{|c|c|c|c|c|c|c|}
\hline \multirow[b]{2}{*}{ Energy/Cost } & \multirow[b]{2}{*}{ Category } & \multicolumn{5}{|c|}{ Length of Delay (yr) } \\
\hline & & 1 & 2 & 3 & 4 & 5 \\
\hline $\begin{array}{l}\text { Unserved energy } \\
\text { (GWh) }\end{array}$ & $\begin{array}{l}\text { Base case } \\
\text { Delay case } \\
\text { Difference } \\
\text { Cumulative } \\
\text { difference }\end{array}$ & $\begin{array}{l}3.59 \\
4.08 \\
0.49\end{array}$ & $\begin{array}{l}7.17 \\
7.83 \\
0.65 \\
1.14\end{array}$ & $\begin{array}{l}6.55 \\
7.17 \\
0.61 \\
1.76\end{array}$ & $\begin{array}{l}6.03 \\
6.61 \\
0.58 \\
2.33\end{array}$ & $\begin{array}{l}5.61 \\
6.15 \\
0.55 \\
2.88\end{array}$ \\
\hline $\begin{array}{l}\text { Annual costs for } \\
\text { unserved energy } \\
\left(\$ 10^{6}\right)\end{array}$ & & 7.61 & 10.12 & 9.50 & 8.96 & 8.46 \\
\hline $\begin{array}{l}\text { Cum. costs for } \\
\text { unserved energy } \\
\left(\$ 10^{6}\right)\end{array}$ & & & 17.73 & 27.23 & 36.19 & 44.65 \\
\hline $\begin{array}{l}\text { Operating costs } \\
\left(\$ 10^{6}\right)\end{array}$ & $\begin{array}{l}\text { Base case } \\
\text { Delay case } \\
\text { difference } \\
\text { Cumulative } \\
\text { difference }\end{array}$ & $\begin{array}{l}6.61 \\
6.62 \\
0.01\end{array}$ & $\begin{array}{l}7.54 \\
7.55 \\
0.01 \\
0.02\end{array}$ & $\begin{array}{l}7.75 \\
7.77 \\
0.02 \\
0.04\end{array}$ & $\begin{array}{l}7.94 \\
7.96 \\
0.02 \\
0.06\end{array}$ & $\begin{array}{l}8.14 \\
8.16 \\
0.02 \\
0.08\end{array}$ \\
\hline
\end{tabular}

a All costs are reported in Dec. $1988 \$$.

TABLE 10 Increases in Capital Cost for a 1 Unit Delay in Power Pool $7^{\mathrm{a}}$

\begin{tabular}{lrrrrrr} 
& & \multicolumn{5}{c}{$\begin{array}{c}\text { Costs }\left(\$ 10^{6}\right) \text { per Length } \\
\text { of Delay }(\mathrm{yr})\end{array}$} \\
\cline { 3 - 7 } \multicolumn{1}{c}{ Cost Item } & Baseline & 1 & 2 & 3 & 4 & 5 \\
\hline Total capital cost & 463.3 & 463.3 & 463.3 & 463.3 & 463.3 & 463.3 \\
AFUDC & 50.5 & 77.4 & 103.3 & 129.3 & 154.7 & 183.0 \\
Total & 513.8 & 540.7 & 566.6 & 582.6 & 618.0 & 646.3 \\
Difference from baseline & & 26.9 & 52.8 & 78.8 & 104.2 & 132.5 \\
AFUDC as a \% of total & 10.2 & 14.3 & 18.2 & 22.2 & 25.0 & 28.3 \\
\hline
\end{tabular}

a All costs are reported in Dec. $1988 \$$. 
TABLE 11 Trends in Estimation of Coal-Fired Plant Costs (unadjusted for inflation)

\begin{tabular}{llccc}
\hline Year & $\begin{array}{c}\text { Type of } \\
\text { Estimate }\end{array}$ & $\begin{array}{c}\text { Estimate } \\
(\$ / \mathrm{kW})\end{array}$ & $\begin{array}{c}\text { Actual } \\
(\$ / \mathrm{kW})\end{array}$ & $\begin{array}{c}\text { Actual-to } \\
\text { Estimate-Ratio }\end{array}$ \\
\hline \multirow{2}{*}{1971} & Retrospect $^{\mathrm{a}}$ & 111 & 157 & 1.41 \\
1972 & Retrospect $^{\mathrm{a}}$ & 122 & 176 & 1.44 \\
1973 & Retrospect $^{\mathrm{a}}$ & 133 & 243 & 1.83 \\
& Plant-Specific $^{\mathrm{a}}$ & 125 & 168 & 1.34 \\
1974 & Retrospect $^{\mathrm{b}}$ & 150 & 237 & 1.58 \\
& Plant-Specific $^{\mathrm{a}}$ & 123 & 187 & 1.52 \\
1975 & Retrospect $^{\mathrm{b}}$ & 180 & 275 & 1.53 \\
1976 & Retrospect $^{\mathrm{b}}$ & 205 & 347 & 1.69 \\
1977 & Retrospect $^{\mathrm{b}}$ & 242 & 313 & 1.29 \\
\hline
\end{tabular}

a Blake et al. (1976).

b Calculated from Mitre data using their methods but incorporating updated plant costs from DOE (1978).

\subsubsection{Operating Risk}

In terms of operating risks, two scenarios were evaluated: unplanned outages and reduced unit efficiency. To estimate the costs associated with decreased unit performance and reliability, power pool 11 was selected for further analysis because a PFBC was projected for construction in the near term (1996). The heat rate on all new PFBC units was increased by $10 \%$ to estimate the impact of reduced unit efficiency. All new PFBC units were affected so that the impact on system operations could be calculated. (To change the heat rate of only one unit would likely result in negligible system changes).

Table 12 identifies the increased system costs associated with the increased PFBC heat rate. In most standard analyses of this impact, the present discounted value of the cost would be calculated to assess the effect of selecting a PFBC on the utility's total cost of operations over the planning period. If we assume for simplicity that the annual cost increase is $\$ 3$ million and the plant life is 30 years, the undiscounted cost of lower unit efficiency amounts to $\$ 90$ million.

In Table 13, the additional system costs associated with an increased forced outage rate for the PFBC unit are presented. These costs amount to approximately $\$ 1$ million per year (the sum of both operating and unserved energy costs). Once again, if we

TABLE 12 Power Pool 11 Increased Operating Costs Associated with Increased Heat Rate of a PFBC Unit

\begin{tabular}{cccc}
\hline & \multicolumn{3}{c}{ Year } \\
\cline { 2 - 4 } Item & 2000 & 2005 & 2010 \\
\hline Cost $\left(10^{6} \$\right)$ & 2.5 & 3.2 & 3.4 \\
\hline
\end{tabular}


TABLE 13 Forced Outage System Costs Associated with a PFBC Unit: Power Pool 11

\begin{tabular}{|c|c|c|c|}
\hline \multirow[b]{2}{*}{ Component } & \multicolumn{3}{|c|}{ Costs in Year } \\
\hline & 2000 & 2005 & 2010 \\
\hline Operating cost ${ }^{a}$ & 0.33 & 0.5 & 0.56 \\
\hline Increased unserved energy ${ }^{b}$ & 12.55 & 11.92 & 11.11 \\
\hline Cost for increased unserved energy ${ }^{a}$ & 0.63 & 0.60 & 0.56 \\
\hline
\end{tabular}

assume a 30 -yr plant life, these costs would amount to a $\$ 30$ million increase in undiscounted costs. If these two operating cost components are given an equal weight, then the operating risks generate a potential $\$ 60$ million increase in costs.

\subsubsection{Environmental Risks}

Environmental costs are more difficult to quantify. Whereas in the past, environmental costs could be examined by the need to retrofit existing plants to meet current environmental standards, innovative technologies are designed to meet or exceed existing emission standards. Conventional technologies can be constructed that would typically reduce $\mathrm{SO}_{2}$ emissions by $90 \%$. Although newer technologies could achieve $95 \%$ to $\geq 99 \% \mathrm{SO}_{2}$ reductions, there is a risk defined by a positive probability that the technology could fail to reduce $\mathrm{SO}_{2}$ emissions to $90 \%$. If an innovative technology fails to meet what a conventional technology would have yielded, an opportunity cost is imposed on the operator. This cost could be approximated by the number of emission allowances the utility must purchase to achieve the $90 \%$ reduction target of the conventional technology.

The expected cost in terms of environmental control failures for choosing a CCT instead of a conventional unit can be derived as follows. A 500-MW PC/FGD is assumed to emit 55,260 tons of $\mathrm{SO}_{2}$ year - burning $5 \%$ sulfur coal and operating at capacity factor of $65 \%$, a heat rate of $9,800 \mathrm{Btu} / \mathrm{kWh}$, and an $\mathrm{SO}_{2}$ removal efficiency of $90 \%$. Assuming the CCT has similar operating characteristics and is able to control $\mathrm{SO}_{2}$ emissions at $90 \%+$, no costs are incurred. If, however, the CCT unit controls emissions at a lower rate, environmental costs will be incurred either through $\mathrm{SO}_{2}$ allowances that must be purchased for compliance (with Title IV of CAAA of 1990), offsetting that unit's emissions by increasing controls (emission reductions) on units in the utility system, or through reducing generation and purchasing outside power. Table 14 indicates the increase in $\mathrm{SO}_{2}$ emissions for specified $\mathrm{SO}_{2}$ removal efficiencies below $90 \%$. Table 15 indicates the relative costs of failure on a ton per year basis. Examination of these two tables allows an upper bound cost to be 
TABLE 14 Controlled $\mathrm{SO}_{2}$ Emissions Differentials

\begin{tabular}{llllll}
\hline \multicolumn{1}{c}{ Item } & \multicolumn{5}{c}{ Differentials (ton/yr) } \\
\hline & & & & & \\
Removal rate & 0.7 & 0.75 & 0.8 & 0.85 & 0.9 \\
Excess $\mathrm{SO}_{2}$ & 11,050 & 8,300 & 5,500 & 2,760 & 0 \\
\hline
\end{tabular}

TABLE $15 \mathrm{SO}_{2}$ Control Costs $^{\mathrm{a}}$

\begin{tabular}{ccc}
\hline Item & $\begin{array}{c}\text { Wet FGD } \\
\left(\$ / \text { ton of } \mathrm{SO}_{2}\right)\end{array}$ & $\begin{array}{c}\mathrm{SO}_{2} \text { Allowances } \\
\left(\$ / \text { ton of } \mathrm{SO}_{2}\right)\end{array}$ \\
\hline Levelized removal costs & $250-550$ & $100-1,500$ \\
\hline
\end{tabular}

a Note that using reduced utilization and purchasing power off-system were not costed out.

determined. The upper bound of $\$ 16$ million occurs if only $70 \% \mathrm{SO}_{2}$ removal is achieved and if the firm purchases allowances at $\$ 1,500 /$ ton. This, of course, assumes that a wet flue-gas desulfurization (FGD) could not be retrofitted to the system's current plants, and no offsystem sales could be obtained.

Assuming that there is a $20 \%$ probability of each emission failure occurring and that allowances and wet FGD costs are both approximately $\$ 500$, a range of expected costs can be derived. Given these control costs, expected environmental costs range from $\$ 0-\$ 5$ million. Given the assumptions, the expected environmental control cost of adopting a CCT is $\$ 2.8$ million. Assuming a 25\% probability of environmental underperformance, the expected cost is $\$ 0.7$ million.

\subsubsection{Technological Risk}

Technological risks arise when plants become prematurely obsolete or fail to operate. In either case, the cost associated with the plant cancellation or abanoionment and method of treatment by the regulatory authorities will determine the expected cost exposure of this risk. The probability of incurring these costs is based on the probability that the technology will fail or become obsolete.

One of the critical regulatory policy failures of the past has been the lack of development of any optimal cancellation policy (McDermott 1984). As a result, the cost exposure associated with plant cancellations has little, if any, relation to economic conditions. Data on coal plant cancellations and expenditures at the time of cancellation have not been compiled; however, some evidence on nuclear plant expenditures does exist to highlight this 
dilemma (see Table 16). The wide range of cost exposure is reflected in the range of expenditures, running from less than $\$ 50$ million to approximately $\$ 900$ million. Given that the expected cost of the innovative technology being considered could range from $\$ 463.3$ million to $\$ 699.5$ million, a conservative estimate of the cancellation cost might run as high as one-third of the expected capital costs (i.e., between $\$ 154$ million and $\$ 233$ million). Lacking further information, a value of $\$ 200$ million is assumed to calculate the ICR.

Table 17 shows the final process of calculating the ICR. By assuming that each major risk category has an equal probability of occurring, the ex ante calculation of the ICR is derived by multiplying the probability times the expected cost of each risk category and then summing. The result is a probabilistically weighted average of the incremental costs; this value can be used to estimate the magnitude of incentive necessary to induce a utility or NUG to undertake an innovative technology project. This estimate will be used in the simulation $r$ alternative incentive mechanisms (discussed in Section 5) to identify the incentive program that minimizes the expected impact on utility revenues, rates, and financial conditions. 


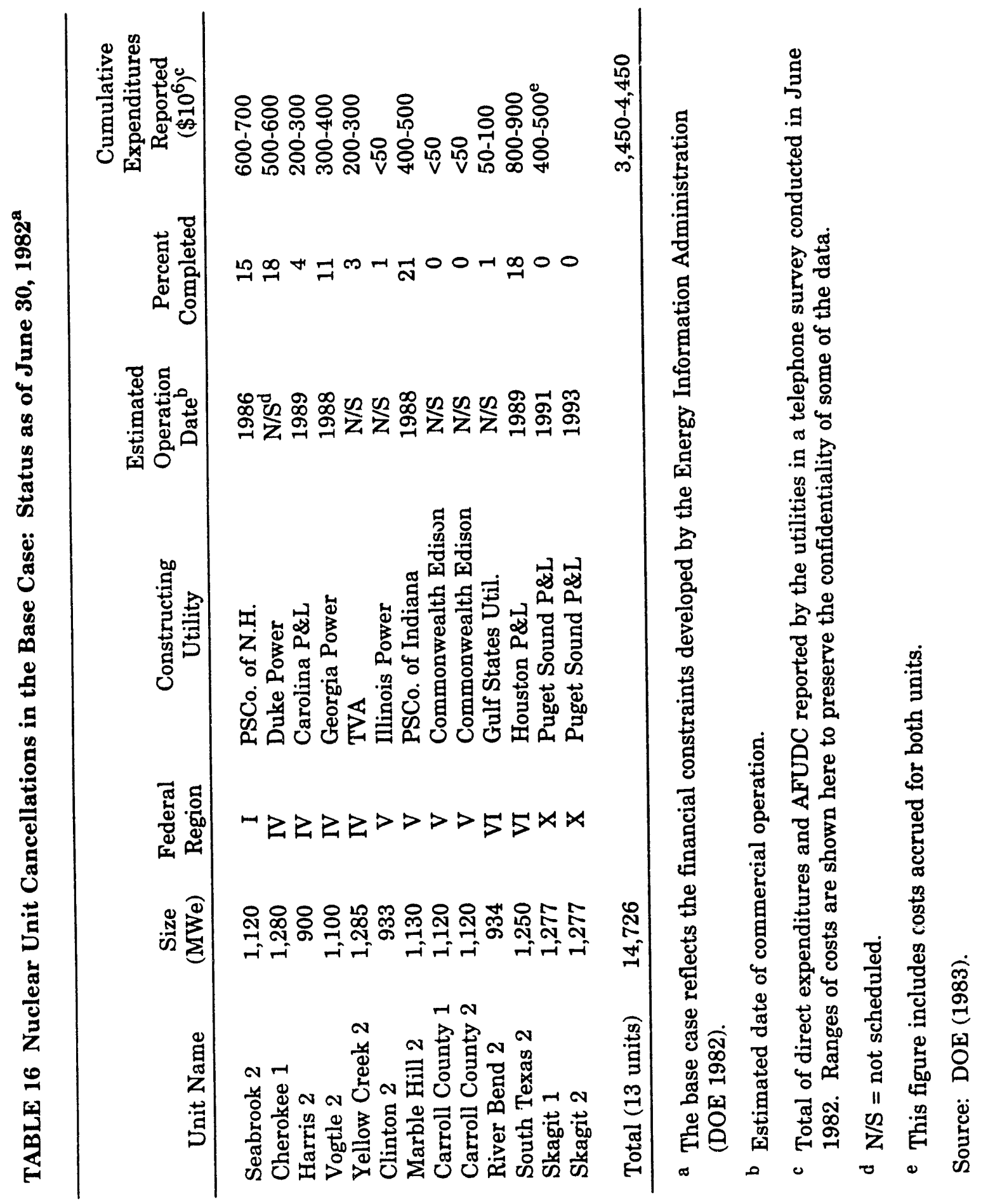


TABLE 17 Hypothetical Incremental Cost of Risk

\begin{tabular}{lcrc}
\hline Risk Category & Probability & $\begin{array}{r}\text { Expected } \\
\text { Cost }\left(\$ 10^{6}\right)\end{array}$ & $\begin{array}{r}\text { Incremental } \\
\text { Cost }\left(\$ 10^{6}\right)\end{array}$ \\
\hline Construction & $0.25 \times$ & $142.1=$ & 35.5 \\
Operation & $0.25 \times$ & $60.0=$ & 15.0 \\
Environmental & $0.25 \times$ & $2.8=$ & 0.7 \\
Technological & $0.25 \times$ & $200.0=$ & 50.0 \\
& & & 101.2 \\
Total ICR & & & \\
\hline
\end{tabular}




\section{RECOGNITION OF SPECIFIC RISKS AND ADOPTION OF SPECLALIZED AND GENERAL REGULATORY INCENTIVE MECHANISMS}

Incentives can be designed to achieve cost control in two ways: they can be designed to (1) meet specific or specialized circumstances or (2) operate in a systemic fashion as part of the overall system or scheme of operation. Over the last two decades, regulators have become increasingly aware of the need to recognize the specific risks associated with various aspects of a utility's operations and to devise incentive mechanisms that treat these specific issues (NERA 1991). As a result, some experimentation has occurred in the development of specific incentive mechanisms to overcome the adverse effects of these risks and cost control problems.

To date, regulators have developed and used incentive mechanisms to offset operating risks, including plant availability, efficiency (heat rates), system reliability measures, fuel cost control, and total factor productivity (NERA 1991). Most of these mechanisms establish performance targets (with upper and lower bounds) and either penalties or rewards for meeting the targets. In other cases, more generic mechanisms consistent with the traditional financial focus of regulators have been used, such as target equity return levels. Combining target equity returns with sharing rules allows partial retention of excess returns or partial increases, if below target levels are earned in any period.

More recently, the entire nature of the regulatory process and its incentive structure has been challenged. The deregulation of various telecommunication markets and natural gas markets has led to the examination of systemic incentive mechanisms such as price cap regulation, competitive bidding, and profit sharing mechanisms (Brown et al. 1991; Lyon 1991). While receiving greater attention during the recent process of deregulation, the issues of systemic incentives and the efficacy of regulation have historically been issues within the regulatory and academic community. Westfield (1971) was one of the first investigators to query whether the traditional form of regulation provided insufficient incentives to invest in new technologies. In his model, Westfield found that ceiling price (price-cap) regulation provided greater incentives to innovate than rate-of-return or mark-up regulation.

Moreover, Smith (1974) noted that rate-of-return regulation could lead to a bias in the type of technical changes that a utility may adopt. Magat (1976), however, $h$;s shown Smith's results to be an artifact of his model choice and has shown that "the rate of innovation selected under ceiling-price regulation is faster than the innovation rate chosen without regulation and also faster than rates selected under either rate of return or mark-up regulation" (Magat 1976, p. 479).

The operative factor in ceiling-price or price-cap regulation is the lag between price adjustment and cost changes. Sweeney (1981) has noted that if the lags are short and regulation "tight" - where prices are adjusted to closely match cost changes - regulatory lag can loose its positive regulatory effect. And Wein (1968, p. 63) has noted:

For it is not only lag in regulation which provides incentives and penalties towards improvement. It is lag in the non-regulated world which does the 
same. If all competition were perfect and all readjustments instantaneous in the competitive world, there would be no financial incentives to change, as Schumpeter has pointed out. The advantage which the innovator gets is time: his competitors cannot imitate him too quickly.

It may be possible through the use of both specific and systemic incentives to create an environment that promotes the progressiveness of innovation. To the extent that progressive innovations are adopted, the consumer benefits in the long-run in terms of reduced costs of service, greater reliability, and reduced environmental damage. In the following discussion, a wide range of alternative incentive mechanisms are presented and discussed with respect to their ability to mitigate specific risks associated with innovative technology adoption and thereby advance the development and provide economic benefits to consumers.

\subsection{ALTERNATIVE INCENTIVE PROGRAMS}

The basic rationale for the development and implementation of innovative technology incentive programs by regulators is twofold: (1) to offset the inherent risks facing utilities or provide a reward for risk taking, and (2) to develop a base of information on the cost and efficiency characteristics of the innovation that can be used by utilities seeking to deploy this technology. In addition, incentives are needed to assure adequate cost control measures are adopted. (See Kahn and Stoft [1989] for a discussion of issues in designing performance incentives based on cost sharing.)

The set of possible regulatory incentives needed to induce risk taking can be divided into two categories: those that reduce the risk faced by utilities and those that provide a reward for risk taking. The types of risks facing a utility adopting an innovative technology were identified by the Innovative Control Technology Advisory Panel in a report on commercialization incentives prepared for the Secretary of Energy (ICTAP 1989). The risks consisted of capital risk, operating risk, regulatory risk, and environmental risk.

These risks can be described briefly as follows. Capital risks are associated with the possible loss of either or both the return on capital and/or the return of capital. This can occur when a PUC fully or partially disallows all or portions of the utility's construction costs or reduces the allowed rate of return on its investments. Operating risks are associated with the potential failure of the plant to perform up to its expected (design) efficiency or its failing to operate entirely. Regulatory risk is a generic term encompassing the PUC's treatment of operating and capital expenses within the regulatory process, for example, prudence or used and useful disallowances. Environmental risk entails the possibility that the technology adopted or the construction site will not meet local environmental standards or will face significant incremental costs of meeting new or additional regulations. Each of these risks or a combination of them is faced by a utility adopting an innovative technology to supply electrical load requirements.

The alternative incentive approaches available to address the four risk categories will be discussed briefly below and in more detail in Section 4.6. In Table 18, each of the 
TABLE 18 Risk Classification

\begin{tabular}{|c|c|c|c|c|}
\hline $\begin{array}{l}\text { Incentive } \\
\text { Category }\end{array}$ & Capital Risk & $\begin{array}{l}\text { Performance/ } \\
\text { Operating Risk }\end{array}$ & Regulatory Risk & $\begin{array}{c}\text { Environmental } \\
\text { Risk }\end{array}$ \\
\hline \multirow[t]{3}{*}{$\begin{array}{l}\text { Reduce } \\
\text { project } \\
\text { risk }\end{array}$} & $\begin{array}{l}\text { Prospective } \\
\text { prudence } \\
\text { (preapprove } \\
\text { capital } \\
\text { expense caps) }\end{array}$ & $\begin{array}{l}\text { Immediate cost } \\
\text { recovery through } \\
\text { FACs of CCT } \\
\text { expenditures } \\
\text { and/or replace- } \\
\text { ment of fuel cost }\end{array}$ & $\begin{array}{l}\text { Elimination of } \\
\text { retroactive used } \\
\text { and useful tests }\end{array}$ & $\begin{array}{l}\text { Preapproval of } \\
\text { accelerated } \\
\text { siting process }\end{array}$ \\
\hline & CWIP & & $\begin{array}{l}\text { Prudence } \\
\text { abandonment } \\
\text { rules }\end{array}$ & \\
\hline & $\begin{array}{l}\text { Sliding-scale } \\
\text { mechanism }^{\mathrm{a}}\end{array}$ & & & \\
\hline \multirow[t]{3}{*}{$\begin{array}{l}\text { Reward } \\
\text { risk } \\
\text { taking }\end{array}$} & IROR & $\begin{array}{l}\text { Rapid amortiza- } \\
\text { tion of CCT } \\
\text { expenditures }\end{array}$ & $\begin{array}{l}\text { Amortization of } \\
\text { abandoned/ } \\
\text { canceled plants }\end{array}$ & $\begin{array}{l}\text { Discretionary } \\
\text { use of bonus } \\
\text { emission } \\
\text { allowances }\end{array}$ \\
\hline & & $\begin{array}{l}\text { Additional cost } \\
\text { recovery via } \\
\text { avoided cost } \\
\text { pricing for } \mathrm{CCT}^{\mathrm{b}}\end{array}$ & & \\
\hline & & $\begin{array}{l}\text { Energy or } \\
\text { demand charge } \\
\text { premium based } \\
\text { on availability/ } \\
\text { capacity factor }\end{array}$ & & \\
\hline
\end{tabular}

a The sliding-scale mechanism would be symmetrical with regard to cost overruns and underruns. The mechanism would allow for partial recovery of expense overruns; there would be a shared savings if a cost underrun occurred.

b The CCT would be permitted a kWh premium equal to the difference between the system avoided cost and the variable CCT cost.

alternative incentives is classified with respect to the risk addressed and whether it reduces risks or gives rewards. In some cases, the incentive is capable of mitigating more than one type of risk and could serve as either a risk-reducing or reward incentive.

Prudence rules, whether they cover new capital costs or the abandonment or cancellation of a plant, are essentially designed to reduce the capital cost and regulatory risks. If utility management understands the rules under which they are making investment decisions, the elimination of these uncertainties will result in a more cost-effective set of decisions. Preapproved capital expense caps act in a similar fashion, with the additional advantage that a financial reward can also be earned, if construction costs can be kept below 
the cap level. The incentive could be designed to allow the utility to put into the rate base the expense cap when actual construction costs are less than that level.

The amortization and depreciation programs provide an accelerated return of capital to stockholders, which, in a present discounted value sense, increases the reward to stockholders and shortens the payback period of investments. CWIP works in a similar fashion but has the added advantage that cash flow occurs during the construction period, while the amortization/depreciation programs provide cash flow after the project is completed. Because cash flow is provided during construction, additional savings can occur from reduced borrowing needs.

Under the accelerated depreciation program, intertemporal cash flows are altered by a change in the timing of the company's tax bill. If the deferred taxes that accumulate are treated as a rate-base item, stockholders will earı an additional return on the project. By expending some or all of the project's costs, a utility reduces the investment payback period and acquires an accelerated cash flow. Once again, if these costs are passed through to customers during the project, they act like CWIP in reducing the overall financing costs of the project.

With regard to IROR, regulators have a number of options available. They could estimate the premium for undertaking similar risks within the capital market and allow the utility to earn this rate on the portion of the company's rate base associated with the innovative technology. Alternatively, they could simply prescribe a return that is sufficient to induce utilities to adopt the innovative technology.

Under the Clean Air Act Amendments of 1990 (P.L. 101-549), particular innovative technologies (e.g., DSM or renewables) can receive bonus emission allowances, whereas other innovative technolozies (e.g., CCTs) could receive extension allowances for selecting these technologies (see $\$ 409$ ). State PUCs could choose to allow the utility the freedom to sell, bank, or use these allowances as offsets in an unrestricted fashion. This could result in additional revenues that serve to reward the utility (McDermott and South 1991).

In many cases, a combination of these policies is available that simultaneously offset risks and provide rewards for risk taking. In some cases, regulators may allow the utilities to reveal their own preferences by selecting the incentives of their choice to either offset risks or be rewarded for bearing risks. Because not all firms or managers have the same preferences toward risk bearing, allowing a choice of incentives will reach a larger portion of the utility marketplace.

In addition to incentives being employed to reduce the risk of an innovative project, incentives are also used to stimulate increased cost control activities. Table 19 summarizes the incentives available to achieve this goal. As noted, incentives can achieve cost control in two ways: they can be systemic in nature or targeted to specific activities. In general, the nature of the incentive is determined by its application. Regulators can employ prudence 
TABLE 19 Cost Control Classifications

\begin{tabular}{llll}
\hline Incentive Category & Prudence Reviews & Target Mechanism & Automatic Adjustment \\
\hline $\begin{array}{l}\text { Systemic } \\
\text { incentive }\end{array}$ & Management audit & $\begin{array}{l}\text { Systemwide cost } \\
\text { performance and } \\
\text { incentive rates of return }\end{array}$ & Price cap mechanism \\
Specific incentive & Targeted audit & $\begin{array}{l}\text { Specific power plant cost } \\
\text { or reliability target }\end{array}$ & $\begin{array}{l}\text { Construction cost cap } \\
\text { mechanism }\end{array}$ \\
\hline
\end{tabular}

reviews, develop cost or performance targets, or develop automatic mechanisms. Given the wide range of alternative mechanisms, regulators can combine a set of incentives that encourages a utility or NUG to undertake a risky project, while simultaneously providing an incentive to control costs. For example, on the basis of our ex ante incremental risk analysis (see Section 3), a utility could be granted the option of building an innovative technology under a construction cost-cap mechanism. The cap would be determined by taking the standard estimate of capital costs (e.g., $\$ 400$ million) and adding the incremental cost of risk (e.g., $\$ 75$ million). If the utility can keep the cost of construction below $\$ 475$ million, it can keep the difference as a reward for cost control. If the plant cost rises above $\$ 475$ million, the stockholders will bear the burden. In this fashion, an incentive has been created that both induces risk taking and rewards cost control. In the next sections, the alternative incentive mechanisms available are reviewed in detail.

\subsection{INCENTIVE RETURN MECHANISMS}

Among the generic approaches, state regulators have attempted to formalize the concept of the zone-of-reasonableness for rate-of-return calculations as a means of stimulating efficiency. ${ }^{25}$ Florida, Michigan, South Carolina, and Virginia have employed rate-of-return

25 Prior to the Hope Natural Gas decision, it was established that a "fair" rate of return would lie within a "zone of reasonableness" that would be determined as a question of fact by an administrative tribunal. See Federal Power Commission v. Natural Gas Pipeline Co., 315 U.S. 575, 585-86 (1942) where it was noted that:

By long standing usage in the field of rate regulation, the 'lowest reasonable rate' is one which is not confiscatory in the constitutional sense. . . . Assuming that there is a zone of reasonableness within which the Commission is fr ee to fix a rate varying in amount and higher than a confiscatory rate, ... the Commission is also free under Section 5(a) to decrease any rate which is not the 'lowest reasonable rate.' It follows that the Congressional standard prescribed by this statute coincides with that of the Constitution, and that the courts are without authority under the statute to set aside as too low any 'reasonable rate' adopted by the Commission which is consistent with constitutional requirements. 
adjustment mechanisms that are considered to produce returns that are still fair but that also provide for penalties and rewards. ${ }^{26}$ Perhaps the most formal zone-of-reasonableness mechanism was developed by New Mexico. Known as the COSI plan (cost-of-service index), this mechanism defined a formal zone of reasonableness for equity returns along with a formal lag adjustment period that allowed the utility to reap the reward of returns above the maximum for a specific period and punished the utility for returns less than the minimum. At the time of adjustment, the rates would be adjusted to bring the utility back within the zone; see Kaufman and Profazich (1979). Similar mechanisms are being considered and adopted for telephone and electric utility companies to induce greater efficiency (Lyon 1991; Lowry 1991).

Incentive mechanisms and the concern for cost control and rewarding utilities for risks are not entirely modern phenomena. As early as 1855 in England, the so-called "sliding-scale" approach was employed by the Sheffield Gas Act of 1855, which permitted the company to pay a dividend of $8 \%$ if gas prices were over 84 cents. It could, however, declare dividends of $10 \%$ if the price was less than this level. In the United States, the Washington Plan was employed from 1925 to 1955 to regulate Potomac Electric Power Co. ${ }^{27}$ If a company's earnings rose above $\mathbf{7 . 5 \%}$, the rates would be lowered in the following year to absorb half the excess. If earnings fell below $7.5 \%$ for five years, $7 \%$ for 3 years, or $6.5 \%$ for one year, rates would be increased to allow a $7.5 \%$ return.

The FERC contemplated a sliding-scale-type mechanism in the Alaskan gas pipeline case. There the IROR mechanism explicitly accounted for the risks created by the introduction of the mechanism itself with the result that a risk premium would be included to compensate in part for this additional risk in order to maintain capital attraction and compensate for the business risk associated with the project. ${ }^{28}$

\subsection{NON-RATE OF RETURN INCENTIVE MECHANISMS}

Besides the incentive mechanism focusing on the rate of return, states began in the late 1970s to employ lag mechanisms in the treatment of automatic fuel adjustment clauses. These lags were designed to induce efficient fuel choice and to minimize the fuel cost and

25 (...continued)

From this it would seem the rate of return must be set no less than the cost of capital in order to ensure a chance that the company's market value will equal book value and hence avoid the issue of confiscation. But it is only the chance to earn this return and not a guarantee.

${ }^{26}$ See NERA (1991) for a review of these specific mechanisms.

27 On the Sheffield Plan, see Evetts (1922), and for general discussion of rate-of-return oriented incentive mechanisms, see Holthausen (1979).

28 FERC Order No. 31, Determination of Incentive Rate of Return, Tariff and Related Issues, June 1979. 
purchased power expenditures of utilities. ${ }^{29}$ The problem facing regulators in the $1970 \mathrm{~s}$ involved rapidly rising fuel costs due in part to the OPEC oil embargo. As an incentive, regulatory lag in effect transferred more of the risks to the utilities than conditions warranted. Likewise, an automatic fuel adjustment clause (FAC) resulted in the consumer bearing the full cost of fuel purchasing decisions insulating utility management from the cost of errors. Automatic adjustments also do not provide any incentive to the utility management to find ways of minimizing costs.

Two approaches were employed to ensure a sharing of these specific and unique risks arising in the fuel supply market. One approach was to employ a time lag in the adjustment process that forced the utility to cover the difference between the present revenue allowed for fuel costs and actual fuel costs (Violette and Yokell 1982). This ostensibly created an incentive for utility managers to employ management techniques that would minimize the difference in costs and thereby reduce the future price increases faced by consumers. The second technique was the establishment of a target fuel price based on appropriately weighted market prices for boiler fuels. In essence, this method constituted a form of yardstick competition where the utility's costs are compared to a market basket of fuel costs as the "yardstick" measure of performance (Schleifer 1985). This was then combined with an adjustment process that would allow a partial pass-through or price reduction that was based on the difference between actual and target fuel costs. For example, if actual fuel costs were higher than target fuel costs by one cent per $\mathrm{kWh}$, the adjustment mechanism would allow a one-half cent increase in the fuel costs. Likewise, if actual fuel costs were below the target a one-half cent decrease would be passed through to the customer.

This is an example of how specific incentive mechanisms can be employed to address unique risks associated with specific aspects of a utility's decision making process. Such mechanisms can have a profound effect on both short- and long-run decisions. The fuel adjustment incentives influence the dispatching of power, the maintenance scheduling of plants, and fuel purchasing strategies in the short run. In the long run, such mechanisms influence the plants selected for future construction, long-term purchasing strategies on the bulk power market, and the speed of new plant construction. In designing such incentive mechanisms, care must be taken to evaluate both the short- and long-run implications to ensure that a strategy is adopted that minimizes the long-run utility service.

\subsection{RECOGNIZING TECHNOLOGICAL RISK: EFFICIENCY STANDARDS AND INCENTIVES}

Many states are beginning to analyze and adopt objective efficiency standards that are used as a basis for adjusting a utility's allowed rate of return upward or downward. ${ }^{30}$

29 See FTC (1977) and ICC (1979).

30 See Siandards for Public Utility Management Efficiency (1985), 65 PUR 4th 189, Iowa S.C.C. 
In some cases, management audits are used as the basis of evaluation, ${ }^{31}$ while in other cases measures of overall productivity are employed to evaluate a utility's success in controlling costs and managing operations correctly. ${ }^{32}$ More recently, measures of total factor productivity have been examined by both state commissions and utilities. For example, Otter Tail Power Company has been employing a total factor productivity mechanism internally since the early $1980 \mathrm{~s}^{33}$ The employment of such mechanisms and measures is indicative of the regulator's recognition of the need to provide reward to offset risks, and reward or punish management for good and bad decisions, respectively.

\subsection{RISK-SHARING MECHANISMS}

The concept of risk has taken on greater importance in the regulatory process since the $1970 \mathrm{~s}$ and has taken on greater scope than ever before. Whereas in the past risk analysis was relegated to the analysis of the allowed rate of return, in today's environment, risk analysis is employed in construction, fuel choice, conservation, and other important policy decisions of both companies and regulatory commissions.

Traditionally in the competitive market, there is no guarantee of success nor protection against failure other than the legal guarantees provided by limited liability laws and the protection offered by "Chapter 11." Any other "risk sharing" that occurs in a competitive market can only arise by negotiations between suppliers and buyers through mutually agreed upon contractual clauses. In these cases, risk sharing mechanisms such as minimum payments, cancellation penalties, or cost sharing clauses have been developed. The benefits from such clauses arise from the final price paid and the services received. If one party to the contract is forced to bear all the risks of success or failure, the price paid for the product may be significantly higher than if a sharing arrangement exists.

Thus, risk sharing mechanisms are employed to lower the ultimate costs of transactions. ${ }^{34}$ Risk sharing issues arise before regulatory commissions on a broad range of questions from rate design, fuel cost recovery, excess capacity, and construction planning.

31 See Management Audits (1986), Electric Utilities, 73 PUR 4th 66, 68, West Virginia P.S.C.

32 See Crew and Kleindorfer (1987), Seagraves (1984), Baumol (1982), Gale (1982), and Costello and Cho (1984).

33 See Kjellerup $(1984,1985,1988)$, for an in-depth discussion of the Otter Tail program and references therein.

34 See Stutz (1986); and Markham (1988). This article lists 21 examples of risk-sharing cases heard before regulatory commissions. 


\subsubsection{Risk Sharing: Rate Base Phase-ins and Prudence Reviews}

One of the most frequently employed forms of risk sharing used in regulation today is the phase-in of rate base additions. ${ }^{35}$ By adopting a phase-in approach, regulators achieve a number of objectives including the sharing of new plant costs between utility stockholders and consumers. If it is known in a prospective fashion that costly plants will be phased in rather than placed in the rate base in their entirety, the utility will have an incentive to minimize construction costs. Phase-ins are also used to (1) reduce rate shock, (2) maintain rate stability, (3) match the benefits and costs to customers over time from a plant, and (4) preserve the financial integrity of a utility.

Another approach to risk sharing is the use of prudence reviews where the reasonableness of construction expenses is evaluated, and any part disallowed is considered to represent the stockholders' share of expenses. The problem with prudence reviews lies in the ambiguity surrounding the definition of prudence. ${ }^{36}$ The risk that a full recovery of costs may not occur can lead some utilities not to undertake investments that are of a legitimate nature. As much as $36 \%$ of a plant's construction costs have been disallowed from rate base, as in the case of Nine Mile Point Unit 2 in New York, with an average of $15.9 \%$ disallowed for the 12 plants considered as of 1987 (Laros and Houbold 1987).

The use of ex post audits and managerial performance studies, however, is not standardized but constitutes an analysis of unique events under specific localized conditions and as such does not constitute objective risk-sharing agreements. The problem from a risk assessment point of view is that such procedures can induce greater uncertainty with regard to the adoption of innovative projects, raising the cost of such undertakings or preventing 1. tilities from seriously considering the alternative. This is especially true if the project $s$ iould be canceled as a result of technical problems or for other financial and economic reasons. Since the 1970s, plant cancellations have become more frequent, and the potential for abandonment decisions continues to rise. ${ }^{37}$ The fact that adverse incentives are created could result in potential losses to consumers in terms of reduced environmental quality,

${ }^{35}$ For a summary of these cases, see Sponseller (1985), Nagelhout (1988), and Washington University Law Quarterly (1976).

36 The first attempt at such a definition was given by U.S. Supreme Court Justice Brandeis:

The term prudent investment is not to be used in a critical sense. There should not be excluded from the finding of the case, investments which, under ordinary circumstances, would be deemed reasonable. The term is applied for the purpose of excluding what might be found to be dishonest or obviously wasteful or imprudent expenditures. Every investment may be assumed to have been made in the exercise of reasonable judgment unless the contrary is shown.

Concurring opinion of Justice Brandeis, Missouri ex rel. Southwestern Bell Telephone Co. v. Missouri Public Service Commission, 262 U.S. 276 (1923).

${ }^{37}$ See Pierce (1984), Zimmerman (1988), Massela (1981), and Crawfis (1982). 
higher operating costs, and future shortfalls in capacity (Lazo 1988). At present, the U.S. Supreme Court is examining the treatment of its review of Barasch v. Pennsylvania Public Utility Commission. ${ }^{38}$ The FERC recently allowed the Boston Edison Company to recover its canceled plant costs, ${ }^{39}$ and in Massachusetts and at the FERC, preapproval processes have been established for recovering construction costs. ${ }^{40}$

\subsection{ALTERNATIVE INCENTIVE MECHANISMS TO ADDRESS TECHNOLOGICAL RISK}

In both theory and practice, a number of existing mechanisms could provide incentives for utilities to undertake innovative projects. This section examines each option in some detail. Appendix A describes the various methods of calculating rates of return.

At least 16 methods provide incentives for undertaking a project that involves an innovative technology. These are as follows:

- Prospective prudence,

- Prudence abandonment rules,

- Accelerated depreciation,

- Rate base treatment of deferred taxes,

- CWIP,

- Avoided cost rates,

- Treatment of subsidies,

- Expensing demonstration costs,

- IROR,

- Investment tax credits,

- Special treatment of emission allowances,

- Amortization of abandoned projects,

- Property tax,

38 See Clemmons (1988).

39 Boston Edison Co., 1988, 42 FERC Para. 61, 374, 92 PUR 4th 337.

${ }^{40}$ Department of Public Utilities (1988). 
- Cost caps,

- Preapproval of plan/expenditures, and

- Sliding-scale incentives.

Each of these methods is discussed below with regard to the nature of the risks that the method addresses and the pros and cons associated with the application of each method.

\subsubsection{Prospective Prudence}

One of the greatest threats facing utility managers today is that the total expenditures or some fraction of expenditures on a project will be denied inclusion as either rate base or operating expenses. This practice creates a potential threat to the bottom line earnings not only in the present, when expenditures occurred, but also in the future, when the allowed revenue requirement may be reduced. Financial risk for the shareholders is dramatically increased. This threat creates a significant disincentive toward the undertaking of an "innovative" project in the sense that an expert prudence review may interpret innovative as being risky and unwarranted. Any "excess" costs would be deemed unnecessary with the decision often disregarding the initial reasons for undertaking the project in the first place.

The FERC has recognized this problem and has stated that prospective prudence recognizes that when a regulatory decision is made contemporaneously with the investment decision, (1) the decision is more likely to correspond with reality, because loss of memory of the contemporaneous facts is averted, and (2) the temptation to "improve" on contemporaneous facts through the inestimable benefit of hindsight is avoided. ${ }^{41}$

Some form of prospective prudence would minimize risk; this approach, however, creates a problem in that the incentives for cost control are diminished to some degree. Prospective prudence by itself may not balance the incentives to control costs while reducing perceived risk associated with the project; what may be necessary is the need to combine this incentive with other measures to create a more comprehensive incentive environment.

A weaker but perhaps more adequate form of prospective prudence focuses on the correctness of the project choice in combination with a target cost of the project, where the utility can retain some fraction of cost overruns as an incentive to control costs while paying some positive fraction of any cost overruns as a penalty for poor cost control.

41 FERC Order No. 138; 18 FERC Para 61, 244 at 61,502 (Trailblazer Case). 


\subsubsection{Prudence Abandonmant}

On another level, the prospective prudence approach could be employed on a narrower scope. The prospective prudence mechanism could be used only in association with the need to abandon the project. This approach has been employed by the FERC in a number of cases, in particular the New England Power and Northern States Power cases. ${ }^{42}$ In these cases the guarantee was limited to a return of capital and not designed to include a return on vapital. Restricting the return to be only of capital provides an incentive foi rudent management of constructior and operation costs and does not necessarily preclude adoption of an innovative technology, if the utility/NUG exercises such cost controls. By not establishing a mandated return on capital, the adopting firm has an incentive to operate with best management practices. This results in a sharing of the risk between ratepayers and stockholders, thus providing an incentive for prudent management practices and an incentive to undertake a more risky project. Whether this incentive is sufficient by itself is a separate question; however, if it is at least allowed as an option, it could meet the needs as seen by companies facing a particular set of options and conditions.

\subsubsection{Accelerated Depreciation}

Accelerated depreciation is a method often employed for the recovery of project costs. This is especially true in situations where the operating life of the plant or technology is shorter than normal. Accelerated depreciation results in a shorter payback period on an investment by raising current cash flows. ${ }^{43}$ In terms of the net present value (NPV) of cash flows, there are no costs or benefits when accelerated depreciation is used. There are some potential offsetting effects resulting from its adoption in a regulatory environment through its effects on deferred taxes and present tax bills.

The chief benefit of accelerated depreciation is the giter cash flows generated during the early years of a project. This extra revenue may be needed to offset any unexpected costs and to cover financial obligations. The extra cash flow improves the interest coverage ratio, potentially lowering the firm's cost of capital. Accelerated depreciation may lower risks to the utility, encouraging the utility to undertake an innovative technology project.

There are two considerations raised through the use of accelerated depreciation; the length of the asset's life and the method employed for depreciating the plant (i.e. double declining balances, straight line, etc.). On the first issue, Revenue Procedures 87-56 of the Internal Revenue Service (IRS) classify utility plants as having a 28-yr life for tax purposes. In some special cases, alternative energy properties (solar, wind, etc.) are given 5-yr lives. The IRS code Section 169 also gives a 5-yr life for pollution control equipment. Thus, some

42 See FERC Order No. 49, 28 FERC Para. 61,054 and Order No. 134, 17 FERC Para. 61,190.

${ }^{3}$ One analysis of this issue that evaluated the tax effects up until 1979 is that of Kiefer (1979). 
precedent exists for treating innovative, low emission technologies as property that could receive accelerated depreciation treatment.

In certain cases, states may wish to apply this method with reference to state income tax payments. While small in magnitude, such an incentive could induce a change in utility behavior when combined with other mechanisms.

\subsubsection{Deferred Tax Treatment}

The selection of the depreciation method for rate base treatment and for tax treatment results in significant cash flow differences for a utility. Rate base treatment typically employs a straight line depreciation schedule, while accelerated rates are used for tax purposes. As a result, the utility increases its expenses for tax purposes, lowering its actual tax bill, while charging customers rates based on the higher straight line tax bill. This difference is called deferred taxes and represents a positive cash flow to the utility. By raising the depreciat on rate used for ratemaking purposes, this cash flow will shrink while operating expenses will rise to reflect the measured depreciation expense. By shortening the time over which the expenses are recovered, the NPV of the cash flows for the utility is increased, representing a positive incentive for undertaking the project.

Alternatively, the PUC could allow the depreciation rates to stand as they are but allow special treatment of the deferred tax balances. Rather than subtracting deferred taxes from the rate base, they could be allowed to earn the composite rate of return on the deferred taxes. This rate of return on the deferred taxes could be equal to either the existing weighted cost of debt or of equity capital. Thus, an incentive is created by either increasing the rate base of the company, or raising the weighted return earned on the rate base, or both. Each of these cases raises the expected revenue flows from undertaking the project and thus increases the incentive to undertake the project. These incentives may be sufficient in themselves or they might be combined with other options, such as prospective prudence of the abandonment costs.

\subsubsection{Construction Work in Progress}

The methods suggested so far have addressed the issue of revenue flows after a project has been completed. For some titilities the more pressing issue concerns the revenue flows during construction. If CWIP is allowed, a utility may be encouraged to undertake the construction of an innovative technology because the present earnings stream is protected. There are obvious questions raised with this approach that have been debated since it was first employed, namely the intergenerational equity problem. Once again, this option could be combined with prudence assurances or other incentives to address broader incentive issues facing the utilities. It is also possible that CWIP could be applied to only the pollution control portion of thr investment. The pollution control pertion of the investment is more straightforward in ? etrofit projects. Alternatively, for innovative technologies where the pollution control is in inherent part of the electricity generating process, separation of the 
pollution control portion of the investment is more difficult, if not problematic (e.g., IGCC). This type of incentive is simple to apply to innovative retrofit technologies such as scrubbers and sorbet injection technology.

\subsubsection{Avoided Cost Rates}

In the spirit of a more competitive environment, the utility undertaking a more innovative and cost-effective approach to supply electricity could be allowed to charge a price based on the use of the conventional technological option. If the innovative technology is more cost-effective than the conventional technology, the utility could be allowed to keep the cost difference as profit. This profit incentive provides the utility with motivation to implement the riskier, innovative technology project. The avoided cost rates approach is also known as the surrogate cost approach.

\subsubsection{Treatment of Grants}

Another alternative would be to provide, for rate-making purposes, special treatment of repayment grants provided by the federal government for innovative projects. Such treatment is a growing concern, since the number of CWIP awards increases. (See DOE [1992, pp. 3-9] for a discussion of the recovery of investment procedures.) This treatment has two advantages. First, it induces the submissions to the program to be as compatible as possible with the goals of efficiency and environmental quality. Second, it provides a financial incentive typically unavailable to utilities. This incentive could take the form of rate-basing the grant at a zero cost of capital or some positive rate. The grant could be included for the duration of the project (in effect acting as CWIP) and then removed upon completion, or only partially included in rate base and depreciated as normal to provide additional cash flow incentives.

\subsubsection{Expensing Demonstration Costs}

The FERC has recognized the need to stimulate innovation through research, development, and demonstration projects. The Commission issued Order 566 specifically to add ess the need. The FEFiC noted that to stimulate the research and development (R\&D) effort of jurisdictional companies, the Commission's rate review and accounting procedures must be classified. In addition, an opportunity for simplified proceedings for preapproval of $R \& D$ program organization would stimulate innovation. ${ }^{44}$

This rulemaking established the criteria for approving R\&D expenditures and assured early review and decisions in the case of requests for advanced approval of the project. Under the rules established by Order 566, the definition of research, development, and demonstration (RD\&D) in Part 201 of the Code of Federal Regulations Definition 28B,

44 58 FPC Para. 2238 at 2239. 
and Part 101 Definition 27B, defines RD\&D expenditures as: Including expenditures for the implementation or development of new and/or existing concepts until operations become technically and economically feasible.

The purpose of innovative technology projects would include the examination of their technical and economic feasibility in order that data can be gathered to assess these characteristics. As such, the FERC could grant exceptions to projects approved for inclusion under the innovative technologies program, allowing cost and rate treatment for the entire life of the project until it has been fully depreciated.

In recognizing the approval of an innovative technology plant under this program, the entire cost of the plant, including "normal" business investments associated with the project, will be treated as RD\&D expenditures. This deviation is designed to provide greater economic incentive to the utility. Protection against abuse of one project rests in compliance with the program criteria and the approval process that will only consider plant designs that the FERC feels constitutes "sufficient" innovative design to warrant inclusion in the program.

Once a plant has received advanced approval for participation in the innovative technologies program, this approval constitutes an assurance that all future expenditures will receive subsequent approval as $R D \& D$ expenditures under the program. This assurance will also extend to the special treatment offered for projects subsequently canceled as described below.

\subsubsection{Incentive Rate of Return}

An IROR compensates directly for the technological risk that a utility is exposed to in undertaking an innovative project. The basic premise is that the marketplace assigns a higher level of risk to the stocks of companies that undertake risky projects and, as such, its stock price drops in order to raise the return earned by stockholders. Most utilities would be unwilling to impose the negative wealth effect on present stockholders in order to undertake the risky project. The IROR is designed to compensate the stockholders in advance, making the necessity for stock prices to adjust irrelevant to the project. In essence, the reward granted for undertaking the project would offset the additional risk as perceived by the stock market.

The process is consistent with the FERC's present approach to rate-of-return determination in that the "market value is a result of the rate making process" 45 rather than market values determining the rates. The FERC would compensate the vtility through the rate making process for the risks associated with a project and therefore determine the market value of the stock. The point is not necessarily that market values will be kept exactly stable, insulating the stockholder, but rather that the signal will be sent to the

45 FERC, Order No. 489 (RM 87-35-000) p. 21. 
market that compensation is being made and the market can still evaluate this information in any way it wishes in formulating the perceived risks regarding the stock.

\subsubsection{Investment Tax Credits}

This vehicle has been used in the past through legislation designed to stimulate investment. It is also possible that state legislators would recognize this approach as a means of stimulating innovative research directly by utilities rather than subsidizing activities based on taxes actually collected. This would give utilities the opportunity to select research projects that would, in their perception, meet their needs more precisely.

\subsubsection{Special Treatment of Emission Alternatives}

One incentive created by the changes brought about by the CAAA of 1990 is the use of the emission allowance as an incentive device (Bailey et al. 1991). State regulators could allow the utility to treat the allowances attained through the construction of an innovative CCT differently than other emission control projects. The profits or cost savings could occur to the utility as a source of potential revenue or profit for stockholders (McDermott and South 1991).

\subsubsection{Amortization of Abandoned Projects}

If an innovative technology should prove to be too expensive or ineffective after construction begins and the utility cancels or abandons the project, then regulators may allow for the rapid amortization of these expenses, and if the PUC so desires, it can either grant or not grant a rate of return on the unamortized balance. These incentives would eliminate the fear of ex post prudence reviews if they are part of a prospective approach to granting incentives.

\subsubsection{Property Tax Incentives}

State legislatures could grant a reduction, temporary or permanent, of the property tax associated with an innovative technology. In many cases, state regulators would have to work closely with legislatures to develop a set of incentives consistent not only with the perceptions of regulators but also consistent with the goals of state and local finance and development objectives. Nevertheless, a wide variety of incentives exist and may have already been employed in practice.

\subsubsection{Cost Caps}

A cost cap jets a maximum allowable cost that may be entered into rates for a particular activity. For example, a firm is allowed to enter $\$ 100$ million of construction 
expenditures into rates. If the firm constructs the project for below $\$ 100$ million, the firm keeps the savings. If construction costs are above $\$ 100$ million, the firm's shareholders bear the entire cost overrun. Cost caps present the benefit of indexing a company's costs (and rates) for inflation, reduce the number of rate hearings, and provide an incentive for the affected firm to lower costs.

Cost caps and related price caps (which set a maximum allowable price) have been used in the telecommunications, rail freight, and electricity industries (Lowry 1991; Brown et al. 1991). The cost caps in these industries have been indexed for a variety of factors including inflation, industrial productivity, and economic growth. These programs typically target a particular facet of business operations rather than overall costs. For example, British Telecommunications had a price cap for line rental, local service, and domestic long distance service costs (Brown et al. 1991).

\subsubsection{Sliding-Scale Incentives}

Sliding-scale incentives have also been called profit sharing. Under a sliding-scale incentive, a firm may keep a portion of its net revenues that are generated above its allocated rate of return. The incentive encourages the affected firm to minimize costs to increase net revenues. By itself, sliding-scale may not necessarily result in efficient pricing levels and higher quality of service. The combination of the sliding-scale mechanism with cost caps tends to encourage more efficient pricing and greater cost efficiency (Holthausen 1979; Brown et al. 1991).

Sliding-scale mechanisms have been used in the rail freight, natural gas, and electricity industries (Brown et al. 1991). The sliding-scale mechanism tends to be applied to a firm's overall rate of return rather than returns from a particular project.

\subsubsection{Preapproval of Plan/Expenditures}

The use of "preapproval of plan" (either construction, expansion, or compliance) as a regulatory incentive mechanism is growing in popularity. Several states have established preapproval of plan for compliance with Title IV requirements (Bailey et al. 1993). Note that preapproval of plan has typically been accepted; preapproval of expenditures has not been accepted.

Preapproval of plan approves the development of a particular project before it begins. Within the preapproval of plan process are baseline costs needed to receive preapjoroval. However, the actual expenditures for the project are still subject to review if they are cleemed inappropriate. Preapproval of plan reduced the regulatory risk present for the devel spment of a new project. 


\section{ANALYSIS OF REGULATORY INCENTIVES FOR THE ADOPTION OF INNOVATIVE TECHNOLOGY BY UTILITY POWER GENERATORS}

\subsection{OBJECTIVES}

This chapter has three objectives. First, utility system total revenue requirements (TRR) are examined and compared based on the addition of PC/FGD versus PFBC technology for baseload generation. Second, the impacts of certain risk events on TRR and equity value are analyzed for first generation PFBC technology. Finally, the use of regulatory incentives for the correction of possible risk events is assessed. From the incentive analysis, the application of ex ante risk assessment will be discussed.

The scenario modeling was accomplished through the use of the Public Utility Planning System (PUPS) model. PUPS is able to generate rate and financial impacts based on alternative technology, regulatory, and financial characteristics.

\subsection{MODELING ASSUMPTIONS}

For purposes of examining the effect of regulatory incentives on technology choice and revenue requirements, a representative mid-size midwestern utility was selected; project budget precluded additional utility systems from being examined at this time. For this "representative" utility, electricity demand growth is assumed to grow at 2.5\%/year. Capacity expansion is driven by the requirement that a reserve margin of $17 \%$ is maintained; any decrease below this margin would provoke the building of additional base and peaking capacity. Roughly $25 \%$ of new capacity is considered to be purely peaking capacity; the rest of load growth is considered to be met by intermediate and baseload construction. Peak load capacity expansion is assumed to be satisfied by natural gas combined cycle (NGCC) units. Intermediate and baseload construction is coal-fired capacity - either PFBC or PC/FGD units depending on the scenario's specifications - burning $4 \%$ sulfur coal. Unit construction of NGCC is assumed to require one year; all coal-fired unit construction is three years in duration. The first 1,400 MW of PFBC capacity is assumed to be first-generation technology and have the possibility of risk events associated with its construction and operacion (see Scenarios 3 and 4 below); any PFBC capacity added beyond 1,400 MW is assumed to be second generation, with negligible probability of risk events.

The technology assumptions are delineated in Table 20 with all duiiar figures expressed in 1988 dollars. "The financial assumptions are listed in Table 21; capacity addition assumptions are listed in Table 22. Finally, fuel cost and price escalation assumptions are provided in Table 23, with environmental/regulatory assumptions defined in Table 24 .

The effects of the alternate baseload technology and risk events are examined in four scenarios:

1. $P C / F G D$ Scenario: all new baseload capacity is PC/FGD technology. 
TABLE 20 Technology Modeling Assumptions ${ }^{\mathrm{a}}$

\begin{tabular}{lccccc}
\hline \multicolumn{1}{c}{ Technology } & $\begin{array}{c}\text { Capital } \\
\text { Cost/kW }\end{array}$ & $\begin{array}{c}\text { Fixed O\&M } \\
(\$ / \mathrm{kW})^{\mathrm{b}}\end{array}$ & $\begin{array}{c}\text { Capacity } \\
\text { Factor }\end{array}$ & $\begin{array}{c}\text { Var. O\&M } \\
(\mathrm{mill} / \mathrm{kWh})^{\mathrm{b}}\end{array}$ & $\begin{array}{c}\text { Heat Rate } \\
(\mathrm{Btu} / \mathrm{kWh})\end{array}$ \\
\hline NGCC (peak) & 488 & 3.7 & .25 & 3.7 & 7,740 \\
PC/FGD & 1,434 & 30 & .65 & 6.0 & 10,044 \\
PFBC & 1,447 & 40 & .65 & 6.5 & 8,980 \\
$\begin{array}{l}\text { PFBC-high forced } \\
\text { outage rate }\end{array}$ & 1,447 & 40 & .45 & 6.5 & 8,980 \\
$\begin{array}{l}\text { PFBC-construction } \\
\text { cost overrun }\end{array}$ & 1,736 & 40 & .65 & 6.5 & 8,980 \\
$\begin{array}{c}\text { PFBC-second } \\
\text { generation }\end{array}$ & 1,200 & 40 & & & \\
\hline
\end{tabular}

a Unless otherwise indicated, cost and performance data were extracted from EPRI (1989).

b In 1988 \$.

c See NES (1991b).

TABLE 21 Modeling Assumptions for Capacity and Finance

\begin{tabular}{lrlr}
\hline Interest rate & $10 \%$ & Equity/Debt Ratio & $50 \%$ \\
Inflation rate & $5 \%$ & Federal Tax Rate & $34 \%$ \\
Required capacity factor & $17 \%$ & State Tax Rate & $6 \%$ \\
Demand growth (\%/yr) & $2.5 \%$ & Property Tax Rate & $1 \%$ \\
\hline
\end{tabular}

TABLE 22 Capacity Additions

\begin{tabular}{crrrrrr}
\hline Capacity & 1996 & 2000 & 2004 & 2008 & 2011 & 2015 \\
\hline Peaking (MW) & 273 & 96 & 156 & 212 & 80 & 220 \\
Baseload (MW) & 700 & 700 & 700 & 700 & 600 & 600 \\
\hline
\end{tabular}


TABLE 23 Fuel Cost

\begin{tabular}{ccc}
\hline Fuel & Price/MMBtu & Real Price Escalation ${ }^{\mathrm{a}}$ \\
\hline Natural Gas & $\$ 2.23$ & $5 \% / \mathrm{yr}$ \\
$4 \%$ Sulfur Coal & $\$ 1.51$ & $1.5 \% / \mathrm{yr}$ \\
\hline
\end{tabular}

a This real price escalation approximates the figures for the NES current policy base case.

TABLE 24 Modeling Assumptions ${ }^{a}$ for Environmental Criteria

\begin{tabular}{lcc}
\hline Technology & $\mathrm{SO}_{2}$ Removal Rate & $\begin{array}{c}\mathrm{NO}_{\mathrm{x}} \text { Emission Rate } \\
(\mathrm{lb} / \mathrm{MMBtu})\end{array}$ \\
\hline PC/FGD & $90 \%^{\mathrm{b}}$ & $.5^{\mathrm{c}}$ \\
PFBC & $95 \%^{\mathrm{d}}$ & $.2^{\mathrm{e}}$ \\
\hline
\end{tabular}

a $\mathrm{SO}_{2}$ allowance cost: $\$ 500$; coal $\mathrm{HHV}: 12,000 \mathrm{Btu} / \mathrm{h}$.

b See South et al. (1991).

c The PC/FGD units are assumed to meet new source performance standards and have low-NO $\mathrm{N}_{\mathrm{x}}$ burner technology installed. See South et al. (1991).

d See South et al. (1991).

e $\mathrm{PFBC} \mathrm{NO}$ emissions are estimated to range from 0.1 $\mathrm{lb} / \mathrm{MMB}$ tu to $0.2 \mathrm{lb} / \mathrm{MMB}$ tu. See South et al. (1991).

2. PFBC Scenario: all new baseload capacity is PFBC technology.

3. FOR Scenario: all new baseload capacity is PFBC; the first $1,400 \mathrm{MW}$ of new baseload capacity is assumed to have increased forced outage rates resulting in a capacity factor of $\mathbf{. 4 5}$.

4. Cost Overrun Scenario: all new baseload capacity is PFBC; the first $1,400 \mathrm{MW}$ of new baseload capacity is assumed to have increased construction costs that are $15 \%$ higher than the PFBC Scenario (2).

Three additional scenarios examine the use of regulatory incentives to alleviate the disincentives (i.e., risk) associated with adopting innovati re generating technologies (in place of conventional technology, i.e., PC/FGD). The purpose of the incentives is to reduce the risk of adopting the innovative technology and encourage cost minimizing behavior on the part 
of the utility. Sliding scale and cost sharing incentives are used in the scenarios. Note that these incentives are only applied to Scenarios 3 and 4 in which a risk event occurs.

5. FOR Incentive 2: Scenario 3 occurs; PUC offers $\mathrm{kWh}$ premium to compensate utility for decreasing FOR; utility improves capacity factor of first generation PFBC to .5 .

6. FOR Incentive 2: Scenario 3 occurs; PUC offers $\mathrm{kWh}$ premium to compensate utility for decreasing FOR; utility improves capacity factor of first generation PFBC to .65.

7. Partial Pass-through: Scenario 4 occurs; PUC permits $50 \%$ cost sharing of construction cost overrun with the ratepayers.

Scenario 1 and Scenario 2 involve the addition of PC/FGD and PFBC capacity respectively in intervals indicated in Table 22. In the scenarios involving PFBC technology, the first two 700-MW units constructed are assumed to be first generation PFBCs with lower capacity factors, greater capital costs, and higher heat rates. After these units are constructed, it is assumed that the utility becomes more efficient constructing and operating the innovative technology. With this knowledge the utility is able to construct second generation PFBCs with dramatically lower construction costs, lower heat rates, and higher capacity factors without innovative technology risk (see Table 20). These second generation units are assumed to be built in 2004, 2008, 2011, and 2015.

The scenarios with risk events occurring (3 and 4) follow the methodology of Scenario 2 excep', for greater forced outage rates or higher construction costs. These two difficulties were chosen to reflect the greatest perceived risks associated with innovative CCTs based on data provided by the CCTP and other sources. The magnitudes of these difficulties reflect the upper boundary of difficulties associated with these innovative technologies based on present data. ${ }^{46}$

The regulatory incentive scenarios (5-7) assume that forced outage rate and constructioii cost overruns occur for the first generation PFBCs built. All baseload units constructed afterward are assumed to be second generation PFBCs, and devoid of such risks (and incentives).

For the forced outage rate scenarios (5 anu 6), it is assumed that the firm increases fixed O\&M expenditures to reflect the additional maintenance and capital costs associated with increasing the unit capacity factor (CF) from .45 to .5 in Scenario 5, and fiom .45 to .65 in Scenario 6. Research by M. Corio ${ }^{47}$ provides a basis to calculate the additional fixed O\&M expenditures required to increase the CF. On the bas: of a $1 \%$ increase in the problem

46 Communications with CCTP staff and T. Grahame (DOE/FE).

47 M. Corio, of Applied Economic Research, computed the required O\&M expenditures to increase capacity factors based on historical data, using a proprietary database. 
capacity factor, it was determined that fixed O\&M must rise by the percentages indicated in Table 25. The increased expenditures are assumed to occur during the first year of the unit's operation and continue for 17 additional years, as indicated by Table 25 .

The incentive offered to the firm offsets the additional expenditures needed to increase the CF by .05 in Scenario 5 and .2 in Scenario 6. The present value of the incentive cost (in $1990 \$$ ) is $\$ 16$ million for Scenario 5 and $\$ 36$ million for Scenario 6 . In the case of the $15 \%$ construction cost overrun (Scenario 7), the overrun is equally divided between shareholders and ratepayers. The present value of the cost sharing (in 1990 ) of the overrun is $\$ 148$ million.

\subsection{MODEL RESULTS}

Rate and financial criteria are presented which indicate the impact of the alternative scenarios on the utility and ratepayers. These include (1) present value of utility total revenue requirements and (2) the equity value per share. Also indicated are $\mathrm{NO}_{\mathrm{x}}$ and $\mathrm{SO}_{2}$ emissions attributable to the alternative scenarios. Through the use of this information, inferences regarding the benefits and incentives required for the alternative capacity expansion plans can be drawn.

Total revenue requirements are used to evaluate the impact of regulatory incentives on the adoption of an innovative technology. Total revenue requirements serve as a reliable method of project evaluation from a utility and ratepayer perspective. Ratepayers are directly affected by changes in total revenue required through rate alterations. Utilities must also consider rate impacts as important criteria of project evaluation for several reasons. The minimization of TRR is important due to (1) growing competition in the wholesale energy markets; (2) greater revenue requirements imply higher rates increasing the potential for substitution, reduction, or bypass away from utility gene rated electricity; and (3) large rate impacts potentially resulting in adverse rate rulings from regulators.

In the following discussion, the present value of TRR reflects the sum of
TABLE 25 Fixed O\&M Expenditures Required to Increase Unit Capacity Factors

\begin{tabular}{cc}
\hline $\begin{array}{c}\text { Year in } \\
\text { Operation }\end{array}$ & $\begin{array}{c}\text { Percentage Increase } \\
\text { in Fixed O\&M per } \\
\text { 1\% Increase in CF }\end{array}$ \\
\hline 1 & .0052 \\
2 & .0042 \\
3 & .0034 \\
4 & .0028 \\
5 & .0023 \\
6 & .0018 \\
7 & .0015 \\
8 & .0015 \\
9 & .0009 \\
10 & .0008 \\
11 & .0006 \\
12 & .0005 \\
13 & .0004 \\
14 & .0003 \\
$15-18$ & .0001 \\
\hline
\end{tabular}


the annual TRR from 1990 to the indicated year. The sum of the present value of TRR reflects the impact of alternate baseload technologies on the system's ratepayers. Total revenue requirements include returns on capital expenditures, O\&M expenditures, fuel costs, and other associated utility expenditures. All other things equal, lower total revenue requirements imply greater benefits to ratepayers. The total revenue requirements for the base (no incentive) scenarios are indicated in Table 26.

It is assumed that new baseload generation will be required to purchase allowances each year of operation in order to be in compliance with Title IV of the 1990 CAAA; it is assumed that the utility has no excess allowances, nor can cost-effectively generate them through system offsets. The impact of purchasing required $\mathrm{SO}_{2}$ allowances at a price of $\$ 500 /$ allowance and $\$ 200 /$ allowance on TRR are indicated in Tables 27 and 28 . At present, there is some uncertainty regarding the amount of allowance cost purchases to be passed through to ratepayers along with the sharing of any losses and gains from the sale of allowances. If $100 \%$ of the cost of purchasing new allowances is passed to ratepayers as a noncapital expense, the allowance costs in Table 27 or 28 should be added to the TRR. ${ }^{48}$ Note that the indicated $\mathrm{SO}_{2}$ allowance costs represent "high end" compliance costs. A utility

TABLE 26 Present Value of the Sum of Total Revenue Requirements for Scenarios 1, 2, 3, and 4

\begin{tabular}{|c|c|c|c|c|}
\hline \multirow[b]{2}{*}{ Capacity Added } & \multicolumn{4}{|c|}{$\begin{array}{c}\text { Present Value of Total Revenue } \\
\text { Requirement, by Year }\left(1990 \$ 10^{6}\right)^{a} \\
\end{array}$} \\
\hline & 2000 & 2005 & 2010 & 2015 \\
\hline PC/FGD (Scenario 1) & 14,538 & 19,261 & 23,154 & 26,311 \\
\hline PFBC (Scenario 2) & $\begin{array}{l}14,514 \\
{[+24]}\end{array}$ & $\begin{array}{l}19,131 \\
{[+130]}\end{array}$ & $\begin{array}{l}22,759 \\
{[+395]}\end{array}$ & $\begin{array}{l}25,617 \\
{[+694]}\end{array}$ \\
\hline Increased FOR (Scenario 3) & $\begin{array}{l}14,545 \\
{[-7]}\end{array}$ & $\begin{array}{l}19,215 \\
{[+46]}\end{array}$ & $\begin{array}{l}22,912 \\
{[+242]}\end{array}$ & $\begin{array}{l}25,877 \\
{[+434]}\end{array}$ \\
\hline Cost overrun (Scenario 4) & $\begin{array}{l}14,515 \\
{[+24]}\end{array}$ & $\begin{array}{l}19,131 \\
{[+130]}\end{array}$ & $\begin{array}{l}22,759 \\
{[+395]}\end{array}$ & $\begin{array}{l}25,617 \\
{[+694]}\end{array}$ \\
\hline
\end{tabular}

a Bracketed number indicates savings from adopting PFBC.

48 It follows that if $50 \%$ (or any other percentage) of the cost of allowances is passed through to ratepayers, then the indicated expenditures in Table 27 or 28 should be multiplied by the percentage and added to the TRR. 
TABLE 27 Present Value of the Sum of $\mathrm{SO}_{2}$ Allowance Costs at \$500/Allowance for Scenarios $1,2,3$, and 4

\begin{tabular}{lcccc}
\hline & \multicolumn{4}{c}{$\begin{array}{c}\text { Present Value of Sum of } \mathrm{SO}_{2} \\
\text { Allowance Cost, by Year } \\
\left(1990 \$ 10^{6}\right)\end{array}$} \\
\cline { 2 - 5 } Capacity Added & 2000 & 2005 & 2010 & 2015 \\
\hline F:. FGD (Scenario 1) & 183 & 411 & 626 & 814 \\
PFBC (Scenario 2) & 82 & 185 & 284 & 372 \\
Increased FOR (Scenario 3) & 113 & 249 & 369 & 470 \\
Cost Overrun (Scenario 4) & 82 & 185 & 284 & 372 \\
\hline
\end{tabular}

TABLE 28 Present Value of the Sum of $\mathrm{SO}_{2}$ Allowance Costs at \$200/Allowance for Scenarios 1, 2, 3, and 4

\begin{tabular}{lcccc}
\hline & \multicolumn{3}{c}{$\begin{array}{c}\text { Present Value of Sum of } \mathrm{SO}_{2} \\
\text { Allowance Costs, by Year } \\
\text { Capacity Added }\end{array}$} & \multicolumn{4}{c}{$\left(1990 \$ 10^{6}\right)$} \\
\cline { 2 - 5 } & 2000 & 2005 & 2010 & 2015 \\
\hline PC/FGD (Scenario 1) & 73 & 165 & 250 & 326 \\
PFBC (Scenario 2) & 33 & 74 & 114 & 149 \\
Increased FOR (Scenario 3) & 45 & 100 & 148 & 188 \\
Cost Overrun (Scenario 4) & 33 & 74 & 114 & 149 \\
\hline
\end{tabular}

complying with Phase I and Phase II potentially would offset added $\mathrm{SO}_{2}$ emissions from baseload generation by reduced utilization of existing facilities, allowance pooling with other utilities, Phase I scrubber bonus program, greenfielding old units, or the CCT repowering extension allowance program.

The PFBC scenario indicates significant cost savings to ratepayers when compared to Scenario 1. While the first 1,400 MW of PFBC built have a slightly greater capital cost along with higher fixed and variable O\&M, the PFBC lower heat rates (fuel cost savings) and lower $\mathrm{SO}_{2}$ emissions create lower TRR in the year 2000. Beyond 2000, second generation PFBC units have lower heat rates, higher capacity factors and lower capital costs; the result is that the PFBC Scenario (2), and hence the choice of the PFBC as baseload technology, is preferable to the PCiFGD technology. 
TABLE 29 Equity Value per Share for Scenarios 1, 2, 3, and 4

\begin{tabular}{lcccc}
\hline & \multicolumn{4}{c}{$\begin{array}{c}\text { Equity Value per Share } \\
\text { by Year (1990 \$) }\end{array}$} \\
\cline { 2 - 5 } \multicolumn{1}{c}{ Capacity Added } & 2000 & 2005 & 2010 & 2015 \\
\hline PC/FGD (Scenario 1) & 16.65 & 21.77 & 25.89 & 29.72 \\
PFBC (Scenario 2) & 16.81 & 27.45 & 30.14 & 32.63 \\
Forced outage (Scenario 3) & 16.64 & 23.92 & 28.73 & 32.62 \\
Cost overrun (Scenario 4) & 13.88 & 24.90 & 28.11 & 31.17 \\
\hline
\end{tabular}

While the innovative CCT compares favorably with conventional PC/FGD technology in terms of TRR and equity value, the presence of risk associated with innovative technology may result in conventional baseload technology being chosen. Uncertainty regarding potential operational performance, capital costs, emission controls and regulatory review tend to move risk averse decision makers to a less risky option (i.e, the conventional technology). For example, while the forced outage rate scenario (3) is preferable to ratepayers in all years (with the inclusion of $\mathrm{SO}_{2}$ allowance costs), there exist risks that operational problems may be large enough to shut down the unit for extended periods of time resulting in the use of older generation (and potentially increasing the level of $\mathrm{SO}_{2}$ emissions). Regulators may then penalize the firm for choosing the risky technology, resulting in greater damage to the firm's profitability.

The central problem surrounding utility adoption of innovative power generation technologies - CCTs in particular - stems from the current precommercialization status of many of these technologies. Scenarios 3 and 4 portray the potential difficulties and risks associated with the adoption of innovative CCT such as PFBC. If improvements and risk reduction associated with the adoption of the innovative technology were not perceived by the adopting utility, the first innovative unit adopted by the utility may be its last. ${ }^{49}$

When the performance of a CCT meets industry specifications (i.e., Scenario 2), it is clearly preferable to the PC/FC $n$ scenario (1). However, given the risks associated with this technology's adoption and uncerta inty regarding second generation benefits of the technology,

49 A good example of the rejection of a potentially low-cost technology has occurred with nuclear power. Several construction cost overruns along with after-the-fact prudence review and tests of used and useful have resulted in large losses to several utilities from rate denials and uncompensated abandonment. Innovative, capital intensive projects have the potential for larger costs than comparable traditional technologies. Expected cost difficulties associated with the first unit may cause the technology not to be adopted, despite many indications that in the long run the technology will generate significant cost savings. 
risk-averse utilities would not likely adopt the technology even if it would benefit ratepayers and the utility in the long run. Therefore, regulatory incentives are needed to encourage the utility's adoption of innovative technologies, until these technologies become commercialized and the perceived risks are reduced, if not removed.

Alternative regulatory incentives are applied to reduce the risk of adopting the innovative technology and potentially improve the incentives for proper operation of the technology. The increased outage rate associated with the innovative technology (Scenario 3) is assumed to require additional fixed $O \& M$ expenditures in order to correct this problem. To encourage the utility to correct the problem - and take advantage of the potential cost savings of greater operation of the problem units - a sliding scale $\mathrm{kWh}$ premium is used. Higher capacity factors (from the reduced FOR) on the problem units would result in a greater reward being offered. The end result is the firm's partial compensation for the additional expenditures on fixed O\&M. The increase in fixed O\&M expenditures required to increase the capacity factor by .01 (in order to reduce the forced outage rate) is estimated to be $.52 \%$ during the first year of operation and decline thereafter. ${ }^{50}$

For Scenario 4, involving a 15\% cost overrun for the two first generation PFBCs, a cost sharing mechanism is used. It is assumed that the cost sharing nechanism would be used on a sliding scale basis, i.e., the greater the construction cost overrun, the greater the proportion of this overrun absorbed by the utility. For this particular case, $50 \%$ of the cost overrun is to be absorbed by the utility and $50 \%$ of the cost passed on to ratepayers. The rationale is that the utility should not bear the entire cost of the overrun associated with the innovative technology, as the building of the technology would entail significant benefits to ratepayers in the future.

Total revenue requirements are used as the most obvious means of measuring the benefits of the alternative baseload technology/incentive scenarios. Total revenue requirements for Scenarios 1 and 2 along with the incentive scenarios (Scenarios 5, 6, and 7) are indicated in Table 30. The present values of $\mathrm{SO}_{2}$ allowance costs for the regulatory incentive scenarios are presented in Tables 31 and 32 .

In the year 2000, Scenario 5 and Scenario 7 have greater TRRs than Scenario 1. But in 2000 the TRR for Scenario 5 is less than that of Scenario 3. This occurs because the cost of incentive is partially offset by autitional fuel savings attributable to the first generation PFBC units. Beyond 2000, the incentive declines as the cost of the "repairs" to the first generation units declines. However, the fuel cost savings do not, decline and, with the addition of second generation PFBC units, Scenario 5 generates significant long run savings relative to the $\mathrm{PC} / \mathrm{FGD}$ scenario (1).

50 The estimate was computed by M. Corio (Applied Economic Research) on the basis of examining the forced outage rates, capacity factors, and required expenditures to correct these problems in current and older baseload coal units. Units of newer vintage tend to have lower additional fixed O\&M costs associated with improving the capacity factor. 
TABLE 30 Present Value of the Sum of Total Revenue

Requirements for Scenarios 1, 2, 5, 6, and 7

\begin{tabular}{lrrrr}
\hline & \multicolumn{4}{c}{$\begin{array}{c}\text { Present Value of Total Revenue } \\
\text { Requirement, by Year }\left(1990 \$ 10^{6}\right)^{\mathrm{a}}\end{array}$} \\
\cline { 2 - 5 } \multicolumn{1}{c}{ Capacity Added } & 2000 & 2005 & 2010 & 2015 \\
\hline PC/FGD (Scenario 1) & 14,538 & 19,261 & 23,154 & 26,311 \\
PFBC (Scenario 2) & 14,514 & 19,131 & 22,759 & 25,617 \\
& {$[+24]^{\mathrm{a}}$} & {$[+130]$} & {$[+395]$} & {$[+694]$} \\
FOR Incentive 1 (Scenario 5) & 14,541 & 19,193 & 22,844 & 25,719 \\
& {$[-3]$} & {$[+68]$} & {$[+311]$} & {$[+592]$} \\
FOR Incentive 2 (Scenario 6) & 14,536 & 19,164 & 22,795 & 25,653 \\
& {$[+2]$} & {$[+97]$} & {$[+360]$} & {$[+658]$} \\
Partial pass-through (Scenario 7) & 14,665 & 19,282 & 22,910 & 25,768 \\
& {$[-127]$} & {$[-21]$} & {$[+244]$} & {$[+543]$} \\
\hline
\end{tabular}

a Bracketed number indirates savings from adopting PFBC

TABLE 31 Present Value of the Sum of $\mathrm{SO}_{2}$ Allowance Costs at $\$ 500 / A l l o w a n c e$ for Scenarios 1, 2, 5, 6, and 7

\begin{tabular}{|c|c|c|c|c|}
\hline \multirow[b]{2}{*}{ Capacity Added } & \multicolumn{4}{|c|}{$\begin{array}{c}\text { Present Value of Sum of } \mathrm{SO}_{2} \\
\text { Allowance Costs, by Year } \\
\left(1990 \$ 10^{6}\right)\end{array}$} \\
\hline & 2000 & 2005 & 2010 & 2015 \\
\hline PC/FGD (Scenario 1) & 183 & 411 & 626 & 814 \\
\hline PFBC (Scenario 2) & 82 & 185 & 284 & 372 \\
\hline FOR Incentive 1 (Scenario 5) & 105 & 233 & 348 & 446 \\
\hline FOR Incentive 2 (Scenario 6) & 82 & 185 & 284 & 372 \\
\hline Partial pass-through (Scenario 7) & 82 & 185 & 284 & 372 \\
\hline
\end{tabular}


TABLE 32 Present Value of the Sum of $\mathrm{SO}_{2}$ Allowance Costs at $\$ 200$ Allowance for Scenarios 1, 2, 5, 6, and 7

\begin{tabular}{|c|c|c|c|c|}
\hline \multirow[b]{2}{*}{ Capacity Added } & \multicolumn{4}{|c|}{$\begin{array}{l}\text { Present Value of the Sum of } \\
\mathrm{SO}_{2} \text { Allowance Costs, by Year } \\
\left(1990 \$ 10^{6}\right)\end{array}$} \\
\hline & 2000 & 2005 & 2010 & 2015 \\
\hline PC/FGD (Scenario 1) & 73 & 165 & 250 & 326 \\
\hline PFBC (Scenario 2) & 33 & 74 & 114 & 149 \\
\hline FOR incentive 1 (Scenario 5) & 84 & 187 & 278 & 356 \\
\hline FOR incentive 2 (Scenario 6) & 33 & 74 & 114 & 149 \\
\hline Partial pass-through (Scenario 7) & 33 & 74 & 114 & 149 \\
\hline
\end{tabular}

In Scenario 7, half of the cost overrun for the first generation units built in 1996 and 2000 is allowed into rate base. ${ }^{51}$ This creates greater TRR in both 2000 and 2005 . In 2010 and 2015, the greater fuel cost savings and lower capital expenses associated with the second generation PFBC units lowers TRR below the PC/FGD scenario (1) levels.

While a greater incentive is paid in Scenario 6, the resulting fuel cost savings completely offset its cost and result. in a lower TRR relative to Scenario 1 . The savings increase in later years as the incentive decreases and the second generation PFBCs are constructed.

The total cost of the incentives for Scenarios 5, 6, and 7 to ratepayers from 1996 to 2018 is indicated in Table 33. ${ }^{52}$ Higher TRRs are reduced in Scenarios 5 and 6 through the

51 Note that construction cost sharing incentives can be designed for a variety of results. One method that provides an incentive for lower construction costs is to allow a range of cost sharing around a dead band. The dead band area is the cost of the additional capacity as agreed by the PUC and utility. Cost overruns are shared between the ratepayers and utility, with greater overruns resulting in a greater percentage of the overrun to be borne by the utility. If; however, construction costs are lower than the dead band, the utility is allowed to keep the savings or some portion of the savings. For Scenario 7, it is assumed that despite the presence of an incentive the cost overrun would be $15 \%$ greater than "typical" PFBC costs. The incentive in this role serves as a means of mitigating the risk of adopting an innovative technology.

52 The cost of the incentive does not include administrative costs that would be attendant with additional regulatory programs, but these costs are expected to be relatively small when compared to the incentives' impact on ratepayers. 
TABLE 33 Present Value of Incentive Costs for Scenarios 5,6 , and 7

\begin{tabular}{|c|c|c|c|}
\hline \multirow[b]{2}{*}{ Item } & \multicolumn{3}{|c|}{ Present Value, by Scenario $\left(1990 \$ 10^{6}\right)$} \\
\hline & Scenario 5 & Scenario 6 & Scenario 7 \\
\hline Cost & 16 & 36 & 148 \\
\hline
\end{tabular}

application of the incentive to encourage a reduction in FOR. While TRRs are initially higher in Scenario 7, large long-run TRR savings are present with the use of the PFBC technology. The value of the cost-sharing incentive is the adoption of the PFBC technology, which allows for long-run TRR savings (as compared to the use of PC/FGD baseload technology).

The use of the $\mathrm{kWh}$ premium and cost-sharing incentives increases the equity value of the utility in Scenarios 5, 6, and 7 above that in Scenarios 3 and 4 (see Table 34). Lower fuel costs combined with the incentive payments in Scenarios 5 and 6 generate greater equity value for the firm. Note that in Scenario 5, the higher fuel costs associated with the need to use older generating units (as 1,400 MW of PFBC capacity is at a CF of .5) does not raise the equity value high enough to be comparable with Scenario 2 . The incentive and reduced fuel costs in Scenario 6 allow the equity value per share to approach that of Scenario 2. In Scenario 7, the cost-sharing incentive reduces the impact of the overrun on the utility and results in a higher equity value per share (relative to Scenario 2 except for 2000). In all cases (except for year 2000 in Scenario 7), the equity value per share is greater for the incentive scenarios relative to the PC/FGD scenario (1).

As indicated by the model results, all scenarios involving PFBC generation produce significant cost savings for ratepayers in the long run. With regulatory incentives, risks of adoption of this innovative technology are reduced for the utility and, with the use of sliding scale incentives, greater benefits for ratepayers can be obtained. The drawback with the use of incentives is the possibility of higher rates in the short run.

The PFBC has cost-saving advantages due to (1) lower capital costs in the long run, (2) lower heat rates, (3) improved capacity factors for second generation units, and (4) much lower $\mathrm{SO}_{2}$ emissions and hence, lower expenditures on $\mathrm{SO}_{2}$ allowances. Note the comparison of TRR with allowance costs was purposely kept separate to highlight the significant environmental benefits associated with the use of innovative clean coal technology. While not indicated in the modeling, the PFBC capacity also has greater dispatching flexibility and can be used in a shouldering and cycling role without significant reduction in heat rates.

From the modeling, estimates of $\mathrm{SO}_{2}$ and $\mathrm{NO}_{\mathrm{x}}$ attributable to new baseload capacity wt: ${ }^{\circ}$ obtained for each scenario. The $\mathrm{SO}_{2}$ emission levels are indicated in Table 35 and $\mathrm{NO}_{\mathrm{x}}$ 
TABLE 34 Equity Value per Share for Scenarios 1, 2, 5, 6, and 7

\begin{tabular}{|c|c|c|c|c|}
\hline \multirow[b]{2}{*}{ Capacity Added } & \multicolumn{4}{|c|}{$\begin{array}{c}\text { Equity Value per Share, by Year } \\
(1990 \$)\end{array}$} \\
\hline & 2000 & 2005 & 2010 & 2015 \\
\hline PC/FGD (Scenario 1) & 16.65 & 21.77 & 25.90 & 29.72 \\
\hline PFBC (Scenario 2) & 16.81 & 27.45 & 30.15 & 32.64 \\
\hline FOR incentive 1 (Scenario 5) & 16.75 & 27.32 & 29.98 & 31.24 \\
\hline FOR incentive 2 (Scenario 6) & 16.81 & 27.45 & 30.15 & 32.64 \\
\hline Partial pass-through (Scenario 7) & 15.87 & 26.89 & 29.97 & 31.24 \\
\hline
\end{tabular}

TABLE $35 \mathrm{SO}_{2}$ Emissions Attributable to New Baseload Generation

\begin{tabular}{ccccc}
\hline & \multicolumn{4}{c}{$\mathrm{SO}_{2}$ Emission, by Year (ton) } \\
\cline { 2 - 5 } Technology & 2000 & 2005 & 2010 & 2015 \\
\hline PC/FGD (Scenario 1) & 26,689 & 40,033 & 53,378 & 76,254 \\
PFBC (Scenario 2) & 11,930 & 18,369 & 24,808 & 35,846 \\
\hline
\end{tabular}

emission levels in Table 36. While $\mathrm{SO}_{2}$ allowances internalize the costs of $\mathrm{SO}_{2}$ for the utility system, $\mathrm{NO}_{\mathrm{x}}$ costs are not internalized into the planning process at the present time. ${ }^{53}$

\subsection{INCENTIVE AND EX ANTE ANALYSIS}

As demonstrated in the previous scenarios, innovative PFBC technology provides significant cost savings to ratepayers and benefits to utility shareholders in the long run. The savings are due to (1) higher heat rates associated with $\mathrm{PFBCs},(2)$ lower $\mathrm{SO}_{2}$ emissions,

53 While this document does not address the consideration of externality "costing" within the IRP planning process, several states have begun to implicitly or explicitly include externality considerations in resource acquisition plans. For several regions (e.g., the Northeast), concern about tropospheric ozone and nonattainment difficulties has led to growing consideration of $\mathrm{NO}_{\mathrm{x}}$ emissions from power plants. 
TABLE 36 NO $_{x}$ Emissions Attributable to New Baseload Generation

\begin{tabular}{ccccc}
\hline & \multicolumn{4}{c}{ NO $_{x}$ Emissions, by Year (ton) } \\
\cline { 2 - 5 } Technology & 2000 & 2005 & 2010 & 2015 \\
\hline PC/FGD (Scenario 1) & 23,996 & 35,994 & 47,992 & 68,560 \\
PFBC (Scenario 2) & 10,378 & 16,532 & 22,327 & 32,261 \\
\hline
\end{tabular}

and (3) the learning curve associated with innovative technology. The firm which adopts the first generation of the innovative technology is presumed to learn by doing, lowering the long run cost of constructing and operating this technology type. The problem faced by the planner attempting to encourage the implementation of innovative te.hnology comes largely in the short run or initial years of the technology's commercializa'ion. For regulators, ratepayers and utility, risks associated with the first generation innovative technology may dissuade the adoption of the technology with some type of compensatory incentives. To be effective and acceptable, however, such incentives must be structured in such a way so as not to result in "gold plating" on inefficient power plants.

While the modeling documented in Section 5.3 represents some of the more likely outcomes of adopting the first generation PFBC technology (i.e., operate as designed, construction cost overrun, and increased forced outage rate), it does not present the complete range of risks for the adoption of the innovative technology. ${ }^{54}$ The complete range and magnitude (added costs) of risks are not represented, although the construction and operation failures indicate the likely upper bound of these secondary risks. In addition, there is the possibility of multiple "worst case" events occurring (e.g., environmental control difficulties and increased forced outage rates). The combination of these possible risks tends to reduce the expected benefits to the utility associated with adopting the innovative technology. If one or more of the risk events occur, the utility also faces possible retrospective prudence review, which may further penalize the firm and reduce benefits of the innovative technology to the firm.

To encourage the development of innovative technology and ensure that the firm behaves in a prudent, cost-minimizing manner, regulatory incentives can serve an important role. As indicated in the previous scenarios, regulatory incentives will benefit both the ratepayers and shareholders. Ratepayers benefit by the implementation of the innovative technology, which in the future will generate even greater benefits to ratepayers. In addition, if certain events occur (e.g., cost overruns, delays, increased forced outage rates), the firm has

${ }^{54}$ See Section 3.2 for a comprehensive list of possible risks for adopting innovative technology. 
an incentive to minimize costs through regulatory rewards or penalties. ${ }^{55}$ The firm (1) is rewarded with the potential for greater benefits by adopting the first generation technology, (2) is provided an incentive to operate the technology in the "best" manner possible, (3) suffers penalties (although the magnitude of the penalties is reduced) for noncost minimizing behavior, and (4) gains experience in order to implement second generation "innovative" technology. 56

The magnitude and type of incentive to be used to implement innovative technology become an important choice. The PUC could offer a regulatory incentive based on the likelihood of a "worst case" event occurring. ${ }^{57} \mathrm{~A}$ menu of incentive options could also be offered, allowing the utility to choose the incentive that it considers most likely to reduce or reward risk-taking associated with the innovative technology. Several incentives could be proposed to be used in the event of one or more "worst case" events occurring.

The question of incentive magnitude is an important one. As indicated in Section 3, there is an incremental cost of risk that is equal to the difference between the cost of the innovative technology and the cost of the conventional technology. To implement the incentive program, a multi-variate analysis of key utility financial statistics to examine the impacts of the alternative technologies should be completed along with a cost assessment as done in Section 3. A comparison of the key financial statistics under the alternative regimes, along with an assessment of the probability of the alternative innovative technology scenarios occurring would enable regulators to determine the proper regulatory incentive reward/penalty structure.

As indicated in the Section 4.3 analysis, alternative scenarios can be used to determine the impacts on utility financial statistics. If, for example, construction cost overruns are predicted to be the most likely problem, a cost-sharing mechanism based on rewards and penalties can be designed. Assume that the utility is extremely short-sighted and expects cash flow for any baseload technology to be at least as good as a PC/FGD option in $2000 .^{58}$

55 These rewards and penalties should encourage the firm to take the necessary measures to ensure the innovative technology operates equal to or better than design specification.

56 The knowledge gained from implementing the innovative technology will be marketable and have significant value. A subsidiary of the utility building the first generation innovative technology should be able to earn substantial rewards for its knowledge. There may even be justification for ratepayers sharing in some of the benefits of the successful subsidiary as the ratepayers bore part of the initial risk of the first-generation technology.

57 For example, if increased outage rates are expected to be the greatest risk of adopting a technology, an incentive such as a $\mathrm{kWh}$ premium could be offered to induce better performance and corrective behavior.

58 This short-sightedness may be explained by (1) utility skepticism about second generation benefits of the innovative technology or (2) "impatient" managers/shareholders desiring greater yields or profits. 
To examine this situation, we will use the ex ante framework described in Section 3. First, we must determine the expected cash flow associated with each possible outcome. The PC/FGD (Scenario 1) cumulative present value of cash flow in 2000 is $\$ 2.40$ billion. If the PFBC is constructed according to previous technical specifications, the cumulative present value of cash flow is $\$ 2.42$ billion. If capital costs are an additional $15 \%$ greater than technical specifications, the cumulative present value of cash flow is $\$ 2.20$ billion. If capital costs are $15 \%$ less than indicated technical specifications, ${ }^{59}$ the cumulative present value of cash flow is $\$ 2.60$ billion.

The second step is to apply the expected probabilities to each of these possible cash flow outcomes. For illustrative purposes it is assumed that ${ }^{60}$ :

- There is a $50 \%$ probability that PFBC technical specifications will be achieved.

- There is a $30 \%$ probability that PFBC costs will be $15 \%$ greater than the technical specifications.

- Finally, there is a $20 \%$ probability that PFBC costs will be $15 \%$ less than the technical specifications.

Applying these probabilities to the expected cash flows identified above produces an expected cumulative NPV of $\$ 2.39$ billion for the innovative technology.

To make the firm indifferent between an innovative and conventional technology, the incremental cost of risk (ICR) to the firm could be calculated using the referenced cash flows. The difference between conventional technology cash flow ( $\$ 2.40$ billion) and the expected cash flow for the innovative technology ( $\$ 2.39$ billion) is $\$ 0.01$ billion. Through the use of regulatory incentives - more preferably a cost sharing/sliding scale regulatory incentive mechanism - this level of incentive ( $\$ 0.01$ billion) should be provided to the firm to make it indifferent between the two technologies. ${ }^{61}$

The implementation of ex ante incentives for the adoption of innovative generating technology could be done with several alternative planning processes. The use of integrated resource planning (IRP) lends itself well to the analysis of alternative generation scenarios.

59 The EPRI TAG ${ }^{\mathrm{TM}}$ (1989) indicates that the indicated cost of the PFBC technology is thought to vary $+/ 15 \%$ around the indicated capital cost of the technology.

60 The expected probabilities are for illustrative purposes only and do not represent the likelihood of events based on engineering data.

61 The actual implementation of the cost sharing instrument could vary widely and offer a wide range of cost sharing rates based on the cost overrun/underrun; (i.e., an underrun of $10-20 \%$ would result in $70 \%$ of the savings being passed on to ratepayers, $-5 \%$ to $+5 \%$ cost overrun would result in the ratepayers paying the previously indicated cost of the unit, and a 10-30\% overrun resulting in the rater "rers paying half of the cost overrun). 
Within the IRP, process rate and reliability questions can be assessed along with potential financial benefits and costs of alternative technologies. Appropriate regulatory incentives can be offered and incentive magnitudes chosen on the basis of the IRP study.

The use of ex ante regulatory incentives for the adoption of innovative technology may also be implemented in conjunction with Phase I and Phase II compliance planning periods for Title IV of the CAAA of 1990. For example, PSI Energy and the Indiana PUC will use incentive regulation to encourage compliance savings. ${ }^{62}$ PSI Energy would be allowed to keep $50 \%$ of the net savings from compliance activities if savings are in excess of $20 \%$ of the market value of allowances. The adoption of an innovative technology such as a CCT could be encouraged by offering a graduated reward based on $\mathrm{SO}_{2}$ reductions (and compliance cost savings) attributable to the unit.

Regulatory incentives for the adoption of innovative technology could also be implemented during the Power Plant Certificate of Need Process. A menu of regulatory incentives could be offered to encourage the adoption of the innovative technology based on the perceived ICR.

Innovative technology, CCTs in particular, can demonstrate significant cost savings to ratepayers and benefits to the adopting utility in the long run. The central problem with any innovative technology comes from the uncertain and risky nature of adopting a precommercialized technology. To overcome a utility's potential aversion to adopting this technology and encourage cost-minimizing behavior on the part of the utility, regulatory incentives for innovative technology are proposed as a means of implementing these technologies in the near term. Once these technologies have been commercialized, greater benefits through environmental improvements, lower fuel costs, and lower construction costs can be realized.

62 See Troxel, G., 1992, PSI Energy Case Study-Making Lemonade without Sulfur, Proceedings of the Electric Utilities and the Environment Conference, Chicago, (September). 


\section{INCENTIVES FOR THE ADOPTION OF INNOVATIVE TECHNOLOGIES FOR NONUTIIITY GENERATORS}

Incentives for innovative technologies should not be limited to public utilities. Within the past decade, nonutility generated power has grown considerably and is projected to provide approximately one-third of all new electricity generation after 2000 (Jabbari and Bussa 1992). Given the importance of this industry in the nation's generating base, opportunities for the adoption of innovative generation should be pursued. NUGs operate under fundamentally different risks and barriers than public utilities do. Therefore, to provide incentives for NUGs to adopt innovative technologies, one must first consider what incentives are needed and what barriers to development are of particular concern.

This section provides an overview of issues surrounding NUG technology choice, market operations, and a brief history of NUG development. Also included are the views of several NUGs on their market, and potential problems with the adoption of innovative generating technologies, CCTs in particular. The unique financing and contractual structure of this industry as it relates to the adoption of innovative technology will also be examined. The overview provides an indication of the need for and effectiveness of alternative incentive mechanisms to encourage the adoption of innovative technologies and highlights the differences of independent power and investor-owned utilities. As before, the primary focus of innovative generation technologies will be CCTs. Much of this discussion, however, would also be applicable to other innovative technologies.

Before the Public Utility Regulatory Policies Act (PURPA) of 1978, there had been steady decline in nonutility generated power (Kahn 1988; Plummer and Troppmann 1990). ${ }^{63}$ During the 1970s, however, several fuel-supply price shocks, supply-side inflation, and utility plan cost overruns led to the passage of PURPA in 1978 (Kahn et al. 1989). PURPA created a class of generators known as qualifying facilities (QFs) ${ }^{64}$ Technological development and the wariness of public utilities to huild additional capacity has helped the Independent Power Producers (IPPs) industry to develop (Plummer and Troppmann 1990).

63 The economies of scale and scope present in the electric utility industry during the 1950s and 1960s caused electricity prices to continually decrease. Consequently, utility-generated electricity gradually replaced self-generated electricity. In the $1970 \mathrm{~s}$, less than $5 \%$ of all electricity was produced by industrial generating sources (Plummer and Troppmann 1990).

64 A QF can be a cogenerator providing heat or steam to a host facility or an electricity generator using a renewable fuel source. QFs using a renewable fuel source have a maximum generating capacity of $80 \mathrm{MW}$. The public utility is required to purchase power from a QF if the QF's power cost is less than the utility's avoided cost of electricity. 


\subsection{NONUTILITY GENERA'TION AND PUBLIC UTILITIES: DIFFERENCES AND CHOICES}

While both investor-owned utilities and NUGs provide the same product (electricity), the two groups fundamentally differ in the ways they are regulated and operated. Public utilities have the obligation to serve all customers at a price decided in the rate-making procedure and have an exclusive franchise to provide electricity to retail buyers within their territory. Investor-owned utilities are highly regulated and come under the jurisdiction of the FERC when engaging in interstate wholesale power transactions and of their state PUCs for purposes of retail rate making. Certain financial restrictions on utility holding companies and their operations are set forth in the Public Utility Holding Company Act (PUHCA) of 1935. This act brings some public utility companies under strict regulation of the Securities and Exchange Commission (SEC) ${ }^{65}$ Finally, public utilities must comply with state and federal environmental and siting regulations.

The nonutility generator is an direct outgrowth of the regulatory process. If the market for electricity were truly competitive (i.e., no natural monopolies and no firms with
market power derived from monopoly power), NUGs and public utilities would compete for markets, resulting in competitive electricity prices. The NUG's role has develuped as a supplier of electricity to electric utilities, which in turn use this power to meet load demand.

Nonutility generators operate with relatively little rate regulation as compared to public utilities, but the market and method in which they sell power is greatly shaped by the state PUCs and other regulations. The PUCs have the ability to influence how NUG power is procured such as through competitive bidding or on avoided cost basis. ${ }^{66}$ Within the realm of integrated resource planning, the PUC can also influence the utility's choice of a NUG project based on a variety of facto $s$, including environmental considerations, in-state resource use, siting, and reliability. NUGs must also meet state and federal environmental and siting requirements, and their ownership is restricted to a certain extent under PUHCA.

\subsubsection{Public Utility Price Regulation}

A fundamental difference between public utilities and nonutility generators is the method used to determine prices charged to its customers. The electric utility pricing process has traditionally involved (1) debates among the public utility, intervenors, and public utility staff about the merits of various tariff proposals; (2) the PUC's decision on the proper rate

65 The public utility and its holding company are classified into three different groups: (1) intrastate utilities, (2) structured as a simple single corporation (no holding company or subsidiaries), or (3) interstate holding company with single state subsidiaries. Interstate utility holding companies come under the greatest regulation of the SEC. Utility ownership of QFs is also limited to less than 50\% (NES 1991a).

66 See Strategic Decisions Group (1989) and Kahn $(1988,1989)$ for details on specific nonmarket factors in avoided cost and bidding. 
of return for the utility's capital structure; and (3) the PUC's permission for the pass-through of approved operating, maintenance, and fuel costs (Joskow and Schmalensee 1986). This method has been traditionally labeled as "cost-plus" pricing. The allocation of the revenue requirements is then distributed among rate payer ${ }^{\prime}{ }^{\prime}$ isses on the basis of cost of service, equity considerations, and even possible compełitive pressures (Joskow 1987).

The industrial organization and regulatory literature indicate that traditional natural monopoly regulation may not be conducive to efficient behavior on the public utility's part. Given the ability for the utility to earn returns on capital, but not on other expenditures, the Averch-Johnson (AJ) effect predicts that public utilities will acquire greater levels of capital than is efficient (Averch and Johnson 1962). Another theory associated with monopoly regulation is $\mathrm{x}$-inefficiency. Given the firm has all noncapital costs "passed though" to ratepayers, the firm has no incentive to minimize these costs. ${ }^{67}$ Given the presence of retrospective prudence reviews in the last two decades, an alternative to the AJ effect has been proposed in which the firm avoids expenditures on capital to minimize the risk of financially damaging prudence reviews. In this case, the firm acquires less capital than the socially efficient level. Given the presence of incentives that encourage inefficient behavior, there has been a belief that under traditional regulation utilities operate in an inefficient manner. ${ }^{68,69}$

\subsubsection{Nonutility Pricing: Competitive Bidding and Avoided Cost}

Nonutility generators face much different pricing criteria. The business environment of the NUG tends to be much more competitive than public utility. Competition for selling NUG power has been reflected in four different procurement methods; these methods include (1) avoided cost contracts for QFs, (2) voluntary negotiation without mandatory PURPA purchase rights for QFs, (3) competitive bidding open to all NUGs, and (4) competitive negotiation, in which bidding is used to select a negotiating pool (NIEP 1990). Through the use of these methods and the resulting competition for power contracts, the price of electricity is forced nearer to its marginal cost of production. In addition, competitive pressures in the NUG power market encourage innovative design and more efficient operations, which may lower the unit cost of electricity.

67 There exists a large body of literature on alternative objective functions for noncompetitive firms in the industrial organization literature. These alternative objective functions have included maximizing the welfare of the firm's managers, maximizing the firm's market share, and others.

68 The growth of incentive regulation, integrated resource planning, and the promotion of competitive power in the 1980 s seems to confirm this belief.

69 Incentive regulation has been pro; sed by many sources, and several programs have been adopted by the states in order to instill the same competitive pressures within the public utilities. For an overview of incentive regulation and rate design, see Joskow and Schmalensee (1986), Costello and Cho (1991), Barakat \& Chamberlain, Inc. (1990), Johnson (1985), and FERC (1989). 
The reasoning behind more innovation in the NUG sector and less innovation in the utility sector can be clearly seen. The risk/reward asymmetry present in the utility sector encourages business as usual or even discourages innovative behavior. Any cost savings generated by the utility would result in lower rates and little or no extra reward for the utility, while cost increases could result in large penalties. The NUGs are encouraged to innovate as there are rewards in the form of obtaining power contracts and in making potential rates of return in excess of the regulated rate of return. The continual drive to obtain power supply contracts and the rewards for innovating should result in lower power production costs by NUGs in the long run.

Power supply procurement can effectively be broken into two groups: avoided cost and competitive bidding. Avoided cost is a direct outgrowth of the PURPA legislarion. In theory, avcided cost is equal to the cost of a given utility producing an extra unit of electricity. Avoided cost typically has two components: a short run or fuel cost and a long run or capacity cost (Kahn 1988). The actual calculation of avoided cost and its components is left to the state PUCs (Kahn et al. 1985). The short-run calculation of avoided cost can be done through the QF In/Out method, in which two simulations are run (including and excluding the QF) with the difference in energy costs being the avoided cost (Kahn 1988). The long-run calculation is more problematic since it involves the estimation of the added cost to the utility of additional capacity.

Within the avoided cost process is the requirement that a utility purchase all QF power that is below its avoided cost (PURPA 1978). An early problem with avoided cost calculations led to the level of avoided cost being greater than the utility's unit cost of production in certain off-peak periods (Kahn et al. 1989; Rozek 1989; Haman-Guild and Pfeffer 1987; Meade 1987). In order to address these problems, several states have separated the need for the utility to pay both long-run and short-run .voided cost and introduced alternative calculations of avoided cost to take into account system characteristics (HammanGuild and Pfeffer 1987).

In cases when the supply of QF electricity exceeds the utility's need for electricity, bidding can be used to allocate the full avoided cost (including the capacity costs), while excess QF power will still be purchased at the short-run avoided cost (Haman-Guild and Pfeffer 1987; Rozek 1989). Through the use of competitive bidding among QFs for small blocks of capacity needed by the utility, several states have attempted to ensure more efficient and useful projects are developed first (Haman-Guild and Pfeffer 1987). While full avoided cost is still paid for QFs receiving the winning bids, the overall price of QF power is reduced as QFs compete in price and nonprice terms, resulting in greater benefits for the ratepayer.

A number of states are considering and have implemented competitive bidding as a way of meeting capacity needs. In many states, utilities needing to expand capacity must consider NUG power as a capacity option. The public utility makes its desire to purchase power known through a Request for Proposals (RFPs) (NIEP 1991; Strategic Decisions Group 1989). The method that a utility employs to allocate its power purchases takes the form of 
either competitive bidding, avoided cost, or contractual bargaining methods (NIEP 1991). The proposals are judged on the basis of a number of characteristics such as power price, reliability, dispatchability, and other fattors (Strategic Decisions Group 1989).

A utility requiring additional capacity submits an RFP. The RFP should indicate capacity and resource types required and tr : evaluation criteria for weighing of bids characteristics (Strategic Decisions Group 198')). Competitive bidding may occur between a wide variety of capacity options, including utility supplied capacity. Several states have QF bidding only (Hamrin et al. 1987; Rose et al. 1991). Other states may allow all resource (e.g., supply- and demand-side) bidding which directly competes for capacity supply (Rose et al. 1991). The particular method and inclusion of competitive bidding will vary by state and utility capacity needs, fuel supply diversity desires, dispatchability considerations, environmental factors, and other considerations (Hamrin et al. 1987; Kahn et al. 1989; Rose et al. 1991; Strategic Decisions Group 1989).

With competitive bidding, the supply price of electricity is reduced below a utility's avoided cost. In some states, nonprice competitive bidding for QFs may be in place, which allows QFs to receive the contracts at the utility's avoided cost (Hamrin et al. 1987). In this case, the QFs compete through characteristics of their project such as dispatchability, reliability, fuel diversity, and other factors. These competitive forces will compel the NUG to operate in such a manner as to minimize costs of production while improving the quality of its product. Because NUGs are operating in a fairly competitive market, marginal changes in a firm's costs will alter its ability to attain power supply contracts.

\subsection{NONUTILITY GENERATOR MARKET ISSUES}

Through conversations with various nonutility electricity generating firms, the NIEP, and other parties, certain factors were consistently put forward as important concerns. ${ }^{70}$ While the independent power producers and qualifying facilities have concerns similar to all businesses, several elements of their business address important regulatory concerns. ${ }^{71}$ The policies of state PUCs, the FERC, state and federal environmental agencies, and local siting boards have direct and important impacts on NUG-generated power.

70 The conversations occurred from June 1991 through October 1991. The primary interviewers were David South, Karl McDermott, and Koby Bailey.

71 The issues of utility self-dealing and potential disincentives for nonutility power purchases are important issues for the NUG industry (NIEP 1991). It is hoped that these issues can be better addressed through proper enforcement and least-cost planning activities on the part of the PUCs and FERC. These issues deal with potential impropriety, which results in less NUG power being purchased and higher costs of electricity for the ratepayer. While the issues of bias toward the use of older facilities and transmission access may be important factors in the competitiveness of NUGs they are included in this discussion due to their (1) relevance in current legislative debates (i.e. transmission) and (2) their potential regulatory solutions beyond that of enforcement. 


\subsubsection{Environmental Considerations and Nonutility Generators}

The growing use of least-cost planning or integrated resource planning (IRP) has led to increasing consideration of the environmental costs of electricity production. Least-cost planning attempts to integrate all the relevant private and social costs of demand and supply side programs to meet increasing load demands (Barakat \& Chamberlain 1990). With passage of the Clean Air Act Amendments of 1990 (P.L. 101-549) and the potential for new legislation on water, land, and multimedia pollution, together with the possibility of greenhouse gas legislation, the environmental effects of electricity generation are an important consideration when building new capacity. In addition, several states have introduced qualitative and quantitative considerations of environmental externalities in their utilities' procurement processes (Cohen et al. 1990). These environmental considerations have affected and will continue to affect technology choice by both utilities and NUGs.

Consideration of environmental externalities amounts to weighing a technology type's environmental cost as a noneconomic factor in a competitive bidding system or a modification to the bid or avoided cost price (Temple, Barker \& Sloane, Inc. 1991). Technologies that tend to discharge higher levels of pollution may receive an add-on to the project price or an unfavorable ranking in the noneconomic factors, while technologies with lower levels of discharges may receive discounts to the project price or more favorable ranking, depending on the state's consideration (Cohen et al. 1990; ERG 1991). ${ }^{72}$ Particular states may also reserve a certain amount of capacity to be met only by certain technologies (Cohen et al. 1990; Hamrin et al. 1987). Many states are and will be considering environmental externality charges for purposes of permit fees (P.L. 101-549; Cohen et al. 1990; Kooney 1990). Environmental externality consideration by states in the bidding and the avoided cost process tend to result in lower emission technologies winning capacity contracts and lower emission technology being built. ${ }^{73,74,75}$

72 In terms of planning and bidding with environmental externalities, the modifiers to price will tend to make higher polluting technologies less attractive due to their greater cost while technologies that pollute less will be more desired for their lower price.

73 This result stems from economic theory in the internalization of externalities. The inclusion of a positive production externality (pollution) into the firm's private cost function will cause the firm to reduce the externality generating behavior. So, the imposition of externality considerations will cause firms to build facilities that pollute less.

74 A perverse result may arise from unit-by-unit oxternality considerations. While cleaner projects may be acquired by the utility, there may be little decreasf, or even an increase in the level of pollution. Cleaner units with lower capacity factors will not greatly affect the dispatch order, which in turn will not significantly alter the amount of pollution generated by the system. The level of pollution from the system may be greater if newer coal tech inologies (with higher capacity factors and lower operational costs) are not chosen but natural gas units are chosen instead (with lower capacity factors and higher operational costs). For further information see Grahame (1991).

75 There is also the issue of the State PUC's ability to assesis the actual damages caused by electricity generation. Consideration of whole fuel cycle cost, accurate assessment of environmental loadings, and the optimal level of emission (i.e., $M C=M B$ ) tend to be beyond the realm of PUC experience. See Berkman (1992); Palmer and Dowlatabadi (1991). 
Several NUGs and NIEP (as indicated in NIEP 1991) believe that there is a bias on the part of utilities toward older, utility-owned generating facilities. The purchase of newer, nonutility generation has a disincentive associated with it as the utility does not earn a return on the power purchased. Therefore, the utility favors repowering or retrofitting older facilities. To better balance the competitive playing field of old versus new sources of power, NIEP and several NUGs propose that utilities desiring to repower plants submit a bid including environmental costs (damage) to be compared with new power bids (NIEP 1991). An alternative solution to this perceived problem, put forth by other sources, is to environmentally dispatch electricity from the system to encourage greater use of the cleaner resources or give set-aside considerations for cleaner resources (Ottinger et al. 1990). Of those NUGs surveyed, and from indications by NIEP, the above incentives should be given to encourage the development of cleaner, lower cost power in order to better balance the new generation choices against older generation.

However, there may be some flaws associated with the above arguments. While older facilities may be less efficient in terms of generation (i.e., higher heat rates) and pollution control, it may be more economic from a ratepayer and utility perspective to retrofit an older facility raiher than construct a new facility. Given identical pollution control requirements, greater control of emissions from a newer facility may be higher cost and the benefits gained by lower pollution levels may not compensate for the added control costs. The added gains from greater pollution control may not justify the added costs of a new facility, and until the time when the costs are justified (other things being equal) it would be inefficient to construct a new facility.

The use of environmental dispatch does not necessarily imply minimizing the social cost of electricity generation. At present, the state-of-the-science in determining externality values, while having received much attention in the scientific literature, still is uncertain in determining accurate externality values. ${ }^{76}$ Also, there may be more cost-effective ways on a systemwide basis of reducing environmental emissions and hence, reducing the social cost of electricity generation than the use of environmental dispatch.

\subsubsection{Siting Issues}

During recent years there has been increased difficulty in siting facilities such as highways, transmission lines, power plants, nuclear plants, landfills, and hazardous waste repositories. ${ }^{77}$ These locally undesirable land uses (LULUs) have led to protest from the

${ }^{76}$ In cases where externality values have been put forward to be integrated into competitive bidding, avoided cost, and IRP, significant debate has occurred about what emissions to measure, the use of damage versus control costs, the level of the damage costs, and how to implement these procedures. Significant debate on this issue has occurred in states such as California and Massachusetts.

77 The literature on the resistance to the siting of such projects is well documented in the media. For a small sample of these problems, see Smith and Desvousges (1988) and Inhaber (1991). 
public and many restrictions on the locations of these projects. Air, water, and land pollutants from power plants along with increased health fears from electromagnetic fields have led to problems in finding siting for these facilities (Ottinger et al. 1990). Combined with the difficulties of building in nonattainment and certain PSD areas, the siting of new capacity has become increasingly difficult (Loeb and Elliott 1993). The added costs of siting decrease the firm's profit margins, and a lengthy siting process endangers the NUG's ability to build capacity and supply power within a time frame acceptable to the utility.

\subsubsection{Transmission Access}

Currently, transmission access through many utility territories occurs only on a voluntary basis. While the transfer of power between utilities in a power pool is routinely done (EEI 1991), access to the use of the power grids has been restricted (DOE 1991b). The utility-owned transmission lines can play a significant role in restricting power supply entrants. ${ }^{78}$ As evident from Virginia Power's 1988 power solicitation, several of the winning bidders were unable to obtain transmission service and unable to supply power (DOE 1991b). Readily available access of transmission would make siting much easier as plants could be built in relatively inexpensive areas (DOE 1991b). Restrictions on transmission access provide a rather serious bottleneck to continued IPP development (Plummer and Troppmann 1990), which in turn distorts competition in the NUG environment and favors utility and local NUG-developed projects.

Limited transmission access will also influence the choice of technologies proposed by the NUG and desired by the utility. Facilities using fuels such as coal, which find it more economical to locate away from customers, will not be proposed if transmission access is limited. Instead, prospective facilities using fuels such as natural gas and fuel oil (which in some cases may have easier, lower cost access to certain areas and may be publicly perceived as cleaner) may be able to obtain siting near the customer and directly link with the buying utility's system. The utility will not request projects for consideration which cannot be relied on to supply power.

\subsubsection{Treatment of Environmental Pass-through.}

Another factor that may distort the ability of NUGs to compete with utility generation projects is the potential change in operating costs due to future regulatory costs (NIEP 1991). While the public utility is able to pass through added operating costs and earı a return on additional capital costs for added pollution control required by stricter environmental regulation, NUGs will usually have a contract in which the price of power and length of the service contract are fixed (NIEP 1991). The NUG may negotiate for some type

78 For example, assume that utility A's territory surrounds utility B's territory. Any electricity produced outside area $B$ must pass through $A$. Utility $A$ can extract monopoly rents or present a barrier to outside power if it chocses in order to supply utility B's power needs itself. 
of front-end loading or changing price scheme (Kahn 1988), although this may not take into account future regulations. ${ }^{79}$

The Virginia State Corporation Commission has refused to allow NUGs the ability to pass unexpected environmental costs to the purchasing public utility (Electric Utility Week 1990). NIEP proposes that some form of contract renegotiation or full or partial pass-through be allowed. The treatment of this issue is problematic for the regulator. Disallowance of cost pass-through could discourage certain types of NUG technology choices (i.e., coal) and put certain present and future NUG projects in an unfavorable financial situation. On the other hand, if complete pass-through is allowed, ratepayers may face the danger of imprudent control expenditures by the NUG. ${ }^{80}$

\subsection{NONUTILITY GENERATOR TECHNOLOGY CHOICE}

From a policy-making perspective, the influence of utility requirements, state environmental considerations, and fuel prices are primary factors in determining the type of NUG technology chosen for a particular area. These factors all play important roles for targeting incentives on a state, regional, and national level. The recognition and inclusion of these influences on regulatory incentive mechanisms may prevent effort being wasted on incentives that might prove impossible (or improbable) to achieve desired policy goals.

Public utility dispatching, diversity, and load demand requirements will greatly affect the projects submitted for an RFP. A utility needing peak demand and high levels of dispatchable power will tend to favor natural gas units, which are more economical in coincidence with peak generation and have very short lead times. ${ }^{81}$ Utilities requiring base load power will tend to favor units with low operating costs at high capacity factors, which tend to have longer lead times (i.e., coal units).

The fuel diversity needs of a utility's capacity will also be reflected in its RFP. Fuel supply diversity provides a method of self-insurance against future price changes in fuel costs. NUG power may serve as a risk-sharing mechanism for the utility; if its own fuel

${ }^{79}$ In theory however, we would expect some type of price premium for service over time to be formed if there is a potential for cost increases in the future. Based on the firm's expectations, some expected cost would be formed based on a range of occurrences and their probabilities. We would imagine that these expected costs, weighed by some level of uncertainty, would be included in any price contract.

${ }^{80}$ Given the history of NUG projects, it is unlikely that noncost minimizing behavior is prevalent. Given the need to compete for power sales in some cases (i.e., the utility agrees to buy "x" amount of power with additional purchases at its discretion), this behavior is unlikely to occur.

81 It should be noted that certain CCTs (such as IGCCs) have the ability to be constructed in module "packages," beginning with the construction of a natural gas unit and later, when baseload generation is needed, being relatively cost-effective to convert to baseload coal units. This added flexibility may offset this type of technology's higher capital costs. 
prices rise, the lower cost NUG power may be relied on, or the NUG may be made to bear the burden of fuel price risk by the utility selecting NUG projects with more volatile fuel costs. CCTs may be a proper means of alleviating fuel price risk in utility systems as the CCT is able to use a wide variety of coal types and coal wastes allowing diversity in the system's fuel supplies.

Fuel transportation costs will also influence the choice of technology within different regions. If there are marginal differences in fuel costs in certain regions, incentive mechanisms can play an important role in influencing technology choice. In areas where there are relatively large differences between natural gas and coal prices, incentives may be of little use to encourage adoption of CCTs. For innovative renewable generation technologies, the presence of constant winds, sunny days, geothermal activity, and the like will also have significant effects on the ability of incentives for the commercialization of innovative technology to encourage the adoption of these technologies. Given limited PUC resources, the innovative technologies considered should be carefully chosen. The goal of innovative technology incentives is to provide encouragement of innovative generating technologies appropriate to a particular region, which may be avoided due to risks associated with this technology, i.e., establish a "level playing field."

Regional, state, and environmental perceptions will also play an important role in determining NUG technology choice. The actual or perceived pollution characteristics of a generating facility will heavily influence its ability to obtain a permit. The "cleanliness" factor of a facility was cited by several NUGs as a reason for restricting units with certain fuels in some states. ${ }^{82}$ Within the past years, the fuel characteristics of a NUG facility have made a difference in permitting and the technology eventually used. As evidence from two proposed coal plants, one near Shenandoah National Park and the other in Florida, the siting of coal-fueled plants (even those which are CCT, as in the case of the Florida project) may be extremely difficult. $^{83}$

The relative acceptance of generating technology and fuel by region may not be as important as unit generating cost. The majority of utility construction in ECAR, ERCOT, and certain regions of SERC is fueled by coal or projected to use coal (NERC 1991). Examination of NERC's generating additions shows that coal units have been and are projected to be built in areas that may have attainment difficulties (NERC 1991). The problem of perceptions

82 The mention of cleanliness of a facility stems from the interview of NUGs from August 1991 to October 1991. Several of the NUGs indicated, however, that CCT and its pollution control qualities should make a difference in the ability to obtain a permit.

83 The Virginia plant was converted to burn a mixture of wood waste and coal, while the Florida plant is to use natural gas. In the Florida case, the choice of natural gas was declared to be due to the lower cost of natural gas, although significant environmental group pressure was apparent. Recently, GWF Power Systems was allowed to begin the operation of a 27-MW natural gas and petroleum coke-fired cogeneration unit. This unit was initially designed as a coal unit, but environmental pressures for local agencies forced the conversion of the facility (Electric Utility Week, 1991). 
against coal may be a matter of showing the fuel's lower cost and low impacts on environmental quality (as in the case of CCTs).

The fuel most used by NUGs is natural gas, amounting to approximately one-half of all NUG capacity. Coal is the next most popular fuel, producing approximately one-fifth of all NUG-generated electricity (NIEP 1991). In NUG projects under construction and planned, natural gas dominates the supply mix along with increased renewable usage (NERC 1991; Smith 1990). The states of Florida, North Carolina, Virginia, and West Virginia are the only states planning significant increases in coal-based NUG capacity, which is also a large part of their NUG fuel supply mix (NERC 1991; Smith 1990). In the states of New Jersey, New York, Massachusetts, and Pennsylvania (primarily using waste coal), there are large amounts of planned (1990-1999) and existing NUG coal capacity, but most NUG projects are natural gas or fuel oil (NERC 1991; Smith 1990). Within other states, either NUG generation is relatively small, coal capacity (MW) is low, or the fuel mix is completely dominated by natural gas or fuel oil (with an occasional municipal solid waste burning facility) (NERC 1991; Smith 1990).

The presence of readily accessible coal fields and the type of electricity demand growth are important factors influencing the choice of fuel/technology between states. Another factor to be considered that has regional scope is the competitive mechanism in place. The type of bidding process may influence the choice of technology. From the NUG interviews, there was not an overall belief that the competitive process will greatly influence the ability of a CCT or innovative generation technology to win an RFP. States such as California, which allow only QF bidding, may alter fuel choice in favor of renewable and cogeneration-oriented technologies. ${ }^{84}$

The ability of incentive regulation to get NUGs to adopt CCTs (and other innovative generation technologies) depends on all of the above factors. Some of the factors emerge from regional differences, such as fuel costs and perceived environmental needs, and may be difficult to overcome with regulation. Other factors stem from anti-competitive barriers to NUGs and unnecessary regulatory hurdles that require conscientious rulemaking to overcome. All these factors must be examined to implement the proper incentives to encourage the further development and deployment of CCT (and other innovative generation technologies).

84 See Decision 91-06-022 before the Public Utilities Commission of the State of California, June 5, 1991, for details of California's QF-only bidding program. 


\subsection{INTERVIEWS WITH NONUTILITY GENERATORS}

Five NUGs and a variety of their personnel were interviewed to determine their opinions on CCT incentives and the perceived risks of CCTs. The following questions were asked:

1. What are the major risks and uncertainties that you perceive in undertaking CCT?

2. How would you rank these risks?

3. Are incentives designed to offset risks associated with a particular technology (CCT) inconsistent with competition in the bulk power market?

4. How would incentives offered to regulated firms competing with IPPs in a competitive or avoided cost environment affect your own supply proposals?

5. Would you be willing to accept incentives if they were offered to IPPs and cogenerators?

6. Do you believe that incentives, if accepted, could lead to further regulatory interference in your operations?

7. If incentives are adopted in a competitive bidding process, should they be restricted to assigning weights to score bids or should they involve actual financial rewards or penalties (i.e. modification to price)?

8. If incentives are offered for the adoption of CCT, how would you rank the following mechanisms?

a. Premium price on kWh supplied;

b. Special fixed monthly payments;

c. Special front-end loading;

d. Guarantee of capital recovery or partial recovery if plant fails to operate or underperforms;

e. Favorable income, property, or state utility tax treatmen:;

f. Availability of low interest loans; and

g. Other.

9. How would these alternatives work to your advantage?

10. Would granted emission allowances for a CCT project provide an incentive?

11. If an avoided cost pricing approach is used, how should incentive be structured? 
12. What are your concerns when considering clean coal options in selecting a technology? Do these concerns vary by region or competitive process?

With these questions, it is hoped that the range of issues dealing with CCT and NUGs would be covered. The responses are broken into three sections covering risk perceptions, incentive mechanisms, and concerns about adopting CCTs.

\subsubsection{Perceived R isks of Clean Coal Technology and Incentive Adoption}

The primary risk of adopting a CCT is the perceived technology risks that could result in construction cost overruns and underperformance of the technology. Implicitly linked to the technology risk is the ability to get financing for the project at a reasonable rate. As the failure of default is greater due to the risk of cost overruns and underperformance, overall risk levels are greater, leading to an increase in financing costs. Further technological risk decreases the ability to get a contractor to accept a fixed-cost contract and guarantee the contracted plant's performance.

Some of the NUGs noted that the type of CCT will make a difference in their perceptions of risks. Technologies such as atmospheric fluidized-bed combustion (AFBC) or integrated coal gasification combined cycle (IGCC) were perceived by the interviewed firms as not extremely high-risk projects even though innovative technology risk is associated with them. Factors such as changing environmental regulation - and the ability of the technology to be flexible to such changes - are also a concern expressed by interviewed NUGs. While sharing risks among different parties is a concern indicated by NUGs, only one NUG indicated that the ability to obtain risk-sharing contracts is a chief uncertainty in CCT adoption.

In terms of willingness to accept incentives for the adoption of CCT, most NUGs favor their use with some caveats. While incentives would aid in the adoption of CCTs, it was believed that incentives should not be created that distort the ability of NUGs to compete with each other and utility supply proposals. In addition, incentives (if accepted) should attach few requirements for the accepting firm other than the actual adoption of a CCT and perhaps some information-sharing with the Department of Energy about cost and performance characteristics of the CCT.

Most NUGs believe that the acceptance of incentives will not promote additional interference, but they do not rule out the possibility of additional interference. An important point brought up by one of the NUGs was the issue of applying for incentives. If incentive requests and governmental requirements are not kept to a minimum, there may be severe problems in terms of effort devoted to applying for an incentive. This may cause some firms that are willing to adopt CCT incentives to be unable to devote enough resources to apply for the incentive. A standardized method of application or fast track for firms with experience developing CCTs was suggested. 
The results of questions 1 and 2 are presented in Table 37, and questions 5 and 6 are presented in Table 38 . The number (out of five) taking a certain position will be noted after the position taken.

\subsubsection{Incentive Mechanisms and Their Effect on Operations}

Beliefs about the best incentives for CCT adoption are more diverse. Their use in NUG operations, however, is very similar. The incentives can be split in three groups for purposes of their effects on operations. The first group is classified as risk reducing; this group includes partial or total capital recovery if a project underperforms or completely fails. While the authors believed that guarantees of low interest loans would lead to risk reductions, the NUGs classified this incentive as primarily revenue enhancing.

The second group is revenue enhancing; these include favorable tax treatment, frontend loading, premium on $\mathrm{kWh}$ supplied, and fixed monthly payments. These methods would

TABLE 37 The Risk Perceptions of CCT and the Acceptance of Incentives

Classification

Major risks

Secondary/lesser risks
Type of Risk

Technology difficulties resulting in cost overrun/underperformance Financing difficulties (ability to obtain capital at reasonable rate)

Changing environmental regulations $\left(\mathrm{CO}_{2}\right.$ regulation concerns)

Bias against coal technologies in competitive process

Ability to obtain risk sharing through contracts for the CCT

TABLE 38 Perceptions of Incentives for the Adoption of CCTs

\begin{tabular}{ccc}
\hline Question & \multicolumn{1}{c}{ Response } & Concerns \\
\hline $\begin{array}{c}\text { Willing to consider } \\
\text { incentives for } \\
\text { adoption of CCTs }\end{array}$ & $\begin{array}{c}\text { Would consider incentives (4) } \\
\text { Would consider incentives in only } \\
\text { one case (1) }\end{array}$ & $\begin{array}{c}\text { Would lead to additional } \\
\text { requirements } \\
\text { Should not cause distortion } \\
\text { of competitive market }\end{array}$ \\
$\begin{array}{c}\text { Incentives lead to } \\
\text { added regulatory } \\
\text { inference }\end{array}$ & $\begin{array}{c}\text { Simple incentives (i.e., subsidies) } \\
\text { would not cause additional } \\
\text { interference, but more } \\
\text { complicated measures could (3) } \\
\text { Would not cause added } \\
\text { interference (1) } \\
\text { Would cause additional } \\
\text { interference (1) }\end{array}$ \\
\hline
\end{tabular}


primarily increase revenues of the firm and aid in the ability of the firm to obtain a supply project or act as insurance in case of technology underperformance. High revenues would enable the firm to lower its bid price and still be assured of good returns. As indicated in McDermott and South (1991), asymmetry of risks will discourage CCT projects, but additional revenue from adopting such a project should cause more CCTs to be developed. The last group includes grants of $\mathrm{SO}_{2}$ emission allowances. Emission allowances have many benefits for the NUG; they may be (1) used to offset risks of underperformance by the CCT pollution control equipment, or (2) used to offset CCTs emissions, be banked for future use, or sold to generate additional revenues.

The opinions about the usefulness of these incentives vary. As indicated in Table 39, capital recovery guarantees and $\mathrm{kWh}$ price premiums were greatly favored. Special front-end loading of payments and favorable tax treatment were not @nnsidered "high-value" incentives to the IPPs.

\subsubsection{Concerns about CCT and the Use of Incentives under Competitive Processess}

This section addresses concerns about CCT incentives and the implementation of incentives in avoided-cost and competitive-bidding processes. The questions addressed in this section include $3,4,7,11$, and 12 .

Incentives for technological development in the bulk power market are, in general, not believed by most to distort competition. But, as mentioned before, care must be taken not to grant incentives between competitors in a manner that would distort the competitive process. As indicated by all NUGs contacted, incentives must be granted equally to create a "level playing field" for all participants in the market.

TABLE 39 Ranking of Incentives for Adoption of CCT

\begin{tabular}{cl}
\hline Rank & \multicolumn{1}{c}{ Incentive } \\
\hline 1 & $\begin{array}{l}\text { Guarantees of partial or total capital recovery if } \\
\text { project underperforms or fails to perform }\end{array}$ \\
2 & Price premium on kWh \\
3 & Low-interest loans available for CCT adoption \\
4 & Fixed monthly payments \\
5 & Special front end loading \\
6 & Favorable income, state, property tax treatment \\
\hline
\end{tabular}


If incentives for CCT (or any other innovative generation technology) are given to regulated firms such as investor-owned utilities and not to NUGs, competition will be distorted. If incentives are granted only to utilities, in the future when CCTs become more commercialized, NUGs may be "crowded out" of the market for baseload power sales. ${ }^{85}$ As indicated by one of the NUGs, because the margins are very close in the competition for power supply, any distortions in favor of any agent will lead to that agent winning the proposal. Several NUGs stated that with only utility incentives, NUGs would be limited to natural gas generation and cogeneration using renewable sources (either partially or completely) in order to obtain proposals. Incentives can have a powerful effect on the market and should be granted in an equitable fashion.

The interviewed NUGs were divided on the treatment of incentives in a competitivebidding process. Over half believed that incentives should enter into the bidding process through the price charged. ${ }^{86}$ Given this characteristic's dominant weight in competitive bidding, these NUGs felt that this consideration was the "bottom line" in getting most projects. In addition,CCTs have economic benefits such as fuel diversity (a wide variety of coal types can be used without lowering plant efficiency) and noneconomic benefits such as lower emissions than conventional facilities. With a lower price and these other beneficial characteristics, more proposals could be won. Two NUGs felt that incentives should be used in assigning incentives as a qualitative factor. The general impression in this case was the NUG should be able to achieve a lower bid in most cases and a greater weighing of the nonprice benefits of a CCT would allow the NUG proposing a CCT to win the bid.

The general consensus on the use of incentives in an avoided-cost environment was that incentives should be structured in the same manner as the competitive bidding environment. The CCT incentive should allow the NUG to offer a lower price per $\mathrm{kWh}$ supplied and, in a case where a competitive avoided-cost environment exists, the environmental benefits of a CCT should rank heavily. Many ielt that because of the ability to get power supply contracts in this environment, an avoided-cost environment was not significantly different than competitive bidding. ${ }^{87}$

85 Presumably, the developing utilities will gain progress along the learning curve and be able to produce these technologies with greater operating efficiencies and lower costs. Combined with CCTs inherently lower $\mathrm{SO}_{2}$ and $\mathrm{NO}_{x}$ emissions, the utilities will have a significant advantage in having their cleaner, more efficient, and lower cost technologies chosen in an RFP or IRP regime. The market could lose the significant competitive role that NUGs play in the wholesale power market if they are unable to compete due to this technology advantage.

${ }^{86}$ Note that price incentives such as a $\mathrm{kWh}$ premium or increased demand charge could also be applied for a NUG (or utility) innovative technology unit that operates above a certain capacity factor or has a high degree of availability.

87 This is not to say that the NUGs in question believe these processes are different, but that the ability of the NUG to supply a quality product at the lowest possible price will not vary with the competitive process used. 


\subsection{NUG CHARACTERISTICS AND DEVELOPMENT}

As indicated by several NUGs, the financing of a project can be the single most important factor in whether a successiul bid can be translated intc a revenue generating project. While the ability to obtain financing is important to many different industries, the capital-intensive product production and relatively small asset base preciude NUGs from exploring several ways of obtaining project capital. ${ }^{88}$ This section will explore and explain the reliance of NUG development on bank-related financing and the risk criteria that these financial centers assess when entering into NUG project development. In Section 7, a NUG project will then be modeled to compare a PC/FGD facility with an IGCC in order to determine debt payback periods and incentive magnitudes needed to place these technologies on ecuivalent financial terms.

The NUG industry is highly dependent on debt for project development. While this is true for many industries in the economy, the NUG industry has several unique features. The NUG competes in a relatively competitive market for the right to sell power to a regulated firms. The power generating industry is also one of the most capital-intensive industrial sectors. In addition, the NUG industry tends to be single-product-oriented and possesses lower levels of very nonliquid assets (primarily plant capital). The combination of these factors makes NUG ventures more risky and requires contractual and debt obligation in order to operate. This section will examine NUG projects in light of their capital-intensive ventures, the need for multiple risk sharing contracts, and their ability to obtain project financing.

\subsubsection{Capital-Intensive Nature of NUGs}

As an industry, electricity generation is the most capital-intensive of all corporate undertakings (Electric Perspectives 1991). Capital-intensive technologies require several years of construction time during which no revenue is generated by the project and large costs are incurred. In order to facilitate project development, the firm must obtain a large amount of capital at the onset of a project to cover these uncompensated costs. After the project is developed and operating, the firm may then begin to generate revenues from the facility that are used to pay back its debtors and reward equity holders.

To raise the necessary financial capital, the firm has the options of internal generation of funds, the equity market, the bond market, and the loan market (banks and related services). To obtain financial capital at a reasonable rate, the firm must be able to ensure that it is able to pay back its creditors and provide its shareholders with a reasonable return on equity, given some level of risk. Within the past two decades, the public utility industry has found that its highly expensive and capital-intensive projects (nuclear and large

${ }^{88}$ In contrast, utilities have relatively easy access to debt financing through bond issuances and borrowing. Utilities have tended to have lower risk levels than other industries (although this is not true in all cases); they tend to have a large existing store of assets (power plants, transmission grid) and a large and relatively stable cash flow. 
coal units $)^{89}$ face limited abilities for cost recovery. ${ }^{90}$ For the most part, the industry has been able to absorb these losses due to its large asset base and a relatively certain stream of revenue from its franchise territory. The NUG industry, however, bears greater risks than the public utility industry. While projects undertaken by the NUG industry ard utility are similar, the NUG industry tends to be single asset (power plants only) and lacks the vertical integration of utilities, reducing their ability to generate funds internally. These factors along with revenue uncertainty (unlike the public utilities' cost-plus pricing that provides for relatively certain revenue stream) make the ability to obtain large amounts of equity relatively expensive. So, the debt market tends to be the major supplier of financial capital for the NUG industry.

\subsubsection{Expense Contracting and Cost Pass-through}

A utility establishes a power supply contract with a NUG at a price equal to or below the utility's avoided cost, which is coupled with assurances of that power supply's reliability and dispatchability. As the utility is faced with an obligation to serve, reliability guarantees are necessary. The NUG also needs certain assurances and protection against various risks. The most important contract for the NUG is with the utility over the NUG's revenue flows. The revenue flows are essential for debt repayment and any return on equity for its shareholders.

To better allocate cost-side risks, the NUG contracts for services with turnkey contracts or cost guarantees among a variety of parties. For a project to demonstrate itself as viable and profitable, it must demonstrate some fixed-price commitment for construction costs. A turnkey (fixed cost) contract from a contractor is important to attract debt financing along with the ability to demonstrate itself as a viable and low risk technology project. In terms of operating cost control, factors such as fuel supply contracts to ensure the ability to generate electricity and some arrangement for the rennvery of fuel costs are needed.

Fuel costs risks are handled in a number of ways. A fuel cost index clause reduces the risk exposure of the NUG to fuel price swings by effectively averaging the increases (or

89 For example, the Missouri PSC denied rate-base treatment of Iatan 1 coal unit as the utility had excess capacity at the time when the plan was completed. The Pennsylvania PUC rejected the nuclear unit Susquehana 1 as imprudent because of current excess capacity. In 1984, the Massachusetts DPU issued an order that the prudence of the planning would no longer be considered relevant to rate-base decisions; future construction would be rate based only if the plant were used and useful when it came on-line. For further examples of disallowances, see ICTAP (1989).

90 The failure to recover all of the costs of these highly capital intensive facilities has been due to large cost overruns, electricity demand falling below projected demand, new baseload units partially failing used and useful reviews, and ex post prudence reviews. With these facilities allowed only partial cost recovery, it has become rather risky for utilities to develop such projects. One of the outgrowths of the series of cost overruns and falling electricity demand has been the development of IPPs and QFs to bear some of the construction risks. 
possible decreases) in these prices. The fuel price risk can be shifted to the fuel supplier through locking a set fuel prices for certain fuel types. The fuel supplier then reduces overall risk by systematic diversification of the fuel risks. This entails the supplier drawing on other suppliers, fuel sources, and storage to meet fixed contractual demands. For cost-sensitive O\&M operations, additional contracts are used to put caps on expenses.

These multiple contractual obligations better allocate the cost and revenue risks over those parties that are better able to manage those risks. The ability to assure the contractual connections is very important to the lending institution in its decision to supply capital. The contractual obligations are seen by the lender as a means by which a project can succeed and provide payback to its lenders.

\subsubsection{Debt Financing and Leverage}

As indicated before, the capital intensive nature of the NUG industry along with some inherent risks make the ability of the NUG to obtain equity capital more costly. Higher returns on equity as demanded by the market will make it difficult for the firm to acquire a significant portion of its capital through equity. So, to acquire needed capital, the firm must turn to the debt markets for a majority of its financing. The debt coverage of NUGs tends to be $80 \%$ or higher.

According to interviews with NUGs, the ability to obtain financing is the chief barrier to CCT selection. The CCT is much more capital intensive than a like-sized natural gas unit, and it has significant cost and operation risks. The major money center that was interviewed indicated that assurances must be provided that a project will work and be able to repay its debts. For this reason, it restricts financing to only proven, low-risk technologies and will not consider more risky, innovative technologies. As indicated by the NUGs and a major money center, if the NUG is unable to obtain financing, the NUG is unable to begin a power supply project.

The presence of developer/operator equity has been indicated as a possible signal to lending institutions that the performance of the project will directly affect the owners, indicating a greater incentive for success of the project. In addition, the presence of developer/operator equity in the project will provide a greater incentive for performance as the project's profit can, in turn, be transferred to dividends, once the necessary debt payments are made. The incentive for greater performance and reliability may result in the lowering of the firm's cost of capital as perceived performance and development risks are reduced. 


\subsection{QUALITATIVE RISK ASSESSMENT OF NUG PROJECTS: A FINANCLAL VIEW ${ }^{91}$}

While many characteristics of financial dealings are project specific, there tend to be general areas of risk which are usually examined. These risk factors are considered very important in the evaluation of a project's future success and will influence the financial institution's desire to fund a project. The generic factors include the following:

- Economic viability,

- Construction risks,

- Regulatory risk,

- Fuel availability and price, and

- Operation and maintenance.

Within each of these sets of risks are questions involving the ability to assess the risk of loaning to a NUG project. The key points under these sections will be examined with a special emphasis toward examining the role of technology choice in risk assessment.

\subsubsection{Qualitative Risk Factors}

Economic viability examines the project in terms of future growth, the present market, and the general economic environment. Probably the most important economic factor examined by the lender is the question of the need for the project. The long-term need and ability to obtain sales contracts for the project's output will affect the project's revenue stream and ability to repay creditors and offer a return on equity. The source of the revenue is also important for contracting purposes. A positive environment ${ }^{92}$ for the project's power is considered necessary to avoid potential refusals for long-term power purchases. There is also a question of the host's capability to pay for power to ensure that project costs can be recovered through a certain revenue stream. Previous financial relationships with the lender are also used to assess the credit worthiness of a project.

Another key factor in assessing risk is the regulatory effect on the marketplace. If, for example, certain regulatory benefits (i.e., tax credits, subsidies) were removed, would the project generate positive economic profits? Revenues that occur only because of regulatory barriers or incentives create extreme risks, if these are central to the firm's positive cash flows. Finally, the NUG's financial interest and willingness to stand behind a project must

91 Much of this information come from conversations with a major financial institution that has organized project financing of several NUG projects.

92 Positive environment implies both actual, long-term need for the project's power and PUC support and recognition of that energy need. 
be assessed. Obviously, a NUG that does not invest resources into a project does not have an overly large incentive to ensure project success and provide assurances to the project creditors.

Construction risks are desired to be fairly low. To achieve this end, projects which do not employ "well-tested and conventional technologies" are, in most cases, rejected without additional risk coverage from the NUG, developer, and possibly other vendors. Given NUG reliance on the debt market (primarily through loans, not bond issues), CCTs may face serious difficulties in obtaining project capital. Obtaining turnkey or fixed cost construction agreements from a capable contractor is an important factor to prevent excessive capital costs from overwhelming the NUG's finances. The technology of the project also comes into question, with low risk being the primary criterion for project loan evaluation. The questions of obtaining the necessary operating permits, reliable contractor, projected budget, and testing of the project's ability to meet required financial performance are also important. These factors stress the ability to develop a project without any undue delays and costs that would reduce the project's ability to pay back creditors.

Regulatory risk embraces the project's need to acquire permits involving pollution emissions and siting. In the past, local political pressure has, in many ways, made these two issues interrelated as perceived reductions in environmental quality have been associated with power plant emissions and transmission lines. As local political pressure has grown along with the complexity and time required to move siting and operating permits through state and local agencies, the costs to the project developers increase. The risk of project delay (and the more serious risk of inability to site the project) will affect the financial center's loan-making process. Delay implies possible cash penalties on the developing firm from the buyer and possible restrictions on the technology or fuel used by the developer. Changes in technology or fuel use in order to get the project the necessary operating and siting permits will most likely alter the project's dispatchability, reliability, and costs in a significant manner. Alteration of these factors may endanger the project's ability to successfully operate. These types of regulatory barriers and risks can only serve to reduce the potential for project success. ${ }^{93}$

A project's financial viability will also require a reliable fuel supply along with the NUG's ability to pay for the chosen fuel, given possible volatile fuel markets. If market conditions prevent contractual agreements for fuel supply and price, the NUG should demonstrate that it possesses adequate cash flows, fuel reserves, and competitive access to a range of fuel supply options to ensure the future plant's operations will not be unduly disrupted. A central issue in evaluating the risk of the project will be the ability to get contractual fuel arrangements and, if not, the NUG's ability to self-insure against these risks.

93 CCTs may not face as many difficulties as other coal units have in acquiring the necessary environmental and siting permits due to lower emission rates and ability of these facilities to offset dirtier baseload generation from a utility's system. For a comparison of conventional coal unit and clean coal technology emission rate differences, see South et al. (1990). 
To address this fact, it is important to arrange with the contracting utility to have fuel-costrecovery wechanisms available for evaluating risk.

Also of importance to project lenders and investors are the project's operating costs. Two questions are asked to address these risks. First, is the operator capable of operating the facility efficiently and reliably? Failure of reliable service and inefficient operations may endanger the power supply contract of the NUG and will result in lower net revenues. for the project. Second, are the technological operating risks limited by the operators? This factor may reduce the ability of a NUG choosing a CCT to obtain capital, unless some O\&M costs can be guaranteed (around some deadband).

\subsubsection{Importance of Contractual Assurances and Guarantees}

The qualitative assessment of a project's viability entails a variety of contracting issues and assurances. If more assurances and contracts can guarantee a variety of costs and revenue streams, the risk inherent in such an undertaking declines and the financial institution will be more likely to provide capital and provide that capital at a lower rate. The ability to acquire low-cost capital will improve the NUG's financial standing and potentially increase its ability to obtain equity at a lower cost. The ability to obtain lower financing rates will, in turn, improve the project's ability to generate returns for payback and return on equity. The financially healthy project will then improve the NUG's ability to go forward on future projects.

Failure to get contractual guarantees will not necessarily condemn a project but may present it with greater difficulties and a lesser ability to generate profits for the owners. The major assurance required is the ability of the facility to operate in an efficient manner without undue downtime. Lending institutions consider this issue important in their decision to provide capital. A facility that fails to operate or significantly underperforms will mean financial loss to the project owner and possibly to the lender. Innovative projects may face difficult problems attempting to acquire capital through these sources.

From the policymakers' and lenders' perspective, the contractual terms of the NUGutility, NUG-lender, and NUG-suppliers can serve as incentives for performance and reliability. As indicated before, the contractual terms also serve as a means of allocating risk to those parties which are best able to bear the risk. In terms of the utility-NUG contractual agreement, the setting of a fixed price per $\mathrm{kWh}$ - for construction and O\&M costs allocates this operating risk to the party that is best able to bear this risk, the NUG. With the risk being borne by the NUG, there is an incentive to operate in the most efficient manner as possible as all cost overruns will lower shareholder returns, while all cost savings will increase shareholder returns. Along the same lines, turnkey construction contracts allocate construction risks to the party best able to cope with this risk, the builders. 


\subsubsection{Quantitative Risk Criteria}

The quantitative criteria are primarily based on insurance and financial companies' financial ratio requirements for project lending. The length of debt repayments is a key factor in evaluating the potential competitiveness of a project. Shorter repayment times will tend to lead to higher costs and reduce the ability of a project to be competitive. This, in turn, will reduce the desire of the financial institution to provide capital. Long debt repayments will increase overall project cost and will raise questions about the project's longterm viability and ability to generate revenues. The typical repayment period is considered to be 10 to 15 years. In addition, such factors as the debt service coverage ratio, the debt service reserve fund, and the loan-to-value ratio are considered. Finally, certain credit and exposure policies are provided.

The debt service coverage ratio is the operating income after $O \& M$ and capital cost but before interest and taxes divided by principal and interest. At a minimum (as indicated by a financial institution involved in these projects), the typical level should be 1.15:1. The debt service reserve fund (the cash collateral available to only project lenders) should be no less than six months of interest payments. This reserve is to assure the availability of time for a solution of any potential problems. The loan-to-value ratio measures the economic worth of a project to lenders and third party purchases. The typical loan-to-value ratio should be no more than $75 \%$ of the discounted cash flow of the project.

The term of bank exposures is typically limited to 10 to 15 years, with possible extensions to another 15 years (although an extension this long is unlikely). Exposure is also limited in a project to approximately $\$ 500$ million, with any amount beyond this requiring additional lender scrutiny.

\subsection{FINANCLAL INSTITUTION PROJECT EVALUATION}

The main hurdle in obtaining project financing centers around the ability to recover loans and the project's technology. The chief criterion is will the project operate? To address this concern, many of the major money centers indicate that only projects that employ a demonstrated, low risk conventional technology will be employed.

However, apart from indications by several NUGs and a major money center, innovative generating technologies have been developed and put into operation. In terms of renewable technology, several firms have commercialized wind turbines as a means of generating electricity (OTA 1990). From all indications, these projects are able to operate in a reliable manner. Also, $\mathrm{AFBC}$ has attained relatively widespread use, amounting to more than 4,000 MW (since 1982) of converted and constructed power as reported by the American Boiler Manufacturers Association (ABMA). Given the relatively commercial status of these technologies, there should not be great resistance to their development by lenders and NUGs. Presumably, AFBC is thought to be a risky technological venture to those NUGs without development and operation experience with AFBC and those lending institutions that have not examined and supported AFBC projects. 
If the factor of risky technology can be addressed and guarantees granted for the technology's performance, an innovative technology would potentially be considered. These guarantees would come in the form of capital recovery guarantees for the NUG, which would then be passed to the lenders. Guarantees for O\&M costs and performance characteristics would also be important to ensure the NUG's ability to pay back the financial institution(s).

Once the technology guarantee was established, the various risks - regulatory, project economic viability, and fuel - could be examined along with the NUG's financial structure to assure a measure of safety for the lenders. The quantitative criteria should be met in most cases along with consideration of the project's viability and contractual assurances with the builders and operators. The approval of the regulatory bodies is also extremely important, given that several approved and financially backed coal projects have been forced to switch fuel in the face of permitting pressures and difficulty in siting due to local resistance. Finally, fuel considerations should be addressed in terms of short- and longterm supply contracts, access to pipelines or rail/barge traffic, and the potential for the fuel prices to fluctuate. Natural gas provides a greater risk in terms of cost fluctuations, predicted cost increases, and fuel supply uncertainty, but factors such as ability to obtain permitting and construction and operating contracts tend to favor these units.

\subsection{NUG PAYBACK PERIOD MODEL}

NUG project evaluation is typically based on the project finance structure. As Kahn (1988) indicates: "Project finance structure means simply that revenues associated with a project must be sufficient to meet all costs without outside infusion of funds after initial capitalization." With project finance structure, the project's revenues must be adequate to meet both debt service and cash requirements. To generate early positive cash flows, the project will bear more debt (greater leverage usually implies a low weighted average cost of capital) than the typical corporate project (Kahn 1988). As indicated by one of the major money centers, the NUG project's typical goal is to meet its debt service obligations and retire its debt so that all funds after the debt retirement can be used for payments to equity. As Kahn and the major money center indicate, generating early positive cash flows to meet debt obligation, principal retirement, and operating costs are important factors when determining a project's viability.

Our concentration centers around the type of project chosen to win an RFP. Assuming that various nonmonetary benefits will make all projects more or less equal, we can proceed with the modeling. ${ }^{94}$ Given that cash flows will be equal for any of the chosen technologies, for example IGCC versus PC/FGD, the technology chosen will be based on the length of the payback period. All other things equal, a project that is able to generate shorter

94 By this state we imply that if the projects meet relatively the same requirements of dispatchability, environmental considerations, reliability, etc., the technology chosen by the NUG will be based on project economics. 
payback periods will mean more of the project's life can be dedicated to returns on and of equity.

When comparing innovative and standard technology project economics, we face the specter of risks which distort project choices resulting in standard technologies being chosen more often. ${ }^{95}$ To evaluate which project is chosen, we would ideally determine the net present value of both options, including expected costs and excepted revenues. To better incorporate risk aversion, a utility function based on expected net present value is used. Mathematically, the comparison would be:

$$
\begin{gathered}
\sum_{i=1}^{n} \frac{E\left(r_{i}-C_{i}\right)}{(1+K)^{i}} \\
\sum_{i=1}^{n} \frac{E\left(r_{i}^{I}-C_{i}^{I}\right)}{\left(1+K^{I}\right)^{i}}
\end{gathered}
$$

In Equation 6.1, the standard technology project's costs and revenues can be considered to have relatively low and known variances. The yearly revenue flow is indicated by $\mathbf{r}_{\mathrm{i}}$ and costs by $\mathrm{C}_{\mathrm{i}}$. The cost of capital is $\mathrm{K}$. Contractual agreements will further reduce revenue and cost risks for the standard technology.

The notation in Equation 6.2 follows that of Equation 6.1, except superscript I denotes the innovative technology. The innovative technology cost and revenue risks are greater. While the NUG does not face the same regulatory risks of the public utility, technology risks are still present. Expected cost variance from construction cost overrun risk, operations risks, emission control variance, and unintended maintenance expenditures are typical cost-side risks encountered. On the revenue side, plant delays, unintended downtime, and failure to develop a working plant will create revenue risks. Given the wider variance of risk for the innovative technology, the innovative technology will provide the shareholders with greater downside risk, resulting in the choice of the standard technology.

Fur purposes of determining an incentive(s) to encourage and reward risk-taking in order to further commercialize technologies such as CCT, the best method would be to determine the variance of costs and impacts of these variances on project choice. The knowledge and distribution of a priori risk are difficult, if not impossible, to acquire. Therefore, the measurement of expected costs and revenues for this modeling is fruitless.

95 The innovative technology is not in full commercialization or is in demonstration status when the projects are chosen. Given noncommercialization, a variety of technological risks not present with the standard technology are present. 
Instead, the choice of project technology will be based on the debt repayment period. If both projects have identical debt repayment periods, either technology would be chosen for the project. But, given a capital cost learning curve, ${ }^{96}$ innovative technologies tend to have higher capital and operating costs. ${ }^{97}$ Given the technology risk, higher estimated engineering costs, ${ }^{98}$ and public good nature of information, innovative technologies will not be developed or will be developed at a less than optimal pace. To speed the pace of adoption, incentives are needed for the implementation of these technologies. The magnitude of the incentive required is determined by comparing the debt repayment period of the innovative and standards technology, other things being equal. To make the firm indifferent between the two technologies based on debt repayment periods, some incentive would be offered. The correct magnitude of the incentive will make the firm indifferent between the two technologies.

The incentive encourages the adoption of the innovative technology by providing a reward for risk taking or by reducing the risk of adopting an innovative technology. A pricerelated incentive, such as a premium, encourages technology adoption by providing a reward. An incentive that reduces risk is more problematic even though higher fixed monthly payments and special front-end loading may lower the cost-risk to the firm of implementing the technology. This ex ante approach to risk represents a tractable method to providing incentives for the adoption of an innovative technology.

\subsection{CONCLUSION}

Development of an innovative generating technology outside the rate base - by entities such as IPPs, QFs, affiliated power producers (APPs), or the recently reclassified exempt wholesale generators (EWGs) - may be a method to encourage innovative technology commercialization. First, the unit is outside the rate base, so the ratepayers do not bear either the risk if the plant fails to operate or added costs if it underperforms. Second, regulatory risk should greatly decrease because the facility does not present price risks to the ratepayers, and, if it can win the RFP, this should imply that it is the least-cost option. Third, the regulatory asymmetry of risk is not present for these firms. If the innovative technology fails to operate as expected, the firm bears the burden of additional costs; however, if the technology is successful, the firm captures all the benefits from its risk-taking.

96 The basic premise of the capital cost learning curve is that as a capital technology progresses from demonstration to commercial status, there are declines in construction and operations costs. It can be assumed that with these cost declines come reductions in construction and operational risks. This argument is very similar to the learning-by-doing argument.

97 In Technical Annex 2 to the NES (1991b, p. 92), capital costs are shown to be declining for a variety of innovative technologies. These costs are based on engineering estimates from a variety of sources.

98 The higher engineering costs of innovative technologies probably incorporate several of the possible risks, given that there exists a range of costs and experiences in developing demonstration CCTs. 
The NUG industry's unique risk-reward relationship makes these prime candidates for the adoption of innovative technology, but financing barriers (risk aversion of lenders) may inhibit the more rapid adoption of innovative generating technologies. In addition, market and regulatory barriers, such as fuel costs and transmission access in some regions, may limit the ability of innovative technologies to enter these markets and hence make the use of incentives ineffective. Market and regulatory effects must be taken into account by the state PUC when determining the proper incentives and magnitudes of the incentives to encourage the adoption of innovative technologies. 


\section{ANALYSIS OF INCENTIVES TO ADOPT INNOVATIVE TECHNOLOGY BY NONUTILITY POWER GENERATORS}

\subsection{OBJECTIVES}

The objectives of this chapter are twofold. First, the impact of adopting PC/FGD or an IGCC power project on debt payback period and net present value (NPV) will be examined. Second, the ex ante incentive required to encourage the adoption of the innovative technology in the face of innovative technology risks will be analyzed. For modeling purposes, the IGCC is assumed to face two alternative innovative technology risk events. ${ }^{99}$ The first event is an outcome of construction cost risk, where the cost of constructing the project is greater than indicated by EPRI TAG ${ }^{\mathrm{TM}}$ specifications (EPRI 1989). The second event corresponds to operational risks where the forced outage rate (FOR) is increased.

The scenario modeling was accomplished through the use of the Public Utility Planning System (PUPS) model. PUPS is able to generate rate and financial impacts based on alternative technology, regulatory, and financial characteristics.

\subsection{MODELING ASSUMPTIONS}

A coal-burning, baseload IPP project was chosen for this analysis. The IPP's financial data, demand, and energy charges are reflections of a contractual loan agreement with a lending institution and a power purchase agreement with a utility. The two baseload coal scenarios are: (1) a 200-MW pulverized coal-wet limestone FGD (PC/FGD) using 4\% sulfur coal, and (2) a 200-MW IGCC using $4 \%$ sulfur coal. The two risk event scenarios are (1) the IGCC has an increased FOR resulting in a capacity factor of .5 (from .45; IGCC FOR Scenario), and (2) the IGCC construction cost is $15 \%$ greater than baseline construction costs (IGCC Cost Overrun Scenario).

The operational and construction characteristics for the four scenarios are presented in Table 40. The financial and tax assumptions are summarized in Table 41. Environmental considerations are delineated in Table 42.

For the IGCC scenarios, it is assumed that these units are first-generation units as indicated by EPRI TAG ${ }^{\mathrm{TM}}$ (EPRI 1989). As indicated in NES (1991b), through the CCT program, IGCC commercialization will produce declines in construction and operations costs. Presumably, the innovative nature of the technology would imply some joint development by IPP and contractors. Second-generation benefits would then be able to be captured by these groups after experience is gained developing this type of innovative technology.

99 The choice of these innovative technology risks is for illustrative purposes only and does not reflect an increased probability of these particular risk events occurring. 
TABLE 40 Operational and Construction Characteristics (\$ 1992)

\begin{tabular}{|c|c|c|c|c|}
\hline Characteristic & PC/FGD & IGCC & $\begin{array}{c}\text { IGCC- } \\
\text { Cost } \\
\text { Overrun }\end{array}$ & $\begin{array}{c}\text { IGCC- } \\
\text { Forced } \\
\text { Outage } \\
\text { Rate }\end{array}$ \\
\hline Construction cost $(\$ / \mathrm{kW})$ & 1,673 & 1,807 & 2,078 & 1,807 \\
\hline Construction time & 3 years & 3 years & 3 years & 3 years \\
\hline 1st year operational & 1994 & 1994 & 1994 & 1994 \\
\hline Unit capacity (MW) & 200 & 200 & 200 & 200 \\
\hline $\begin{array}{l}\text { Average annual capacity } \\
\text { factor }\end{array}$ & .65 & .65 & .65 & .5 \\
\hline Heat rate $(B t u / k W h)$ & 10,210 & 9,320 & 9,320 & 11,230 \\
\hline Fixed O\&M $(\$ / k W / y r)$ & 44.4 & 52.4 & 52.4 & 52.4 \\
\hline Variable O\&M (\$/MWh) & 7.9 & 3.8 & 3.8 & 3.8 \\
\hline $\begin{array}{l}\text { Demand charge }(\$ / \mathrm{kW} / \mathrm{mo}) \\
\text { (all units) }\end{array}$ & 22.1 & & & \\
\hline $\begin{array}{l}\text { Energy charge ( } \$ / M W h \text { ) (all } \\
\text { units) }\end{array}$ & 7.9 & & & \\
\hline $\begin{array}{l}\text { Coal cost ( } \$ / M M B t u) \text { (all } \\
\text { units) }\end{array}$ & 1.51 & & & \\
\hline
\end{tabular}

Source: EPRI (1989).

Not included in the cost assumptions are the various values and costs of certain by-products such as elemental sulfur and gypsum (South et al. 1990). Also not included are the added costs of ash and sludge disposal. If these factors were considered, the IGCC would have considerable waste disposal cost savings as it produces $40 \%$ less disposal waste than comparable PC/FGD units (South et al. 1990). Another factor that is not addressed in the modeling assumptions is potential delays and additional costs due to siting and permitting difficulties. As indicated in Chapter 6, IPP (and utility) coal projects have tended to have difficulties in obtaining siting and environmental permits. Pulverized coal projects may not include delay costs in the modeling. The IGCC is significantly "cleaner" in terms of $\mathrm{SO}_{2}$ and $\mathrm{NO}_{\mathrm{x}}$ emissions and may find siting and permitting less costly.

For IPP (and QF) projects, the energy charge is. based on the marginal cost of electricity production derived from fuel and variables costs. Based on reality, the IGCC 


\begin{tabular}{lr}
$\begin{array}{l}\text { TABLE } 41 \text { Modeling } \\
\text { Assumptions for Financial } \\
\text { Characteristics }\end{array}$ \\
\hline Inflation rate & $5 \%$ \\
Intere $\downarrow$ rate & $10 \%$ \\
Discount rate & $5 \%$ \\
Federal tax rate & $34 \%$ \\
State tax rate & $6 \%$ \\
Property tax rate & $1 \%$ \\
Equity ( $\%$ of total capital) & $15 \%$ \\
\hline
\end{tabular}

TABLE 42 Modeling Assumptions for Environmental Criteria

\begin{tabular}{|c|c|c|c|c|}
\hline Technology & $\begin{array}{c}\mathrm{SO}_{2} \text { Remuval } \\
\text { Rate } \\
\end{array}$ & $\begin{array}{c}\text { Annual } \mathrm{SO}_{2} \\
\text { Emissions }^{\mathrm{a}} \text { (ton) }\end{array}$ & $\begin{array}{c}\mathrm{NO}_{\mathbf{x}} \begin{array}{l}\text { Emission } \\
\text { Rate }\end{array} \\
\text { (lb/IMMbtu) }\end{array}$ & $\begin{array}{c}\text { Annual } \mathrm{NO}_{\mathrm{x}} \\
\text { Emissions } \\
\text { (ton) }\end{array}$ \\
\hline PC/FGD & c $2 \%$ & 3,813 & $.5^{b}$ & 2,857 \\
\hline \multirow[t]{2}{*}{ IGCC } & $98 \% c$ & 707 & $.27^{\mathrm{d}}$ & $1,061^{\mathrm{e}}$ \\
\hline & $\begin{array}{l}\text { Allowance } \\
\text { cost: } \$ 500\end{array}$ & & & \\
\hline
\end{tabular}

This assumes that the project operates at an average annual capacity factor of .65 .

b The PC/FGD units are assumed to meet new source performance standards and

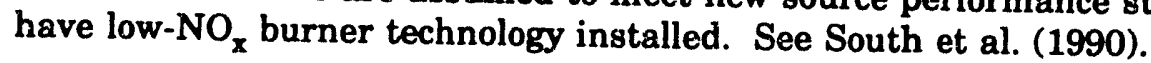

c Note that $\mathrm{IGCC} \mathrm{SO}_{2}$ removal rates range from $95 \%$ to $99.9 \%$. See South et al. (1990).

d See EPRI (1989).

e Note that estimated $\mathrm{NO}_{\mathrm{x}}$ emission rates have been estimated to be as low as 1 ton per MW-yr at a capacity factor of 7 with a heat rate of $9,000 \mathrm{Btu} / \mathrm{kWh}$. The $\mathrm{NO}_{x}$ emission rate would then be $.03624 \mathrm{lb} / \mathrm{MMBtu}$. See South et al. (1990). 
project should have a lower energy charge than the comparable PC/FGD project given that its fuel costs are approximately $10 \%$ lower and its variable costs are approximately 50\% lower. Comparing the PC/FGD and IGCC projects based on these criteria alone, the IGCC project should always win power supply contracts. In order to compare the projects in terms of risk impacts and to demonstrate the potential benefits of adopting an innovative technology, the demand and energy charges for a PC/FGD project were used. While this may seem distortionary, it demonstrates (1) the effect of the innovative technology's lower costs and (2) the impacts of risk events on IGCC present value and payback period when compared to the PC/FGD.

To encourage the adoption of the innovative technology, incentives are offered to overcome the incremental cost of risk. Two ex ante scenarios are addressed. The first assumes that there is a $50 \%$ probability of a $15 \%$ construction cost overrun event; the incentive used to address this risk is cost sharing. Half the cost overrun is absorbed by the IPP; the other half is front-end loaded into the demand charge for the years 1994-1996.

The second ex ante scenario assumes that there is a $20 \%$ probability of a forced outage risk event in which no correction to the outage rate can occur. There is a $40 \%$ probability that increased FOR occurs but can be corrected; additional fixed O\&M expenditures of approximately $.05 \% /$ year for 8 years are required to decrease the FOR. ${ }^{100}$ There is a $40 \%$ probability that no problems will occur with the IGCC. The incentive used to encourage adoption of the IGCC is similar to the contractual incentive used in the Ocean State Power project. The firm is rewarded with a demand charge bonus based on decreasing the FOR.

The chief modeling goals were to compare two alternative technologies under conditions of innovative technology risk and examine the use of ex ante risk analysis in providing incentives for the adoption of an innovative technology. Because of the emphasis on technology risk, risk sharing contractual rewards and penalties were not included in the modeling. The powe $r$ purchase contract between the utility and IPP typically includes several incentives and disincentives centering around availability and performance levels. ${ }^{101}$

\subsection{MODEL RESULTS}

Two financial criteria are used to indicate the impacts of alternative risk events on the IPP project. These include (1) debt payback period measured from the first year of project operation to the year when the project's debt is zero and (2) net present value (NPV) of the project based on an assumed 30-year life. From this analysis, an examination of the energy cost to society can be made based on the alternative projects.

100 This is based on an analysis of forced outage rates, capacity factors, and additional O\&M expenditures completed by Applied Economic Research.

101 See Kahn (1991) for an examination of risk allocation through contractual measures for NUGs. 
Debt payback period is one method used by the financial community as a means of evaluating the acceptability of alternative power projects (other development projects). IPP projects are usually financed using the project finance method (Kahn 1988). With the project finance method, the project has a one time infusion of equity and debt at initiation. After this, the project is essentially on its own with debt payments derived solely from project revenues.

For the IPP equity holders, quicker debt repayment implies a greater period of time in which project earnings can be solely dedicated to the shareholders. Therefore, shorter debt payback periods can infer higher returns to equity holders. For the financial community, debt payback period is a crucial criterion for the provision of project debt. Typical debt payback periods are between 15 and 20 years. Those projects that require longer than 20 years are usually considered too risky for lenders and are usually rejected. ${ }^{102}$ Projects with debt payback periods between 15 and 20 years will be considered preferable to those projects with longer payback periods.

Net present value is a typical method of evaluating the value of alternative projects. The typical project acceptance criterion for this evaluation method is a positive NPV. Under conditions of limited investment assets, the project with the highest NPV will tend to be chosen by the firm. Note that debt payback period is also used to evaluate the choice of projects by the firm, although it tends to be a secondary criterion for investment decisions.

The results of the four base case scenarios (the PC/FGD scenario, the IGCC scenario, the IGCC with $15 \%$ construction cost overrun, and the IGCC with increased FOR) are indicated in Table 43.

TABLE 43 Financial Criteria for Base Case Scenarios

\begin{tabular}{lcc}
\hline \multicolumn{1}{c}{ Scenario } & $\begin{array}{c}\text { Debt payback } \\
\text { period (yr) }\end{array}$ & $\begin{array}{c}\text { Net Prese-t Value } \\
\left(1992 \$ 10^{6},\right. \\
30 \text {-year life) }\end{array}$ \\
\hline $\begin{array}{l}\text { PC/FGD project } \\
\text { IGCC project }\end{array}$ & 16 & 2.21 \\
$\begin{array}{l}\text { IGCC project with 15\% construction } \\
\text { cost overrun }\end{array}$ & 16 & 54.56 \\
$\begin{array}{l}\text { IGCC project with increased forced } \\
\text { outage rate }\end{array}$ & 21 & -78.95 \\
\hline
\end{tabular}

102 According to Mr. Kamyar Jabbari of First Chicago Corporation, IPPs requiring greater than 20 years to complete are usually summarily rejected, although some exceptions have been made. 
Comparing the PC/FGD and IGCC project scenarios, the IGCC project is clearly the preferable choice. The NPV of the IGCC is approximately $\$ 52$ million better than the PC/FGD project. Due to the higher capital cost associated with the IGCC, the debt payback period with the PC/FGD is identical (16 years). While the IGCC has significantly larger capital costs ( $\$ 130 / \mathrm{kW}$ greater), the operating efficiencies compensate for the initially higher capital costs. The largest savings difference between the two projects is fuel savings due to the IGCC lower heat rates and combined cycle properties. ${ }^{103}$ Also, lower variable operating costs and $\mathrm{SO}_{2}$ allowance purchase savings generate greater benefits for the IGCC project.

The risk-event scenarios represent potential problems associated with innovative technologies. One of the most important factors associated with NUG adoption of innovative technology is the high proportion of debt associated with these projects. The greater IGCC capital costs with a $15 \%$ construction cost overrun translate into significantly greater debt and debt payments. Because of the high proportion of debt to equity, the operational cost savings are not large enough to compensate for the higher debt and debt payments. In this scenario, the debt payback period is 21 years and the NPV is $-\$ 78.95$ million. The FOR scenario causes the loss of operational savings and results in worse heat rates (and hence comparatively greater fuel cost per $\mathrm{kWh}$ ) than the PC/FGD. In this case, the greater debt payments and greater operational costs cause the project to have a payback period of 24 years and a NPV of $-\$ 127.43$ million.

When examined on a expected net present value basis, the IGCC may not be the preferred option. For example, assume that there is a .5 probability that the IGCC project will operate according to technical specifications. Also assume that there is a .5 probability that the IGCC will incur a $15 \%$ construction cost overrun. Multiplying the .5 probability by the NPV of the IGCC which operates according to technical specifications and by the NPV of the IGCC project with a 15\% construction cost overrun results in a expected NPV of $-\$ 12.19$ million. If the probability of a $15 \%$ construction cost overrun is .5 , the IGCC project would not be chosen.

In the case of a potential increased forced outage rate, assume there is a .5 probability that the IGCC operates according to technical specification. Also assume there is a .5 probability that the IGCC will have an increased FOR which results in the capacity factor of the unit decreasing from .65 to .5. Multiplying the .5 probability by the NPV of the IGCC, which operates according to technical specifications, and by the NPV of the IGCC project with an increased FOR results in a expected NPV of $-\$ 36.44$ million. Under these conditions, the IPP will again not choose the IGCC project.

To encourage the more rapid adoption and commercialization of innovative technologies and take advantage of the potential benefits associated with innovative technologies, incentives may be required. These incentives should encourage (1) the adoption of the innovative technology either by reducing the risk or rewarding the risk taking and

103 The IGCC generates electricity from both the combustion of the gasified coal and from the waste steam produced by this generation. 
(2) efficient operation. The market and associated power purchase contractual agreements already provide incentives for NUGs to operate in an efficient manner. A NUGs ability to win an RFP with a least-cost bid ${ }^{104}$ demonstrates the project's low price, and due to contractual obligations (energy and demand charges), a price cap is created. The price cap provides the NUG an incentive to operate in the most efficient manner possible in order to generate greater profits. If the NUG fails to operate below the price cap, it pays the penalty in lost profits. Also, the developing and operating companies (they may be the same or different firms) have certain contractual obligations placed on them that cause them to operate with contractually determined construction and operating cost caps. In addition, project failure will reflect unfavorably on these firms resulting in potential penalties in winning RFPs.

Two ex ante incentive scenarios were examined. The first scenario addresses the construction cost overrun risk associated with the innovative IGCC technology. The second scenario addresses the FOR risk associated with the innovative technology.

For the construction cost overrun incentive scenario, it was assumed that the probability of the $15 \%$ cost overrun was .5. If a cost overrun occurred, half of cost of the overrun would be borne by the NUG; the other half would be front-end loaded into the demand charge. Presumably, an incentive would be designed that would split the cost of the overrun based on the level of the cost overrun. For example, a $20 \%$ overrun would only allow $40 \%$ of the overrun to be front-end loaded, and a $10 \%$ overrun would allow $60 \%$ of the overrun to be front-end loaded. This incentive accomplishes two goals. First, it compensates the firm for risk-taking if a cost overrun occurs, and, second, it encourages the firm to minimize construction costs as greater overruns result in more costs being borne by the NUG.

One goal of the incentive is to make the IPP indifferent between the choice of the IGCC and the PC/FGD. It is assumed that the IPP will consider these options equivalent if their expected NPVs are within $+1-25 \%$. Note that the level incentive required to make the IPP indifferent between the choice of the conventional technology and the innovative technology is equal to the ICR.

The incentive used in the case of a construction cost overrun was $50 \%$ front-end loading of the construction cost overrun. It was found that if $\$ 7$ million of the cost overrun was included in the IGCC's charges in 1994, $\$ 7$ million in 1995, and $\$ 5$ million in 1996, the expected NPV of choosing the IGCC (with a .5 probability of a $15 \%$ construction cost overrun) would be perceived equivalent to the PC/FGD's NPV. Assume there is a .5 probability that the IGCC operates according to technical specifications. Assume also there is a .5 probability that the IGCC has a $15 \%$ construction cost overrun, but part of the overrun is front-end loaded into charges as previously indicated. Multiplying the .5 probability by the NPV of the

104 Least cost implies not only a low price but also a variety of other noneconomic factors that make the unit the "best" for utility. 
IGCC, which operates according to technical specifications, and by the NPV of the IGCC project with a $15 \%$ construction cost overrun with the given incentive results in an expected NPV of $\$ 2.93$ million. The NPVs are indicated in Table 44.

With a construction cost overrun of $15 \%$ for the IGCC and assuming the above frontend loading incentive pattern, the NPV of the incentive (in $1992 \$$ ) is $\$ 16.51$ million. ${ }^{105}$

To evaluate the NPV of the savings of these technologies to society, the PC/FGD and IGCC total costs are compared. First, the total cost of the PC/FGD technology is calculated. Total costs include total construction cost, fixed $O \& M$ cost, variable $O \& M$ cost, total fuel cost, and the cost of $\mathrm{SO}_{2}$ allowances over the project's 30-year life. These costs are derived from the technical assumptions in Tables 40,41, and 42. The total cost of the PC/FGD is $\$ 1.59$ billion (1992 \$). For the IGCC project with the potential for a $15 \%$ cost overrun, the total costs are calculated for the IGCC that operates according to technical specification and the IGCC that has a 15\% construction cost overrun. The total costs of the two IGCC outcomes are then averaged. The average or expected total cost (assuming a .5 probability of either event occurring) is $\$ 1.50$ billion (1992 $\$$ ). Adding the cost of the incentive, the expected IGCC cost is $\$ 1.51$ billion (1992 \$). Comparing the total cost of the PC/FGD and IGCC (with the potential for a cost overrun) indicates that the choice of the IGCC will reduce total project costs by approximately $\$ 79$ million (1992 $\$$ ). Note that the cost calculation does not include externality costs.

For the increased forced outage rate scenario, assume that there are three possible states of the world. There is a .4 probability that the IGCC operates according to previously indicated technical specifications, a .2 probability that the forced outage rate risk event occurs and cannot be corrected by increased capital/fixed O\&M expenditures, and a .4 probability that the forced outage rate risk event occurs but can be corrected to the IGCC's

TABLE 44 Construction Cost Overrun Scenario with Incentive

\begin{tabular}{lcc}
\hline & $\begin{array}{c}\text { Debt } \\
\text { Payback } \\
\text { Period } \\
(\text { Scenario })\end{array}$ & $\begin{array}{c}\text { Net Present Value } \\
\left(1992 \$ 10^{6},\right. \\
30 \text {-year life })\end{array}$ \\
\hline $\begin{array}{l}\text { IGCC scenario (no incentive added) } \\
\text { IGCC construction cost overrun } \\
\text { with incentive }\end{array}$ & 16 & 54.56 \\
\begin{tabular}{l} 
Expected value \\
\hline
\end{tabular} & 19 & -48.69 \\
\hline
\end{tabular}

105 Total of annual incentive in 1994-1996 ( $\$ 7$ million, 7 million, and 5 million, respectively) discounted at $5 \%$ to 1992. 
scenario level by increased fixed O\&M expenditures averaging $.05 \%$ over 15 years. ${ }^{106}$ The incentive offered is based on an incentive mechanism similar to that used in the Ocean States Power contract (Kahn 1991). If a threshold level of availability is reached (capacity factor), a yearly demand charge bonus is allowed for every percentage point above a threshold level of availability.

The modeling assumes two levels of performance - performance according to technical specifications (an average annual capacity factor of .65) and reduced availability due to increased forced outage rates (an average annual capacity factor of .5). The modeling assumes no penalty is applied to the increased forced outage rate project, and a reward is given for performance at the level of technical specifications (an average annual capacity factor of .65). In practice, a sliding scale incentive for the demand charge and availability has been used to reward and penalize the NUG based on its level of availability. The demand charge/availability incentive has two interlinked goals. First, the firm is rewarded by adopting and operating an innovative technology in a cost-effective manner, and, second, the firm is encouraged to operate the technology in a prudent and profit-maximizing (cost-minimizing) manner.

The incentive is equal to the increased level of fixed O\&M expenditure needed to restore the IGCC to a capacity factor of .65 . The incentive level required to compensate for the increased FOR is $\$ 8.05$ million (1992 $\$$ ). We assume that in any case where the IGCC has a capacity factor of .65 the incentive is applied. Table 45 indicates the NPVs associated with the IGCC operating according to technical specifications and with the incentive reward, the IGCC with an increased FOR and capacity factor of .5, and the IGCC which initially has an increased FOR, but has the demand charge incentive to increase its capacity factor to .65 .

TABLE 45 Forced Outage Rate Scenarios and Incentives

\begin{tabular}{lcc}
\hline \multicolumn{1}{c}{ Scenario } & $\begin{array}{c}\text { Debt } \\
\text { Payback } \\
\text { Period } \\
\text { (yr) }\end{array}$ & $\begin{array}{c}\text { NPV }\left(1992 \$ 10^{6},\right. \\
\text { 30-year life })\end{array}$ \\
\hline IGCC scenario with incentive & 15 & $\$ 74.42$ \\
IGCC-forced outage rate no correction & 24 & $-\$ 127.43$ \\
IGCC-forced outage rate correction and incentive & 18 & $-\$ 2.03$ \\
Expected value & & $\$ 2.25$ \\
\hline
\end{tabular}

106 Note that these probabilities are for discussion purposes only and do not reflect empirical evidence regarding the probability of various events occurring. The forced outage rate scenario with no probability of correction was chosen to reflect a true worst-case scenario for the NUG developing innovative technology. 
Assume that there is a .4 probability of the IGCC operating according to technical specifications and has the demand charge incentive. Assume a .4 probability of the IGCC having initial FOR difficulties, but with the incentive increase its capacity factor to .65 . Finally, assume a .2 probability that the IGCC has an increased FOR, but there is no chance to correct the difficulties. Multiplying these probabilities by the NPVs indicated in Table 45, the expected NPV of the IGCC is $\$ 2.25$ million (1992).

To evaluate the NPV of the benefits of these technologies, compare the total costs of PC/FGD and IGCC. First, the total cost of the PC/FGD technology is calculated. This includes total construction cost, fixed $O \& M$ cost, variable $O \& M$ cost, total fuel cost, and the cost of $\mathrm{SO}_{2}$ allowances over the project's 30-year life. These costs are derived from the technical assumptions in Tables 40,41 , and 42 . The total cost of the PC/FGD is $\$ 1.59$ billion (1992 \$). For the IGCC project with the potential for an increased forced outage rate, the total costs are calculated for the IGCC that operates according to technical specification and has the demand charge incentive, for the IGCC that has uncorrectable forced outage rates, and for the IGCC that initially has an increased forced outage rate but is able to correct the problem and is aided by a demand charge incentive. The total costs for each of these IGCC scenarios are then calculated, including the incentive costs, total construction cost, fixed O\&M cost, variable O\&M cost, total fuel cost, and the cost of $\mathrm{SO}_{2}$ allowances over the project's 30-year life. Given that the actual cost outcome is uncertain for the IGCC (i.e., there is the potential for an increased FOR), the expected costs are calculated by assuming there is a .4 probability of the IGCC operating according to technical specifications, a .4 probability of the IGCC having initial FOR difficulties, but with the incentive increase its capacity factor to .65 and a .2 probability that the IGCC has an increased FOR, but there is no chance to correct the difficulties. The expected cost of the IGCC is $\$ 1.56$ billion (1992 $\$$ ). The expected savings difference between the PC/FGD and IGCC is approximately $\$ 33$ million (1992 $\$$ ).

\subsection{CONCLUSION}

Ex ante incentive analysis was used to estimate the incentive level required to make the NUG indifferent between adopting a conventional technology and an innovative technology. In the case of NUG incentives, the incentive provider may be either the ratepayers that subsidize the purchasing utility with the ex ante incentive required to encourage the NUG to adopt an innovative technology or the utility-NUG contractual relationship.

The utility may provide the incentive for the following reasons: (1) the NUG is an affiliate or the utility has partial equity owner ${ }^{107}$; (2) the utility is able share the technical "knowledge" generated by NUG construction; or (3) through contractual arrangement, an incentive is offered to reward or mitigate risk in exchange for lower energy/demand charges or other considerations. The use of incentives to encourage adoption of precommercialized,

107 Affiliate transactions may be extremely limited and severely examined by the relevant regulatory bodies. 
innovative technology does provide ratepayers and society with significant benefits. The acceleration of innovative technology adoption not only reduces generation-related costs to society but also provides positive "learning" externalities (further reducing the cost of energy generation) and significant environmental benefits in terms of reduced air, water, and solid waste emissions.

Given that NUGs are predicted to provide up to $50 \%$ of the nation's new electricity generation and in the interest of creating a level playing field between utility and NUG power generation, it is important for incentives to be considered for NUG adoption of innovative technology. 


\section{SUMMARY AND CONCLUSION}

Commercialization of innovative technologies in the electricity generating industry is slowed because of risks inherent with new technology, which, in turn, creates regulatory and financial risks. The possible risks for adopting innovative technologies include:

- construction risk

- operational risk

- environmental risk

- technological risk

- regulatory risk

- economic and financial risk.

In addition, a "free rider" problem exists with the information generated from the commercialization of new technologies. The developer may not be able to capture all the benefits of the technology, but it must bear all of the costs and risks. This fact creates a disincentive for companies to adopt innovative technology and encourages the potential developer to wait until others commercialize the technology.

From a policy perspective, if the generating technologies currently in a precommercialization stage were more rapidly commercialized, several national energy policy goals could be achieved (e.g., lower pollution emissions, lower long-run electricity prices, greater use of low-cost domestic energy resources, and lower imports of foreign energy). Given the market failure problems of free riders and uninsurable risks, policy intervention may be justified (i.e., through regulatory incentives for adopting innovative technologies).

To evaluate the types and magnitudes of incentives required to encourage the adoption of innovative technologies, the opportunity cost of espousing the risk must be examined. Risk analysis has two stages: first, the probability of an event occurring must be examined, and, second, the probability of that event's varying consequences must be investigated. Summing the joint or independent probabilities of several events occurring, weighted by the probability of each event's consequences, produces an ex ante expectation of the costs. The difference between an ex ante opportunity cost measure of adopting an innovative technology and the expected cost of the conventional technology is the incremental cost of innovative risk. Theoretically, an incentive of this magnitude is required to equate the expected costs of the options so that a planner (power generation, regulatory or government) would be indifferent between the two options. However, matching the incremental cost of innovative risk to an incentive of like magnitude does not readily lend itself to practical policy making. Incentives for the adoption of risk have two facets. 
The first problem concerns the development of an incentive that can adequately negate the additional risk and uncertainty of adopting an innovative technology. Whether the market is characterized as competitive or regulated, negative externalities (for example, your competitors gain knowledge from your actions) create barriers to the commercialization of new technologies. When these externalities are added to the uncertainties associated with construction costs, reliability characteristics, and operating costs, a significant hurdle must be overcome to encourage managers to adopt an innovative technology.

The second problem concerns providing the developer/operator of the project an incentive to construct and operate the technology as cost effectively as possible. Most regulatory agencies have focused their attention in this area. Specific mechanisms have been designed, including tying rewards and penalties to unit reliability or using price caps to provide firms with an incentive to reduce costs and obtain short-run profits.

The size and type of the incentive necessary to induce a utility or NUG to adopt an innovative technology depend on a number of variables, and each state commission will need to examine the range of uncertainties and opportunity costs that pertain to the technology and conditions (financial, operational, and technical) facing the firm making the choice. No single rule can be applied; incentives are, in a certain sense, idiosyncratic and must be tailored to the special circumstances. Also, utilities and NUGs face fundamentally different operating and financial conditions. Commissions could develop a range of incentive options and allow the utility or NUG to select the single option that offsets their perceived risks most directly.

Ex ante risk analysis provides estimates of excepted costs for the relatively information-starved policymakers. With these estimates, and an examination of the menu of incentives offered, the policymaker can make reasonable decisions regarding the potential magnitude and effectiveness of an incentive.

The cost of the incentive does not necessarily need to be burdensome on society to encourage adoption of innovative technology. Consumers are not faced with the need to subsidize large numbers of plants to deploy a technology. No more than five examples of a technology are required to develop accurate knowledge of the costs and operating characteristics of a technology (Figure 2). Therefore, incentive programs are inherently of a limited nature and associated with a few projects.

When combined with incentives to ensure that the plant is constructed in a least-cost fashion, the consumers' risk in any single utility's jurisdiction is limited. In certain cases, utilities and NUGs could adopt or request incentives that have the potential to leave the ultimate costs paid by customers unaffected. For example, commissions could approve a prospective guaranteed cap on construction costs that would be included in the rate base of the project if it is abandoned. The guarantee may reduce the perceived risks of undertaking the project for the developer and financiers. The cap would also mean that customers would not pay more than a certain amount for the project. A symmetrical incentive could potentially lower the ultimate costs if the financial community perceived this incentive in a positive (or less risky) light and reduced the cost of capital facing the utility or NUG. 
As stated previously, recognition of the idiosyncratic nature of incentives is also necessary for their success. Beyond purely regional concerns regarding access to fuel, siting, transmission, capacity, and environmental operations, NUGs and utilities have fundamentally different natures. Certain barriers faced by NUGs may make an incentive easily applicable to a utility, but impossible for a NUG project. Survey and preference revealing mechanisms should be important tools used by the policymaker to determine which incentives may be effective.

An important example of such a difference between NUGs and utilities deals with the way utility and NUG projects are financed. NUG capital financing is largely debt driven $(80 \%+)$, so NUG projects depend heavily on loans from the banking industry. Many lending institutions refuse to lend to projects that involve precommercialized technologies, which in turn leads to fewer NUGs developing innovative technologies. Assured loans or guarantees combined with incentives for operation performance could be used to overcome this problem.

Several technology scenarios were examined for both the utility and NUGs in order to compare the effect of alternative CCTs with construction and operational risks and a conventional coal technology option on ratepayers and shareholders. Regulatory incentives were applied to those cases were a technology "failure" occurred for the innovative technology. In the utility modeling, the potential risks included a $20 \%$ construction cost overrun and an increased forced outage rate for the first PFBC units built. After the first-generation PFBC units are built, it is assumed that second-generation PFBC units are available that have lower capital costs and improved operational characteristics. The incentives used were of the sliding scale variety. In the case of the cost overrun, a cost sharing mechanism was designed. Through the use of this incentive, the firm would not bear the total impact of a construction cost overrun, reducing the risk of adopting the technology, but still have an incentive to minimize costs as the shareholders bear some of the burden of overrun.

In the case of an increased forced outage rate, the firm receives a $\mathrm{kWh}$ incentive for reducing the forced outage rate. The firm is compensated for additional O\&M expenditures, thus encouraging the firm to operate in the most efficient manner possible and reducing the risk of adopting the innovative technology. The general results of the modeling imply that the adoption of innovative PFBC technology increases rates and reduces cash flows in the early years of the scenarios as compared with the use of conventional coal options. In the long term, however, even with the additional costs of incentives and greater risks, ratepayers and shareholders receive significant benefits. The ex ante method of determining the incremental cost of risk was calculated for a hypothetical situation.

The NUG model examined incentives from the position of a potential lender and from the position of the NUG owner. Two key criteria were examined: payback period and the net present value of the project. Payback period is a critical factor for a lender's evaluation of a project's viability. Lenders typically reject payback periods longer than $15-20$ years. Net present value is a typical method used to evaluate the value of a project to a firm.

The risks for the adoption of an IGCC project instead of the conventional PC/FGD unit include (1) a construction cost overrun of $15 \%$ and (2) an increased forced outage rate. 
The goals are a payback period within the optimal time frame (15-20 years) and discounted cash flows equal to or above the PC-FGD. The incentives used to reduce the risks of adopting the technology and encourage efficient behavior are similar, but not identical to those used in the utility modeling. In the case of a construction cost overrun, a sliding scale mechanism was used to share the construction cost overrun, but the overrun was front end loaded into the demand charge. In the case of an increased forced outage rate, a sliding scale mechanism was used whereby the reduction in the forced outage rate was rewarded by an increase in the demand charge, a mechanism similar to that used in the Ocean States power contract. Even with the additional cost of an incentive (to make the firm indifferent between the choice of innovative and conventional options) and added risks, society receives greater benefits from the adoption of the IGCC technology.

With ex ante cost analysis, information on both the qualitative and quantitative characteristics of a region and industry type, the menu of incentives indicated in Section 4, and ability to analyze the financial effects of a variety of incentives (or provide the firm with the choice of incentive along with some bargaining or "magnitude" revaluation mechanism) the policymaker can provide rationally determined incentives to increase public welfare. 


\section{REFERENCES}

Averch, H., and L. Johnson, 1962, "Behavior of the Firm under Regulatory Constraint," American Economic Review, 52:1052-1069.

Bailey, K.A., et al., 1991, "Clean Coal Technology and Emissions Trading: Is There a Future for High-Sulfur Coal under the Clean Air Act Amendments of 1990?," presented at the 4th International Conference on Processing and Utilization of High Sulfur Coals, Idaho Falls, Idaho, Aug.

Bailey, K.A., et al., 1993, unpublished information, Argonne National Laboratory, Argonne, Ill.

Barakat \& Chamberlain, Inc., 1990, Least-Cost Planning in the United States, EPRI CU-6966, Electric Power Research Institute, Palo Alto, Calif., Sept.

Baumol, W., 1982, Productivity Incentive Clauses and Rate Adjustment for Inflation," Public Utilities Fortnightly 110(2):11-18.

Berkman, M., 1992, Incorporating Environmental Externalities into Resource Planning, Proceedings of the Electric Utility and the Environment Conference, Chicago, Ill., Sept.

Bierman, H., 1984, "We Cannot Measure the Cost of Equity Capital Exactly," Public Utilities Fortnightly 114(4):31-35.

Blake, C., et al., 1976, Analysis of Projected vs. Actual Costs for Nuclear and Coal-Fired Plants, The Mitre Corporation, Fairfax, Va.

Brooks, L., and R. D'Sourza, 1982, "Electric Utility Returns and Risk in the Light of the Three Mile Island," Public Utilities Fortnightly 110(10):26-32.

Brown, L., et al., 1989, Incentive Regulation: A Research Report, report 89-3, Office of Economic Policy, Federal Energy Regulatory Commission, Washington, D.C., Nov.

Brown, L., et al., 1991, "Toward Improved and Practical Incentive Regulation," Journal of Regulatory Economics, 3:323-338.

Brown, Williams, Quinn and Chinn, Inc., 1991, An Overview of Incentive Ratemaking Mechanisms: Application to Interstate Natural Gas Pipelines, Washington, D.C.

Bundwani, R.N., 1982, "Power Plant Scheduling, Construction and Costs: 10-Year Analysis," Power Engineering 86(8):36-49.

California Public Utility Commission, 1991, Decision 91-06-022, June.

Chandy, P., and W. Dukes, 1985, "Regulatory Lag: Another Risk for Public Utilities," Review of Business and Economic Research 21(1). 
Clemmons, W., 1988, "Canceled Plant Costs: Will the Supreme Court Allow Recovery?," Public Utilities Fortnightly 122(7):45-4'7.

Coase, R.N., 1937, "The Nature of the Firm," Economica 4:386-405.

Cohen, S.D., et al., 1990, A Survey of State PUC Activities to Incorporate Environmental Activities into Electric Utility Planriing and Regulation, LBL-28616, Lawrence Berkeley Laboratory, Berkeley, Calif., May.

Costello, K.W, and S.B. Cho, 1984, Incentive Regulation: Issues and Recommendation for Illinois, Iowa State Regulatory Conference, May.

Costello, K.W., and S.B. Cho, 1991, A Review of FERC's Technical Reports on Incentive Regulation, NRRI 91-9, National Regulatory Research Institute, Columbus, Ohio, May.

Cowan, R., 1991, "Tortoises and Hares: Choice among Technologies of Unknown Merit," Economic Journal 101(407):801-814, July.

Crawfis, M., 1982, "A New Approach to Allocating Financial Responsibility for Canceled Nuclear Units: Consumers' Council vs. Public Utility Commission of Ohio," University of Toledo Law Review 13.

Crew, M., and P. Kleindorfer, 1987, "Productivity Incentives and Rate of Return Regulation," in Regulating Utilities in an Era of Deregulation, M. Crew (editor), St. Martin's Press, New York, N.Y.

Department of Public Utilities, 1988, Pricing and Ratemaking Treatment for New Electric Generation Facilities Which Are Not Qualifying Facilities, D.P.U. 86-36-C, Massachusetts Department of Public Utilities and Ocean States Power, May 12.

Dickerson, P., and J. Giglierano, 1986, "Missing the Boat and Sinking the Boat: A Conceptual Model of Entrepreneurial Risk," Journal of Marketing 50:58-69, July.

DOE, 1978, Steam Electric Plant Construction Costs and Annual Production Expenses, DOE/EIA-0033(78), U.S. Department of Energy, Energy Information Administration, Washington, D.C., Dec.

DOE, 1982, U.S. Commercial Nuclear Power, DOE/EIA-0315, U.S. Department of Energy, Energy Information Administration, Washington, D.C.

DOE, 1983, Nuclear Plant Cancellations: Causes, Costs and Consequences, DOE/EIA-0392, U.S. Department of Energy, Energy Information Administration, Washington, D.C., April.

DOE, 1984, Investor Perceptions of Nuclear Power, DOE/EIA-0466, U.S. Department of Energy, Energy Information Administration, Washington, D.C., May. 
DOE, 1989, Report to the Secretary of Energy Concerning Commercialization Incentives, DOE/EH-0083, U.S. Department of Energy, Washington, D.C., Jan.

DOE, 1991a, Analysis of Options to Amend the Public Utility Holding Company Art of 1935, Technical Annex 1, DOE/S-0084P, U.S. Department of Energy, Washington, D.C.

DOE, 1991b, Electricity Transmission Access, Technical Annex 3, DOE/S-0085P, U.S. Department of Energy, Washington, D.C.

DOE, 1991c, Clean Coal Technology Demonstration Program, DOE/FE-0219P, U.S. Department of Energy, Washington, D.C., Feb.

DOE, 1992, Clean Coal Technology Demonstration Program, Program Update 1991, DOE/FE-0247P, U.S. Department of Energy, Washington, D.C., Feb.

EIA, 1978, Steam-Electric Plant Operation and Design Report, DOE/EIA-0474, U.S. Department of Energy, Energy Information Administration, Washington, D.C.

EEI, 1986, Statistical Yearbook of the Electric Industry: 1982, Edison Electric Institute, Washington, D.C.

EEI, 1991, The Operation of Electric Utility Systems: An Overview, position paper, Edison Electric Institute, Washington, D.C.

Electric Perspectives, 1991, "Electric Utilities Remain Most Capital Intensive Industry," 15(5):56.

Electric Utility Week, 1990, "Virginia: Independents Must Absorb 'Unexpected Environmental Costs'," pp. 8-9, Dec. 24.

EPRI, 1982, Models for Investment and Disinvestment Decision Making Uncertainty, EPRI-EA-2204, Electric Power Research Institute, Palo Alto, Calif., Jan.

EPRI, 1986, TAG - Technical Assessment Guide Volume 1: Electricity Supply - 1986, P-4463-SR, Electric Power Research Institute, Palo Alto, Calif., Dec.

EPRI, 1989, TAG TM Technical Assessment Guide, Electricity Supply - 1989, EPRI P-6587-L, Electric Power Research Institute, Palo Alto, Calif., Sept.

ERG, 1991, Environmental Externalities: An Issue in Need of Critical Review, Energy Research Group, Inc., Waltham, Mass., for Edison Electric Institute, Washington, D.C., July.

Evetts, G., 1922, The Administration and Finance of Gas Undertakings, Bonn Brothers, Ltd., London.

FERC, 1979, Determination of Incentive Rate or Return, Tariff and Related Issues, Order No. 31, Federal Energy Regulatory Commission, Washington, D.C., June. 
FERC, 1989, Incentive Regulation for Natural Gas Pipelines: A Specific Proposal for Options, 89-1, Federal Energy Regulatory Commission, Washington, D.C., Sept.

Fitzpatrick, D., 1982, "Does the Negative Risk Premium Really Exist," Public Utility Fortnightly 110(1):27-33.

Flaim, S.J., et al., 1989, A Review of Innovation and Diffusion Theories: Implications of the Potential Adoption of Clean Coal Technologies, ANL/EAIS/TM-14, Argonne National Laboratory, Argonne, Ill., Feb.

FrC, 1977, Report to the Federal Trade Commission on the Use of Automatic Fuel Adjustment Clauses and the Fuel Procurement Practices of Investor Owned Utilities, Federal Trade Commission, Bureau of Competition and Bureau of Economics, Washington, D.C., May.

Gale, W., 1982, "Price Index Components for Utility Rate Adjustment," Public Utilities Fortnightly 109(8):33-38.

Glassman, G., 1978, "Discounted Cash Flow versus the Capital Asset Pricing Model (is g Better than b)," Public Utilities Fortnightly 102(6):30-34.

Gort, W., and R. Wall, 1988, "Foresight and Public Utility Regulation," Journal of Political Economy 96(1):177-188.

Grahame, T., 1991, Direct Testimony before the Massachusetts Department of Public Utilities, DPU 91-131, Oct; also Grahame, T., 1991, Second Round of Testimony before the Massachusetts Department of Public Utilities, DPU 91-131, Dec.

Hagerman, R.L., 1976, "Finance Theory in Rate Hearings," Financial Management 5(1):18-22.

Haman-Guild, R., and J.L. Pfeffer, 1987, "Competitive Bidding for New Electric Power Supplies: Deregulation or Regulation," Public Utilities Fortnightly 120(6):9-20.

Hamrin, J., et al., 1987, Pricing New Generation of Electric Power: A Report on Bidding, National Independent Power Producers, Sept.

Harrington, D., 1981, "Trends in Capital Asset Pricing Model Use," Public Utilities Fortnightly 108(4):27-30.

Hass, J., 1984, "Incentive Systems for Large-Scale Energy Projects," Energy Systems and Policy 8(4):395-431.

Hirshleifer, J., and J. Riley, 1979, "The Analytics of Uncertainty and Information: An Expository Survey," Journal of Economic Literature, 17(4):1375-1421, Dec.

Holthausen, D., 1979, "A Model of Incentive Regulation," Journal of Public Economics 12(1):61-73. 
ICC, 1979, Report to the Governor and General Assembly on the Feasibility of Adopting a Uniform Fuel and Purchase Gas Adjustment Clause, Illinois Commerce Commission, Jan.

ICTAP, 1989, Report to the Secretary of Energy Concerning Commercialization Incentives, DOE/EH-0083, U.S. Department of Energy, Washington, D.C., Jan.

Inhaber, H., 1991, "A Market-based Solution to the Problem of Nuclear and Toxic Waste Disposal," Journal of Air and Waste Management 41(6):808-816.

Jabbari, K, and R.G. Bussa, 1992, Are Ratepayers Benefiting from Independent Power Production? An Examination of the Prevailing Assumptions, presented at Chicago Energy Economists, Chicago, Ill., Jan.

Johnson, L.L., 1985, Incentives to Improve Electric Utility Performance, R-3245-RC, Rand Corporation, March.

Joskow, P.L., 1987, Competition and Deregulation in the Electric Utility Industry, discussion paper, MIT Center for Energy Policy Research Policy, Cambridge, Mass., May.

Joskow, P.L., and R. Schmalensee, 1986, "Incentive Regulation for Electric Utilities," Yale Journal of Regulation 4(1):1-49.

Kahn, E., 1991, Risk Allocation in Independent Power Contracts, LBL-30065, Lawrence Berkeley Laboratory, Berkeley, Calif., April.

Kahn, E., and S. Stoft, 1989, Designing a Performance Based Cost-Sharing System for the Clean Coal Technology Program, LBL-38057, Lawrence Berkeley Laboratory, Berkeley, Calif., Sept.

Kahn, E.P., 1988, Electric Utility Planning and Regulation, American Council for an Energy-Efficient Economy, Washington, D.C.

Kahn, E.P., et al., 1989, Evaluation Methods in Competitive Bidding for Electric Power, LBL-26924, Lawrence Berkeley Laboratory, Berkeley, Calif., June.

Kahneman, D., and A. Tversky, 1979, "Prospect Theory: An Analysis of Decision under Risk," Econometrica 47(2):263-291.

Kaplan, R., 1982, Advanced Managerial Accounting, Prentice-Hall, Englewood Cliffs, N.J.

Kaufman, A., and R. Profazich, 1979, The New Mexico Cost of Service Index: An Effort in Regulatory Innovation, National Regulatory Research Institute, Columbus, Ohio.

Keynes, J.M., 1937, "The General Theory of Employment," Quarterly Journal of Economics 51, p. 214-215.

Kidder, Peabody \& Company, 1982, Electric Utility Generating Equipment: Status Report on Fossil Boilers, 1974-1981. 
Kiefer, D., 1979, Accelerated Depreciation and the Investment Tax Credit in the Public Utility Industry: A Background Analysis, occasional paper no. 1, National Regulatory Research Institute, Columbus, Ohio, April.

Kjellerup, D., 1984, "Total Factor Productivity from the Consumer's Perspective," Public Utilities Fortnightly 113(4):20-23.

Kjellerup, D., 1985, "Total Factor Productivity from the Management's Perspective," Public Utilities Fortnightly 116(4):20-24.

Kjellerup, D., 1988, "Total Factor Productivity from a Proponent's Perspective," Public Utilities Fortnightly 122(13):32-36.

Knight, F., 1921, Risk Uncertainty and Profit, University of Chicago, Chicago, $\mathrm{nl}$.

Koble, A., et al., 1984, The Cost of Capital: Estimating the Rate of Return of Public Utilities, MIT Press, Cambridge, Mass.

Kooney, J., 1990, Comparative Analysis of Monetary Estimates of External Environmental Costs Associated with Combustion of Fossil Fuels, LBL-28313, Lawrence Berkeley Laboratory, Berkeley, Calif., July.

Lambert, R., 1986, "Executive Effort and Selection of Risky Projects," Business Review 17(1):77-88.

Laros, M., and S. Houbold, 1987, "The Shifting Standard of Prudence: Implications for Utilities," Public Utilities Fortnightly 120(9):21-27.

Lazo, S., 1988, "Risk Assessment Applied to Future Electric Supply Capacity," Public Utilities Fortnightly 122(7):20-26.

Loeb, A.P., and T.J. Elliott, 1993, "The Impact of Recent Visibility Litigation on Siting/Modifying New Power Plants: Survey and Analysis," presented at the Conference on Improved Technology for Fossil Power Plants - New and Retrofit Applications, sponsored by the Electric Power Research Institute, Washington, D.C., March 2.

Loomes, G., and R. Sugden, 1982, "Regret Theory: An Alternative Theory of Rational Choice under Uncertainty," Economic Journal 92:805-824.

Lowry, M.N., 1991, "The Case for Indexed Price Caps for U.S. Electric Utilities," The Electricity Journal 30-34, Oct.

Lyon, T.P., 1991, "Incentive Regulation for Electric Utilities: Learning from Telecommunications and Natural Gas," presented at a conference on the Future of Incentive Regulation in the Electric Utility Industry, co-sponsored by The School of Public and Environmental Affairs of Indiana University and PSI Energy, Indianapolis, Ind., Nov. 
Machina, M., 1987, "Choice under Uncertainty: Problems Solved and Unsolved," Journal of Economic Perspectives 1(1).

Magat, W.A., 1976, "Regulation and the Rate and Direction of Induced Technical Change," Bell Journal of Economics 7(2):478-496.

Markham, J., 1988, "The Risk-Sharing Strawman," Public Utilities Fortnightly 122(1):24-27.

Marks, G., and D. Von Winterfeldt, "Not in My Back Yard: Influence of Motivational Concerns on Judgments about a Risky Technology," Journal of Applied Psychology 69(3)408-415.

Massela, I., 1981, "Recouping Abandoned Construction Losses," Public Utilities Fortnightly 107(5):60-64.

McDermott, K, 1980a, Review of Existing Incentive Mechanisms, report to U.S. DOE, cooperative agreement no. DE-FC01-10249, Illinois Commerce Commission Policy Analysis and Research Division, April.

McDermott, K., 1980b, Evaluation and Choice of Incentive Mechanisms, report to U.S. DOE, cooperative agreement no. DE-FC01-10249, Illinois Commerce Commission Policy Analysis and Research Division, Aug.

McDermott, K. 1981, The Choice of an Incentive Mechanism, report to U.S. DOE, cooperative agreement no. DE-FC01-10249, Illinois Commerce Commission Policy Analysis and Research Division, May.

McDermott, K., 1984, The Review of Existing Power Plant Certificates, Monitoring of Power Plant Costs and the Allocation of Power Plant Cancellation Costs, presented to Sunset Task Force on Utility Regulatory Reform, Illinois Department of Energy and Natural Resources, Jan.

McDermott, KA., and D.W. South, 1991, To Mitigate or Not to Mitigate: Regulatory Treatment of Emissions Trading Decisions and Its Effect on Marketplace Incentives, presented at 84th Annual Meeting and Exhibition, Air and Waste Management Association, Vancouver, British Columbia, June.

Meade, W.R., 1987, "Competitive Bidding and the Regulatory Balancing Act," Public Utilities Fortnightly 120(6):22-30.

Merron, E., et al., 1981, Understanding Cost Growth and Performance Short-falls in Pioneer Process Plants, report R-2569-DOE, The Rand Corporation, Sept.

Michigan PSC, 1993, The Michigan Public Service Commission Staff Report on Detroit Edison Company's Integrated Resource Plan.

Mortan, W., 1970, "Guides to a Fair Return," Public Utilities Fortnightly. 
Myers, S., 1972, "Application to Finance Theory to Public Utility Rate Cases," Bell Journal of Economics 3(1).

Nagelhout, M., 1988, "State Regulatory Concerns in Ratebase Phase-ins," Public Utilities Fortnightly 122(6):63-68.

NARUC, 1991, Renewable Energy and Utility Regulation, report to the Committee on Energy Conservation, National Association of Regulatory Utility Commissioners, Subcommittee on Renewable Energy, April 10.

NERA, 1991, Incentive Regulation in the Electric Utility Industry, National Economic Research Associates, Inc.

NERC, 1988, 1988 Electric Power Supply \& Demand for 1988-1997, North America Electric Reliability Council.

NERC, 1991, 1991 Electricity Supply \& Demand for 1991-2000, North America Electric Reliability Council.

NES, 1991a, Analysis of Options to Amend the Public Utility Holding Company Act of 1935, Technical Annex 1, DOE/S-0084P, U.S. Department of Energy, Washington, D.C.

NES, 1991b, Integrated Analysis Supporting the National Energy Strategy: Methodology, Assumptions and Results, Annex 2, U.S. Department of Energy, Washington, D.C.

NIEP, 1991, Competing for Power, National Independent Energy Producers.

Nieves, L.A., et al., 1990, Identification and Estimation of Socioeconomic Impacts Resulting from Perceived Risks and Changing Images: An Annotated Bibliography, ANL/EAIS/TM-24, Argonne National Laboratory, Argonne, Ill., Feb.

Nolan, P.V., 1981, "Incentive Rates of Return," Public Utility Fortnightly 108(3):50-53.

OTA, 1991, Energy Technology Choices: Shaping our Future, OTA-E-439, U.S. Congress, Office of Technology Assessment, Washington, D.C., July.

Ottinger, R.L., et al., 1990, Environmental Costs of Electricity, Oceana, N.Y.

Palmer, K., and H. Dowlatabadi, 1991, Implementing Environmental Costing in the Electric Utility Industry, discussion paper QE91-13-REV, Resources for the Future, Quality of the Environment Division, Washington, D.C., May.

Phelps, G., 1976, "A Different Approach to the Fair Rate of Return," Public Ittilities Fortnightly 98(4):26-30.

Pierce, R., 1984, "Regulatory Treatment of Mistakes in Retrospect: Canceled Plants and Excess Capacity," University of Pennsylvania Law Review 132:497-560. 
Plummer, J., and S. Troppmann, 1990, Competition in Electricity, Public Utilities Reports and QED Research, Inc., Arlington, Va.

Posner, R.A., 1969, "The Natural Monopoly and Its Regulation," Stanford Law Review 21(548).

Public Utility Holding Company Act of 1935, 49 Stat. 803.

Raffiee, K., and J. Wendel, 1988, "The Effects of Aiternative Regulatory Policies on Utility Investment Strategies," Southern Economic Journal 47:840-854.

Rappaport, A., 1978, "Executive Incentives vs. Corporate Growth," Harvard Business Review 57(4):81-88.

Roll, R., and S. Ross, 1983, "Regulation, the Capital Asset Pricing Model, and the Arbitrage Pricing Theory," Public Utilities Fortnightly 111(1):22-28.

Rose, K, et al., 1991, Implementing a Competitive Bidding Program for Electric Power Supply, National Regulatory Research Institute, Columbus, Ohio, Jan.

Rosenberg, N., 1982, Inside the Black Box: Technology and Economics, Cambridge University Press.

Rozek, R.P., 1989, "Competitive Bidding in Electricity Markets: A Survey," The Energy Journal 10(4):117-138.

Schick, F., 1984, Having Reasons: An Essay on Rationality and Sociality, Princeton University Press, Princeton, N.J.

Schleifer, A., 1985, "A Theory of Yardstick Competition," Rand Journal of Economics 16(3):319-327.

Seagraves, J., 1984, "Regulating Utilities with Efficiency Incentives," Public Utilities Fortnightly 113(1):18-23.

Selvidge, J., 1975, "A Three-Step Procedure for Assigning Probabilities to Rare Events" in Utility, Probability, and Human Decision Making, Wendt and Vlek (editors), D. Reidel Publishing Company, Dordrecht-Holland, pp. 199-216.

Sharkey, William W., 1984, The Theory of Natural Monopoly, Cambridge University Press. Shoemaker, P., 1982, "The Expected Utility Model: Its Variance, Purposes, Evidence and Limitations," Journal of Economic Literature 20, June.

Simon, H.A. 1957, Models of Man, Wiley: New York, N.Y. 
Singh, J., et al., 1980, Impact of Government Regulations on Lead Tines of Coal Facilities, Policy Planning and Evaluation, Inc., prepared for the Energy Information Administration, U.S. Department of Energy, Washington D.C.

Smith, D.J., 1990, "Non-Utility Power Producers Face Clean Air Challenge," Power Engineering, Sept.

Smith, V.K., 1974, "The Implications of Regulation for Induced Technical Change," Bell Journal 5(2):623-632, autumn.

Smith, V.K, and W. Desvousges, 1988, "The Valuation of Environmental Risks and Hazardous Waste Policy," Land Economics 64(211).

Sommers, P., 1980, "The Adoption of Nuclear Power Generation," Bell Journal of Economics, 11(1):283-291.

South, D.W., et al., 1990, "Technologies and Other Measures for Controlling Emissions: Performance, Cost and Applicability," NAPAP SOS/T-25, in National Acid Precipitation Assessment Program, Acidic Deposition: State of Science and Technology, Volume IV, Washington, D.C., Dec.

South, D.W., et al., 1991, "Incentive Mechanisms as a Strategic Option for Acid Rain Compliance," presented at the Conference on the Future of Incentive Regulation in the Electric Utility Industry, Public Service of Indiana and Indiana University, Indianapolis, Ind., Nov.

Sponseller, D., 1985, "Ratebase Phase-in Plans for Electric Utilities - A Case Update," Public Utilities Fortnightly 116(2):51-54.

Stick, R., 1970, "'K' is Not the Cost of Capital," Public Utilities Fortnightly 117(7):29-34.

Strategic Decisions Group, 1989, Bidding for Electric Resources: An Industry Review of Competitive Bid Design and Evaluation, EPRI CU-6089, Electric Power Research Institute, Palo Alto, Calif., May.

Stutz, J., 1986, "Risk Sharing in a Regulated Industry," Public Utilities Fortnightly 117(7):29-34, April 3.

Sugden, R., 1991, "Rational Choice: A Survey of Contributions from Economics and Philosophy," Economic Journal 101(407):751-785, July.

Sweeney, G., 1981, "Adoption of Cost-Saving Innovations by a Regulated Firm," American Economic Review 71(3):437-447.

Swenk, C., 1988, "The Cognitive Perspective on Strategic Decision Making," Journal of Management Studies 25(1):41-55. 
Temple, Barker \& Sloane, Inc., 1991, Environmental Exiernalities: An Overview of Theory and Practice, EPRI CU/EN-7294, Electric Power Research Institute, Palo Alto, Calif., May.

Trebing, H.M., 1963, "Toward an Incentive System of Regulations," Public Utilities Fortnightly 72(2):22-37.

Tversky A., and D. Kahneman, 1982, Judgment under Uncertainty: Heuristics and Bias, Cambridge University Press.

Vandell, R., and T. Malernee, 1982, "The Capital Asset Pricing Model and Utility Equity Returns," Public Utilities Fortnightly 102(1):22-29.

VanKuiken, J.C., 1983, An Efficient Simulation Approach for Evaluating the Potential Effects of Nuclear Power Plan Shutdowns on Electrical Utility Generating Systems, ANL/EES-TM-233, Argonne National Laboratory, Argonne, Ill., June.

Veselka, T.D., et al., 1990, Introduction to the Argonne Utility Simulation (ARGUS) Model, ANL/EAIS/TM-10, Argonne National Laboratory, Argonne, Ill., March.

Violette, D., and N. Yokell, 1982, "Fuel Cost Adjustment Clause Incentives: Analysis with Reference to California," Public Utilities Fortnightly 109(12):33-39.

Ward, D.P., 1981, "The Rules of the Game: Regulations and the Power Plant Design Process," Public Utilities Fortnightly 107(7):28-34, March 26.

Washington University Law Quarterly, 1976, "Allocation of the Risk of Constructing Electric Power Plants," (3):517-526.

Wein, H., 1968, "Fair Rate of Return and Incentives: Some General Considerations" in H. Trebing (editor), Performance Under Regulation, MSU Public Utility Studies, East Lansing, Mich., pp. 39-67.

Wendel, J., 1976, "Firm-Regulator Interaction with Respect to Firm Cost Reduction Activities," Bell Journal of Economics 7(2):631-640.

Westfield, F., 1971, "Innovation and Monopoly Regulation" in Technological Change in Regulated Industries, W. Capron (editor), Brookings Institution, Washington, D.C., pp. 1-12.

Wyant, L., 1980, "Essential Elements of Project Financing," Harvard Business Review, 165-173, May-June.

Zimmerman, M., 1988, "Regulatory Treatment of Abandoned Property: Incentive Effects and Policy Issues," Journal of Law and Economics 31(1):127-144, April.

Zimmerman, M.B., 1982, "Learning Effects and the Commercialization of New Energy Technologies: The Case of Nuclear Power," Bell Journal of Economics 13(2):297-310. 


\section{APPENDLX A:}

COMPARISON OF ALTERNATIVE RATE OF RETURN METHODOLOGIES 


\section{APPENDIX A:}

\section{COMPARISON OF ALTERNATIVE RATE OF RETURN METHODOLOGIES ${ }^{108}$}

\section{A.1 INTRODUCTION}

The literature on rate of return dete inination is extensive. Since the Bluefield and Hope decisions, a number of methodologies have been developed to determine the allowed return on equity, which reflects comparable risk and provides for adequate capital attraction. These methodologies are typically based on one of three predominant theories used in financial analysis: the market pricing theory, the opportunity cost theory, or the subjective theory. The market price theory takes one of four forms: (1) the interest coverage theory, (2) the discounted cash flow theory, (3) the earnings-price theory, or (4) the historic investor experience theory. The opportunity cost theory has been used to justify the discounted cash flow: eory, the risk premium theory, and market-to-book comparisons. The subjective theory, the least valid approach, states that the cost of capital is whatever investors believe it to be. No inquiry is made into the reasoning behind their beliefs. This approach has been used to support surveys of stock growth, dividend growth, and other elements of the cost of capital determination process.

All of the approaches used must take into account and normalize for the various managerial and regulatory policies that will affect the investor's perception of the riskiness of a company's return. Such policies include, for example, differences in the capital structure of the firm, decisions regarding tax liability and the structure of the firm (pure electric/gas utility or combination company), the regulatory policy toward fair value or original cost rate base valuation methods, and the flow through of tax benefits. The following methods were examined $i_{2}$ order to select the most appropriate means of identifying and adjusting returns to reflect technological risk:

- Coniparable earnings,

- Price-Earning ratios,

- Discounted cash flow,

- Risk premium,

- Capital asset pricing model,

- Arbitrage pricing theory,

108 Bluefield Waterworks and Improvement Co. v. P.S.C. of W.Va., 262 U.S. 679 (1923), and Federal Pouver Commission v. Hone Natural Gas Co., 320 U.S. 591 (1944). 
- Market-to-book ratio, and

- Credit rating approach.

Each of these methods can be evaluated on its consistency with economic and financial theory, the ease of obtaining data, the cost of using the method, and the accuracy evaluated in historic terms. That is, we would like to know whether or not a method's approach includes assumptions that are easily violated, resulting in the failure to equate the returns to the cost of capital. We would also like to know if the data employed are directly observable and relate to either market results or accounting conventions. And finally, it would be valuable to know whether the method tracks historic data leading to reasonable predictions.

\section{A.2 COMPARABLE EARNINGS}

The comparable earnings method is based in theory on the notion of discovering the opportunity cost of money. It suggests that the return to allow a utility is one that could be earned in a competitive financial market on investments of comparable or similar risk. Generally, the process employed to determine this rate is as follows:

- The accounting returns on the book value of equity are calculated.

- These are usually calculated as averages over specific periods for a large set of firms.

- Some methods for establishing comparability are developed.

- Based on these steps an allowed return, typically an average, is recommended.

Criticisms of this approach are numerous. For example, it is often advocated that other utility stocks constitute a comparable set of firms. This, however, results in a circularity in logic. If the accounting return is a function of the allowed return granted, how can the accounting return be used to establish the allowed return? In using accounting returns, problems arise due to the accounting conventions eniployed in determining the income earned by the utility, and these measures are susceptible to large measurement errors.

In addition, there is often no attempt to demonstrate that the selected groups of companies are of an equivalent risk class, it is simply asserted that they are of equal risk. The use of average returns is, in fact, antithetical to the measurement of risk, since averages are measures of central tendency and not dispersion, which is a more accurate measure of risk. Finally, the use of book values is inappropriate - the Hope case suggested returns on 
investments of similar risk and the value of investments are more accurately portrayed by the market value of the investment, not the book value. ${ }^{109}$

The comparable earring method relies on considerable ad hoc judgment concerning the nature of the sample that constitutes a comparable set of risky firms. Experts differ on the indicators employed such as capital intensity, capital labor ratio, lines of business, financiai ratios, etc. Once a sample has been selected, the method for calculating the return on equity generally relies on historic book or accounting data. Thus, the book earnings are compared to the book value of the firm's equity to obtain a book rate of return. This type of approach relies far too much on historical conditions that are irrelevant to the future activities of a firm, especially with regard to the undertaking of risky, innovative projects that have no comparable historic counterparts.

The data (i.e., accounting numbers) for this method are readily available, but they do not reflect true rates of return being earned, especially during inflationary periods, the loss of adjustments of a special nature, or more general volatile economic conditions. In general, these historic measures of book returns do not track the actual rates of return nor the cost of capital in an accurate fashion.

\section{A.3 PRICE-EARNINGS RATIO}

This method is, in many ways, a half-way house between the comparable earning and discounted cash flow method. It was frequently employed between 1930 and 1970. This method claims that the cost of capital is equal to the ratio of book earnings to the market value or price of the company's stock. However, the book earnings that have occurred historically in any period do not have any logical relationship to a particular market day measure of the stock price or to an average stock price. Thus, using book earnings ard market measures in this fashion is assuming a misleading and false relationship.

The price-earnings method is related to the discounted cash flow method if a number of assumptions are made:

$$
\mathbf{r}=\frac{\mathbf{E}}{\mathbf{P}}
$$

where:

$$
\begin{aligned}
& \mathbf{r}=\text { cost of capital, } \\
& \mathbf{E}=\text { earnings, and } \\
& \mathbf{P}=\text { market price. }
\end{aligned}
$$

109 Federal Power Commission v. Hope Natural Gas Co., 320 U.S. 591 (1944). 
If earnings are assumed to equal dividends (thus retained earnings), we have:

$$
\mathbf{r}=\frac{\mathbf{D}+\mathbf{R E}}{\mathbf{P}}
$$

where:

$$
\begin{aligned}
\mathrm{D} & =\text { dividends, and } \\
\mathrm{RE} & =\text { retained earnings, }
\end{aligned}
$$

and

$$
\mathbf{r}=\frac{\mathbf{D}}{\mathbf{P}}+\frac{\mathbf{R E}}{\mathbf{P}}
$$

If the growth of a firm is based on the retained earning so that

$$
\frac{\mathbf{R E}}{\mathbf{P}}=\mathbf{g}
$$

where:

$$
\mathrm{g}=\text { growth, }
$$

then we have the equivalent of the discounted cash flow model, which is

$$
\mathbf{r}=\frac{\mathbf{D}}{\mathbf{P}}+\mathbf{g}
$$

There are many problems with this assumption, and furthermore, the price-earnings method essentially assumes that there are no growth opportunities so that $g=0$. This can result in a serious bias in the estimates of the cost of capital.

The assumption necessary for the price-earnings ratio to be an accurate measure of the cost of equity is that the market price or value of the investment equals the book value.

In competitive financial markets, however, the market value of an investment will usually be above or below the book value over time. Whenever the book value is greater than the market value, the cost of capital will be greater than the allowed return and visa versa. It is only when the market value is in equilibrium with the book value that the price-earnings ratio accurately reflects the true cost of capital. ${ }^{110}$ The reason this method is frequently employed is that the data are readily available, and the results may track historical events

110 See Stick (1970), for proof of this proposition. 
fairly well in periods of stability. The difference of a few basis points can make a significant difference in the earnings and revenues of regulated firms.

\section{A.4 DISCOUNTED CASH FLOW METHOD}

The discounted cash flow approach represents an attempt to measure the market's opportunity cost of capital. This approach differs from the price-earnings ratio in that it employs investors' expectations as an element in the calculation process. Another strength of this approach is its simplicity in both theoretical terms and in calculating the results. The DCF method calculates the cost of capital as follows:

$$
\mathbf{r}=\frac{\mathrm{D}}{\mathrm{P}}+\mathbf{g}
$$

The expectations of investors enter this formula through the calculation of $\mathrm{g}$, the expected growth rate. One of the weaknesses of this approach is that in the calculation of the expected growth rate, historical data are often used to extrapolate a growth rate that is used as a proxy for market expectations. Alternative methods employ forecasts by market experts, historical growth rates of per share earnings, dividends, and the book value of the utility.

There are a number of criticisms of this approach. The DCF method claims that the cost of capital is essentially a mechanical relationship between the dividend yield and the growth of the firm over time. It is a method that is tautological in nature and does not derive from basic market behavior relationships. Problems can also arise over the estimation of the growth rate of any stock, and in general historical trends cannot be assumed to continue into the future. Also, there is the traditional problem of what constitutes comparably risky investments. Thus, the strong assumptions employed in this approach often result in violations occurring over historic periods used to estimate growth rates. Regulatory lag, alternative reinvestment strategies, and the like often result in overestimation and underestimation of the true cost of capital. The data, however, are readily available, which is why the method issued frequently. From a theoretical standpoint, it is not historic, but expected, yields and growth rates that are required, and the model only performs well in periods of stable economic conditions.

\section{A.5 RISK PREMIUM APPROACH}

The risk premium approach employs the premise that the common equity of a utility is more risky than the fixed income securities (debt) issued by the same firm. The cost of capital, $\mathrm{K}_{0}$ is found by adding an explicit risk premium to the current interest costs of debt, $\mathrm{K}_{\mathrm{o}}$ so, $\mathrm{K}_{\mathrm{o}}=\mathrm{K}_{\mathrm{o}}+$ equity risk premium. The means of estimating the risk premium vary greatly, often employed to measure $K_{0}$, while the historical differences (typically between average returns on equity and bonds) are employed to measure the risk premium. This 
method is susceptible to a number of manipulations, such as the choice of the base interest rate, the time period, and the alternative set of comparable risky assets employed to calculate the risk premium. The ad hoc nature of the selection process makes this method liable to the same criticisms as that of the comparable earnings method.

An alternative approach to estimating the risk premium employs forecasts to estimate the cost of equity capital and then subtracts the bond yield from this rate to obtain an estimate of the risk premium. The central question with this approach is that if the equity cost estimates are accurate, they already reflect the market's expected risk premium and, therefore, there is no need to compute a risk premium. The major problem with this approach is that the validity of bond and equity markets has created instances where negative risk premiums have been estimated. In effect, this implied a change in the relative riskiness of the bond and stock markets, with bonds becoming relatively more risky. This was especially true during the $1.980-1983$ period of high interest rate validity. The advantages of this method are that the data are readily available, the calculations are relatively simple, and the theoretical models simplistic. The critical issue is, basically, the selection of the data to calculate the interest rate and alternative assets for establishing the risk premium.

\section{A.6 CAPITAL ASSET PRICING MODEL}

The capital asset pricing model (CAPM) was the first equilibrium model employed to estimate the required return for bearing risk. The model employs a portfolio selection approach as the framework for its analysis. This approach assumes investors hold efficient portfolios (e.g., highest expected return with the lowest variance in returns). The CAPM approach is not identical with a portfolio approach but merely relies on portfolio theory. The CAPM applies specific assumptions about the working of capital markets.

Risk is divided into two types: (1) unsystematic or diversifiable (unique) risk and (2) systematic or market (nondiversifiable) risk. A stock adds systematic risk to a portfolio because in portfolio choice, unsystematic risk is eliminated through portfol io diversification.

The CAPM takes the following form:

$$
E\left(J_{j}\right)=J_{f}+\beta_{j} \times\left[E\left(r_{m}\right)-J_{f}\right] .
$$

This implies the expected return for asset $\mathrm{E}\left(\mathrm{J}_{j}\right)$ is equal to the risk-free rate $\left(\mathrm{J}_{\mathrm{f}}\right)$ plus the assets $\left(\beta_{\mathrm{j}}\right)$, times the difference between the expected market rate $[\mathrm{E}(\mathrm{r})]$ and the risk-free rate $\left(J_{f}\right)$. The difference represents a risk premium or systematic risk and the $\beta$ represents the contribution of the stock's validity in the systematic risk of the portfolio. Mathematically, $\beta$ is represented as 


$$
\beta_{j}=P_{j m} \times\left[\begin{array}{c}
J_{j} \\
\cdot \\
\cdot \\
J_{m}
\end{array}\right],
$$

where $P_{j m}$ is the return on the firm's stock $K_{j}$ times the standard deviation of the stock's return $\left(J_{j}\right)$ and the market return $\left(J_{m}\right)$. The value of $\beta$ is considered a complete characterization of the risk that requires market compensation.

Empirically, care must be taken to ensure that an appropriate measure of the riskfree rate is employed and that an appropriate measure of market returns is used to establish the risk premium. Data are readily available, and standard ordinary least-squares estimation techniques are employed to estimate the return equation. Although theoretically sound and consistent with standard financial theory, the CAPM approach has been criticized in many situations where incomplete diversification of portfolios occurs. Therefore, unique risk remains a problem, and investor preferences can result in an asymmetric distribution of returns. Changes in other company-specific policies may also lead to biased estimates. Others suggest that the Standard and Poor's or Dow Jones index employed as a market return proxy violates the theoretical assumptions that "all" stocks or assets are represented in the estimate of the market return.

Problems also exist in terms of the empirical implementation of this CAPM approach. For example, what assumptions should be employed concerning the underlying utility functions of investors, the normality of returns, and the efficiency of markets? How should $\beta$ be calculated, and what are the implications of the time period selection on the stability of the estimated $\beta$ ? How sensitive is the risk premium to alternative measures of the market return and risk-free rate?

Many questions have also been raised regarding the idea that $\beta$ is a sufficient measure or comprehensive measure of risk. Many specific factors play a role in systematic risk such as inflation, business cycles, technology, and others. What may be more important for regulaiory analysis is to identify and isolate the specific causes of systematic risk.

One potential advantage of this approach is as a method for estimating the risk associated with adopting innovative technologies. This process would select firms known for their innovative production technology and those which employ more conservative production technologies. The difference between the estimated $\beta$ for these two portfolios would give a first-order approximation of the financial market's perception of the riskiness associated with the adoption of a more innovative production technique. 


\section{A.7 ARBITRAGE PRICING THEORY AND MULTIFACTOR MODELS}

One approach to identifying the multiple factors underlying the market risk premium is the arbitrage pricing theory (APT). The APT approach assumes that a firm's return depends on its sensitivity to a large number of factors such as market movements, inflation, interest rate movements, technological factors, etc. The risk premium is sensitive to movements in these factors over time. If there are $i$ factors overall, then

$$
E\left(r_{j}\right)=r_{f}+\left[E\left(r_{m}\right)-r_{f}\right] \times\left[O_{i} B_{i}\right] .
$$

Equation A. 8 implies the expected return for asset $j$ is equal to the risk-free rate of return $\left(r_{f}\right)$ plus the difference between the expected market rate $\left(r_{m}\right)$ and the risk-free rate $\left(r_{f}\right)$ multiplied by a vector $B_{i}$ or the various characterizations of risk, given different factors with $B_{i}$ being the $i$ 'th return. If the returns are affected over time by these factors, one or more of the $O_{i}$ will be significant, and their relative sizes will vary over time.

This approach would allow the opportunity to isolate the potential importance of technological risk as a factor influencing systematic risks in the market portfolio. The B for this technological component of risk might serve as a means of quantifying any risk premium to reward the undertaking of innovative projects.

The problem with the APT approach as with most other approaches is the use of historical data to compute an expected future return. This makes the approach susceptible to the variations associated with the time period chosen for estimation. There is also a problem that as the number of securities employed in the estimation process grow, the number of important factors explaining risk increases.

\section{A.8 MARKET-TO-BOOK RATIOS}

The use of the market-to-book ratios approach is based on the idea that fair regulatory treatment would result in the market value of a firm equaling its book value. Thus, if

$$
\frac{F M}{B V}=\frac{R O R}{r},
$$

where:

$$
\begin{aligned}
\mathbf{M} & =\text { is the market value, } \\
\mathrm{BV} & =\text { is the book value, } \\
\mathrm{ROR} & =\text { is the allowed rate of return, and } \\
\mathbf{r} & =\text { the cost of capital, }
\end{aligned}
$$


then:

$$
\mathbf{r}=\mathrm{ROR} / \mathrm{M} / \mathrm{BV} .
$$

Suppose at an allowed return of $10 \%$, the market-to-book ratio was .5. This would imply the cost of capital to be $20 \%$. This simplistic approach is best thought of as a method to check the results of other methods and is difficult to defend as a sole measurement technique for the cost of capital.

Alternatively, other factors besides the rate of return may affect the market-to-book ratio such as leverage, technology, customer composition, etc. Some attempts have been made to employ these factors. When reasonable measures are available to explain the market-to-book ratio and then attribute causal importance to these factors, a certain circularity is introduced - use of current market value may bias future market value by anticipating an increase in the utility's allowed rate of return.

\section{A.9 MARKET-TO-REPLACEMENT-COST RATIOS OR Q-RATIOS}

On the theory of investment, J.M. Keynes once noted that it was the difference between the market value of an asset and its replacement cost that stimulated or retarded investment. If the market value is greater than replacement cost, the building and sale of the asset could occur at an instant profit. In the opposite case, losses occur and disinvestment results. The same approach as in the simple market-to-book analysis can be used but with a substitution of replacement costs for book values. The only value to the replacement cost approach is that these costs are forward looking and not historical in nature. Their data are readily available on $10 \mathrm{~K}$ financial reports.

\section{A.10 CREDIT RATING APPROACH}

This approach, in effect, "backs in" to the appropriate rate of return needed to maintain particular credit rating standards in order to preserve the utility's ability to attract capital. For example, particular interest coverage ratios are typically associated with a certain level of bond rating. Given a particular set of financial conditions, the rate of return necessary to meet this target coverage ratio could be calculated in order to meet the credit ratings. Theoretically, this approach is letting the market value of the stock determine the return rather than the other way around. Although it can be used to offset risk, it may also destroy the incentive to control costs, if it is known that the next time around a higher return will be forthcoming.

\section{A.11 INCENTIVE RATES OF RETURN AND THE GENERIC ROR PROCESS}

Through 1983, the FERC determined the rate of return on common equity for jurisdictional electric utilities on a case-by case basis. This procedure was modified in 
July 1984 with issuance of Order 389 (18 CFR Part 37), which established a process for determining benchmark rates of return and applying them in specific cases. This procedure was in turn modified on January 29, 1988, by Order 489 (53 FR 3342), which specified the curreni procedure for determining and updating the benchmark rate of return. The benchmark rates of return derived through these generic determinations are advisory only; they are intended to provide guidance to companies and investors in individual rate cases and to serve as a reference point for Commission deliberations.

As a result of Orders 389 and 489, the Commission has applied the benchmark rate of return to all rate filings of jurisdictional utilities, except as provided in 18 CFR 37.8 and 37.6 (b). Of particular relevance to the proposed rulemaking is paragraph 37.6 (b)(ii), which states that the benchmark rate will not be binding if:

The Commission determines that the risk of the public utility operations under the rate schedule at this time of filing is significantly different from the average risk for the jurisdictional operations of public utilities.

Thus, the technological risk that exceeds the one inherent in the benchmark rate of return, (such as that associated with the adoption of innovative emission control technologies or clean coal technologies), would be considered an exception by the Commission and serve to justify a return in excess of the benchmark level. However, Order 538 (RM91-17-000) abolished the use of one benchmark rate of return. One FERC Commissioner indicated that benchmark proceedings:

have not provided one Commission with a significantly better understanding of industry tres ds, nor provided an appropriate forum to study the financial and operating circumstances of one electric utility industry.

The rate of return on common equity is again to be determined on a case-by-case basis.

Emerging from the idea of generic rate-of-return determination is the concept of an innovative rate of return. A FERC Commissioner recently outlined the requirements for acceptance of innovative rate applications. ${ }^{111}$ Applications standards would be accepted if they satisfy the following standards:

- Prospective in nature, rewarding future performance;

- Specific techniques clearly and concisely stated and understood by all parties;

- Quantifiable estimate of consumer benefits;

- Explicit, "up-front" review based on defined standards with the assumption that initial implementation is experimental;

111 FERC (1991). 
- Implementation feasible under existing law; and

- Regulators willing to recognize success (if at the end of a review period a company's rates are determined to be lower than they should have been, they can be adjusted for profit potentiality).

Because public utility companies that rely on low-cost, low-emission technologies would be considered to have extraordinary technological risk, not reflected in the industry average return, an adjustment to the rate of return on equity could be proposed to compensate for this risk. This technological risk adjustment or incentive rate of return would be added to the rate of return on common equity.

To date, few electric utility companies have constructed such innovative emission control or clean coal technologies. Thus, empirical evidence to derive the appropriate risk adjustment is sparse or nonexistent. However, it should be consistent with the standard espoused in Bluefield Water Works \& Improvement Company v. Public Service Commission of West Virginia "that a utility should have an opportunity to earn returns comparable to regulated companies of similar risk levels." ${ }^{112}$ A utility could propose that a risk adjustment be derived from equity returns earned by high risk (technology) industrial firms and be added to the benchmark or other determination of the return applicable at the time of the rate filing. The determination of a risk adjustment in this manner is also consistent with governing legal standards on utility returns set out in Federal Power Commission v. Hope Natural Gas Company, ${ }^{113}$ that finds that "the return to the equity owner should be commensurate with returns on investments in other enterprises having corresponding risks" and "moreover, should be sufficient to assure confidence in the financial integrity of the enterprise so as to maintain its credit and attract capital." For purposes of this analysis, it is postulated that the electric utility risk (from the adoption of innovative emission control technologies) is equivalent to that of an unregulated, high-technology industry.

A number of alternative methods have been examined to determine the appropriate adjustment for risk in the rate of return. There is a long history of development, application, and controversy surrounding all of these risk calculating mechanisms. For this reason, the methods, details, and problems of these approaches are provided elsewhere.

112 Bluefield Waterworks and Improvement Co. v. P.S.C. of W.Va., 262 U.S. 679 (1.923).

113 Federal Power Commission v. Hope Natural Gas Co., 320 U.S. 591 (1944). 


\section{BIBLIOGRAPHY}

Bierman, H., 1984, "We Cannot Measure the Cost of Equity Capital Exactly," Public Utilities Fortnightly 114(4), Aug. 16.

Breen, W., and E. Lerner, 1972, "On the Use of B. in Regulatory Proceedings," Bell Journal of Economics 3(2).

FERC, 1991, Commissioner Terzic Says He Will Seek Incentive Regulation Proposals, news release (Federal Energy Regulatory Commission) Nov. 19.

Fitzpatrick, D., 1982, "Does the Negative Risk Premium Really Exist?" Public Utilities Fortnightly 110(1), July 8.

Gagerman, R., 1976, "Finance Theory in Rate Hearings," Financial Management, Spring.

Glassman, G., 1978, "Discounted Cash Flow versus the Capital Asset Pricing Model (Is g better than b)," Public Utilities Fortnightly, 102(6), Sept. 14.

Harrington, D., 1981, "Trends in Capital Asset Pricing Model Use," Public Utilities Fortnightly, 108(4), Aug. 13.

Kolbe, A., et al., 1984, The Cost of Capital: Estimating the Rate of Return of Public Utilities, MIT Press, Cambridge, Mass.

Mortan, W., 1970, "Guides to a Fair Rate of Return," Public Utilities Fortnightly, July 2.

Myers, S., 1972, "The Application of Finance Theory to Public Utility Rate Cases," Bell Journal of Economics, 3(1).

Phelps, G., 1976, " A Different Approach to the Fair Rate of Return," Public Utilities Fortnightly, 98(4), Aug. 12.

Stick, R., 1970, "K Is Not the Cost of Capital," Public Utilities Fortnightly, March 12.

Vandell, R., and T. Malernee, 1978, "The Capital Asset Pricing Model and Utility Equity Returns," Public Utility Fortnightly, 102(1), July 6. 
APPENDIX B:

MODELING APPROACH AND ASSUMPTIONS 


\section{APPENDIX B:}

\section{MODELING APPROACH AND ASSUMPTIONS}

\section{B.1 INTRODUCTION}

In this study, the Argonne Utility Simulation (ARGUS) model was used to determine the least cost expansion plan for the period 1995-2015. From the least cost expansion plans, changes were made to account for the uncertainties in construction time and operating parameters. ARGU, was developed at Argonne National Laboratory as an integrated utilitysystem analysis package to examine a broad range of emission-control strategies and energy policy issues.

The ARGUS model used for this analysis consists of four major modules: Build, Dispatch (ICARUS), Coal Supply and Transportation (CSTM), and Emissions and Controls (ECM). Each module can be run in a stand-alone mode or with the other modules. ARGUS has the capability of simulating utility power production and utility coal markets, minimizing the cost of expanding electric power capacity, estimating related atmospheric emissions from utilities, and computing a least-cost emission-reduction strategy (Veselka et al., 1990). Within the model, various facets of the utility sector and the coal industry interact. A schematic diagram of the ARGUS modules used in this analysis is shown in Figure B.1.

The entire ARGUS modeling system was used to determine a baseline capacity expansion plan for each power pool. The Build module adds new units in dynamic response to load growth and capacity changes. The Dispatch module calculates unit-level capacity factors and provides the Build module with information on the expected operation of the system.

The CSTM module forecasts delivered coal prices based on the volume of coal, supply region, and transportation route. Coal market prices are based on regional coal demand from all economic sectors. Utility coal demands are supplied to this module via the Build and Dispatch modules. CSTM minimizes the delivered coal price for each individual consumer of coal.

The ECM module determines the least cost strategy to meet emission control regulations and computes sulfur dioxide $\left(\mathrm{SO}_{2}\right)$ emissions from the electric utility sector. The unit level emissions are controlled such that the costs in each region are 1 , nimized.

\section{B.2 DISPATCH MODULE}

The Dispatch module contains a probabilistic production-cost model called the Investigation of Costs and Reliability in Utility Systems (ICARUS). ICARUS calculates reliability and production cost information on a unit-by-unit basis. ICARUS models detailed unit-by-unit operating characteristics such as fuel cost, forced outage rate, scheduled 


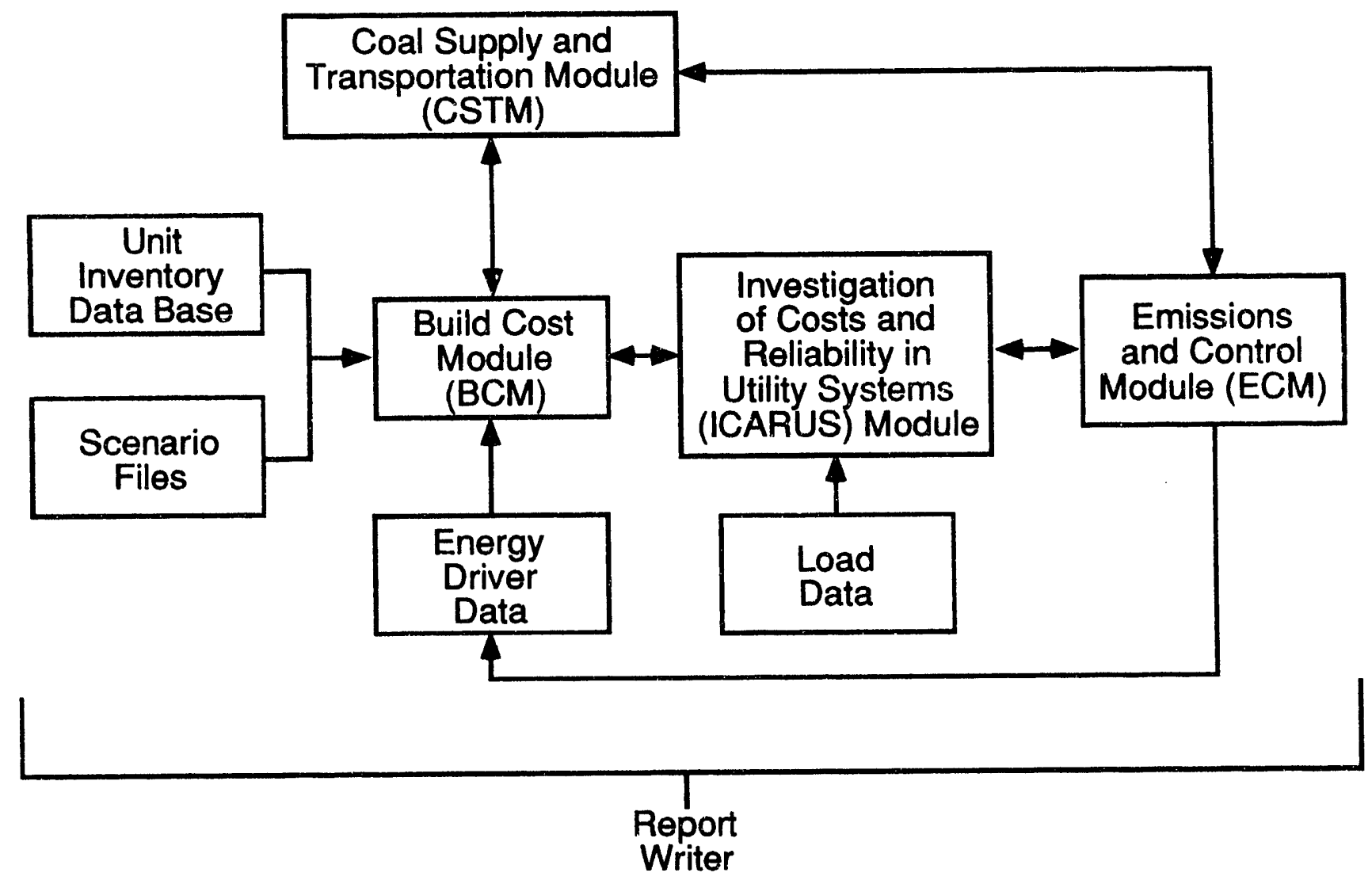

FIGURE B.1 Interaction of Build, Dispatch, Emissions and Control, and Cost Supply and Transportation Modules in ARGUS (Source: Veselka et al. 1990)

maintenance, heat rate, and fixed and variable operation and maintenance (O\&M) costs. These components are used to compute system reliability measures (such as loss-of-load probability and unserved energy) and production costs. The computed system loading order reflects dispatching priorities and recognizes system-dependent limitations, such as spinning reserve. Energy assignments for each block of capacity are determined by a procedure that parailels the convolution process but that uses an efficient algorithm to determine each unit's capacity factor (Van Kuiken 1983).

The input requirements for ICARUS fall into two major categories: load data and unit data. The load data required by ICARUS include monthly load duration curves and annual peak demands. The load data for this analysis were based on the regional North American Electric Reliability Council (NERC) projections through 2000. After 2000, annual peak load growth was based on the National Energy Strategy (NES). The monthly peak loads and lnad shapes will be selected from previous analyses done for the NES. The unit data file requires the following information for each unit: unit size, capital cost, fixed and variable $O \& M$ costs, fuel type, fuel cost, heat rate, scheduled maintenance, and equivalent forced outage rate. A detailed description of the ICARUS model can be found in Guziel et al. (1990). 
The ICARUS input data for existing units are based on the Argonne Power Plant Inventory (APPI). APPI is a database of operating and planned generating units in the United States; it is current through the end of 1988. This database is updated biannually based on information in the regional NERC reports ${ }^{114}$ (ECAR 1989; ERCOT 1989; NPCC 1989; MAAC 1989; MAIN 1989; MAPP 1989; SPP 1989; SERC 1989; WSCC 1989), reports from the DOE Energy Information Administration (EIA), and other sources. All NERCannounced nonutility generators and new capacity additions scheduled to come on-line after 1995 were removed from the inventory. This assumption provided more opportunity for clean coal technologies (CCTs) to be selected and provided the opportunity to look at potential benefits from a nonprescribed build schedule.

Unit operating characteristics (fixed O\&M, variable O\&M, heat rate, forced outage rate, and scheduled maintenance) are based on regional data as defined in the Electric Power Research Institute (EPRI) report on regional systems (EPRI 1981) and other historic data. Fuel price tracks for existing and new capacity are based on regional variation as assumed in the NES.

Output from ICARUS includes annual summaries of capacity, generation, cost, and reliability for the entire generating system. If requested, period-specific and unit-specific generation and cost data can be obtained.

\section{B.3 BUILD MODULE}

New generating capacity is added to the each power pool by the Build module to satisfy future load growth. The amount of additional capacity needed is determined on the basis of projected peak-load requirements plus a target reserve margin, compared to the amount of existing and planned capacity. Future load growth can be satisfied by adding new units. The slate of new candidates will be the same for each power pool in this analysis. The list of new candidate units includes AFBC, IGCC, PFBC, NGCC, and GT.

The Build module considers three separate forecast periods: near-term, mid-term, and long-term; see Figure B.2. During the near-term period, no new units are added except those defined by NERC. The mid-term period is used to gradually adjust the reserve margin of a power pool from its current level to a target level. This period provides an interval in which new capacity can be smoothly phased into the system rather than a large overnight increase in new sapacity. In this period, capacity is adjusted up (or down) so that at the end

114 The regions are as follows: ECAR East Central Area Reliability Coordination Agreement, ERCOT Electric Reliability Council of Texas, NPCC Northeast Power Coordinating Council, MAAC MidAtlantic Area Council, MAIN Mid-America Interpool Network, MAPP Mid-Continent Area Council, SPP Southeast Power Pool, SERC Southeastern Electric Reliability Council, and WSCC Western System Coordinating Council. 


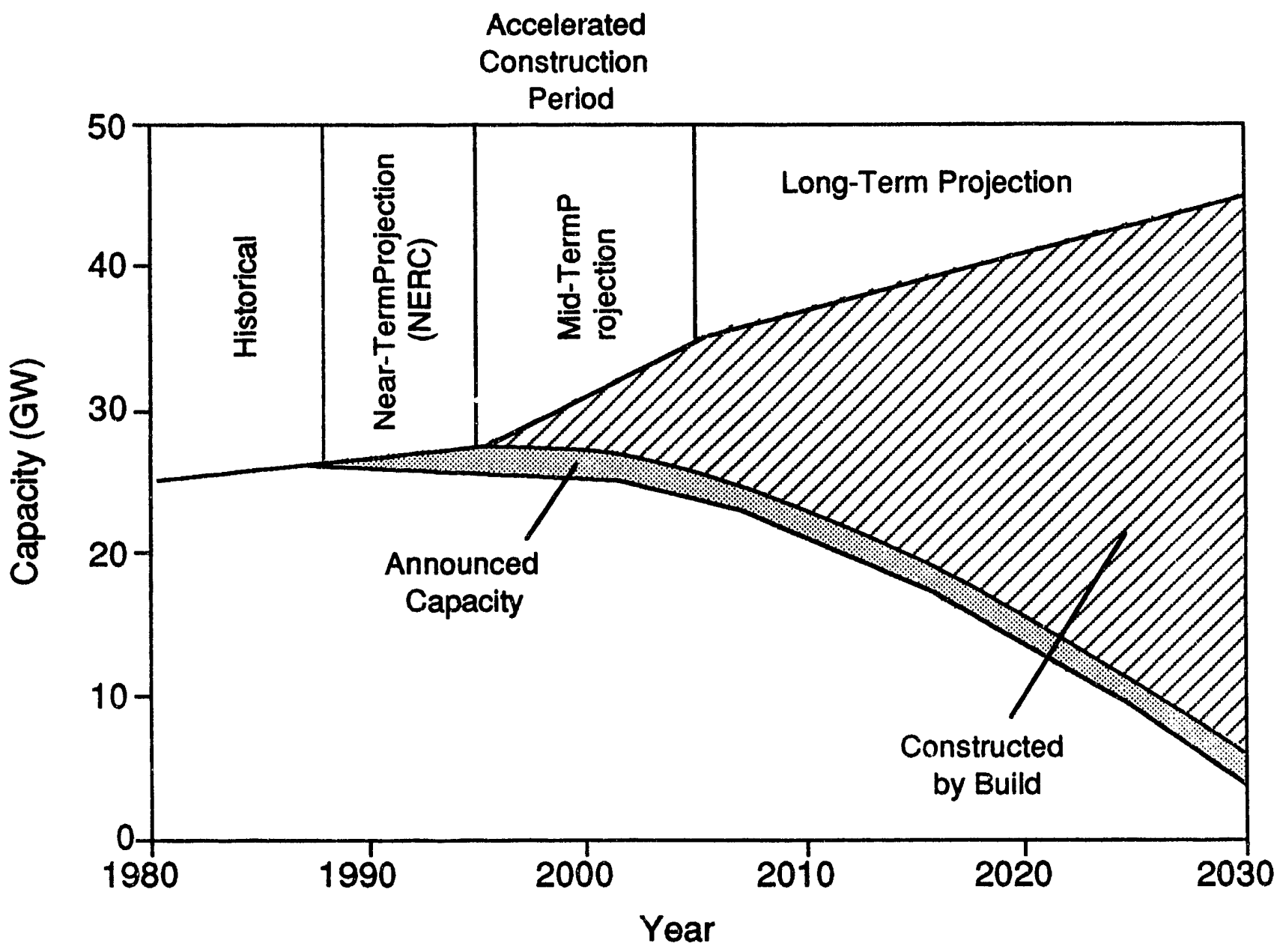

FIGURE B.2 ARGUS Forecast Periods (Source: Veselka et al. 1990)

of the mid-term forecast period, the target reserve margin is achieved. The length of the midterm period is specified by the user. During the long-term period, the Build module adds new capacity to maintain the target reserve margin.

As shown in Figure B.1, the Build module is linked with the Dispatch module. The Dispatch module uses unit and load data to calculate generation and system reliability results for a historic year. On the basis of information from Dispatch, an annual equivalent load duration curve (ELDC) is constructed in the Build module to determine the anticipated capacity factors of the new candidate units. The potential capacity factor of a candidate unit is determined by calculating its full-load running cost in comparison with those of other units in the system. The actual or potential capacity factor is determined by looking at the capacity factor of other units with a sinilar full-load running cost. All units with a higher full-load running cost would have an adjusted capacity factor after the new unit is loaded. The Build module factors into the cost decision the costs of the entire system when a new unit is added. 
In this study, new capacity additions were selected on a "least-cost" basis; this analysis does not include repowering as an option for new capacity additions. Inclusion of repowering in the build slate would potentially delay new "greenfield" CCT units.

\section{B.3.1 Dispatching and Emission Penalty}

In order to maintain the emissions cap on a the least cost basis after 2005 , this study incorporated a shadow price into the cost analysis performed in the Build module and included in the Dispatch module. The marginal control cost (shadow price) added in the Build module affects the economic competitiveness of units. It also affects the Dispatch module by increasing the relative economic loading order of a unit as explained in the following equation.

$$
\text { Load Ordering }=\text { VOM }+ \text { Fuel }+\left\{\left[(E R * H R) / 10^{3}\right] *[\mathrm{MC} / 2000]\right\},
$$

where

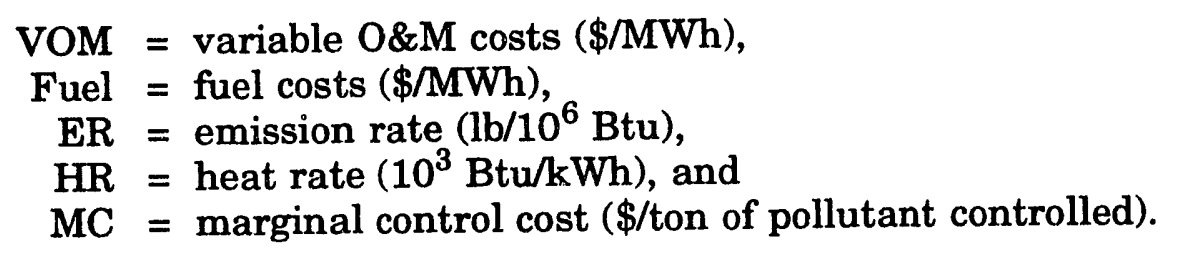

The shadow price is used to simulate environmental concerns such as maintaining an emission cap. Normally, an economic loading order is determined by rank ordering the units based on their variable O\&M cost, heat rate, and fuel cost. However, when emission penalties are included, units that produce higher emissions have higher costs, which results in a lower loading order position. Under an economic dispatch, capacity factors of units with a shadow price and high emission rate decrease because their variable cost increases, while the capacity factor of units without a shadow price increases or remains constant. Capacity factors of controlled units may increase because their higher variable costs are offset by the lowered emissions.

The shadow price level affects decisions that are made on a least-cost basis. In general, CCTs are favored because of their lower emission rate. Units with lower emissions displace the generation from units that have higher emission rates by being dispatched earlier in the loading order. CCTs displace the generation of old units because of their efficient operation, which results in lower systemwide emissions and costs.

\section{B.4 EMISSIONS AND CONTROL MODULE}

The ECM computes the amount of $\mathrm{SO}_{2}$ emitted from the electric utility sector and the cost of implementing emission-control regulations and strategies. The ECM shows how the choices that a utility makes (e.g., type of fuel, dispatching order, capacity- $\epsilon$ xpansion method, and pollution-control method) can affect its emissions. These effects include 
(1) changes in emissions associated with a particular unit, (2) changes in fuel-consumption levels at existing units due to changes in dispatching, and (3) changes in coal demand that will alter coal market prices and transportation costs.

The ECMV estimates unit-level emissions of $\mathrm{SO}_{2}$ by applying emission factors to fuel consumption besed on an AP-42 (EPA 1985). Projections of $\mathrm{SO}_{2}$ emissions from coal- and oilfired units are based on unit size, capacity factor, boiler heat rate, and fuel quality. The fraction of sulfur retained in the boiler's bottom ash depends on the type of fuel burned. Removal efficiencies for $\mathrm{SO}_{2}$, where applicable, were obtained from the EIA Form 767 data. Flue-gas desulfurization (FGD) modules were installed on new units by the ECM of ARGUS and operated at a removal efficiency that allows them to meet $\mathrm{SO}_{2}$ emission regulations.

The ECM determines the least-cost method of achieving emission reductions by comparing the total levelized costs of a range of available control methods on a unit-level

basis. For strategies that mandate unit-level emission-rate limits, ECM can find the leastcost compliance method for each individual unit. The control methods include coal switching and blending, as well as the installation of $\mathrm{SO}_{2}$ control technologies. For strategies that allow interstate and intrastate trading, ECM determines the amount of reduction for each unit so that the sum of the control costs over all units is minimized.

The ECM interacts extensively with CSTM and ICARUS (see Fig. B.1). It uses coal alternatives from CSTM and capacity factors from ICARUS to determine the least-cost control strategy. However, selection of an emission control option primarily through coal switching or installation of pollution-control equipment will affect variable costs and may change the original dispatching priorities. The ICARUS dispatching priorities are based on relative economic rankings, with recognition of other factors such as spinning reserves. Any changes in dispatching order are likely to affect unit level generation and likewise their associated emissions. When the model first runs, ECM passes variable costs from the initial control strategy to ICARUS. A control strategy that involves fuel switching not only changes dispatching priorities but also alters the price paid for the coal. ICARUS re-dispatches units using the modified unit costs. ECM reduces $\mathrm{SO}_{2}$ emissions in small increments so that the impacts on the coal market from any one emission-reduction step are nominal.

\section{B.5 COAL SUPPLY AND TRANSPORTATION MODULE}

The CSTM determines the least-cost combination of supply sources and ransportation routes for each demand source on a per Btu basis. First, it estimates coal market prices on the basis of regional demands for coal from all economic sectors. To generate market prices, CSTM estimates regional coal production patterns and coal transportation routes. Second, CSTM supplies the Build and ECM with a set of delivered coal-cost and coal-quality options. The Build module uses the CSTM resilts when evaluating how a new generating unit will operate. The ECM uses the set of coal types furnished by CSTM to represent the alternative fuels that a system can burn as part of its overall emission-control strategy. 
The CSTM input data are grouped into three major categories: demand, supply, and transportation. CSTM uses supply curves from the Resource Allocation and Mine Costing (RAMC) model (EIA 1987). RAMC provides cost data on coal supply for the 32 supply regions shown in Figure B.3. Every region has a separate curve for one or more of the 60 different coal types that may be produced in that region. CSTM modifies the original RAMC supply curve by dividing the single RAMC curve into two curves, one representing deep mines and the other representing surface mines, but still uses the same ranges for heating values and mine prices that define the supply curves in RAMC. Prices fluctuate as a result of different mining methods, size of mining operations, reserve characteristics, and depletion effects.

The transportation data define the network that connects 32 coal supply origins to 48 demand centers. The transportation cost is affected by distance, terrain, congestion, variable fuel costs, cost escalators for fuels and facility upgrades, and competition. CSTM first computes the production cost for each coal supply region and coal type. It then matches supply sources to transportation routes to find the lowest delivered costs.

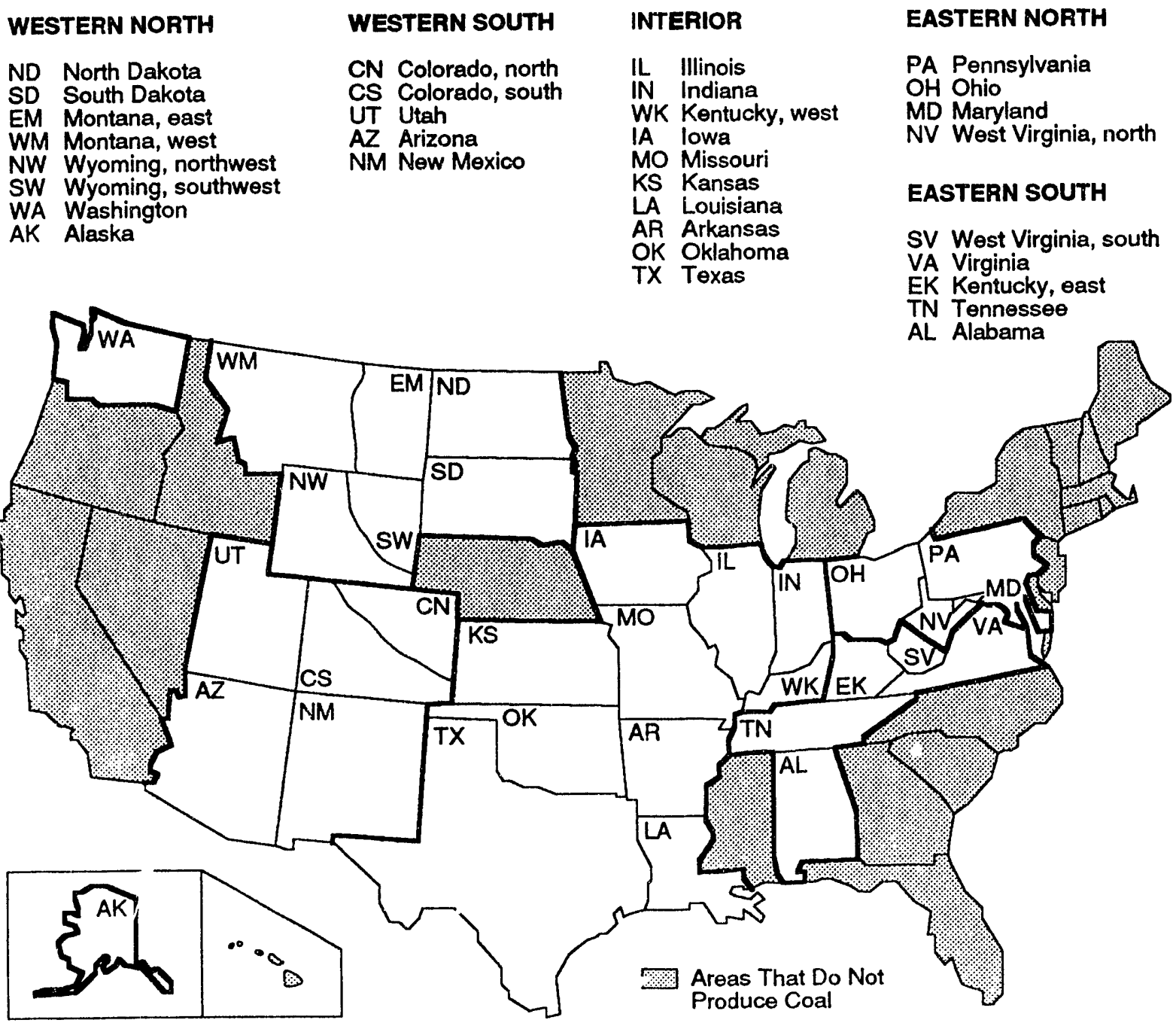

FIGURE B.3 CSTM Supply Regions (Source: Veselka et al. 1990) 
Coal demand for a particular region is based on the amount (in $10^{12} \mathrm{Btu}$ ), geographic region, economic sector, and range of acceptable coal types. There are 44 domestic demand regions. CSTM allows demand to be met by one supply region or a combination of different regions. 


\section{REFERENCES}

Clean Coal/Synfuels Newsletter, 1991, "States Rush to Fill Policy Void: Ohio, Pennsylvania Cite Clean Coal," (March 11):3.

Clean Coal/Synfuels Newsletter, 1991, "Clean Air Act Amendments Compliance: Illinois Plan Calls for Technology Options," March 25: 1,2,6.

Clean Coal/Synfuels Newsletter, 1991, "Ohio Includes Technology Role in Clean Air Impact Bill," (April 25): 5-6.

Clean Coal/Synfuels Newsletter, 1991, "Pennsylvania Coal Plan Provides Support for Newer Technologies," 6:1,3.

Clean Coal/Synfuels Newsletter, 1991, "Ohio Moves to Promote Scrubbers, Coal Technology, Illinois at Brink," July 8: 4,6.

DOE, 1991, Integrated Analysis Supporting the National Energy Strategy: Methodology, Assumptions, and Results, DOE/S-0086P, U.S. Department of Energy, Washington, D.C.

ECAR, 1989, Coordinated Regional Bulk Power Supply Program, Volume 1, East Central Area Reliability Coordination Agreement, IE-411, April.

EIA, 1990, Electricity Supply: Supporting Analysis for the National Energy Strategy, SR/NEW/90-03, U.S. Department of Energy, Energy Information Administration.

EIA, 1987, Documentation of Resource Allocation and Mine Costing (RAMC) Model, DOE/EIA-0401, U.S. Department of Energy, Energy Information Administration, June.

EPA, 1985, Compilation of Air Pollutant Emission Factors, AP-42, U.S. Environmental Protection Agency, Sept.

EPRI, 1981, The EPRI Regional Systems, P-1950-SR, Electric Power Research Institute, July.

ERCOT, 1989, Coordinated Regional Bulk Supply Program, Electric Reliability Council of Texas, April.

Guizel, K., et al., A User's Guide to ICARUS: A Model for Investigating Cost and Reliability in Utility Systems, ANL/EAIS/TM-19, Argonne National Laboratory, Argonne, Ill.

Holstein, M.P., 1991, Technologies and Cost for Meeting New Clean Air Standards, The Sixth Annual Cogeneration and Independent Power Marker Conference, New Orleans, La.

MAAC, 1989, Coordinated Regional Bulk Power Supply Program, Mid-Atlantic Area Council, April. 
MAIN, 1989, Coordinated Regional Bulk Power Supply Program, Mid-America Interpool Network, April.

MAPP, 1989, Coordinated Regional Bulk Power Supply Program, Mid-Continent Area Council, April.

NPCC, 1989, Coordinated Regional Bulk Power Supply Program, Northeast Power Coordinating Council, April.

SERC, 1989, Coordinated Regional Bulk Power Supply Program, Southeastern Electric Reliability Council, April.

SPP, 1989, Coordinated Regional Bulk Power Supply Program, Southeast Power Pool, April.

Van Kuiken, J.C., 1983, An Efficient Simulation Approach for Evaluating the Potential Effects of Nuclear Power Plan Shutdowns on Electrical Utility Generating Systems, ANL/EES-TM-233, Argonne National Laboratory, Argonne, Mll., June.

Veselka, T.D., et al., 1990, Introduction to the Argonne Utility Simulation (ARGUS) Model, ANL/EAIS/TM-10, Argonne National Laboratory, Argonne, Il., March.

WSCC, 1989, Coordinated Regional Bulk Power Supply Program, Western System Coordinating Council, April. 
APPENDIX C:

NONUTILITY GENERATORS: TECHNOLOGY CHOICE UNDER THE CLEAN AIR ACT AMENDMENTS OF 1990 


\section{APPENDIX C:}

\section{NONUTILITY GENERATORS: TECHNOLOGY CHOICE UNDER THE CLEAN AIR ACT AMENDMENTS OF 1990}

\section{C.1 INTRODUCTION}

Nonutility generators (NUGs) come under a wide range of environmental legislation including state and local environmental and siting regulations and federal environmental regulations. As most NUGs have been constructed after 1977, all must meet EPA's new source performance standard (NSPS). ${ }^{115}$ The Clean Air Act Amendments (CAAA) of 1990 (P.L. 101-549) will present additional compliance problems for the NUG industry. In addition to added controls on air toxics, ${ }^{116}$ increasingly strict NSPS requirements, ${ }^{117}$ and the ability of states to internalize externalities via permitting fees on fuel, technology, and emissions, ${ }^{118}$ Title IV of the CAAA of 1990 requires $\mathrm{SO}_{2}$ allowances be held equal to a unit's $\mathrm{SO}_{2}$ emissions on an annual basis. ${ }^{119}$ The increased costs caused by internalizing the cost of air pollution will effect the choice of generating technology and fuel used for both utilities and NUGs.

Nonutility generators will be required to begin holding transferable emission allowances beginning in 2000 or Phase II of the acid rain program. Each electricity generating unit with a nameplate capacity greater than $75 \mathrm{MW}$ will be effected by Phase II and will receive allowances based on its baseline emissions multiplied by 1.2 divided by $2000 .^{120}$ All new electricity generating units after 2000 will be required to hold $\mathrm{SO}_{2}$ allowances equal to annual tons of $\mathrm{SO}_{2}$ emitted and will receive no allocated allowances. ${ }^{121}$

The change in environmental compliance costs will alter NUG project economics. The central question for this discussion is: will the change in compliance costs due to the

115 The Clean Air Act Amendments of 1970 created the concept of the NSPS that puts an upper limit on stack emissions of all facilities constructed after implementation of the Act. The NSPS standard for $\mathrm{SO}_{2}$ for coal-fired utility boilers is $1.2 \mathrm{lb}$ of $\mathrm{SO}_{2}$ per $\mathrm{MMBtu}$. $\mathrm{NO}_{\mathrm{x}}$ standards are to be revised as of January 1,1994 . As most of the growth in nonutility electricity generation has taken place after the Public Utility Regulatory Policies Act of 1978, these newly constructed facilities must meet NSPS restrictions.

116 Section 301-306, P.L. 101-549.

117 Section 101-106, P.L. 101-549.

118 Sections 502-504, P.L. 1U1-549.

119 Section 403, P.L. 1U1-549.

120 Section 405, P.L. 101-549.

121 Section 403, P.L. 101-549. 
need for $\mathrm{SO}_{2}$ allowances affect the viability of coal as a fuel type, even if it is a CCT? Several issues must be addressed to answer this question.

After 2000, all new generating construction must obtain $\mathrm{SO}_{2}$ allowances to operate. There is a potential for utility collusion, which would create difficulties in obtaining $\mathrm{SO}_{2}$ allowances for the NUGs, which will, in turn, affect their ability to operate. If the NUGs are able to acquire allowances, the added cost of the coal option, either additional capital costs for CCTs or flue-gas desulfurization (FGD) costs will raise the cost of using coal. In a market where natural gas is the fuel of approximately $40 \%$ of all NUGs (NIEP 1991), these added costs may tip the competitive balance to natural gas, depending on how the added cost impacts coal-using NUG prices. As the NUG power supply market is very competitive and firms win contracts based on marginal bidding differences, the impacts could be significant.

In addition, changes in fuel prices for NUGs burning coal due to compliance requirements may make older utility units (which are allowed the "WEPCo fix") to potentially compete with the newer, cleaner power. Some firms may use these units to compensate for additional required capacity rather than turning to more efficient and cleaner power due to cost differences. All these issues related to the CAAA of 1990 will play a role in NUG technology choice and the ability of CCT development/deployment in this market.

\section{C.2 ABILITY TO OBTAIN ALLOWANCES AND DIRECT SALE PROGRAM}

To ensure that NUGs are able to obtain $\mathrm{SO}_{2}$ allowances, the U.S. Environmental Protection Agency (EPA) has instituted the Direct Sale Program and given the NUGs the independent power producers written guarantee. ${ }^{122}$ A fear of policymakers was the potential for anti-competitive behavior in the $\mathrm{SO}_{2}$ allowance market whereby utilities would collude and restrict buying and selling of allowances to only utilities. This would deny NUGs the ability to obtain $\mathrm{SO}_{2}$ allowances that are a necessary input to coal- and oil-fueled electricity generation. In order to defeat any potential anti-competitive forces in the allowance market, the independent power producers written guarantee allows NUGs to buy allowances in the direct sale program before the utilities and guarantees that those purchased allowances will be available for the lifetime of the NUG unit using the allowances. Allowances in the Direct Sale program cost $\$ 1,500$ per allowance, well above most predicted estimates of $\mathrm{SO}_{2}$ allowance prices (Holstein 1991; Niemeyer 1990). ${ }^{123}$

If NUGs are forced to rely on the Direct Sale Program exclusively, their cost of compliance when implementing coal and oil projects will be greater, putting them at a comparative disadvantage to natural gas and older utility units which may be retrofitted. If a scenario develops in which NUGs are restricted from obtaining allowances, the use of

122 See EPA, 1991.

123 The market price of allowances will depend on many factors, the most important being the utilities' (and NUGs) marginal cost of $\mathrm{SO}_{2}$ control. Most estimates of the allowance price range from $\$ 200-\$ 1000$. 
coal and fuel oil technology will decline as these firms substitute toward lower cost natural gas technologies, since no $\mathrm{SO}_{2}$ allowances are need. ${ }^{124}$

However, the above scenario seems unlikely. Given that $\mathrm{SO}_{2}$ allowances can be traded across wide geographic areas, it seems unlikely that an eastern utility will not sell allowances to an NUG elsewhere, as they are extremely unlikely to engage in any sort of competition. Given that western states may have allocated $\mathrm{SO}_{2}$ allowances in excess of their requirements (due to their lower $\mathrm{SO}_{2}$ emissions), and that these utilities are unlikely to compete in eastern power pools, NUGs could potentially obtain large quantities of allowances from the West. Also, with development of either an EPA-supervised auction, or further development of the Chicago Board of Trade (CBOT) $\mathrm{SO}_{2}$ futures market, it seems unlikely that utility collusion would exert pressure in these markets.

A scenario that restricts the availability of allowances may be more likely to occur if allowance markets fail to develop or if the $\mathrm{SO}_{2}$ allowance market is extremely thin. This situation could arise if the following occur: (1) utilities facing quantity uncertainty about allowances available in the market resort to hedging (hoarding) allowances for future growth and self-insurance; (2) state legislative actions distort the true marginal costs of control and inh: hit allowance trading, which will distort the price signals of $\mathrm{SO}_{2}$ allowances, further inhibiting market formation; and (3) external markets, such as the CBOT, fail to develop due to the above factors.

In the short run, problems (1) and (2) are most likely to occur and slow the growth of the $\mathrm{SO}_{2}$ allowance market; in the long run, however, this market should develop. With a quantity constrained market developing such as the one indicated above, $\mathrm{SO}_{2}$ allowance prices will rise while the ability to obtain allowances will become uncertain. In terms of NUG technology choice, if the above scenario(s) occur, the choice of any coal project witho: $t$ the ability to acquire $\mathrm{SO}_{2}$ allowances would be risky. The added risk could translate into greater difficulties in acquiring capital for the NUG and a degradation of that NUG's ability to win a utility RFP using a coal project. Once again, natural gas technologies (and other noncoal tecinologies) would be favored in terms of obtaining bids, cost, and riskiness.

\section{C.3 EXAMINATION OF $\mathrm{SO}_{2}$ ALLOWANCE ECONOMICS ON NUGS' COMPLIANCE COSTS}

The heavy weight assigned to project price in capacity Requests for Proposals (RFPs) makes the price of the NUGs' energy of great importance (Strategic Decisions Group 1989). The additional costs of Title IV (acid rain) will directly effect the price that the NUG can charge for power. Because of coal's $\mathrm{SO}_{2}$ emissions, coal projects may be disadvantaged when compared with natural gas projects, because of greater compliance costs and comparable energy costs.

124 This is assuming that natural gas prices to not rise precipitously as compared to fuel oil and coal and make coal with the Direct Sales allowances the least cost option. 
The following data compare the use of Illinois Basin Coal at 3.96\% sulfur and Powder River Basin Coal at $0.6 \%$ sulfur. In three scenarios, allowance prices are $\$ 1,500$ (allowances from Direct Sale only), $\$ 700$ (greater $\mathrm{SO}_{2}$ control costs and fewer allowances in the market), and $\$ 400$ (allowance market is generating lower allowance prices). ${ }^{125}$ A $300 \mathrm{iMW}$ boiler with a capacity factor of $75 \%$ is assumed for the scenarios. The results of the scenarios and capital costs are presented in Tables C.1, C.2, and C.3. The wet FGD is assumed to use Illinois bituminous coal and the dry FGD uses Wyoming subbituminous coal. All capacity factors except NGCC are assumed to be between .65-.70. The NGCC has a capacity factor of .30.

The overall cost effects of purchasing additional allowances have a large impact on project economics and profits. In terms of comparing natural gas NUG projects against FGD coal units and CCTs, however, these relatively low operating costs may make an important difference. The chief advantages of coal technologies over natural gas units are lower fuel costs and stability of fuel costs over time. Advanced gas technologies such as NGCC may be more competitive against coal and may have lower nonfuel O\&M cosis, lower capital costs, and no need to control $\mathrm{SO}_{2}$ emissions. Table C.4 indicates the NES policy base case utility fuel costs of natural gas and coal over time.

The weighted cost of fuel costs per $\mathrm{kWh}$ and $\mathrm{SO}_{2}$ allowance compliance costs takes into account the environmental costs of $\mathrm{SO}_{2}$ emissions along with the relative efficiency of the different technology and fuels. The IGCC is assumed to be using coal in a new, greenfield facility. The results are presented in Table C.5.

Under assumptions of the NES base case, with the allowance prices and $\mathrm{SO}_{2}$ emissions reduction indicated, and relying on wet FGD and IGCC technologies using high sulfur coal, coal technologies have a significant operating cost advantage. The impact of $\mathrm{SO}_{2}$ allowances on the competitiveness of coal technologies is not exceedingly great in terms of incremental costs. As indicated in Table C.1, the capital cost of the NGCC is 50\% less than the least-cost coal option. Furthermore, natural gas technologies have advantages in terms of dispatchability, short construction lead times, and are significantly cleaner in terms of $\mathrm{SO}_{2}$, $\mathrm{NO}_{\mathrm{x}}$, and $\mathrm{CO}_{2}$ emissions. These factors along with lower costs of capital per $\mathrm{kW}$ may decrease the benefits gained from coal units' operating cost advantages. Compounding this fact is that IGCCs technological risk may negatively impact its cost competitiveness with natural gas.

Given the NES base case utility fuel costs and the development of a well working $\mathrm{SO}_{2}$ allowance market, newer coal technologies (especially CCTs) will not be greatly effected by Title IV. In terms of comparative advantage of natural gas units over IVUG CCT units, all of the above factors would be weighed in the NUG technology decision process.

125 The following cost examples are from M.P. Holstein (1991). 
TABLE C.1 $\mathrm{SO}_{2}$ Compliance Costs - Capital and Incremental Costs $^{\mathrm{a}}$

\begin{tabular}{llcl}
\hline \multicolumn{1}{c}{ Technology } & $\begin{array}{c}\text { Capital } \\
\text { Costs } \\
(1989 \$ / \mathrm{kW})\end{array}$ & $\begin{array}{c}\text { Nonfuel } \\
\text { Variable O\&M } \\
(\text { mills } / \mathrm{kWh})\end{array}$ & $\begin{array}{c}\% \text { Reduction } \\
\text { in } \mathrm{SO}_{2}\end{array}$ \\
\hline Pulverized coal wet/dry & 1,535 & 11.7 & $90 \%$ \\
AFBC & 1,300 & 10.2 & $90 \%$ \\
PFBC & $1,440 / 1,200$ & 13.0 & $90 \%$ \\
IGCC & $1,425 / 1,280$ & 8.9 & $95 \%$ \\
NGCC & $680 / 640$ & 5.2 & No $\mathrm{SO}_{2}$ \\
Gas steam & 960 & 5.3 & $\mathrm{No} \mathrm{SO}_{2}$ \\
\hline
\end{tabular}

a Cost as of $2000 / 2010$.

Sources: EPRI (1989); DOE (1991).

TABLE C.2 $\mathrm{SO}_{2}$ Compliance

Cost Allowances for Illinois Bituminous $^{a}$

\begin{tabular}{lrrr}
\hline & \multicolumn{3}{c}{$\begin{array}{c}\text { Allowance Price } \\
(\$)\end{array}$} \\
\cline { 2 - 4 } Technology & 400 & 700 & 1,500 \\
\hline Wet FGD & 12 & 18 & 46 \\
AFBC & 14 & 20 & 50 \\
PFBC-CC & 11 & 13 & 45 \\
IGCC & 5 & 8 & 22 \\
\hline
\end{tabular}

a Additional $\$ / \mathrm{kW}$ on annual basis.

Source: Holstein (1991). 
TABLE C.3 $\mathrm{SO}_{2}$ Compliance Cost Allowances for Wyoming Subbituminous ${ }^{a}$

\begin{tabular}{lrrr}
\hline & \multicolumn{3}{c}{$\begin{array}{c}\text { Allowance Price } \\
(\$)\end{array}$} \\
\cline { 2 - 4 } Technology & 400 & 700 & 1,500 \\
\hline Dry FGD & 4 & 7 & 20 \\
AFBC & 6 & 9 & 24 \\
IGCC & 2 & 3 & 5 \\
\hline
\end{tabular}

a Additional $\$ \mathrm{k} / \mathrm{W}$ on annual basis.

Source: Holstein (1991).

TABLE C.4 Price of Electricity Generation Fuel $^{2}$

\begin{tabular}{ccc}
\hline Year & Natural Gas & Coal \\
\cline { 1 - 2 } 2000 & 4.64 & 1.78 \\
2010 & 6.27 & 2.02 \\
2020 & 7.78 & 2.17 \\
2030 & 8.86 & 2.39 \\
\hline
\end{tabular}

a $\$ 1989$ per MMBtu.

Source: U.S. Department of Energy (1991). 
TABLE C.5 Marginal Costs ${ }^{\text {a }}$ per Fuel, O\&M, and $\mathrm{SO}_{2}$ Allowances

\begin{tabular}{llll}
\hline & \multicolumn{3}{c}{$\begin{array}{c}\text { Marginal Cost }(\$ / \mathrm{kWh}), \\
\text { by Allowance Price }\end{array}$} \\
\cline { 2 - 4 } Technology & $\$ 400$ & $\$ 700$ & $\$ 1,500$ \\
\hline Wet FGD & .0314 & .0322 & .0354 \\
IGCC $^{\mathrm{b}}$ & .0259 & .0262 & .0279 \\
NGCC & $.0404^{\mathrm{c}}$ & & \\
\hline
\end{tabular}

a $\$ 1989$ and year 2000 fuel prices.

b IGCC is chosen as the sole CCT technology at this point in time due to the relatively short time until its commercialization and its general acceptance by the NUG industry as an acceptable generating technology.

c $\mathrm{No} \mathrm{SO}_{2}$ allowances needed. 


\section{REFERENCES}

EPA, 1991, Notice of Proposed Rule Making, Auctions, Direct Sales, and Independent Power Producers Written Guarantee Regulations, U.S. Environmental Protection Agency, Federal Register, 56(100): 23744-23759.

EPRI, 1989, TAG TM Technical Assessment Guide, Volume 1: Electricity Supply - 1989, Revision 6, Electric Power Research Institute, Palo Alto, Calif., Sept.

Holstein, M.P., 1991, "Technologies and Costs for Meeting New Clean Air Standards," presented at the Sixth Annual Cogeneration \& Independent Power Market Conference, held in New Orleans, La.

Strategic Decisions Group, 1989, Bidding for Electric Resources: An Industry Review of Competitive Bid Design and Evaluation, EPRI CU-6089, Electric Power Research Institute, Palo Alto, Calif., May.

U.S. Department of Energy, 1991, Integrated Analysis Supporting the National Energy Strategy: Methodology, Assumptions, and Results, DOE/S-0086P, Washington, D.C. 
APPENDIX D:

FEDERAL AND STATE REGULATORY INCENTIVES

FOR THE ADOPTION OF CLEAN

COAL TECHNOLOGY 


\section{APPENDIX D:}

\section{FEDERAL AND STATE REGULATORY INCENTIVES FOR THE ADOPTION OF CLEAN COAL TECHNOLOGY}

The primary means through which clean coal technologies (CCTs) have been initiated into demonstration projects has been the Clean Coal Technology Program (CCTP). A variety of public laws have authorized the joint funding of 50 projects for the first five rounds of the program. ${ }^{126}$ In addition, the primary incentive mechanism for private development has been technical information and subsidies provided by federal and state governments. While the CCTP solicitations have allowed CCTs to progress into a demonstration stage, further incentives would speed the commercial development and adoption of CCTs. Recently, several pieces of legislation on the state and federal level have been enacted that directly or indirectly seek to speed the deployment of CCTs.

Title IV of the Clean Air Act Amendments (CAAA) of 1990 (Public Law 101-549) provides incentives for the development of CCTs. In Phase II, those units choosing to repower with CCT receive a four-year extension on Phase II compliance. ${ }^{127}$ In addition, all experimental and demonstration CCTs expected to run not longer than five years are freed from new source review (NSR). ${ }^{128}$

The passage of the CAAA of 1990 (P.L. 101-549) and the creation of the National Energy Strategy (NES) has caused several legislative responses at the state level with regard to the use of coal. The states enacting and proposing legislation are primarily high-sulfur coal producing states whose utilities' fuel supply is largely high-sulfur coal. In the interest of promoting continued use of their coal, and easing burdens of complying with the CAAA of 1990 on state utilities and rate payers, these states have enacted or proposed legislation which encourages the use of high-sulfur coal and in some ways encourages the development/deployment of CCTs.

The Energy Policy Act of 1992, Title XIII authorizes additional research into a variety of innovative coal technologies. However, no regulatory incentive mechanisms are proposed.

DOE (1991).

127 Section 405 .

${ }^{128}$ Section 405 . 
Pennsylvania, West Virginia, Ohio, Indiana, and Illinois have all enacted legislation to promote coal use and create incentives for CCTs. ${ }^{129}$ Table D.1 describes the incentives offered for CCT development in the states listed above. All of these states have also indicated in their Clean Air Act "response" legislation that any utility choosing to fuel switch away from in-state coal must submit a plan indicating that this is the least-cost compliance option including the local socioeconomic effects of such a decision. While this measure does not provide a direct incentive, it does encourage the continued use of local high-sulfur coal. This, in turn, may encourage the repowering of older facilities with CCT in order to have the plant's life extended and avoid coming under NSR.

Several other states have in the past provided nonetary subsidies for the development of CCTs in association with the CCTP. ${ }^{130}$ In addition, many states provide tax incentives in the form of property and corporate income tax for the development of energy saving technologies and research and development. CWIP is also available to utility construction projects in several states, but the treatment of CWIP is usually on a project basis and is not always $100 \%$. In these cases, CWIP is likely to be used to offset rate shocks rather than encourage technological development or deployment.

129 The respective state level CCT and coal use legislation is found in the West Virginia Code, Chapter 24-2-1g; the Ohio Amended Substitute Senate Bill 143; the Indiana Senate Enrolled Act 514; and the Illinois Senate Bill 629. Tnecifics of the Pennsylvania legislation can be found in the Clean Coal Synfuel Letter Dated 4/11/91.

130 For a listing of state programs that include CWIP, various tax incentives, and subsidies for that may apply as potential incentives for CCT development see DOE (1989). 
TABLE D.1 CCT Incentive Program: High-Sulfur Coal States and Proposed by FERC

Pennsylvania Up to $100 \%$ construction work in progress (CWIP) for the repowering or upgrading a plant to use Pennsylvania coal. $20 \%$ tax credit for research and development on CCT which results in increased or continued use of state coal. One dollar tax credit per ton of in-state coal used above a baseline level.

West Virginia CWIP allowed for innovative generating construction.

Tax credits/reductions for CCT projects.

Ohio Utility compliance preapproved.

Preapproval of utility AR Compliance Plan

CWIP surcharge for CCT and FGD

May pass CCT R\&D costs through FAC

Funding of CCTs through coal subsidies

One dollar tax credit per ton of in-state coal used above a baseline level

Indiana CWIP is permitted for CCT and scrubber development. Preapproval of AR Compliance Plan

Coal board support/subsidy

Illinois CWIP for new construction which decreases $\mathrm{SO}_{2} / \mathrm{NO}_{\mathrm{x}}$ emissions. Coal board proposes several mechanisms for CCT adoption

Sources: Clean Coal/Synfuels letter, 3/25/91, 4/29/91, 5/6/91, 7/8/91; West Virginia Code, Chapter 25-2-1g; Ohio's Amended Substitute Senate Bill 143; Indiana's Senate Enrolled Act 514; and Illinois' Senate Bill 629; S. 1220 Report No. 102-72. 


\section{REFERINCES}

DOE, 1991, Clean Coal Technology Demonstration Program, U.S. Department of Energy DOE/FE-0219P, Waskington, D.C., Feb.

DOE, 1989, Report to the Secretary of Energy Concerning Commercialization Incentives, U.S. Department of Energy, Office of Environmental Analysis, DOE/EH-0083, Washington, D.C., Jan. 

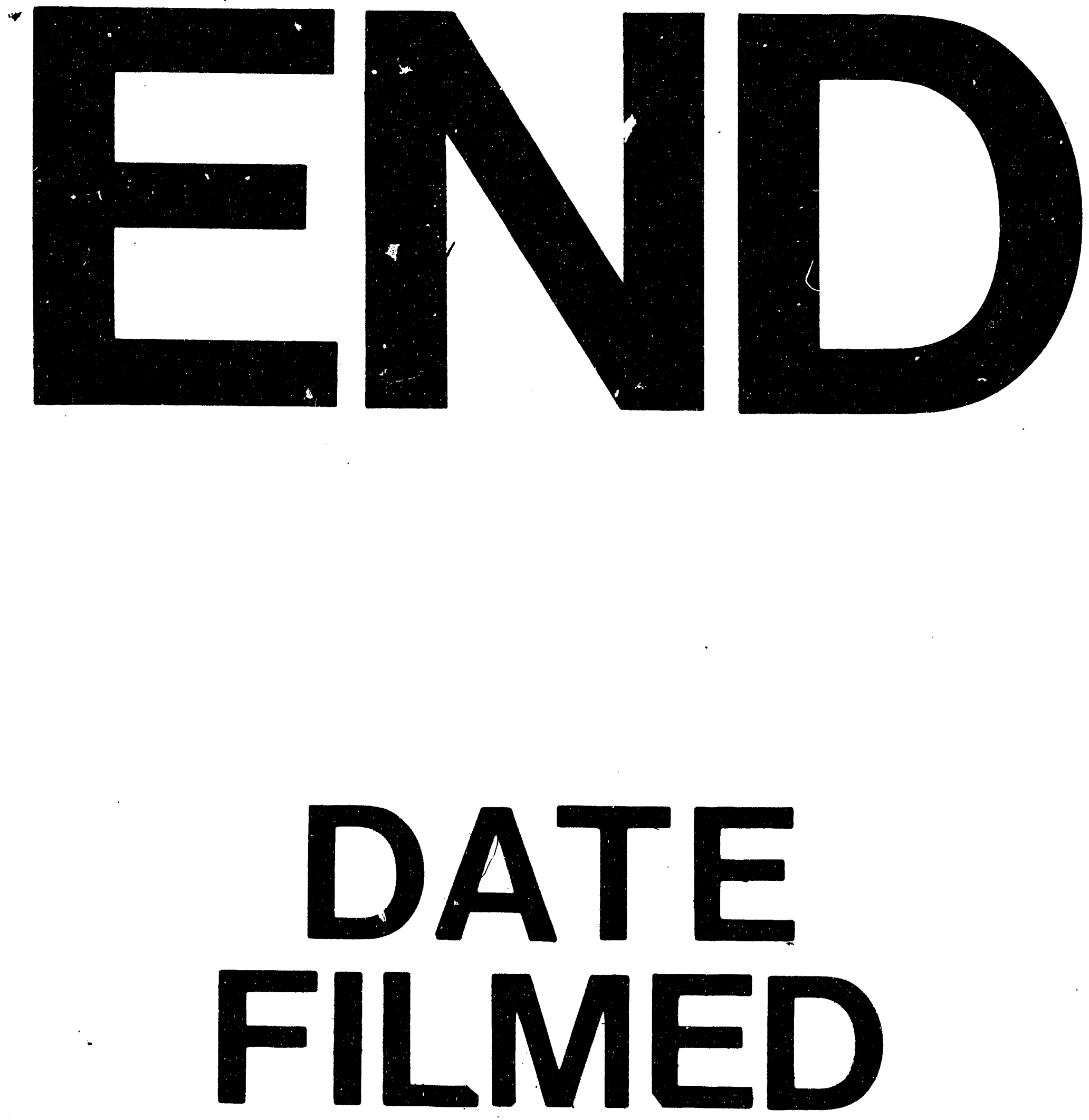

f

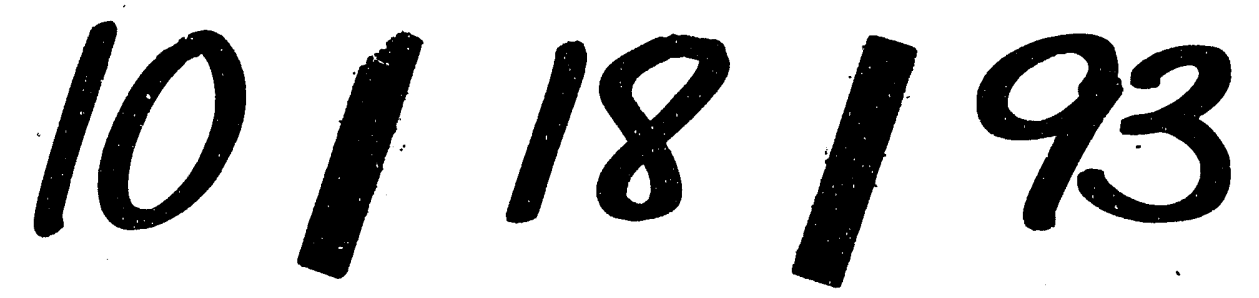


. 